$N R D=40$

DOT HS-802 488

\title{
A COMPARISON OF DRUG USE IN DRIVER FATALITIES AND SIMILARLY EXPOSED DRIVERS
}

Contract No. DOT-HS-4-00941

July 1977

Final Report

PREPARED FOR:

U.S. DEPARTMENT OF TRANSPORTATION

NATIONAL HIGHWAY TRAFFIC SAFETY ADMINISTRATION

WASHINGTON, D.C. 20590

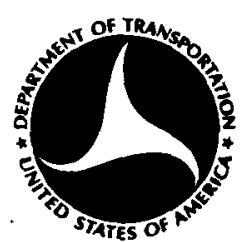

Document is available to the public through the National Technical Information Service, Springfield, Virginia 22161 
This document is disseminated under the sponsorship of the Department of Transportation in the interest of information exchange. The United States Government assumes no liability for 1 ts contents or use thereof. 


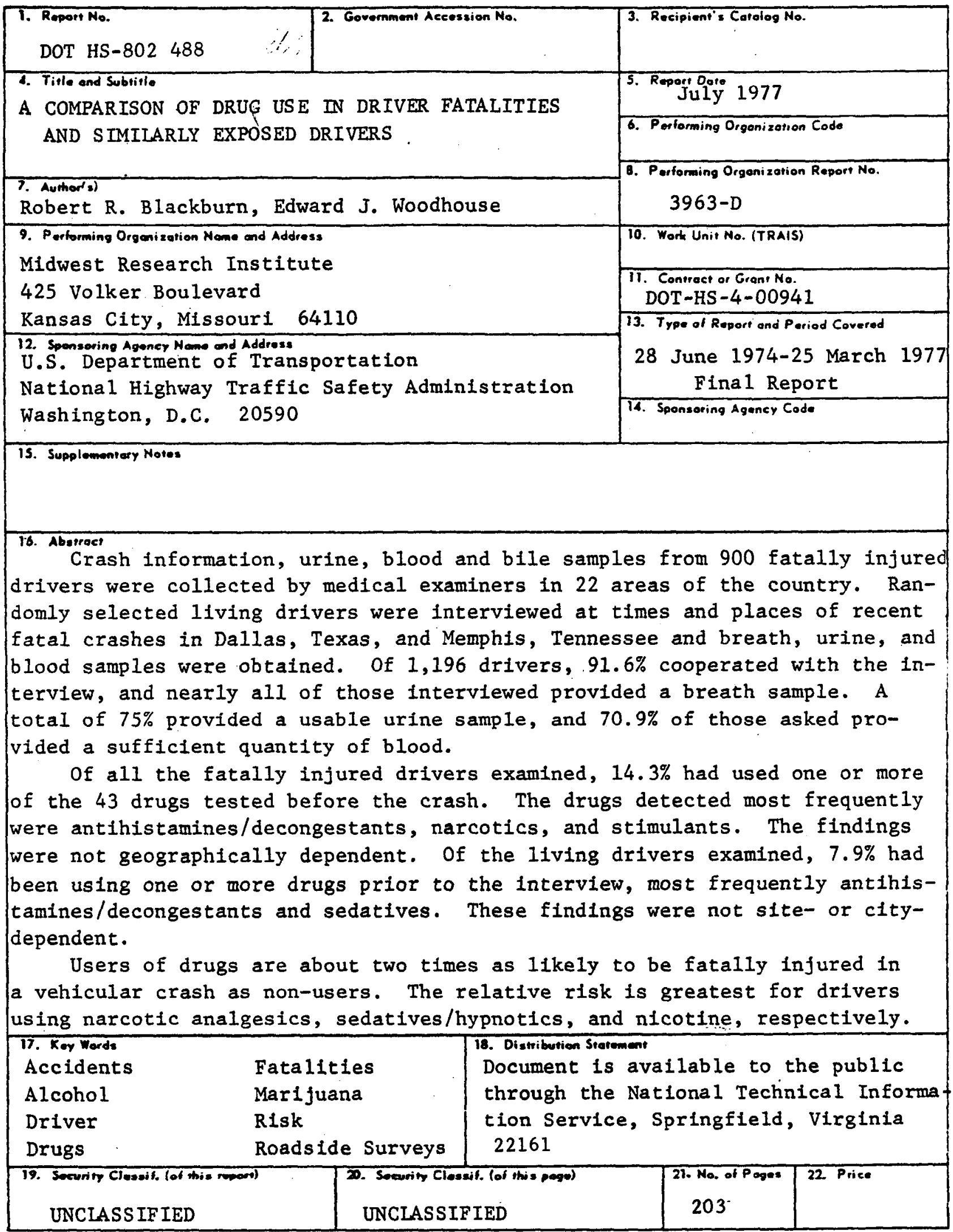

Form DOT F 1700.7 (8-72)

Reproduction of complered pege evethorizod 
METRIC CONVERSION FACTORS

Approximate Conversions to Metric Messures

Symbel When Yen Know Multiply by To find Symbol

in
$h$
$r d$
$m i$
$r$

$i n^{2}$
$h^{2}$
$r d^{2}$
$m^{2}$

H. ax

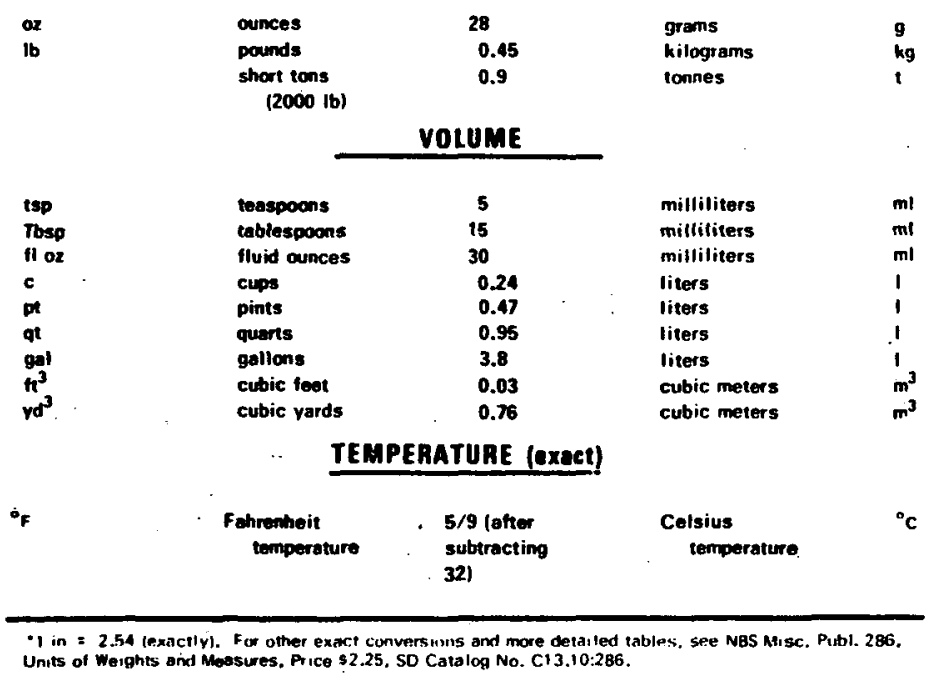

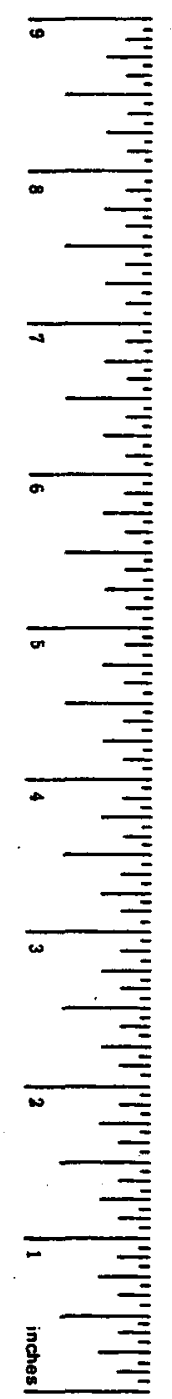

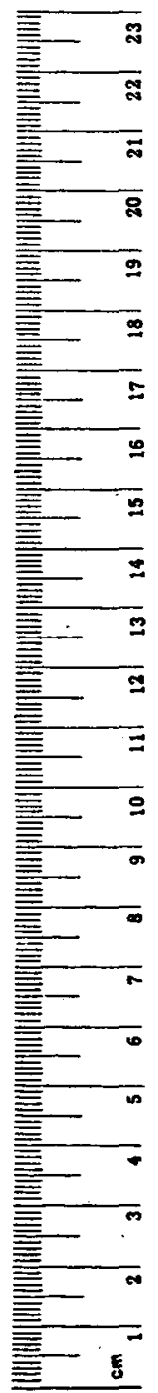

Approximate Conversions from Metrie Monsares

Srmbol

When You Know

Multiply by

To find

$$
\text { LENGTH }
$$

mm millimeters

$\begin{array}{ll}\mathrm{cm} & \text { centimeters } \\ \text { meters }\end{array}$

mmaters

0.04 incheses

0.4
3.3
1.1

kilameters

0.6

miles

$\frac{\text { AREA }}{\text { square centimetors } \quad 0.16}$

square centimeters

square meters

hectares $\left(10,000 \mathrm{~m}^{2}\right)$

0.16
1.2
0.4

2.5

square incties square rands equare miles

$\mathrm{km}^{2}$

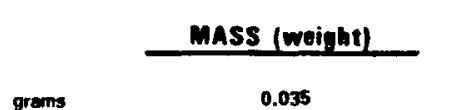

(a)

$\mathrm{g}$
$\mathrm{kg}$
$\mathrm{t}$

grams
hilograms
tomnes

0.035

2.2
1.1

pounces

shert tons

\begin{tabular}{|c|c|c|}
\hline & VOLUME & \\
\hline millititers & 0.03 & thuid ancoss \\
\hline liters & 2.1 & pinss \\
\hline liters & 1.06 & guarrs \\
\hline $\begin{array}{l}\text { liters } \\
\text { cubic maters }\end{array}$ & $\begin{array}{l}0.26 \\
35\end{array}$ & gollons \\
\hline
\end{tabular}

\section{TEMPERATURE (exaet)}

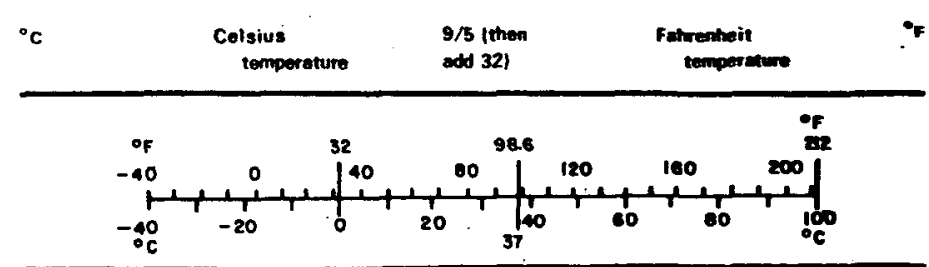




\section{PREFACE}

This report was prepared under Contract No. DOT-HS-4-00941 for the Department of Transportation, National Highway Traffic Safety Administration. The authors gratefully acknowledge the assistance provided by Mr. Peter Ziegler and Dr. Marvin Levy, NHTSA, the Contract Technical Managers. The discussions and suggestions provided by Drs. Monroe Snyder and Fred Benjamin, NHTSA were also much appreciated.

Mr. Robert Blackburn, Manager, Driver and Environment Programs, and Dr. Edward J. Woodhouse, Principal Chemist were the the Principal Investigators. Mr. Blackburn was responsible for securing the cooperation of city officials, the planning and operation of the roadside surveys and the analysis of all data. Dr. Woodhouse was responsible for securing the cooperation of medical examiners, the collection of specimens of fatally injured drivers and the chemical analysis of all specimens. The principal investigators were assisted throughout the project by Dr. William D. Glauz; Manager, Transportation Systems Section and by Dr. Florence I. Metz, Director of the Chemical Sciences Division and Dr. Sophia S. Fotopoulos, Head, Behavioral Sciences Laboratory.

Many other MRI staff members played a key role in this project. Mr. S. W. Graves, Ms. K. Haskins, Ms. P. Emily and Mr. J. Windels conducted the chemical analysis of blood, urine and bile specimens.

The roadside surveys were supervised by the first author, Dr. L. Bruce McDonald and Messrs. Douglas Harwood, Jerry Graham, and Robert Paulsen. They were assisted by Messrs. Ahmed Mors1, Patrick Heenan, and Barry Sanders.

Statistical analysis and related activities were the responsibility of Mr. Michael Sharp assisted by Ms. Rosemary Moran. Mr. Barry Sanders was responsible for all computer programing operations.

The collection of specimens from fatally injured drivers would not have been possible without the cooperation of the medical examiners involved in this project. Their assistance is gratefully acknowledged.

The roadside surveys would not have been possible without the cooperation of many public officials from the clties of Dallas, Texas and Memphis, Tennessee. In particular, their assistance was invaluable in arranging press conferences, providing traffic control personnel, and in locating registered nurses who assisted in the survey. 
Finally, the authors wish to publicly thank the 1,255 motor1sts who participated in the survey, donating their time and the necessary specimens. Their cooperation was extremely high - a very necessary factor contributing to the successful performance of this profect.

Approved for:

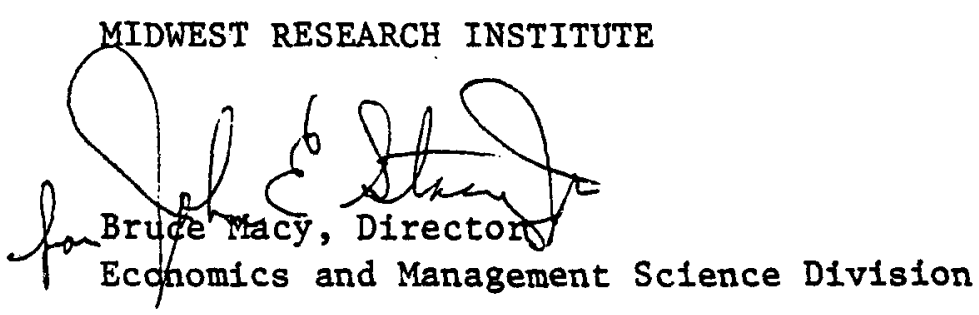




\section{ADDENDUM}

NHTSA Order 170-2 regarding technical reports (November 5, 1976) indicates that the responsible Associate Administrator or his designee is allowed two weeks for review of the final report and development of an addendum if one is necessary. Because of the current staff shortage, it has not been possible to review this report adequately within the permitted time. Therefore, this report is being published prior to a thorough internal review. It is clear, however, that before the results of this report can be interpreted appropriately or conclusions drawn regarding future action (e.g., further research), a number of points-pertaining to the nature of the data collected, chemical analyses performed, drug-driver interaction, etc.--warrant careful review and analysis. After this review, it is expected that a substantive "addendum" will be prepared and made available to readers on request. 
TABLE OF CONTENTS

$\underline{\text { Page }}$

Summary. . . . . . . . . . . . . . . . . . 1

I. Introduction .................. 7

II. Research Approach and Methodology. . . . . . . . 9

A. Community Selection for Fatally Injured Driver Specimens and Data. . . . . . . . . 9

B. Development of Procedures for the Collection of Fatally Injured Driver Specimens and Data. . . . . . . . . . . . 11

C. Collection of Fatally Injured Driver Specimens and Data............. . 14

D. Community Selection for Exposed (Living) Driver Surveys. . . . . . . . . . 14

E. Survey Plan for Collecting Fluid Samples from Living Drivers . . . . . . . . . 19

F. In-Field Survey Procedure ......... 23

G. Development of Chemical Analysis Methods and Their Application to Driver Specimens . . . 26

H. Data Used and Statistical Analysis Performed. ............. 42

III. Research Findings and Interpretation of the Data. . . 44

A. Screening of the Fatally Injured Driver Data. . . . . . . . . . . . 44

B. Fatally Injured Driver Crash Data...... 50

C. Description of Survey Respondents . . . . . 51

D. Driver Drug Findings. . . . . . . . . . 62

E. Relative Risk of a Fatal Accident Involvement. . . . . . . . . . . . 76

F. Alcohol Usage Among Drivers . . . . . . 92

G. Fatally Injured and Living Driver Factors Com-pared with Drug Usage... . . . . . 96

H. Other Findings. ............. 103

IV. Conclusions and Recommendations. . . . . . . . 107 


\section{TABLE OF CONTENTS (Continued)}

\section{List of Figures}

Figure

T1tle

Page

1 Analytical Screen for Determination of Drugs in

Body Flulds of Drlvers. . . . . . . . . . .

2

Extraction Assembly . . . . . . . . . . . . .

Sample Size Screening Effects . . . . . . . .

\section{List of Tables}

Table

Title

Page

1 Kits Dispatched and Collected ...........

List of Potential Sampling Areas. . . . . . . .

3 Drugs and Drug Groups Included in the Analytical Screen. ..................

4 Thin-Layer Chromatographic Characteristics of Acldic and Neutral Drugs . . . . . . . . . . .

5 Th1n-Layer Characteristics of Basic Drugs . . . .

6 Gas Chromatographic Conditions, Internal Standards, and Absolute and Relative Retention Times.....

Extraction Efficiencies for Drugs Found in Driver Specimens ....................

8 Drugs Reported on Crash Data Forms às Being Administered to Victims After the Crash. . . . . . . . 


\section{TABLE OF CONTENTS (Continued)}

\section{List of Tables}

Table

Title

$\underline{\text { Page }}$

10 Summary of Dallas Drug Surveys. . . . . . . . . 53

11 Summary of Memphis Drug Surveys . . . . . . . . . 54

12 Summary of All Drug Surveys . . . . . . . . . 55

13 Summary of Living Driver Samples Analyzed for Drugs . . 56

14 Demographic Characteristics of Respondents. . . . . . 59

15 Other Observed Characteristics of Respondents ..... 61

16 Incidence of Drugs in Fatally Injured Drivers for Whom Urine Samples were Available . . . . . . . . 64

17 Incidence of Drugs in Fatally Injured Drivers for Whom Blood Samples were Available......... 65

18 Incidences of Drugs in Fatally Injured Drivers for Whom Bile Samples were Available......... 66

19 Incidences of Drugs in Fatally Injured Drivers for Whom Both Blood and Urine Samples were Available. .

Incidences of Drugs in Fatally Injured Drivers for Whom Blood, Urine and Bile Samples were Available..

Quantitated Drugs in 587 Fatally Injured Drivers for Whom Both Blood and Urine Samples were Available. .

Incidence of Drugs in Living Drivers for Whom Urine Samples were Avallable. . . . . . . . . . .

23 Incidence of Drugs in Living Drivers for Whom Blood Samples were Available. . . . . . . . . . . 


\section{TABLE OF CONTENTS (Continued)}

\section{List of Tables}

Table

Title

Page

Incidence of Specific Drugs Found in Living Drivers for Whom Both Blood and Urine Samples were Available....

Comparative Data for Dallas Drivers Evidencing Drugs and for Whom Urine Samples were Available . . . . . 78

Comparative Data for Dallas Drivers Evidencing Drugs and for Whom Blood Samples were Avallable . . .....

Comparative Data for Dallas Drivers Evidencing Drugs and for Whom Both Blood and Urine Samples were Available . . . . . . . . . . . . . . . .

Comparative Data for Memphis Drivers Evidencing Drugs and for Whom Urine Samples were Avallable . . . . .

Comparative Data for Memphis Drivers Evidencing Drugs and for Whom Blood Samples were Avallable . . ....

Comparative Data for Memphis Drivers Evidencing Drugs and for Whom Both Blood and Urine Samples were Available . . . . . . . . . . . . . . . .

Comparative Data for Memphis Plus Dallas Drivers Evidencing Drugs and for Whom Urine Samples were Available . . . . . . . . . . . . . . . .

Comparative Data for Memphis Plus Dallas Drivers Evidencing Drugs and for Whom Blood Samples were Available . . . . . . . . . . . . . . . . Evidencing Drugs and for Whom Both Blood and Urine Samples were Available. . . . . . . . . . . . 


\section{TABLE OF CONTENTS (Concluded)}

\section{List of Tables}

Table

$\underline{\text { Title }}$

Page

35 Comparative Data for all Drivers Evidencing Drugs and for Whom Urine Samples were Available . . . . .

Comparative Data for all Drivers Evidencing Drugs and for Whom Blood Samples were Available . . . . .

Comparative Data for all Drivers Evidencing Drugs and for Whom Both Blood and Urine Samples were Available . . . . . . . . . . . . . . . .

Comparative Data for Drivers Evidencing Drugs at Any Level . . . . . . . . . . . . . . . . .

Comparative Data for Alcohol Considering all Drivers for Whom Both Blood and Urine Samples were Available . . . . . . . . . . . . . . .

Time of Day Versus Percentage of Drinking and Driving for Fatally Injured Drivers . . . . . . . . . .

41 Time of Day Versus Percentage of Drinking and Driving for Living Drivers. . . . . . . . . . . . . .

42 Drugs Combined with Alcohol in Fatally Injured Drivers . . . . . . . . . . . . . . . .

43 Drugs Combined with Alcohol in Living Drivers . . . .

44 Correlates to Drug Usage and Driving Among Fatally Injured Drivers . . . . . . . . . . . . . 100

Correlates to Drug Usage and Driving Among Living Drivers . . . . . . . . . . . . . . . .

46. Comparative Data for Male only Drivers Evidencing Drugs and for Whom Both Blood and Urine Samples were Available. . . . . . . . . . . . . . . 
A study was undertaken to determine whether or not particular drugs or drug types are over-involved in fatal crashes. The primary objectives of the study were the collection and chemical analysis of body fluid samples from fatally injured drivers and from a sample of living drivers similarly exposed. The chemically analyzed data from the living drivers were compared with the data from the fatally injured drivers to determine the relationship between drug usage by drivers and highway fatalities. The objectives of the study were met through a five-task research plan involving: (1) obtaining cooperation and development of procedures; (2) collection of samples from fatally injured drivers; (3) collection of samples from exposed drivers; (4) laboratory analysis of specimens; and (5) statistical analysis and interpretation of data.

The fatally injured driver data were collected by medical examiners in 22 areas of the country, each consisting of one or more counties. The data fell into two categories: (1) crash data information describing the circumstances of the fatal accidents; and (2) urine, blood and bile samples which were chemically analyzed for drugs. Finger and lip swabs were also collected (for detection of marijuana) but were not chemically analyzed.

The collection of fatally injured driver data began in November 1974 and was completed on December 16, 1975, in all areas except in the Cities of Dallas, Texas and Memphis, Tennessee. The collection in Dallas and Memphis continued through September 5 and August 27, 1976, respectively, to provide an adequate fatally injured driver sample in those two communities for subsequent comparisons with living drivers.

A total of 994 fatally injured driver specimen kits were received during the collection period of which 900 were chemically analyzed. The following fluids were supplied in adequate amounts: 637 (70.8\%) urine, $825(91.7 \%)$ blood, $492(54.7 \%)$ bile, $587(65.2 \%)$ both blood and urine, $326(36.2 \%)$ all three fluid samples, and $832(92.4 \%)$ complete set of swabs. Crash data were provided in all 900 cases.

Two communities, Dallas, Texas, and Memph1s, Tennessee, cooperated with MRI in the conduct of roadside surveys to determine drug use among similarly exposed (living) drivers. Eleven surveys were conducted in Dallas between May 30, 1975, and September 13, 1976; eight surveys were conducted in Memphis between November 11, 1975, and September 2, 1976. The surveys were conducted at sites at which a driver was fatally injured (died with 4-1/2 hr of the crash) and for whom fluid specimens were submitted by the community medical examiner. Surveys were also 
conducted at some fatally injured driver crash sites at which it was later determined that the medical examiner had falled to collect the required specimens. A total of 105 sampling sites were used in the study: 73 sites in Dallas and 32 in Memph1s. The survey procedure consisted of stopping randomly selected male motorists at the time of day and day of week of the fatal crash, conducting the interview, and requesting breath, urine and blood samples. Ifp and finger swab samples were also collected for detection of marijuana, but they were not chemically analyzed. An average of one dozen interviews were performed at each crash site.

of 1,255 motorists stopped during the surveys, data from 1,196 drivers at acceptable sites were retained for subsequent analyses- 759 drivers in Dallas and 437 drivers in Memphis. Of these 1,196 motorists, 91.6\% cooperated with the interview, and breath samples were obtained from nearly all of those interviewed. Likewise, nearly all consented to give a urine sample, but only $67.2 \%$ of the drivers were able to produce a sufficient urine quantity on demand.* Also, of the motorists asked, $70.9 \%$ were able to provide a sufficient blood quantity.

The drivers encountered in the two communities had very similar demographic characteristics, and only small differences between the motorists from the two areas were noted. For instance, whereas the Memphis motorists were either white or black, the Dallas sample included many Mexican Americans as well. More blacks were interviewed, on a percent basis, in Memphis than in Dallas. The Dallas drivers tended to be less educated and younger than the Memphis drivers. The Memphis drivers interviewed tended to live mainly in Memphis; the Dallas drivers tended to be from Dallas as well as towns within the county.

Quantitative tests were performed on the living and fatally injured driver fluid specimens for 43 drugs, which were classifled into seven drug groups: (1) sedatives and hypnotics, (2) tranquilizers, (3) stimulants and antidepressants, (4) antihistamines and decongestants, (5) narcotic analgesics, (6) hallucinogens, and (7) miscellaneous, Quantitative tests for the hallucinogen, LSD, were performed using only the urine samples collected from the fatally injured drivers. In addition, quantitative determinations of the blood alcohol content were performed on both breath and blood samples obtained from the living drivers and on the blood samples collected from the fatally injured drivers. Qualitative tests were also performed for nicotine (evidence of tobacco smoking) and salicylates (evidence of aspirin) using the living and fatally injured driver fluid specimens collected.

The total chemical analysis scheme involved: the preparation of specimens, including hydrolys is of glucuronides and sulfate ether,

* The total sample was Increased to $75 \%$ by means of a "ma11-back" procedure. 
and extraction of the hydrolyzed specimens using a nonionic resin; the qualitative examination of the extracts by thin layer chromatography; and finally the quantitative confirmation of thin layer findings by gas chromatography. The statistical analysis of the fluid sample findings included findings confirmed by gas chromatography and quantitated at any level of concentration. The concentration of the drug in the fluid sample was not utilized as a parameter. Blood alcohol was determined using a gas chromatographic technique on blood head-space. ISD was assayed using radioimmunassay techniques.

The findings in fatally injured drivers were analyzed in 10 categories: each of the seven drug groups; one or more drugs, regardless of the drug group; nicotine; and salicylates. Moreover, five possible fluid sample combinations were considered: (1) urine separately, (2) blood separately, (3) bile separately, (4) urine and blood, and (5) urine, blood and bile. The incidences of drugs in the 22 submission areas, including Dallas and Memphis, were also examined but it was determined that the incidences did not differ significantly from area to area.

For cases in which both urine and blood findings from fatally injured drivers were available, the incidence of one or more drugs was about $12 \%$ (with a $95 \%$ confidence interval of $\pm 8.4 \%$ ) in $\mathrm{Dallas}$, about $24 \%$ $(+14.6 \%)$ in Memphis, and $14.3 \%( \pm 2.8 \%)$ overall. The most commonly detected drug was the antihistamine and decongestant, phenylpropanolamine, with the sedative, phenobarbital, second. Another antihistamine and decongestant, chlorpheniramine, the narcotic, codeine, and the stimulant, amphetamine, were also frequently encountered.

Nicotine was found in $64.7 \%( \pm 3.9 \%)$ of the fatally injured drivers and salicylates were found in $17.4 \%( \pm 3.1 \%)$. LSD was found in $1.2 \%$ $(8 / 669)$ of the fatally injured drivers. A11 of these drivers evidencing LSD were males, 25 years old or less. Five of the eight $(62.5 \%)$ were judged to be culpable, which is not significantly different from the total fatally injured driver population.

The incidences of drugs in the living drivers were examined in a manner similar to that used for the fatally injured drivers. These incidences were also compared by site within each survey community and between the two communities of Dallas and Memphis. The incidences were found not to differ significantly between sites or between cities. For cases for which both urine and blood findings were avallable, the incidence of one or more drugs was about $8.6 \%( \pm 2.6 \%)$ in Dallas, and $6.7 \%$ $( \pm 2.9 \%)$ in Memphis, or about $7.9 \%( \pm 1.9 \%)$ overall. The number of living drivers involved was relatively small in that only 40 out of 463 Dallas drivers and 19 out of 282 Memphis drivers evidenced one or more drugs. 
As with the fatally infured drivers, the most commonly detected drug among the living drivers was the antihistamine and decongestant, phenylpropanolamine with the sedative, phenobarbital second. Another antihlstamine and decongestant, chlorpheniramine was also found to be prevalent, more among the Dallas 1iving drivers than among Memphis drivers.

About $56 \%( \pm 3.6 \%)$ of the living drivers has been smoking tobacco while $19.2 \%( \pm 2.8 \%)$ of the drivers had been using salicylates.

All but one of the 59 living driver drug detections resulted from the urine samples, rather than the blood samples. This is almost the same situation as that found for the fatally injured drivers, in which all but five of the drug detections resulted from the urine samples.

The incidences of drugs in fatally injured and living drivers were compared, to yleld relative risks of belng fatally injured as a driver in a crash. This was done separately for Dallas, Memphis, and the combination of the two communities. The relative risks were also determined by comparing the incldences of drugs in all fatally injured drivers with the incidence of drugs in all living drivers. The totality of the fatally injured driver data is statistically homogeneous and therefore serves as a description of the incidence of drug use among such drivers. The same is true about the totality of living driver data. Thus, the totality of all drug findings for both fatally injured and living drivers is the statistically preferred estimator for the incidence of drug usage for any location. From a statistical perspective, the relative risks based on all the data collected are to be preferred over the risks calculated for Dallas or Memphis alone since the increased sample size results in a more precise estimate of the relative risk. Also, there is no statistical evidence to indicate drug usage among living drivers was any different at crash sites for which fluid samples were avallable from the fatally injured driver than at those crash sites for which fluid samples were not available.

The comparisons of the relative incidences of drugs in all fatally injured drivers with those in all living drivers indicate that fatally injured drivers are significantly more likely to have been using drugs than similarly exposed (living) drivers. The comparisons imply that drivers using drugs have a relative risk of about 1.8 (with a $95 \%$ confidence interval of 1.3 to 2.5 ). The danger is greatest with narcotic analgesics with a relative risk of about 19 (with a $95 \%$ confidence interval of 5.1 to infinity); followed by sedatives and hypnotics with a relative risk of about 1.9 (with a $95 \%$ confidence interval of 1.1 to 3.5 ); and nicotine at 1.2 (with a $95 \%$ confidence interval of 1.1 to 1.3 ). 
The relative risks for the other drug groups were all greater than unity, but the data samples are not large enough to make very powerful statements regarding their significance. (The lower confidence limits on the relative risk for these latter drug groups were all less than unity.)

The study reconfirmed alcohol as the most abused drug among drivers; it plays the leading role among drugs as a causative factor in fatal crashes. Drivers who would be legally intoxicated in most states (BAC of $0.10 \%$ or more) were found to be far more likely to be fatally injured in a crash than sober drivers. The relative risks were 3.27 , 10.41 , and 30.31 for BAC ranges of 0.05 to $0.09,0.10$ to 0.14 , and 0.15 to 0.19 , respectively (with attendant confidence intervals).

In further confirmation of previous findings, alcohol usage depends strongly on time of day for both the fatally injured drivers (at time of crash) and the living drivers (at time of interview). For both sets of drivers, the majority of all the drunk drivers was detected in the late evening and early morning hours. The only significant finding between time of day and other drug usage was that antihistamines and decongestants were over-involved in the morning and late afternoon to early evening hours among living drivers. Drug usage among the fatally injured drivers was mildly dependent on time of day, but in an opposite sense to that found for alcohol usage. However, the relationships between time of day and drug usage were not statistically significant.

Among the fatally injured drivers, the use of antihistamines and decongestants, and one or more drugs, were found to be significantly related, in a negative sense, with alcohol usage. Of those evidencing one or more drugs, $57.1 \%$ also had positive BAC's $(0.01+)$, whereas a significantly higher percentage $(68.4 \%)$ of the fatally injured drivers not using drugs had positive BAC's. The same negative association was found between alcohol usage and the other drug groups (except the miscellaneous group), but these drug incidence levels were too small to detect statistical significance. There is no statistical evidence to indicate that alcohol and drug usage are related among living drivers.

A number of fatally injured and living driver factors were compared with drug usage and examined for statistical importance. The use of antihistamines and decongestants was significantly related to season of the year among fatally injured drivers but not among living drivers. Fatally infured drivers had used these drugs relatively more frequently in the fall and less in the summer. For living drivers, however, season of the year was significantly related to the use of salicylates and the category "one or more drugs." Salicylates were over-involved in the 
summer and fall and under-involved in the other seasons. The use of one or more drugs was over-represented in the fall and winter and underrepresented in the spring and summer.

Culpability of the fatally injured drivers was not found to be related to drug usage. Nelther was race significantly related to drug usage.

The age and sex of the fatally infured drivers were significantIy related to usage of one or more drugs. Drivers 50 years and older were more likely to have been using one or more drugs while very young (19 years or less) and middle aged drivers ( 30 through 49) were less likely to have been using one or more drugs. A total of $23.1 \%$ of the fatally injured female drivers were using one or more drugs, compared to only $13.0 \%$ of the fatally injured male drivers. However, the $14.3 \%$ incidence of one or more drugs found for all fatally injured drivers is distorted by only $1.3 \%$ by the inclusion of fatally injured females, because they constituted only a small portion of the sample (13.3\%).

The high incidence of drug usage among female fatalities prompted a correction of the relative risks by including only males in the calculations. The corrected relative risks are lower for each drug group (except for analgesics/narcotics and miscellaneous) than the risks determined from a combination of male and female fataliy injured drivers. The greatest changes in risk were for sedatives and hypnotics, which decreased from 1.90 for all drivers to 1.61 for males only. (In addition, the lower confidence limit went below unity.) The risk for other drugs changed as follows: 1.69 to 0.97 for tranguilizers; 1.27 to 1.04 for antihistamines and decongestants; 2.54 to 2.93 for miscellaneous drugs; 1.81 to 1.64 for one or more drugs.

Finally, an analysis was conducted to determine the incidence of individual drug groups among living drivers at drug-involved fatal crash sites. Only two living drivers were found to have any drug in their system at the drug-involved fatal crash sites. The drugs detected in these two drivers did not match the drugs found in the drivers fatally injured at those sites. This shows the extremely low probability (zero in this study) of finding a given drug among living drivers at a fatal crash site where the same drug was found in the dead driver. 


\section{INTRODUCTION}

This report describes a study to compare drug use in driver fatalities and living drivers exposed to the same driving environment. The high incidence of both prescription and illegal drug use, and the knowledge that a particular drug--alcohol--is over-involved in traffic fatalities, has raised suspicion that other drug use may be an important traffic safety problem.

Research was needed to determine if particular drugs were over-involved in traffic fatalities. Such research must give particular attention to the sampling of fatally injured drivers and to the sampling of a comparison group of "simflarly exposed but not involved". drivers. Thus, the research study presented in this document was designed to determine whether or not particular drugs are over-involved in fatal crashes within a defined geographic area. The study accomplished this objective by determining the absolute incidence of drug involvement in driver fatalities, and the incidence relative to drivers similarly exposed but not involved.

The study was a logical exterision of the Midwest Research Institute studies recently completed for the National Highway Traffic Safety Administration. These studies, "The Incidence of Drugs in Fatally Injured Drivers" (DOT Contracts Nos. DOT-HS-119-1-173 and DOTHS-119-3-627) and "Drug Use Among Drivers" (DOT Contract No. DOT-HS119-2-440), developed new analytical techniques, devised collection techniques for fatally injured and living driver specimens, and applied these techniques to an initial study of the incidence of drugs in fa-. tally injured and living drivers. While the results of these studies indicated that certain drugs may indeed be a highway safety problem, the data were not sufficient to reliably determine the relative risk of a driver becoming involved in a fatal crash when he has one or more drugs in his system. Further data needed to be generated in which particular attention was paid to the sampling of both fatally injured drivers and "similarly exposed but not involved" drivers. The objectives of the study were met through a five-task research plan involving: (1) obtaining community cooperation and development of procedures; (2) collection of samples from fatally injured drivers; (3) collection of samples from living drivers; (4) laboratory analysis of specimens; and (5) statistical analysis and interpretation of data. 
Section II of this report presents the research approach and methodology used in the study. His subdivisions describe how each of the above tasks were accomplished. The next section describes the screening of the fatally injured driver specimens, the analysis of the crash data, the nature of the living driver respondents and their cooperation, drugs found in both fatally injured and living driver samples, the relationship between the fatally injured and living driver findings, results relative to alcohol, and an analysis of the comparison between driver factors and drug usage.

The report ends with conclusions and recommendations, followed by the appendices which contain backup material. 


\section{RESEARCH APPROACH AND METHODOLOGY}

This section of the report describes the approaches taken to accomplish each of the five tasks of the research plan. Subsection $A$ deals with the selection of communities to provide the fatally injured driver specimens and data. Subsection $B$ discusses the development of procedures for the collection of the fatally injured driver data while the collection of the specimens and data from the fatally injured drivers is presented in Subsection $C$. The selection of the communities for the exposed (living) driver surveys is discussed in Subsection D. Subsection $E$ describes the survey plan for collecting flutd samples from living drivers while Subsection $F$ discusses the field survey procedures used. Subsection $G$ discusses the development of the chemical analysis methods and their application to the driver specimens collected. Finally, Subsection $\mathrm{H}$ briefly describes the data used and statistical analyses performed in the study.

\section{A. Community Selection for Fatally Injured Driver Specimens and Data}

The goal of this portion of the study was to select communities within the contiguous United States that would provide fluid specimens and data from 900 fatally injured drivers in a 10-month perfod. In addition, the selection would include two major communities from which samples from 150 fatally injured drivers would be obtained in the 10-month period and approximately 25 other smaller communities from which samples from 750 fatally infured drivers would be obtalned in the same time period. The fatally infured drivers from the two large communities would be compared with living drivers, simflarly exposed, obtained from the same two communities.

These requirements for fatally injured driver specimen and data collection were not possible to meet in the proposed 10-month period. Instead, two large communities were selected for survey for perods of 20 and 22 months in order to collect sufficient driver specimens and data. For the remaining 750 drivers, 22 smaller areas were selected to provide this number of fatally injured drivers over a period of 14 months. The factors influencing our selection of these communities are listed below.

1. Selection of two large communities: The selection of two large communities capable of providing a combined 150 fatally injured drivers in a 10-month period was complicated by two major factors: 


\section{a. Obtaining the cooperation of the medical examiner;}

b. Obtaining cooperation of the city officials to allow a survey of living, similarly exposed drivers.

The latter factor was necessary because it was the obfective of this program to compare drug incidences in fatally infured drivers and living drivers in the two major communities studied.

Several large communities were contacted by letter and telephone requesting cooperation for the collection of fatally injured drivers. The medical examiners of these communities were advised of the goals and requirements of the program and asked to reply if they were able and willing to cooperate. A sum of $\$ 20$ would be paid to the cooperating medical examiner for each set of fatally injured driver specimens and data recelved during the study. Expressions of willingness to cooperate were received from the medical examiners in nine major areas; Dallas, Texas; Detrolt, Michigan; Houston, Texas; Miami, Florida; Jacksonville, Florida; Oakland, California; Atlanta, Georgia; Tampa, Florida; and Memphis, Tennessee. Other large communities were unable to cooperate because of legal problems or medical examiners' lack of time, interest, or funds.

of these nine areas, only two areas were also willing to cooperate in allowing concurrent surveys for living, similarly exposed drivers. These areas were Dallas, Texas, and Memph1s, Tennessee (see Section II-D). The other seven large communities refused to cooperate or were unable to cooperate because of legal problems.

Thus, Dallas, Texas, and Memphis, Tennessee, were selected as the two major communities in this program for collection of 150 total fatally infured drivers, and for the living driver surveys.

2. Selection of the other communities: The selection of up to 25 other (smaller) communities to provide fluid specimens and data from 750 fatally injured drivers was dependent for the most part on the willingness of medical examiners to cooperate in supplying specimens and data from fatally injured drivers. Over 40 communities were contacted by letter and telephone, advised of the program goals and requirements and asked to reply if they. were able and willing to cooperate. As with the larger communities, a sum of $\$ 20$ would be pald for every set of fatally injured driver specimens and data received during the study. Thirteen communities expressed willingness to cooperate in the program; 
these 13 communities were then combined with the seven larger communities which had already expressed willingness to cooperate in collection of fatally injured drivers for a total of 20 communities. These communities were:

$$
\begin{aligned}
& \text { Detroit, Michigan } \\
& \text { Houston, Texas } \\
& \text { Miami, Florida } \\
& \text { Jacksonville, Florida } \\
& \text { Oakland, California } \\
& \text { Atlanta, Georgia } \\
& \text { Tampa, Florida } \\
& \text { Orlando, Florida } \\
& \text { Kansas City, Missouri } \\
& \text { Portland, Oregon } \\
& \text { Wheaton, Illinois } \\
& \text { Albuquerque, New Mexico } \\
& \text { Las Vegas, Nevada } \\
& \text { Minneapolis, Minnesota } \\
& \text { Everett, Washington } \\
& \text { Butler, Pennsylvania } \\
& \text { Daytona Beach, Florida } \\
& \text { Appleton, Wisconsin } \\
& \text { Chester, Illinois } \\
& \text { Eau Claire, Wisconsin }
\end{aligned}
$$

A listing of the medical examiners cooperating in this study is given in Appendix A, Table A-1.

The above list of communities is used here and elsewhere as an abbreviation for the areas submitting fatally injured driver samples. Each of the collection areas consisted of one or more counties in add1tion to at least part of the referenced community. A list of the extent of each submitting area is discussed in Section III-B.

\section{B. Development of Procedures for the Collection of Fatally Injured Driver Specimens and Data}

The procedures for the collection of fatally infured driver specimens and data were identical in all of the 22 areas involved in the study (20 areas to supply 750 drivers, 2 areas to supply 150 drivers). 
The medical examiners in all 22 areas were, upon indicating willingness to cooperate, advised in detail of the driver specimen and data collection requirements. Medical examiners were requested to provide data and physiological specimens from every driver fatally injured in their furisdictions during the collection period. An additional requirement was imposed that the driver must have died within 4-1/2 hr of the accident. This additional requirement was designed to reduce the problems associated with the administration of drugs between the time of crash and time of death, and consequent confounding of the drug analysis data. If it was not possible for the medical examiner to collect physiological specimens (e.g., if the driver was incinerated at the accident site) crash data were still requested to be forwarded to MRI. If the medical examiner was not able to furnish all the physiological specimens required, he was asked to provide written information as to the reason for this. Described below are the collection requirements imposed for the collection of fatally infured driver data and specimens for this program.

1. Data requirements: To collect data regarding the crash victim and the circumstances surrounding the crash, a crash data form was provided in duplicate with the crash collection kit. This form was to be completed by the medical examiner for each accident and supported, if possible, by the police accident report. The data to be included on this form consisted of the date and time of the accident, the date and time of victim's death, the date and time the samples were taken, the samples taken, the reasons why any samples were not taken, the drugs known administered between the time of accident and death, the location of the crash, the type and number of vehicles involved and the type of crash, other people involved in the crash, conditions most likely contributing to the crash, and finally, the age and sex of the victims. One copy of the completed crash data form was sent to MRI; the other was retained by the medical examiner for his records. A copy of the crash data form is shown in Appendix A, Figure A-1.

2. Physiological specimen requirements: The medical examiners were requested to provide from each eligible fatally infured driver the following specimens:

Blood, $60 \mathrm{ml}$ for alcohol and drug analysis

Urine, $45 \mathrm{ml}$ for drug analysis

Bile, $25 \mathrm{ml}$ for drug analysis

Swabs of the hands, lips and palate for evidence of marijuana contact 
Five $\mathrm{ml}$ of blood were required to be preserved with oxalate and fluoride for blood alcohol analysis. The remaining blood was preserved with oxalate only. Urine and bile specimens were not chemically preserved. Shipment and storage were under refrigerated conditions. The procedures for physically accomplishing the collection of data and specimens are described below.

3. Collection procedures: In order to collect the previously mentioned data and specimens, MRI provided the medical examiners with collection kits. These specimen and data collection kits specifically consisted of the following items.

a. An insulated mailer container of polyurethane foam and cardboard with MRI return address and airmail postage paid.

b. A kit I.D. card in duplicate.

c. A crash data form in duplicate, with prepaid return

envelope.

d. A urine collection bottle, $50 \mathrm{ml}$ size, with superior quality screw cap seal totally constructed of shatter-proof polypropylene.

urine bottle.

e. A bile collection bottle, $30 \mathrm{ml}$ size, similar to the

f. A blood collection bottle, $80 \mathrm{ml}$ size, similar to the urine bottle but containing potassium oxalate as an anticoagulent. Vacutainers, needles, and vacutainer holder for blood collection.

g. A $7 \mathrm{ml}$ vacutainer containing oxalate and fluoride for blood alcohol analysis.

h. A hands, lip and palate swab sub-kit consisting of four cotton swabs, four glass tubes with tight fitting screw caps, and a vial of $70 \%$ ethanol.

1. Instructions for use of the kit.

j. Artificial ice bags to refrigerate the samples in

shipment. 
The medical examiners were requested to ship back the refrigerated specimens as soon as possible. The crash data forms could be malled back at a later, more convenlent date. Coples of the collection kit Instruction sheet and I.D. card are shown in Appendix A, Figures A-2 and $A-3$, respectively.

\section{Collection of Fatally Injured Driver Spec1mens and Data}

Using the procedures described earlier, data and specimens were collected from medical examiners in 22 communities. A total of 1,121 kits were dispatched and 994 kits were recelved back at MRI with data and specimens. The kits from Dallas, Texas, and Memphis, Tennessee were collected over a period of 22 and 20 months, respectively. In all other areas, the kits were collected over a 14 -month period.

Of the $994 \mathrm{kfts}$ recelved, 900 were chemlcally analyzed and retained for further investigations. The remaining $k i t s$ were rejected because they did not meet the rigid requirements for the program. Reasons for rejecting kits included:

Fatally infured person was not a driver

Driver Ilved for more than $4-1 / 2$ hr after crash

Crash was out of the medical examiners furisdiction

More is said in Section III-A about the screening of the fatally injured driver data.

Table 1 shows the number of kits dispatched to each area, and those collected and analyzed.

It was not possible in all cases for the medical examiner to supply all the requested specimens. Out of the total of 900 drivers kits meeting the requirements of the program, 637 (70.8\%) supplied urine, $825(91.7 \%)$ supplied blood, $492(54.7 \%)$ supplied bile, 587 (65.2\%) supplied both blood and urine, 326 ( $36.2 \%$ ) supplied all three fluid samples, and $832(92.4 \%)$ supplied a complete set of swabs. Crash data were provided in all cases.

\section{Community Selection for Exposed (Living) Driver Surveys}

One of the major tasks of the contract was to survey and collect fluid samples from 1,200 exposed (1iving) drivers at the time and 
TABLE 1

KITS DISPATCHED AND COLLECTED

\section{Area \\ Kits Dispatched}

Dallas, Texas

Detroit, Michigan

Houston, Texas

Miami, Florida

Jacksonville, Florida

Oakland, California

Atlanta, Georgia

Memphis, Tennessee

Tampa, F1orida

Orlando, Florida

Kansas City, Missouri

Portland, Oregon

Wheaton, Illinois

Albuquerque, New Mexico

Las Vegas, Nevada

Minneapolis, Minnesota

Everett, Washington

Butler, Pennsylvania

Daytona Beach, Florida

Appleton, Wisconsin

Chester, Illinois

Eau Claire, Wisconsin
168

100

82

80

80

60

62

69

50

49

46

39

51

43

28

24

20

16

19

18

8

9

Total 1,121

Kits Collected Total Analyzed

$164 \quad 123$

$88 \quad 86$

$73 \quad 69$

$73 \quad 68$

$73 \quad 63$

$57 \quad 56$

$55 \quad 52$

$53 \quad 47$

$45 \quad 45$

$45 \quad 43$

$40 \quad 40$

$39 \quad 39$

$40 \quad 36$

$39 \quad 26$

$27 \quad 26$

$20 \quad 19$

$19 \quad 18$

$14 \quad 14$

$13 \quad 13$

$11 \quad 11$

$3 \quad 3$

$3 \quad 3$

$994 \quad 900$ 
places of fatal crashes. In the Inftial conception of the program it was anticlpated that the living driver surveys would be conducted in two metropolitan areas that usually each experlence about 80 sultable driver fatalities (or a total of 150 driver fatalities) in a 10-month period. In order for a fatality to be of use in the study, it must be that of a driver who dies within $4-1 / 2$ hr of the crash.

The requirements on the survey communities were very demanding and certainly beyond the control of the study. From an initial study of accident statistics only four cities satisfled the requirements: New York, Los Angeles, Chicago and Detroit. The likelihood of obtaining the cooperation for living driver surveys in one or two of these communities was doubtful, and in some cases impossible. Therefore, an alternate plan was developed using three communities providing a total of 150 driver fatalities in a 10-month, or longer period.

A major effort was undertaken to locate three potential survey communities that would satisfy the following set of sampling requirements :

1. The community must provide a sufficlent sample size of fatally injured drivers. Approximately 50 driver fatalities were needed from each community in a 10 -month period.

2. The medical examiner of the community must be willing to cooperate by submitting all approprlate driver fatality fluld samples along with complete fatal crash data.

3. The police department of the community must be willing to cooperate in the conduct of the roadside surveys.

4. The mayor (or equivalent) of the community must be in agreement with the surveys.

5. The legal authorities of the community must not have any legal objections to the surveys.

6. NHTSA must approve the communtty selection.

If any one of these requirements could not be met, the survey process could not take place in the given community. Yet, each requirement was a major hurdle. It was understood from the beginning of the search that if three communities could not be found satisfying all six of the requirements, some concessions would be necessary. 
A 1ist of 26 potential sampling areas was developed from driver fatality data obtained from numerous medical examiners, from telephone contacts with various city police departments and from data on motorvehicle traffic deaths collected by the National Safety Council. These areas are given in Table 2. Communities with less than 50 driver fatalities in a 10-month period were included in the list for consideration in case one or two communities with greater than 50 driver fatalities could be found to cooperate with the study.

MRI personally contacted a number of communities to solicit their cooperation in the study. NHTSA in Washington sent letters to the regional administrators of NHTSA describing the project and asking for their assistance in contacting some of the communities. The balance of the communities not contacted by MRI were contacted by representatives from the NHTSA regional offices. It was soon determined that possibly only one or two communities on the list would satisfy all of the requirements. Dade County, Florida was Interested in the study but the police participation needed was somewhat doubtful. The willingness of Las Vegas and Clark County, Nevada (and several other areas) to cooperate in the study was never determined. The Nevada area was subsequently ruled out because of the operational difficulties posed by the need to conduct roadside surveys in a county wide, predominately rural area.

Some of the responses to the inquiries expressed legal objections, some said that the police could not cooperate, and some sald the political environment would not allow the surveys to be conducted. At the time of the inquiry, there was serious doubt that the roadside surveys could be legally conducted in west coast states because of state regulations. Five favorable replies, however, were obtalned from those initially contacted. These communities were Dallas, Texas; Memphis, Tennessee; Houston, Texas; Tampa, Florida; and Atlanta, Georgia.

Visits were made to each of these five communities to describe the objectives of the program and to present some of the detalls of the planned survey. Meetings in each community were held between MRI, representatives of NHTSA, and various city/county officials. The community officials involved in most of the meetings included representatives from the Mayor's office, Governor's or City Traffic Safety Offices, Police, Traffic, Health and Legal Departments. A brochure describing the roadside drug usage survey was distributed before the meetings. This document gave the background for the survey, objectives of the program, procedures to be followed in the survey, and the need for the community cooperation. 
TABLE 2

\section{LIST OF POTENTIAL SAMPLING AREAS}

Area

New York, New York

Los Angeles, California

Miami and Dade County, Florida

Chicago, Illinois

Oakland and Alameda County,

California

Detroit, Michigan

Philadelphia, Pennsylvania

Tampa and H11lsborough County, Florida

Las Vegas and Clark County, Nevada

Dallas, Texas

Jacksonville, Florida

Orlando, Orange and Osceola

Counties, Florida

Houston, Texas

Phoenix, Arizona

Atlanta, Georgia

Wheaton, Illinols and DuPage County,

Illinois

Kansas City; Missouri

Memphis, Tennessee

Albuquerque and Bernalillo County, New Mexico

Nashville, Tennessee

Portland, Oregon

Everett and Snohomish

County, Washington

Columbus, Ohto

Minneapolis, Minnesota

Denver, Colorado

Indianapol1s, Indiana
Estimated Number of

Driver Fatalities in

a 10-Month Period.

(Based on 1973 Data

Except Where Noted)
Willingness to

to Cooperate with Roadside

Surveys

No

No

Possibly

No

100

99

75

$70 *$

66

51

46

45

39

38

36

$33 *$

33

$32 *$

31

31

$30 *$

$27 *$

23

23

17

17

16
No

No

No

No

Unknown

Yes

No

Unknown

No

Unknown

No

Unknown

No

Yes

Unknown

No

No

No

No

Unknown

No

No

* 1972 Accident Data. 
In these meetings it was stressed that MRI would coordinate all survey planning and activities. Also, the assistance of the various governmental agencies was discussed. The assistance of the police and traffic departments was required in selecting safe and suitable sampling locations. Pollce officers would be needed to provide traffic control and perform the act of stopping vehicles for sampling, under the direction of survey personnel. The assistance from the Health Department was needed in publicly backing the survey, approving of the fluid sampling procedures and helping arrange for registered nurses to be assigned to the survey. The Legal Department's help was sought in answering any legal problems.

As a result of these meetings, both Dallas and Memphis agreed to cooperate in the surveys. The extension of cooperation by the various agencies within these two cities came relatively quick after the initial meetings. Such was not the case in the other chree communities. The decisions by Houston, Tampa, and Atlanta not to cooperate in the study came after considerable time delay. Their decisions were based upon legal, political and police objections.

At this point in the search for survey communities, only two communities had been found from a list of 26 potential survey areas. However, neither of these two satisfied the first requirement. Thus, it was obvious that a relaxation of the community requirements must be made. The first requirement was modified.

It was decided between MRI and NHTSA that surveys would only be conducted in two communities--Dallas and Memphis--and that these surveys would be conducted over a 16-month period instead of a 10-month period as was originally planned. Using the most recent fatal accident data from these two areas it was estimated that a sum of 132 driver fatalities would be recorded in these areas in this period of time. This was considered a suitable substitution for the 150 driver fatalitles originally sought.

\section{E. Survey Plan for Collecting Fluid Samples from Living Drivers}

A survey sampling plan was developed after Dallas and Memphis were selected as the survey communities. The sampling in both communIties was to be conducted during the same time of day, day of week and at locations of previous crashes wherein a driver(s) was fatally injured. 
The traffic moving on the same street and in the same direction as the fatally injured driver was to be sampled. The fatal crash sites used were to be those for which the fatally injured driver died within 4-1/2 hr of the crash and for which spectmens were obtained and analyzed for drugs. There are several reasons for establishing a time limitation on the collection of fluid samples from the fatally injured drivers. First, the time lapse between the time of the crash and death will influence the estimate of the drivers condition at the time of the crash. This time effect is well known for alcohol, but not for other drugs. Clearly, the change in the body condition will be dependent on the specific drug in question. It is therefore important that fluid samples collected represent the state-of-the-body as close to the time of the fatal crash as possible. Secondly, the body fluids will be modified by medications, transfusions and the like that occur as part of the emergency medical procedures. The longer a driver survives, the greater effect these procedures would have upon the laboratory analysis.

Finally, there is the practical consideration regarding the point of diminishing returns. One must balance the loss of precision in the data attendant with longer lapse times agalnst the gain of only a small increase in the sample size.

A 4-hr time limttation has been used in alcohol studies. From a cumulative distribution of survival times for a sample of fatally injured drivers it was found that a limit of 4 . to $4-1 / 2 \mathrm{hr}$ included about $85 \%$ of the cases. Moreover, no appreciable increase in sample size would occur unless the limit were increased to over $10 \mathrm{hr}$. Based upon these data and others discussed in Section III-A, it was decided to establish a 4-1/2 hr time lapse between the time of the crash and death as a reasonable limit.

At the beginning of the study, it was envisioned that two survey trips would be made to each community in a 10-month period. This meant that the time lapse between a fatal crash and a living driver survey at the scene of that crash would vary from 1 or 2 weeks to 5 months. As the study progressed, and before the surveys had commenced, NHTSA expressed concern that, in 5 months, conditions at the scene of the fatal crash might change to such an extent that the living drivers sampled might not be representative of the drivers on the road at the time of the fatal crash. These changes could be due to a number of factors including traffic, seasonality, etc. Therefore, NHTSA suggested that sampling at intervals more frequent than 5 months would be necessary. At this point, a number of survey plans, each incorporating different sampling intervals, were developed. 
The most reliable way to survey motorists at the scene of a fatal crash and to control the conditions surrounding the crash is to center the survey around the exact time of the crash. In other words, be at the crash scene before and after the accident. Obviously, this is 1mpossible. The next best approach would be to survey the motorists at the crash scene exactly 1 week after the accident. This is feasible, but is a very expensive approach. A compromise was established between the 5-month and the 1-week sampling interval in that the living drivers surveyed at a fatal crash site would be surveyed within 6 weeks of the exact time of the accident. NHTSA felt that the living drivers sampled within this 6 week period would be representative of the drivers on the road at the time of the fatal crash.

Based upon an estimated 132 driver fatalities from both communities in a 16-month period, it was decided to conduct 10 surveys in Dallas and 8 in Memphis. The surveys in each community were to be conducted roughly at 6-week intervals, depending, of course, upon the timing of the driver fatalities. This schedule was established to provide the 1,200 living driver samples required by the contract. One extra survey was conducted in Dallas (giving a total of 11 for that community). This was done to increase the sample size of dead and living drivers from Dallas when it was determined that the number of dead drivers usable for living driver surveys from both communities would be less than 132 . Some fatally injured driver data were recelved from both communities before the living driver sampling plan was approved by NHTSA. By the time the plan was approved these driver fatalities were over 6 weeks old and could not be used In the planning of the living driver surveys. The time delay in starting the surveys later required the fatally infured driver sample collection time in Dallas and Memphis to be increased from 16 months to 22 and 20 months, respectively.

Early in the study, arrangements were made with both the Dallas and Memphis Police Departments to send us, on a weekly basis, a listing of the number of fatalities plus hard copies of the accident reports for the fatal driver accidents. These data were assembled and when the 5 th week anniversary of the oldest driver fatality was observed, a survey schedule for the community was developed. The schedule finally developed included crash locations where drivers had been killed between 1 and 6 weeks previous to the planned starting date of the survey. The medical examiners office was contacted during the survey planning to determine if the appropriate fluid specimens had been collected from the fatally injured drivers. The timing of some of the surveys was such that many times the fluid samples from the medical examiners office did not arrive at MRI for chemical analysis until after the survey had been conducted. 
Once the survey schedule was established, the police accident reports were studied and a personal inspection of each driver fatality crash site was made. A survey location close to the crash site was selected utllizing all safety requirements. In some cases the interview location selected was on private property. A signed statement was then obtained from the property owner of the site granting permission to use their off-street parking areas for the motorist's interviews.

The time of sampling at a given site was matched perfectly as far as time of day and day of week was concerned. The sampling at each site in Memphis was done over a 3-hr interval centered as near as possible at the time of the previous crash. Inftially, a 2-hr sampling - period was used at each site in Dallas. This was later changed to a $2-1 / 2$ hr period to provide an adequate sample for Dallas. The longer sampling period was chosen for Memphis to help equalize the number of living drivers surveyed from each community. (Memphis was expected to have fewer driver fatalities than Dallas.)

Every effort was made to use every fatally injured driver crash site. However, some slight shift in site locations was necessary. There are valid reasons for making these changes and reasonable guldelines for doing so. For instance, no sampling was done on freeway facllities or under conditions where speed, congestion, or both might create traffic congestion and/or an accident situation. The sampling site for a freeway crash was located at the end of the first downstream exit ramp from the crash location. Two-way walkie-talkles were used among the survey crew sometimes when working these off-ramp sites to ensure that the motorists interviewed had passed the fatal crash scene. In some cases, the sampling site on a non-freeway-type highway was moved a few hundred feet upstream or downstream of the site of the crash where an area of enforced reduced speed was avallable. Likewise, when a crash occurred in an urban setting at an intersection, the sampling point was sometimes moved a block or two upstream of the intersection where a more sultable location for placing the moblle laboratory could be found.

Sampling was not generally restricted because of anticipated low traffic volumes. At a couple of survey sites only two to three motorists were intervlewed. However, one survey site was omitted from consideration when it was discovered we would be surveying motorists at 3 AM coming out of a dead end street which contained only four residences. Under these conditions we did not expect any traffic. 
MRI, in accordance with the Department of Health, Education and Welfare's (DHEW's) regulations on "Protection of Human Subjects," (45 CFR 46 as ammended) has established a Human Subjects Committee. This committee consists of several technical and administrative representatives from MRI, several physicians, a professor of psychology from a state university, a lawyer, several representatives of civic organizations, and a housewife. This committee reviews research proposals prior to submission and research plans after acceptance for compliance with DHEW and MRI policy regarding the protection of rights of human subjects. In all programs involving human subjects, the research plan must contain a protocol that informs the subjects of the risks and benefits of the research and requires their informed consent for participation. If at any time the Chairman of the Human Subjects Committee determines that the human subjects are being placed at greater risk than approved by the committee, he can order the research stopped pending review and approval by the committee.

A protocol for the living driver surveys was developed early in the study and submitted to the MRI Human Subjects Committee for approval. This was a voluntary action and one not required by the contract. The protocol was approved by the commlttee before the surveys were begun. The comittee regularly reviewed the project throughout the period the surveys were conducted. A survelllance form (see Appendix B, Table B-1) was submitted quarterly to the Human Subjects Committee. In addition, briefing reviews were held semi-annually with a subcommittee to ensure that the rights of the living drivers stopped during the surveys were being protected and that the approved protocol was being followed. The minutes of these semi-annual briefing reviews were then submitted to the Human Subfects Committee for review and action, if necessary. Excerpts from minutes of several of the Human Subjects Committee Meetings dealing with the review of the study are presented in Appendix B, Table B-2. At no time during the study did the committee consider the protocol violated, nor the rights of the living drivers compromised.

\section{F. In-Field Survey Procedure}

A press briefing was held in each community 1 day prior to the start of the first survey period in that community. The briefings were held in municipal bulldings and were presided over by the Director of the Health Department and a representative from MRI. Reporters from 
local newspapers, radio and TV stations attended the meetings and gave us excellent mass media publicity. The favorable survey publicity helped to give us a higher-than-expected cooperation rate from the motorists:

The roadside survey procedure was patterned after that used previously in another study of drug use among drivers.* A major item of equipment used during the survey was a moblle laboratory. This was a rented motor home which contained heating, cooling, refrigeration and sanitary facilities together with counter and storage space capabilities and necessary seating arrangements for effective interviewing. The unit contained its own power generating equipment for both. Internal and external lighting. Four flood lamps were placed on the roof of the motor home to provide lighting of the immediate parking area. A sign describing the nature and backing of the survey was placed on the side of the motor home, in view of the motorist. A portable, diamond-shaped sign alerting motorists to the roadside survey was mounted on its own support and placed on the curb upstream of the survey site.

The sampling crew consisted of an MRI fleld supervisor, an MRI assistant, a locally hired registered nurse for drawing blood, and a police officer to direct traffic and intercept randomly selected vehicles. When possible, particularly late a night, a locally hired driver was used to assist intoxicated motorists to their next destination. The police officers were a necessary and integral part of the survey. They were effective at stopping motorists and undoubtedly contributed considerably to the high degree of motorist cooperation achleved.

The survey procedure was as follows. When another interviewee was needed, the supervisor would draw a number from a table of random numbers, wait the number of seconds corresponding to the number selected and then notify the police officer. The latter would then stop the next male motorist (who could reasonably be stopped safely) and direct him to the survey supervisor. The supervisor would introduce himself to the motorist and explain that he was conducting a drug survey for the U.S. Department of Transportation. He assured the motorists that his cooperation was voluntary and anonymous, and that nothing we found could be used against him. The motorist was given a letter from the Traffic Safety Coordinator (in Dallas) or the Director of the Memphis and Shelby

* Glauz, W. D., R. R. Blackburn, "Drug Use Among Drivers," Contract No. DOT-HS-119-2-440 (MRI Project 3668-E), Midwest Research Institute Final Report, February 1975 (DOT-HS-801411). 
County Traffic Safety Coordinating Committee (In Memphis) requesting his cooperation (see Appendix C). The motorist was then asked to enter the van to answer some questions.

Once in the van, the driver was asked a series of questions about his age, health and what medication, if any, he was taking. A Breathalyzer test was administered by the assistant. The driver was then given a standard urine sample bottle and asked to step into the restroom and give us a urine sample.

When he returned, we asked him for a blood sample. Each driver asked for a blood sample was also offered $\$ 10$ in order to maximize the willingness of the motorist to donate the sample. The registered nurse withdrew a 20 to $30 \mathrm{ml}$ sample using standard Vacutainers. Blood samples were not requested from motorists who were under the legal age of consent or whe, in the opinion of the nurse, had chronic health problems.

The final sample requested of the motorist were finger and $11 p$ swabs (for detection of marijuana). A Q-tip dipped in ethanol was rolled around the 11ps to pick up residue of marijuana. A separate Q-t1p, also dipped in ethanol, was used to swab the digits of each finger on the right hand. The same process was repeated for the left hand using a third Q-tip. The three Q-tip samples were then placed in separate screw top glass tubes. It was later decided not to chemically analyze the swabs and they were discarded.

After each fluid and swab sample was collected, it was coded with the corresponding interview number. The samples were then refrigerated until they were shipped by alr to MRI, where they were refrigerated until chemically analyzed.

At the end of the survey the motorist was given the Breathalyzer result, some literature, and an opportunity to ask questions. We used all reasonable means to prevent the driver from continuing to drive if his blood alcohol concentration (BAC) was at or above the local legal presumptive limit. This included encouraging him to let a sober passenger do the rest of the driving, or requesting that someone else, such as our part-time driver, drive him to his local destination.

A number of motorists consented to give a urine sample but could not produce a specimen at the time, or gave an inadequate amount (less than $20 \mathrm{ml}$ ). These motorists were asked to place a urine sample In a coded specimen bottle furnished for that purpose, within the next 
several hours. The drivers were requested to write on the label the date and time of the sample, and place $1 t$ in the furnished, self-addressed, stamped mailer.

In most instances, the motorist interviews were conducted withIn the van. However, when a motorlst was reluctant to leave his car, every attempt was made to conduct the interview at the car. This approach permitted the reluctant motorist to take a more favorable attitude toward the survey and enabled us to obtain the interview and breath sample at the car. At the conclusion of the outside interview we asked for a urine and blood sample with the offer to pay $\$ 10$ for the samples. Many times the offer of payment was sufficlent to get the motorist out of his car, into the van, and to provide the necessary fluid samples.

\section{G. Development of Chemical Analysis Methods and their Application to Driver Specimens}

The physiological specimens collected from both fatally injured drivers (FID) and similarly exposed living drivers (SELD) were analyzed for drugs and alcohol as follows:

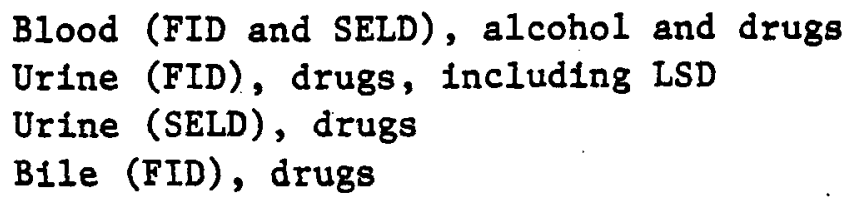

In addition, small samples of all blood specimens were reserved for marijuana analysis by radioimmunoassay. This assay was not conducted on this project--1,669 I ml plasma specimens were shipped to White Memorial Medical Center, Los Angeles, California for analysis on a separate project. The alcohol swabs of the hands, lips and palate, collected for marijuana contact analysis, were not analyzed on this project.

This section describes the experimental methodology developed for the analysis of these specimens. Plasma, bile, and urine were examined for 43 drugs which were quantitatively analyzed (these drugs are given in Table 3). In addition, nicotine and sallcylates were analyzed qualitatively, and alcohol determinations were conducted on blood samples. LSD analyses were conducted on fatally injured driver urine specimens. 
TABLE 3

DRUGS AND DRUG GROUPS INCLUDED IN THE ANAIYTICAL SCREEN

Sedatives and Hypnotics

Phenobarbital (Luminal)

Pentobarbital (Nembutal)

Amobarbital (Amytal)

Secobarbital (Seconal)

Butabarbital (Butisol)

Butobarbital (Butethal)

Diphenylhydantoin (Dilantin)

Glutethimide (Doriden)

Methaqualone (Quaalude)

Tranquilizers

Meprobamate (Miltown)

Chlordiazepoxide (Librium)

Diazepam (Valium)

Chlorpromazine (Thorazine)

Promazine (Sparine)

Thioridazine (Mellaril)

Trifluoperazine (Stelazine)

oxazepam.

Stimulants and Antidepressants

Methylphenidate (Ritalin)

Imipramine (Tofrani1)

Amitriptyline (Elavil)

Amphetamine (Dexedrine)

Methamphetamine (Desoxyn)
Antihistamines and Decongestants

Chloropheniramine

Diphenhydramine

Tripelennamine

Methapyriline

Pheny 1propanolamine

Narcotic Analgesics

Nalorphine (Nalline)

Morphine

Codeine

Meperidine (Demerol)

Cocaine

Methadone (Dolophine)

Hydromorphone (Dilaudid)

Propoxyphene (Darvon)

Hallucinogens

Dimethyltryptamine (DMT)

Diethyltryptamine (DET)

Mescaline

2,5-dime thoxy-4-methy lamphe tamine (STP)

Miscellaneous

Phendimetrazine

Procalne

Lobeline

Quinine 
An analytical methodology was developed based on prior methodologies used for analysis of drugs in driver spectmens.*

The total analytical scheme involves: the preparation of spec1mens, including hydrolysis of glucuronides and sulfate ethers, and extraction of the hydrolyzed specimens using a nonionic resin; the qualitative examination of the extracts by thin-layer chromatography; and finally the quantitative confirmation of thin-layer findings by gas chromatography. Blood alcohol was determined using a gas chromatographic technique on blood head-space. LSD was assayed using radioimmunoassay techniques. Figure 1 depicts the total analytical scheme.

The methodologles were developed and evaluated using blood, urine and bile specimens spiked with known levels of the drugs of interest. Continuous inclusion of standards and controls throughout the development and application of these methods ensured quality control.

Described below are the following pertinent descriptions of the analytical methodology.

Preparation of specimens for analysis of drugs. Analysis of plasma, urine and bile.

Analysis of fatally infured driver urine for LSD. Analysis of blood for alcohol.

Supplies and reagents for analyses.

1. Preparation of specimens for analysis of drugs: Upon receipt, specimens were refrigerated until preparation. Storage was overnight only. The amounts of material recelved were measured and logged in. The unpreserved blood was centrifuged to produce plasma. Fifteen milliliters of plasma, $10 \mathrm{ml}$ of bile, and $20 \mathrm{ml}$ of urine were removed for analysis and remaining fluids were stored frozen to awalt marijuana and LSD analysis. If the amounts mentioned above were not available, then $1 \mathrm{ml}$ was frozen for future use and the remaining fluid (measured) was used in the analysis described in this document. Five milliliters of whole fluoridated blood was refrigerated to awalt blood alcohol analysis.

* Woodhouse, E. J., "The Incidence of Drugs in Fatally Infured Drivers," Contract No. DOT-HS-119-3-627 (MRI Profect 3747-C) Midwest Research Institute Final Report, October 1973. 


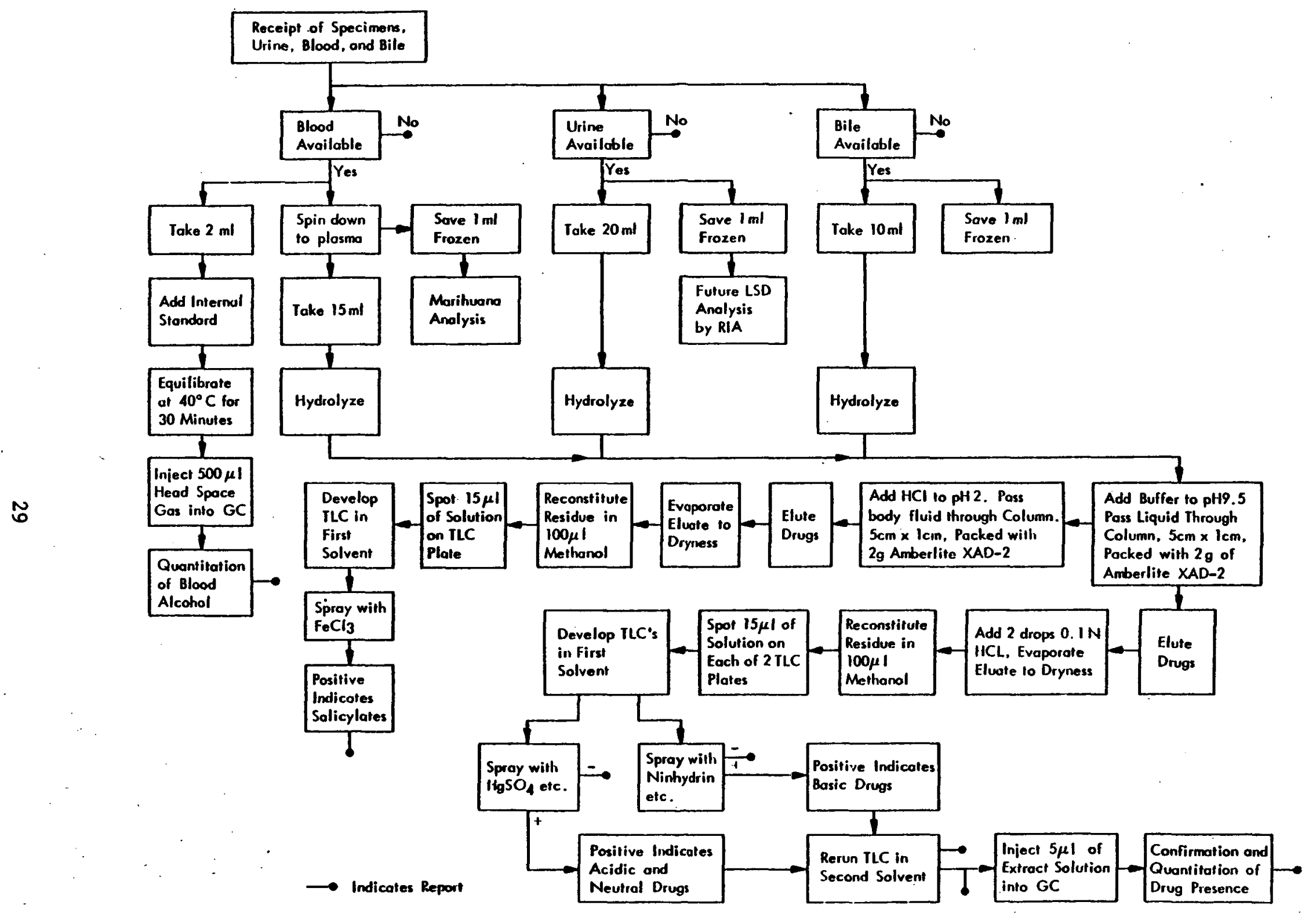

Figure 1 - Analytical Screen for Determination of Drugs in Body Fluids of Drivers 
2. Analysis of plasma, urine and bile for drugs: Plasma and urine samples from fatally infured and living drivers and bile samples from fatally injured drivers were analyzed for 45 drugs--all those shown in Table 3 plus salicylates and nicotine. All analyses were quantitated except those for salicylates and nicotine. Described below are the hydrolysis and extraction, thin-layer chromatographic and gas chromatographic analysis steps.

a. Hydrolysis and extraction: The analysis involved hydrolysis of the fluids to free any drugs present from conjugates. Drugs in body fluids are often largely present as conjugates with glucuronic acid and as ethereal sulfates. When present as such, they are not extracted and detected in an analytical scheme such as presented here. Liberation of glucuronides and sulfates was accomplished using a mixture of glucuronidase and sulfatase enzymes as follows. To prepare the enzyme solution, $6.8 \mathrm{~g}$ of sodium acetate trihydrate was dissolved in $250 \mathrm{ml}$ distilled water. To this solution was added $600 \mathrm{mg}$ of sulfatase (Type H-1, Sigma) containing glucuronidase. Five milliliters of this solution was added to $20 \mathrm{ml}$ of urine, $10 \mathrm{ml}$ per $15 \mathrm{ml}$ of plasma, and $10 \mathrm{ml}$ per 10 $\mathrm{ml}$ of bile. The body fluids were then adjusted to $\mathrm{pH} 5.0$ with $6 \mathrm{~N}$ hydrochloric acid and incubated in covered containers at $37^{\circ} \mathrm{C}$ for $24 \mathrm{hr}$. After incubation, all specimens were filtered and prepared for extraction.

Extraction of drugs from all body fluids was accomplished using a nonionic resin, Amberlite XAD-2, avallable from Rhom and Haas, Inc. The resin used was as provided by Brinkmann Instruments, Inc., for its "Drug Skreen" system. The body fluid was buffered and passed through a column of the resin. The drugs were retained on the colum and then eluted with an organic solvent. The detailed process was as described below.

The absorbent cartridges, as shown in Figure 2, were placed in aspirator racks without the filter cartridges. Each adsorbent cartridge contained a $5 \mathrm{~cm}$ colum of $2 \mathrm{~g}$ of resin.

The absorbent cartridges were moistened with $5 \mathrm{ml}$ of distilled water. The filtered; hydrolyzed body fluids were taken to $\mathrm{pH} 7$ with sodium hydroxide and then buffered at $\mathrm{pH} 9.5$ by the addition of 3 $m l$ of a buffer consisting of a mixture of saturated sodium bicarbonate with saturated sodium carbonate added to adjust the pH to 9.5. The body fluids were then passed through the adsorbent cartridges. The fluid passing through the cartridge was retalned for further use in salicylate determination. 


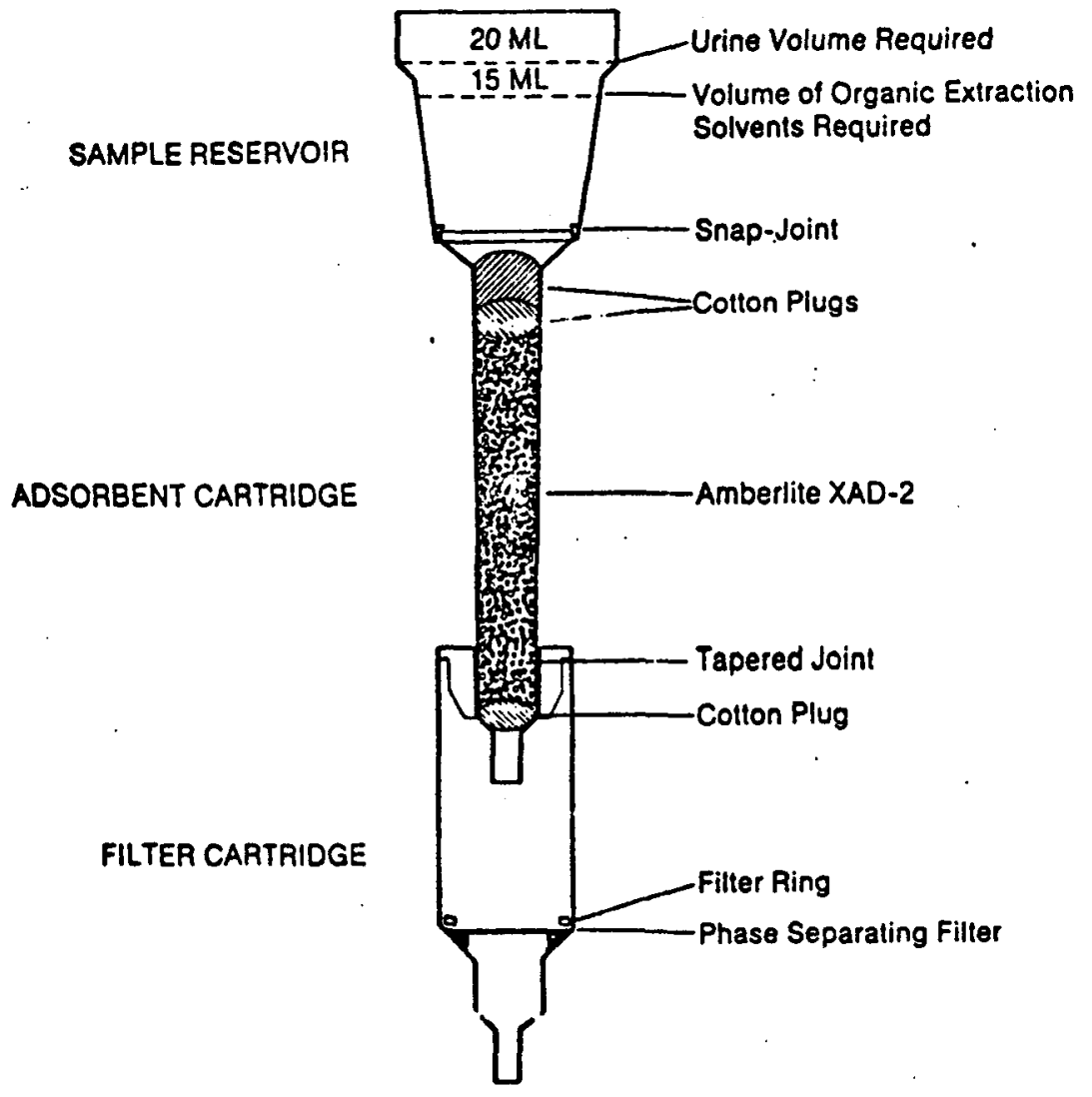

Figure 2 - Extraction Assembly 
The adsorbent cartridges were aspirated for $20 \mathrm{~min}$ to remove water, and then placed in the filter cartridges for elution. The cotton plugs were removed from the top of the adsorbent cartridge, the phase separating paper was wet with elution solvent (1,2-dichloroethane/ ethyl acetate, $4: 6)$ and $15 \mathrm{ml}$ of elution solvent passed through the adsorbent cartridge in three $5 \mathrm{ml}$ batches. The eluate was collected in a glass conical evaporation vessel, acidifled with 2 drops of $0.1 \mathrm{~N}$ hydrochloric acid and evaporated to dryness at $45^{\circ} \mathrm{C}$ in a water bath under ventilation. This eluate contained all barbiturates, neutral and basic drugs. The original body fluids were then adjusted to $\mathrm{pH} 2$ with hydrochloric acid and passed through fresh adsorbent cartridges to retain the salicylates which were then eluted with $15 \mathrm{ml}$ of elution solvent $(1,2-$ dichloroethane/ethyl acetate, $4: 6$ ) and evaporated to dryness at $45^{\circ} \mathrm{C}$ in a water bath under ventilation.

Thus, two extract residues resulted from each body fluid, one containing all drugs of interest except salicylates; the other contalning the salicylates. These extract residues were reconstituted in $0.5 \mathrm{ml}$ methanol, transferred to $1 / 2$ dram glass vials, evaporated to dryness at room temperature, capped tightly and stored frozen to await analysis. Control specimens of urine and plasma spiked with drugs were run with every batch of driver specimens to monitor the extraction performance.

b. Thin-layer chromatographic analysis for drugs: Extract residues from blood, urine, and bile were examined for the presence of drugs using thin-layer chromatography. Both resldues were examined; the salicylates residue, and the residue containing all other drugs of interest.

(1) Salicylates residue: The salicylates residues were reconstituted in $0.1 \mathrm{ml}$ of methanol and $15 \mu 1$ spotted onto thinlayer chromatographic plates ( 20 by $20 \mathrm{~cm}, 250 \mu$ Silica Gel G) along with standards of aspirin and salicylic acid. The plates were developed for $15 \mathrm{~cm}$ in a saturated tank containing ethyl acetate/methanol/ammonia, $85: 10: 5$. After development, the plates were dried in air at room temperature and sprayed with ferric chloride $(5 \mathrm{~g}$ ferric chloride in $100 \mathrm{ml}$ distilled water) to visualize the salicylates. The salicylates (aspirin and salicylic acid) appear as purple spots on a tan background with an $R_{f} 0.07$. Detection sensitivity is $1 \mu_{8}$ on the plate and in the range of 1 to $2 \mu \mathrm{g} 1 \mathrm{ml}$ in body fluids. Confirmation could be achieved by using a second solvent (benzene/methanol/acetic acid, 45:8:4) in which salicylates exhibited a mobility of 0.68 . 
(2) Other drug residue: These residues were reconstituted in $0.1 \mathrm{ml}$ of methanol and $15 \mu 1$ was spotted on each of two thinlayer chromatographic plates (20 by $20 \mathrm{~cm}, 250 \mu$ Silica Gel G). Up to 10 specimens and 8 group drug standards were spotted per plate. Both of the plates were developed in a saturated tank containing ethyl acetate/methanol/ammonia, 85:10:5. The plates were then air-dried at room temperature. One plate was examined for acidic and neutral drugs (sedatives and hypnotics), the other plate examined for basic drugs (opiates, amphetamines, tranquilizers, etc.).

c. Acidic and neutral drugs: The thin-layer chromatographic plate was visualized by spraying with mercuric sulfate, diphenyl carbazone and vanilin successively, noting all color formation between and after sprays. Mercuric sulfate $\left(\mathrm{HgSO}_{4}\right)$ spray consisted of a solution of $5 \mathrm{~g}$ of mercuric oxide in $100 \mathrm{ml}$ water to which $20 \mathrm{ml}$ of concentrated sulfuric acid was added, and the whole solution diluted to $250 \mathrm{ml}$ with distilled water. Diphenyl carbazone (DPC) spray consisted of $100 \mathrm{mg}$ diphenyl carbazone dissolved in $50 \mathrm{ml}$ chloroform and stored in a dark bottle. The vanillin spray consisted of $5 \mathrm{~g}$ of vanillin dissolved in $100 \mathrm{ml}$ concentrated sulfurlc acid. This latter spray was stored, refrigerated, and made up fresh weekly.

The thin-layer chromatographic characteristics of the acidic and neutral drugs are shown in Table 4. If tentative positives were found in the body fluid extracts using the first solvent, they were rerun using the second developing solvent (chloroform/acetone, 90:10, unsaturated tank).

d. Basic drugs: The thin-layer chromatograpilic plate was visualized by spraying with ninhydrin (500 $\mathrm{mg}$ in $100 \mathrm{ml} \mathrm{l-butanol}$ ) and warming the plate under ultraviolet light. This was followed by spraying the cooled plate with lodoplatinate (IOP) spray and noting all color formation between and after sprays. Ninhydrin spray was stored refrigerated. Iodoplatinate spray was prepared by dissolving $1 \mathrm{~g}$ of platinum tetrachloride in $100 \mathrm{ml}$ of water and mixing this solution with $300 \mathrm{ml}$ of water containing $10 \mathrm{~g}$ of potassium lodide. This solution was refrigerated and diluted $1: 1$ with $2 \mathrm{~N}$ hydrochloric acid prior to use. The thin-layer characteristics of the basic drugs are shown in Table 5 . If tentative positives were found in the body fluld extracts using the first solvent, they were rerun using the second developing solvent (Benzene/methanol/ethyl acetate/ammonia, 75.5:13.0:10.0:1.5, saturated - tank). 


\section{THIN-LAYER GHROMATOGRAPHIC GHARACTERISTICS}

OF ACIDIC AND NEUTRAL DRUGS

\section{Group}

Standard

$1 \quad\left\{\begin{array}{l}\text { Glutethimide } \\ \text { Secobarbita1 } \\ \text { Amobarbita1 }\end{array}\right.$

$\leftarrow \quad 2 \quad\left\{\begin{array}{l}\text { Meprobamate } \\ \text { Pentobarbital } \\ \text { Butobarbital }\end{array}\right.$

$3 .\left\{\begin{array}{l}\text { Diphenylhydantoin } \\ \text { Butabarbital } \\ \text { Phenobarbital }\end{array}\right.$
Sensitivity Limit of

Standard on Plate
$(\mu g)$
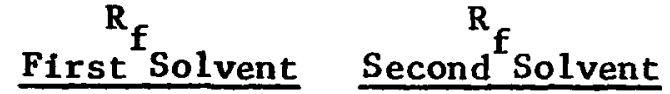

2

0.5

0.5

0.77

0.46

0.42

0.58

2

0.5

0.5

0.46

0.39

1

0.5

1

\subsection{4}

0.42

0.23
0.70

0.56

0.50

0.05

0.51

0.45

0.28

0.45

0.39
Colors

$\mathrm{HgSO}_{4}$ DPC Vanillin

White Red -

White Blue -

White Violet -

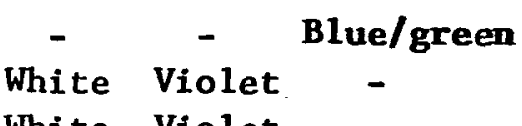

White Violet -

White Violet -

White Violet -

White Violet -

Note: The sensitivity limit for detection in body fluids is in the range of 0.25 to $0.5 \mu \mathrm{g} / \mathrm{ml}$ for barbiturates and diphenylhydantoin, and $1 \mu \mathrm{g} / \mathrm{ml}$ for glutethimide and meprobamate. 


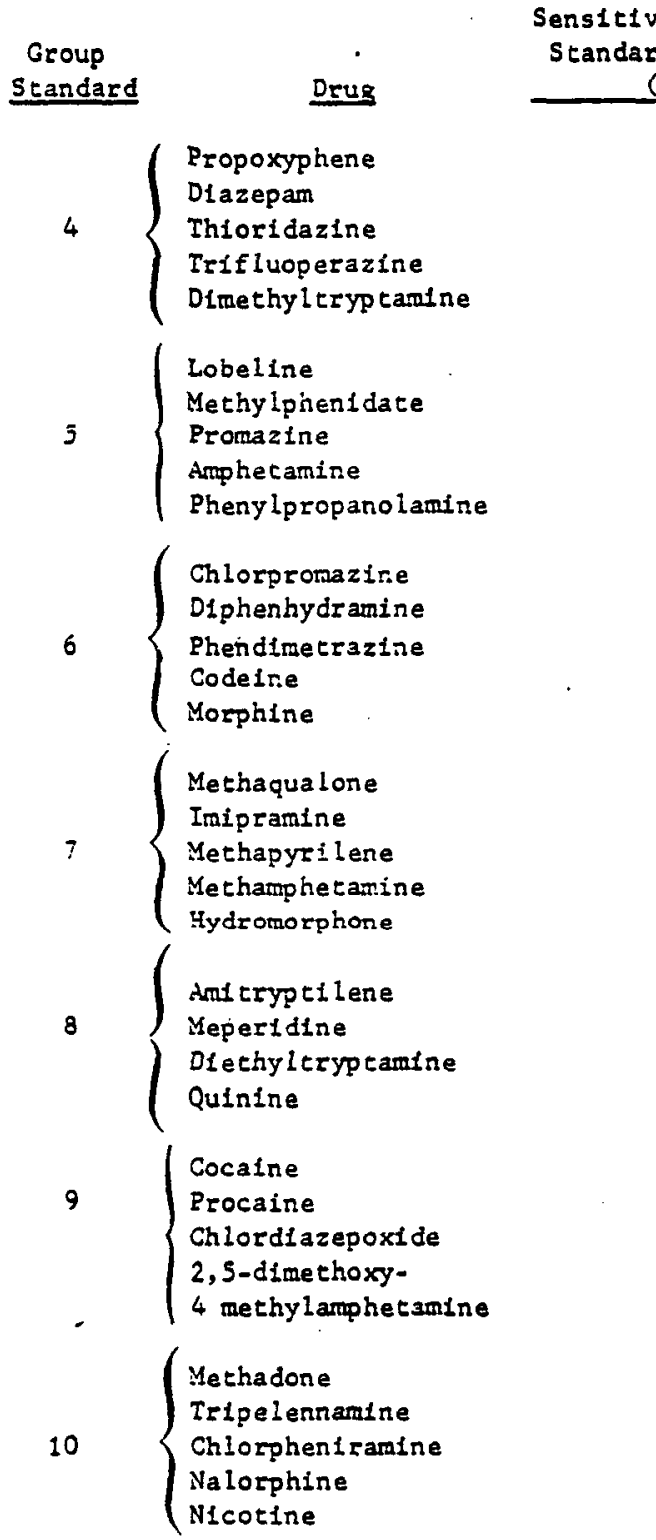

$(\omega g)$
$(-g)$
(ug)

2
2
1
1

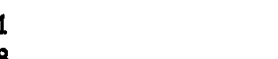

1

2

2

1

1

1

4

4

1

2

2

0.73
0.66

0.66

0.38

0.14

0.71

0.63

0.63

0.44

0.73

0.68

0.48

0.43

0.75

0.70

0.56

0.29

0.60

$\begin{array}{ll}1 & 0.75 \\ 1 & 0.70 \\ 1 & 0.56 \\ 1 & 0.29 \\ 1 & 0.60\end{array}$

Note: The sensitivity limit for detection of the basic drugs in body flulds is in the range of 0.5 to 1 ig/mi for all drugs except the following: methylphenidate $\sim 4 \mathrm{Hg} / \mathrm{ml}$; phendimetrazine $\sim 2-8 / \mathrm{ml}$; and methamphetamine $\sim 2+\mathrm{g} / \mathrm{ml}$. 
It should be stressed at this point that the thin-layer chromatographic findings on the body fluids were not taken as conclusive evidence of a drug or drugs except in the case of nicotine and the salicylates. In screening for more than 40 drugs, it was not possible to achleve complete separation of all drugs in any one developing solvent. The use of two developing solvents resolved this problem to a significant degree but even so, the thin-layer results were still regarded as tentative except in the case of nicotine and salicylates which were recorded in a large percentage of the body fluids with definitive thinlayer chromatographic characteristics.

Body fluid extracts yielding tentative positives for the drugs of interest (excepting nicotine and salicylates) were subjected to gas chromatographic confirmation and quantitation as described in the next section.

e. Gas chromatographic analysis for drugs: Gas chromatographic analysis was performed on those body fluid extracts indicating positives for drugs on the thin-layer chromatographic screen. The extracts, as used for the thin-layer work, were dosed with a known amount of Internal standard and examined on a Tracor Model MT220 gas chromatograph. Two columns were employed in this investigation: (1) a $6 \mathrm{ft} x$ $4 \mathrm{~mm}$ glass column with $3 \%$ OV-1 on $80-100$ supelcoport; and (2) a $3 \mathrm{ft} x$ $4 \mathrm{~mm}$ glass colum with $1 \%$ CHMD on 100-120 Gas Chrom Q. The carrier gas was nitrogen at a flow rate of $60 \mathrm{ml} / \mathrm{min}$, detector (flame lonization) temperature was $260^{\circ} \mathrm{C}$, injector port temperature was $240^{\circ} \mathrm{C}$. The column temperature was varied. One to five microliters of the extract was injected onto the column. Table 6 shows the column, conditions, and the internal standard, absolute, and relative retention times for the drugs of interest on these columns. Pure standards with internal standards were injected immediately before each run. The resulting gas chromatograms yielded the amount of drugs present (if confirmed) in the extract. The internal standards were used as a check on both the retention time and peak height data.

In order to calculate the amount of drug present in the original body fluids, extraction efficiencles were obtained for each drug found in the body fluids and confirmed by gas chromatography. Specimens of human urine and plasma were spiked with pure drugs at levels of 1,2 , 5 and $10 \mu \mathrm{g} / \mathrm{ml}$ in duplicate. These specimens were hydrolyzed, extracted and reconstituted in exactly the same manner as the driver body fluids. Gas chromatography then revealed the amount extracted and thus the extraction efficiency. Extraction efficlencles determined in the program 
TABLE 6

GAS CHROMATOGRAPHIC CONDITIONS, INTERNAL STANDARDS, AND ABSOLUTE AND RELATIVE RETENTION TMES

\begin{tabular}{|c|c|c|c|c|c|c|c|}
\hline$\theta^{\circ}$ & & & & & Drus Reten & Ion Times & \\
\hline & Temper & tuxe ${ }^{\circ} \mathrm{C}$ & Internal & Absolut & $(\min )$ & Rela & Ive \\
\hline Drug & Colum 1 & Colum 2 & Standard & Colum 1 & Column 2 & Colum 1 & Colum 2 \\
\hline Amphetamine & 140 & 120 & Phenylpropanolamine & 1.7 & 0.8 & 0.71 & 1.33 \\
\hline Mechamphetamine & 140 & 120 & Phenylpropanolamine & 2.1 & 0.8 & 0.88 & 1.33 \\
\hline Phenylpropanolamine & 140 & 120 & Amphetamine & 2.4 & 0.6 & 1.41 & 0.75 \\
\hline Pentobarbital* & 180 & 150 & Phenobarbital & 3.3 & 2.0 & 0.42 & 0.36 \\
\hline Amobarbltal* & 180 & 150 & Phenobarbital & 3.0 & 2.8 & 0.38 & 0.51 \\
\hline Secobarbital* & 180 & 150 & Phenobarbital & 3.8 & 3.4 & 0.48 & 0.62 \\
\hline Butabarbital* & 180 & 150 & Phenobarbital & 2.5 & 2.3 & 0.32 & 0.42 \\
\hline Bucobarbital* & 180 & 150 & Phenobarbital & 2.5 & 2.2 & 0.32 & 0.40 \\
\hline Phenobarbi tal* & 180 & 150 & Pentobarbital & 7.9 & 5.5 & 2.39 & 2.75 \\
\hline Glutethimide & 200 & 190 & Procalne & 1.4 & 5.5 & 0.52 & 1.57 \\
\hline Diphenylhydan Eo1n* & 200 & - & Methadone & 7.9 & - & 2.08 & - \\
\hline Tripelennamine & 200 & 190 & Anf tripeyline & 2.1 & 2.4 & 0.47 & 0.47 \\
\hline Methapyrilene & 200 & 190 & Anitriptyine & 2.2 & 2.9 & 0.49 & 0.57 \\
\hline Diphenhydramine & 200 & 190 & Anitriptyline & 1.4 & 1.3 & 0.31 & 0.25 \\
\hline Chlorphenf ramine & 200 & 190 & Ant triptyline & 2.6 & 2.7 & 0.58 & 0.53 \\
\hline Imipramine & 200 & 190 & Anf triptyline & 5.3 & 6.4 & 1.18 & 1.25 \\
\hline Amitriptyline & 200 & 190 & Imipramine & 4.5 & 5.1 & 0.85 & 0.80 \\
\hline Methylphenidate & 200 & 190 & STP & 0.9 & 0.8 & 1.50 & 1.00 \\
\hline Meperidine & 200 & 190 & STP & 0.9 & 0.7 & 1.50 & 1.40 \\
\hline Phendimetrazine & 200 & - & STP & 0.4 & - & 0.67 & - \\
\hline Dimethyl tryp tamine & 200 & 190 & Amltriptyline & 1.1 & 3.8 & 0.24 & 0.75 \\
\hline Diethyl eryptamine & 200 & 190 & Amstriptyine & 1.9 & 4.4 & 0.42 & 0.86 \\
\hline $\begin{array}{l}2,5 \text {-Dime thoxy-4- } \\
\text { methyl amphetamine (STP) }\end{array}$ & 200 & 190 & Meperidine & 0.6 & 0.5 & 0.67 & 0.71 \\
\hline Meprobamate & - & 190 & Procaine & - & 2.2 & - & 0.53 \\
\hline Methaqualone & 200 & 190 & Procaine & 3.8 & 11.4 & 1.41 & 3.26 \\
\hline Lobeline & 200 & 190 & Methadone & 1.3 & 2.2 & 0.34 & 1.83 \\
\hline Propoxyphene & 200 & 190 & Methadone & 4.4 & 3.1 & 1.16 & 2.58 \\
\hline Methadone & 200 & 210 & Procalne & 3.8 & 1.2 & 1.41 & 0.34 \\
\hline Cocaine & 200 & 210 & Methadone & 4.9 & 3.0 & 1.29 & 2.50 \\
\hline Procaine & 200 & 210 & Mechadone & 2.7 & 3.5 & 0.71 & 2.92 \\
\hline Chlorprowazine & 250 & 240 & Promazine & 2.7 & 2.7 & 1.59 & 1.69 \\
\hline Promazine & 250 & 240 & Chlorpromazine & 1.7 & 1.6 & 0.63 & 0.59 \\
\hline Tr1fluoperazine & 250 & 240 & Chlorpromazine & 2.9 & 3.7 & 1.07 & 1.37 \\
\hline Thiorfdazine & 250 & - & Chlorpromazine & 8.1 & - & 3.00 & - \\
\hline Chlord1azepoxfde & 250 & 240 & Chlorpromazine & 1.9 & 7.6 & 0.70 & 2.81 \\
\hline Diazepan & 250 & 240 & Chlorpromazine & 1.6 & 4.6 & 0.59 & 1.70 \\
\hline Codeine & 250 & 240 & Nalorphine & 1.5 & - & 0.71 & - \\
\hline Morphine* & 250 & 240 & Nalorphine & 1.3 & - & 0.71 & - \\
\hline Nalorphine & 250 & - & Codeine & 2.1 & - & 1.40 & - \\
\hline Hydromorphone* & 250 & - & Nalorphine & 1.8 & - & 0.86 & - \\
\hline Quinine & 250 & - & Chlorpromaz ine & 3.9 & - & 1.44 & - \\
\hline
\end{tabular}

* Methyl derivatives: produced by on-colum methylation using 0.2 M erimechylanilinium hydroxdde (Meth-Elute); $1 \mathrm{Hg}$ of Meth-Elute per $3 \mathrm{Hg}$ of drug. 
are listed in Table 7. There is no significant difference in extraction efficiencles run at different spiking levels or between plasma and urine except in the cases noted in Table 7 . Bile was not avallable in sufficent quantities to run extraction efficiency experiments; it was assumed that the extraction efficiencies from bile would be the same as from plasma and urine.

3. Analysis of fatally injured driver urine for LSD: Urine samples from 669 fatally injured drivers were assayed for LSD using radioimmunoassay. Samples were run in batches of 30 to 40 with standards for calibration of each run and control samples to check accuracy and reproducibility. Tritiated LSD was mixed with the samples in a buffered solution, anti-LSD antiserum was added, and the mixture incubated overnight at $0^{\circ} \mathrm{C}$. Charcoal was then added to remove unbound $L S D$, the mixture centrifuged and the supernatant containing bound LSD was removed for scintillation counting. The more LSD present in the original urine, the less tritiated LSD was present in the supernatant which was counted. Quantitation was effected using calibration curves. All samples were tested in duplicate. All positive findings were verified by diluting the urine and reassaying. Such diluted samples were required to stay on the standard curve for verification. The sensitivity limit of this methodology for LSD in urine was $100 \mathrm{pg} / \mathrm{ml}$. Specific detalls for the RIA methodology are as follows:

\section{Reagents}

Phosphate buffer: $0.01 \mathrm{M}$ sodium phosphate plus $0.15 \mathrm{M}$ sodium chloride titrated to $\mathrm{pH} 7.4$ with $4 \mathrm{~N}$ sodium hydroxide.

Tritiated LSD: New England Nuclear: diluted to appropriate activity with ethanol and ascorbic acid. Lyophilized before use and reconstituted in phosphate buffer.

Antiserum: Collaborative Research LSD antiserum: diluted to appropriate concentration with phosphate buffer.

Scintillation medium: $6 \mathrm{~g}$ "Omnifluor" per liter of toluene/ "Triton X-100" (2:1).

\section{Procedure}

In a typical run, $0.3 \mathrm{ml}$ phosphate buffer is added to a glass test tube $(20 \mathrm{ml})$. An $0.1 \mathrm{ml}$ antiserum is added, followed by $0.1 \mathrm{ml}$ of the test sample (urine, control or standard). An $0.1 \mathrm{ml}$ of tracer solution $1 \mathrm{~s}$ added and the mixture incubated at $0^{\circ} \mathrm{C}$ for $24 \mathrm{hr}$. The $0.2 \mathrm{ml}$ of 
TABLE 7

\section{EXTRACTION EFFICIENCIES FOR DRUGS FOUND IN DRIVER SPECIMENS}

\section{Drug}

Phenobarbital

Phenylpropanolamine

Chloropheniramine

Pentobarbital

Methaqualone

Amphetamine

Quinine

Methapyrilene

Meprobamate

Secobarbital

Propoxyphene (Urine)

Propoxyphene (Plasma)

Amitriptyline (Urine)

Amitriptyline (Plasma)

Amobarbital

Dipheny1hydantoin

Phendimetrazine

Cocaine

Methadone

Promazine

Tripelennamine

Butabarbital (Urine)

Butabarbital (Plasma)

Diphenhydramine

Thioridazine

\section{Extraction Efficiency}

$32 \pm 11 \%$

$6 \pm 2 \%$

$54 \pm 11 \%$

$40+7 \%$

$64+5 \%$

$50 \pm 7 \%$

$48 \pm 7 \%$

$64 \pm 6 \%$

$54+6 \%$

$51 \pm 7 \%$

$75 \pm 6 \%$

$31+7 \%$

$54 \pm 8 \%$

$33+11 \%$

$41 \pm 8 \%$

$46 \pm 11 \%$

$58 \pm 10 \%$

$49 \pm 11 \%$

$45 \pm 9 \%$

$35 \pm 8 \%$

$54 \pm 7 \%$

$43 \pm 5 \%$

$28+4 \%$

$51+15 \%$

$17 \pm 5 \%$ 
a $1 \%$ suspension of charcoal in phosphate buffer 1 s added, the mixture shaken on a "Vortex" and left to stand for $20 \mathrm{~min}$ in $1 \mathrm{ce}$. The mixture was then centrifuged at $1,800 \mathrm{rpm}$ for $10 \mathrm{mIn}$, and the supernatant $1 \mathrm{~m}-$ mediately transferred to scintillation vials containing $10 \mathrm{ml}$ of a mixture of toluene/"Triton-XI0O" (2:1) containing "Omnifluor." The vials were then counted in a liquid scintillation counter. The radioactivity of the supernatant is inversely proportional to the amount of LSD present in the unknown, standard or control sample. LSD concentrations in unknowns are calculated from standard curves prepared in each run of 40 samples.

4. Analysis of blood for alcohol: Blood specimens obtained from drivers were assayed for blood alcohol using gas chromatography of the head-space above the blood. The blood was preserved with fluoride to prevent in-situ formation of alcohol after collection.

Blood ( $2 \mathrm{ml}$ ) was placed in a $20 \mathrm{ml}$ serum bottle and acetonitrile ( $1 \mathrm{ml}$ of a 1:300 acetonitrile/water solution) added. The bottle was sealed with a rubber septum and placed in a water bath at $40^{\circ} \mathrm{C}$ for $30 \mathrm{~min}$. The vapor above the blood $(500 \mu 1)$ was infected into a $100 / 120$ mesh Porapak $Q$ column, 2 ft $\times 1 / 8$ in. stalnless steel. The column temperature was $110^{\circ} \mathrm{C}$ and the carrier gas nitrogen flow was $50 \mathrm{cc} / \mathrm{min}$.

These conditions yielded good peak shape and separation for ethyl alcohol and acetonitrile (internal standard). A standard curve was prepared over the concentration range 0.050 to $0.500 \%$ blood alcohol by spiking blood at these levels and adding a known amount of acetonitrile. The ratio of ethyl alcohol to acetonitrile peak was plotted aginst percent alcohol and this curve employed to determine the alcohol concentration in driver blood samples.

\section{Supplies and reagents}

\section{a. Sample preparation}

- Enzyme; Sulfatase, Type Hl, contains sulfatase and $\beta$ glucuronidase, Product No. 59626, Sigma Chemical Co.

- Extraction equipment; "Drug Skreen System," Brinkmann Instruments, Inc.

- Solvents and chemicals; Reagent grade, dried, if approprlate, over molecular sleve. 
b. Thin-layer chromatography

- TLC tanks; glass, to hold $20 \times 20 \mathrm{~cm}$ plates, Product No. 3500-021-6, Brinkmann Instruments, Inc.

- TLC plates; $20 \times 20 \mathrm{~cm}$ glass with $250 \mu$ thick Silica Gel G, Product No. "SIlplate 22," Brinkmann Instruments, Inc.

- Micropipettes; 5, 10, $20 \mu 1$ from Drummond Scientific.

- Hot plates; Corning Model PC35, Matheson Scientific.

- Solvents and spray reagents; Reagent grade.

- Drug Standards; from Applied Science, Inc., and USP.

c. Gas chromatography

- Columns; glass, from Altech Associates, Inc., and Analabs, Inc. Stainless steel columns from Analabs, Inc.

- Column materials; Supelco, Inc.

- GC Syringes; Hamilton 5 and $10 \mu 1$, from Supelco, Inc.

- "Meth-Elute" methylating agent, from Pierce Chemical Co., Product No. 49300.

- Solvents, Reagent-grade, dried over molecular sieve.

d. Radioimmunoassay

- LSD Antiserum; Collaborative Research, Inc., Catalog No. $2-10$.

- Tritiated LSD; New England Nuclear: Catalog No: NET$447,0.25 \mathrm{mCl}(0.0038 \mathrm{mg})$ in $0.25 \mathrm{ml}$ ethanol with $0.25 \%$ ascorbic actd. 
- "Omn1fluor;" New England Nuclear: Catalog No. NEF-906.

- Toluene; scintillation grade, Fisher Sclentific, Catalog No. T-313.

- "Triton X-100;" Packard Instrument Company, Catalog No. 6008084 .

- Other reagents and solvents; reagent grade.

\section{H. Data Used and Statistical Analysis Performed}

The data analyzed in this study came from both fatally injured and living drivers. The data provided by the 22 medical examiners on fatally injured drivers fell into two categories: (1) crash data information describing the circumstances of the fatal accidents (see Appendix $A$ ), and (2) urine, blood and bile samples which were chemically analyzed for drugs. Finger and lip swabs were also collected (for detection of marijuana) but were not chemically analyzed. The bile findings were analyzed only for the fatally injured drivers because they are not directly comparable to any data obtained from the living drivers.

The data collected from living drivers fell into two main categories: (1) motorists' answers to the survey questionnaire (see Appendix B), and (2) breath, urine and blood samples which were chemically analyzed for drugs. Lip and finger swab samples were also collected for detection of marijuana but were not chemically analyzed.

The four types of data collected (crash data and analytical results on the fatally injured driver specimens; and interview data and analytical results on the living driver specimens) were encoded for computer analysis. A listing of the information encoded for each data type is presented in Appendix $C$ along with the format used to keypunch the data. A series of computer programs were written which accepted these data. The output of these programs were used with selected programs from the Statistical Package for the Social Sciences (SPSS) to perform the various statistical tabulations. Chi-square analyses were performed to determine the level of significance of the findings. Relative frequency tabulations were also made of the data collected. The data from Dallas, Texas, and Memphis, Tennessee, were analyzed independently and in combination. 
The statistical analysis of the fluid sample findings considered drug findings confirmed by gas chromatography and quantitated in any body fluid at any level of concentration. The concentration of the drug in the fluid sample'was not utilized as a parameter. The findings in fatally injured drivers were examined for each of the seven drug groups, one or more drugs, nicotine and salicylates. Moreover, five possible fluid sample combinations were considered: (1) urine separately, (2) blood separately, (3) bile separately, (4) urine and blood, and (5) urine, blood and bile. The incidence of LSD was examined considering only the urine samples. The incidences of drugs were also examined by submission area including Dallas and Memphis.

The Incidences of drugs in the living drivers were examined in a manner similar to that used for the fatally injured drivers. These incidences were also compared by site within each survey community and between the two communities of Dallas and Memphis.

The relative incidence of drugs in the living drivers was compared with the relative incidence of drugs in fatally injured drivers. This was done separately for Dallas and Memphis and for the combination of the two communities, considering only those living driver samples collected at fatal crash sites for which fluid specimens were obtained from the fatally injured driver and analyzed for drugs. The relative risks were also determined by comparing the incldence of drugs in all fatally injured drivers with the incidence of drugs in all living drivers.

The relationship between alcohol usage and various factors and between alcohol usage and drug usage were examined for both the fatally injured and living drivers. In addition, a number of dead and living driver factors were compared with drug usage and examined for statistical Importance. Finally, an analysis was conducted to determine the incidence of Individual drug groups among living drivers at drug-involved fatal crash sites. 
III. RESEARCH FINDINGS AND INTERPRETATION OF THE DATA

A large amount of data was obtained during this project. Those data, the results from the statistical analyses of those data, and the appropriate interpretations of the analyses are brought together in this section.

Subsection A deals with the collection of the fatally injured driver data. It discusses the screening of the fatally injured driver data received. Subsection $B$ describes the analyses of the fatally injured driver crash data. Subsection $C$ deals with the living drivers. It describes their acceptance of the survey and their demographic characteristics.

Subsection $D$ presents the detalled drug findings for the drivers. The fatally injured driver drug findings are presented first followed by a description of the drugs found in the living drivers. The fatally injured and living driver drug findings are compared in Subsection $E$. It is within this section that the relative risk of being fatally injured in an automobile crash after ingestion of drugs is discussed.

The results concerning alcohol usage, by itself, and in combination with drug usage are presented in Subsection F. A number of fatally injured and living driver factors are compared with drug usage in Subsection G. Finally, the incidence of drugs in living drivers at drug-involved fatal crash sites is discussed in Subsection $H$.

\section{A. Screening of the Fatally Injured Driver Data}

A total of 994 fatally injured driver specimen kits, each including a crash data form, were returned to MRI from medical examiners in the 22 communities listed in Section II. These victims were tentatively selected by those medical examiners as meeting the criteria set by MRI to be included in the study. The crash data and body fluids associated with these 994 fatally injured drivers were subjected to numerous examinations to remove nonqualifying subjects from the study. 
The first screening of the fatally injured driver data involved a manual examination of the crash data forms and the specimen kits received. The times recorded between crash and death were not considered in this examination. The first screening eliminated 85 victims, leaving body fluids from 909 fatally injured drivers to be chemically analyzed and retained for further analyses. The reasons for the exclusion of these 85 victims include:

1. The crash occurred outside the jurisdiction of the respective medical examiner.

2. The victim was a passenger instead of the driver.

3. The fatality was a nontraffic fatality.

4. The kit was a duplicate of one already received.

5. The kit was returned but unused.

6. The kit was received after the deadline set as cutoff time for data collection.

7. Combinations of two or more of the above reasons.

The data from the remaining 909 fatally injured drivers were further investigated to determine whether any drugs had been administered to the drivers before they died and, if so, whether the results would confound our analytical results. This second screening was performed in two stages, one manually and one by computer, after the chemical analysis results (and crash data) from the 909 victims had been converted to punched cards.

In the first stage of the second screening, seven of the 43 drugs in the screen of the fatally injured driver fluid specimens (see Table 3) were determined to be likely candidates as drugs which might be administered at the crash scene, in an ambulance, or at the hospital to relieve pain, stabilize body functions, or otherwise maintain the life of the victim. The seven drugs were determined from personal communications with a number of medical examiners and from a knowledge of the functions of each drug. The seven drugs are as follows: 
1. Hydromorphine

2. Morphine

3. Procaine

4. Diphenylhydantoin

5. Amitriptylene

6. Diazepam

7. Methylphenidate

Next, all 909 crash data forms were scanned to determine which of the seven medications, if any, were reported by the medical examiners as having been administered to the victims after their crashes. A 1ist of all the drugs reported by the medical examiners is included in Table 8 along with the number of times each drug was reported. Three of the medications listed in Table 8, and marked with an asterisk, were also included in the drug screen.

1. Methylphenidate

2. Diazepam

3. Amitriptylene

In the second stage of the second screening, all analytical results from the 909 fatally injured drivers were screened by computer for incidences of the above seven drugs in any fluid sample. Twelve cases were found with one or more of these drugs in a body fluid. One of the findings was collaborated by the medical examiner's comments on that victim's crash data form. A further search was undertaken for each of the remaining 11 victims to determine whether the drugs detected had been administered after the crash. The appropriate medical examiner was contacted for each case and asked to reinvestigate all avallable records including ambulance reports. Only one of the 11 fatally injured drivers was found to have had drugs administered after the crash. The remaining 10 cases showed no evidence of the detected drugs being administered after the crash. The medical examiners reported that 5 of the remaining 10 victims showed evidence that they were drug users.

The two victims identified as having drugs administered after their crash were deleted from the analysis, reducing the number of fatally injured drivers to 907 . One of the two drivers eliminated died about $5 \mathrm{hr}$ after the crash; the other driver was DOA at the hospital. This shows that an arbitrary time interval between time of crash and death (say 4 or $41 / 2 \mathrm{hr}$ ) cannot be used to totally rule out victims who had drugs administered to them after the crash. The analytical results must be compared with medical examiner records to determine invalid specimens. 
TABLE 8

DRUGS REPORTED ON CRASH DATA FORMS AS BEING ADMINISTERED TO VICTIMS AFTER THE CRASH

\section{Drugs Reported}

Number of Times

Sodium bicarbonate

Lactate

12

Atropine

10

Calcium chloride

Isometheptene

Adrenaline

Saline

Isoprenaline

Lidocaine

Methylphenidate*

Diazepam*

Amitriptyline*

Perphenazine

Phenazone

Chloral hydrate

Acetominophen

Cortizone

Dextran

Normosal

Dexamethasone

Mannitol

Procaine amide

Noradrenaline

Metariminol

Cephalothin

Diazoxide

Reported

5
2
0
7
4
4
3
3
3
2
2
2
2
2
2
2
2
2
2
2
2
1
1
1
1
1

* Medications included in the drug screen. 
The only question to be answered at this point was which of the 907 remaining samples should be discarded from a time-after-crash to timeof-death consideration. Early in the data collection stage of the study, a determination was made not to consider fatal cases where the victim lived beyond $4 \mathrm{hr}$ after the crash. This information was conveyed to the medical examiners, but it was suspected that they could not follow the guidelines too closely.

A final screening of the crash data associated with the remaining 907 fatally injured drivers was also conducted by computer. This screening was performed to identify those drivers that lived longer than $4 \mathrm{hr}$ after the crash. A total of 16 drivers were identified in this final edit. The interval between the time of crash and time of death for these 16 cases ranged from $4 \mathrm{hr} 3 \mathrm{~min}$ to $23 \mathrm{hr} 10 \mathrm{~min}$.

The 16 cases clted above exemplify the degree of inconsistency that emerged between areas and even within individual areas regarding the samples that were submitted. One of the problems faced by the medical examiners was the difficulty in determining the exact time of crash and/or death of victims. Missing or conflicting information frequently gave the medical examiner only a vague idea of the time between crash and death.

Table 9 shows the distribution of the intervals between crash and death for the 907 fatally injured drivers. Table 9 also depicts the frequency of positive drug findings (in any fluid at any level of concentration) within each time interval. There is no evidence that drug Incidence increased as time between crash and death increased (the absolute numbers in the $5+\mathrm{hr}$ time interval are too small to place any significance upon the drug incidence in this time interval). No drivers who died between 4 and $4.5 \mathrm{hr}$ or between 4.51 and $4.99 \mathrm{hr}$ after their crash had any detectable drugs in their body fluids.

The inability of the medical examiners to accurately determine the time of crash and the time of death lead to a premise that a variation of $\pm 15 \mathrm{~min}$ for fixation of time of crash and for time of death should be accepted. For that reason, it was decided to alter the time 11mit between crash and death from $4 \mathrm{hr}$ to 4-1/2 hr. This extension permitted retention of all but seven of the 907 (a total of 900) fatally infured drivers in the analyses. (It also allowed the inclusion of three "otherwise valid" living driver surveys which had been performed at sites where the driver had lived between 4 and 4-1/2 hr.) 


\section{TABLE 9}

DISTRIBUTION OF 907 FATALLY INJURED DRIVERS BY

TIME INTERVAL BETWEEN CRASH AND DEATH

\begin{tabular}{|c|c|c|c|}
\hline $\begin{array}{l}\text { Time Between Crash } \\
\text { to Death (Hr) } \\
\end{array}$ & $\begin{array}{l}\text { Number of Fatally } \\
\text { Injured Drivers }\end{array}$ & $\begin{array}{l}\text { Number of Drivers } \\
\text { With Positive Drug } \\
\text { Findings } \\
\end{array}$ & $\begin{array}{c}\text { Drug } \\
\text { Incidence } \\
(\%) \\
\end{array}$ \\
\hline Dead on arrival (DOA) & 459 & 60 & 13.1 \\
\hline 0 to 0.99 & 259 & 26 & 10.0 \\
\hline 1 to 1.99 & 111 & 12 & 10.8 \\
\hline 2 to 2.99 & 36 & 6 & 16.7 \\
\hline 3 to 3.99 & 16 & 1 & 6.3 \\
\hline 4 to 4.5 & 9 & 0 & 0.0 \\
\hline 4.51 to 4.99 & 2 & 0 & 0.0 \\
\hline $5+\mathrm{Hr}$ & 5 & 1 & 20.0 \\
\hline Unknown & 10 & 1 & 10.0 \\
\hline Total & 907 & 107 & 11.8 . \\
\hline
\end{tabular}


Chapter II discussed the fact that not all of the 900 analyzed crash victims had all fluids returned in the kits. Of the 900 fatally injured drivers determined to be valid crash victims, 637 (70.8\%) supplied urine, 825 ( $91.7 \%)$ supplied blood, 492 (54.7\%) supplied bile, 587 (65.2\%) supplied both blood and urine, 326 (36.2\%) supplied all three fluid samples, and $832(92.4 \%)$ supplied a complete set of swabs.

\section{B. Fatally Injured Driver Crash Data}

Relative frequency tabulations were made of the crash data collected for the 900 fatally injured drivers. The tabulations are presented in Appendix F, Tables F-1 through F-15, for the following items:

1. Number of fatally Injured drivers by collection area;

2. Number of fatal crashes by year;

3. Number of fatal crashes by month of year;

4. Time of day of the fatal crash;

5. Day of week of the fatal crash;

6. Area type of the fatal crash location;

7. Number of vehicles involved in the fatal crashes;

8. Number of people in the fatally injured drivers vehicles;

9. Type of accident;

10. Fatally injured drivers vehicle type;

11. Sex of the fatally injured drivers;

12. Age group of the fatally injured drivers;

13. Culpability of the fatally infured drivers;

14. Total number of fatalfties in all vehicles involved in the fatal crashes; and 
15. Total number of nonfatal injuries in all vehicles involved in the fatal crashes.

No tests for statistical significance were applied to the crash data, however, some observations of the data were made.

The medical examiner from Dallas County, Texas, submitted the largest number of fatally injured driver specimens that were analyzed-a total of 123 drivers (81 from the City of Dallas and 42 from Dallas County, excluding the City of Dallas). The area submitting the next largest number of fatally injured driver specimens that were analyzed (86) was Wayne County, Michigan (including parts of Detroit). A total of 45 fatally injured driver specimens (analyzed) were submitted from the City of Memphis, Tennessee, while two were submitted from Shelby County, Tennessee (excluding Memphis).

A large percentage ( $81.3 \%$ ) of the fatal crashes analyzed occurred during 1975 . About $52 \%$ of the fatal crashes occurred between $8 \mathrm{PM}$ and $4 \mathrm{AM}$, and $38 \%$ occurred on Saturday or Sunday. Slightly over half of the crashes ( $51.4 \%$ ) were single vehicle accidents and $71.5 \%$ of the fatally injured drivers were alone in the crash. About $66 \%$ of the single vehicle crashes involved fixed objects, and $87 \%$ of the multiple vehicle crashes were elther head-on or angle type accidents. About $75 \%$ of the fatally injured drivers were driving passenger cars and $12.7 \%$ were driving motorcycles. Females accounted for $16.3 \%$ of the fatally injured drivers, and $54.8 \%$ of all the dead drivers were 29 years old or less with $22 \%$ between the ages of 20 and 24 . About $72 \%$ of the fatally injured drivers were judged to be culpable. The driver was determined as being culpable if: (1) the crash was a single vehicle accident, or (2) the victims condition or behavior most 1ikely contributed to the crash, as determined from police and medical examiners comments.

\section{Description of Survey Respondents}

1. Driver acceptance: Two communities, Dallas, Texas, and Memphis, Tennessee, cooperated with MRI in the conduct of roadside surveys to determine drug use among similarly exposed (living) drivers. Eleven surveys were conducted in Dallas between May 30, 1975, and September 13, 1976; elght surveys were conducted in Memphis between November 11, 1975, and September 2, 1976. The surveys were conducted at sites within each community at which a driver was fatally injured (died within 4-1/2 hr of the crash) and for whom fluid specimens were 
submitted by the Dallas or Shelby County medical examiners. Surveys were also conducted at some fatally infured driver crash sites at. which it was later determined that the medical examiner had falled to collect the required specimens. A total of 105 sampling sites were used in the study; 73 sites in Dallas and 32 in Memphis. The survey procedure consisted of stopping randomly selected male motorists at the time of day and day of week of the fatal crash, conducting the interview, and requesting breath, urine and blood samples. Ifp and finger swab samples were also collected for detection of marifuana, but they were not chemically analyzed. An average of about one dozen interviews were performed at each crash site.

A total of 1,255 motorists were stopped during the 11 survey periods in Dallas and eight survey perlods in Memphis. Data from 1,196 drivers at acceptable sites were retained for subsequent analyses- -759 drivers in Dallas and 437 drivers in Memphis. The number of people in Dallas and Memphis who agreed to the interview and to other requests are given in Tables 10 and 11 , respectively. Acceptance of the interview was very similar between the two communities. However, the motorists in Memphis tended to be slightly more cooperative than those in Dallas. of the 1,196 motorists stopped, $90.5 \%$ in Dallas and $93.4 \%$ in Memphis cooperated with the interview, giving an overall cooperation rate of $91.6 \%$ (see Table 12). Breath samples (for BAC determintion) were obtained from $87.0 \%$ in Dallas, $91.5 \%$ in Memphis and $88.6 \%$ overall, meaning nearly all of those interviewed provided a breath sample. Likewise, nearly all consented to give a urine sample: $87.0 \%$ in Dallas; $92.0 \%$ in Memphis and $88.8 \%$ overal1. All motorists were not asked for a blood sample, for reasons of age or health. Of those from whom a blood sample was requested, $75.7 \%$ consented. The motorists in the two communities had about the same cooperation rate for the blood sample request: $76.1 \%$ of the people asked in Dallas and $75.1 \%$ asked in Memphis agreed to provide a blood sample.

Overall, about $89 \%$ of the motorists stopped agreed to provide either the urine or blood sample. This remarkably high degree of cooperation resulted from many factors, one of which was the offer of $\$ 10$ for the blood sample or a combination of the urine and blood samples.

Table 13 gives additional information on the obtainment of fluid samples. Although 1,062 motorists consented to give a urine sample, only 511 (67.3) of the drivers in Dallas and 293 (67.0\%) in Memphis-804 and $67.2 \%$ overall--were able to produce a sufficlent urine quantity $(z 20 \mathrm{ml}$ ) on demand. Those who were unable to provide the amount needed at the time of the interview were given a preposted maller and instructed in its use. Many people did cooperate with the mall-back procedure so 
TABLE 10

SUMMARY OF DALIAS DRUG SURVEYS

\begin{tabular}{|c|c|c|c|c|c|c|}
\hline $\begin{array}{l}\text { Survey } \\
\text { Number }\end{array}$ & $\begin{array}{c}\text { Number } \\
\text { Motorists } \\
\text { Stopped } \\
\end{array}$ & $\begin{array}{c}\text { Number } \\
\text { Motorists } \\
\text { Interviewed } \\
\end{array}$ & $\begin{array}{r}\text { Number } \\
\text { BAC's } \\
\text { Obtained } \\
\end{array}$ & $\begin{array}{l}\text { Number } \\
\text { Consented } \\
\text { to Give } \\
\text { Urine } \\
\end{array}$ & $\begin{array}{c}\text { Number } \\
\text { Motorists } \\
\text { Asked For } \\
\text { Blood } \\
\end{array}$ & $\begin{array}{l}\text { Number } \\
\text { Consented } \\
\text { to Give } \\
\text { Blood } \\
\end{array}$ \\
\hline 1 & 133 & 95 & 93 & 94 & 125 & 82 \\
\hline 2 & 103 & 84 & 81 & 82 & 100 & 74 \\
\hline 3 & 70 & 70 & 65 & 66 & 65 & 50 \\
\hline 4 & 60 & 59 & 57 & 56 & 58 & 52 \\
\hline 5 & 73 & 72 & 68 & 69 & 71 & 56 \\
\hline 6 & 67 & 65 & 60 & 57 & 66 & 50 \\
\hline 7 & 53 & 50 & 48 & 47 & 52 & 38 \\
\hline 8 & 22 & 22 & 22 & 22 & 22 & 20 \\
\hline 9 & 56 & 55 & 52 & 52 & 52 & 37 \\
\hline 10 & 34 & 30 & 29 & 29 & 32 & 22 \\
\hline 11 & 88 & 85 & $\underline{85}$ & $\underline{86}$ & 84 & 72 \\
\hline Tota 1 & 759 & 687 & 660 & 660 & 727 & 553 \\
\hline
\end{tabular}


TABLE 11

\section{SUMMARY OF MEMPHIS DRUG SURVEYS}

\begin{tabular}{|c|c|c|c|c|c|c|}
\hline $\begin{array}{l}\text { Survey } \\
\text { Number } \\
\end{array}$ & $\begin{array}{c}\text { Number } \\
\text { Motorists } \\
\text { Stopped } \\
\end{array}$ & $\begin{array}{c}\text { Number } \\
\text { Motorists } \\
\text { Interviewed } \\
\end{array}$ & $\begin{array}{r}\text { Number } \\
\text { BAC's } \\
\text { Obtained } \\
\end{array}$ & $\begin{array}{l}\text { Number } \\
\text { Consented } \\
\text { to Give } \\
\text { Urine } \\
\end{array}$ & $\begin{array}{l}\text { Number } \\
\text { Motorists } \\
\text { Asked For } \\
\text { Blood } \\
\end{array}$ & $\begin{array}{c}\text { Number } \\
\text { Consented } \\
\text { to Give } \\
\text { Blood } \\
\end{array}$ \\
\hline 1 & 67 & 62 & 61 & 61 & 65 & 57 \\
\hline 2 & 28 & 26 & 25 & 25 & 28 & 20 \\
\hline 3 & 79 & 71 & 70 & 70 & 79 & 48 \\
\hline 4 & 33 & 32 & 32 & 32 & 33 & 30 \\
\hline 5 & 39 & 37 & 37 & 37 & 36 & 32 \\
\hline 6 & 90 & 88 & 85 & 85 & 86 & 64 \\
\hline 7 & 42 & 37 & 38 & 37 & 40 & 29 \\
\hline 8 & 59 & 55 & $\underline{52}$ & $\underline{55}$ & $\underline{59}$ & 40 \\
\hline Total & 437 & 408 & 400 & 402 & 426 & 320 \\
\hline
\end{tabular}


TABLE 12

\section{SUMMARY OF ALL DRUG SURVEYS}

\begin{tabular}{|c|c|c|c|c|c|c|c|}
\hline $\begin{array}{c}\text { Survey } \\
\text { Area } \\
\end{array}$ & $\begin{array}{c}\begin{array}{c}\text { Number } \\
\text { of }\end{array} \\
\text { Surveys } \\
\end{array}$ & $\begin{array}{c}\text { Number } \\
\text { Motorists } \\
\text { Stopped } \\
\end{array}$ & $\begin{array}{c}\text { Number } \\
\text { Motorists } \\
\text { Interviewed } \\
\end{array}$ & $\begin{array}{c}\text { Number BAC's } \\
\text { Obtained } \\
\end{array}$ & $\begin{array}{l}\text { Number } \\
\text { Consented } \\
\text { To Give } \\
\text { Urine } \\
\end{array}$ & $\begin{array}{c}\text { Number } \\
\text { Motorists } \\
\text { Asked For } \\
\text { Blood } \\
\end{array}$ & $\begin{array}{c}\text { Number } \\
\text { Consented } \\
\text { To Give } \\
\text { Blood } \\
\end{array}$ \\
\hline Dallas & 11 & 759 & $687(90.5 \%)$ & $660(87.0 \%)$ & $660(87.0 \%)$ & $727(95.8 \%)$ & $553(76.1 \%)$ \\
\hline Memphis & 8 & 437 & $408(93.4 \%)$ & $400(91.5 \%)$ & $402(92.0 \%)$ & $426(97.5 \%)$ & $320(75.1 \%)$ \\
\hline Tota 1 & 19 & 1,196 & $1,095(91.6 \%)$ & $1,060(88.6 \%)$ & $1,062(88.8 \%)$ & $1,153(96.4 \%)$ & $873(75.7 \%)$ \\
\hline
\end{tabular}


TABLE 13

SUMMARY OF LIVING DRIVER SAMPLES ANALYZED FOR DRUGS

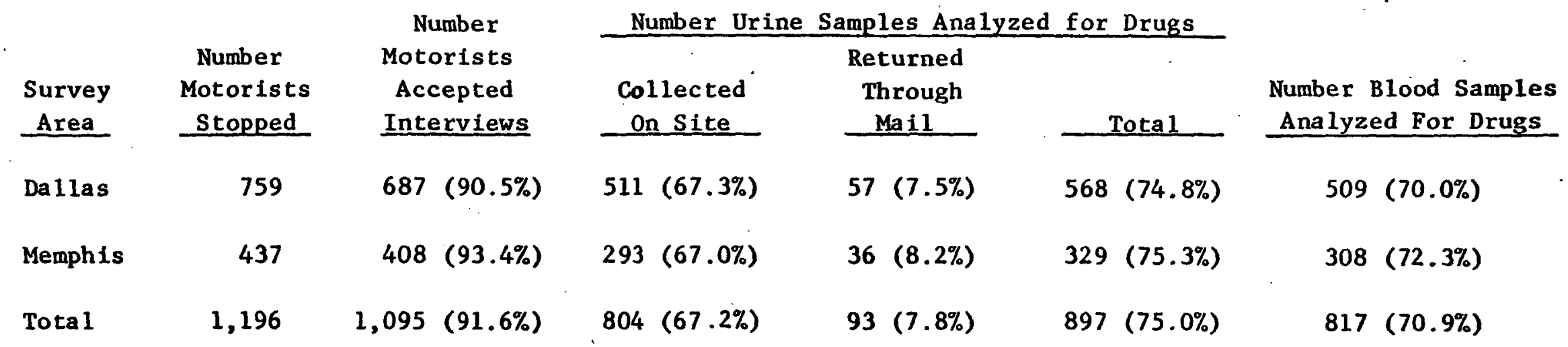


that, as a result, urine samples were obtained from $75 \%(897 / 1,196)$ of the motorists stopped. Of the number of mailers given out, $26.9 \%$ (93/ 346) were returned with suffucient quantity for use in the analysis.

Although 873 motorists consented to give a blood sample (see Table 12), samples were obtained and analyzed for only 817 ( $70.9 \%$ of motorists asked for a sample--see Table 13). Several factors contributed to this, but the major reason for this difference was that the nurse was unable to locate a suitable vein.

The overall cooperation rate of the motorists in providing either a urine or blood sample is higher than the cooperation rates for each fluid sample, taken one at a time. For example, $81.4 \%$ of all motorists stopped, were able to produce either a urine or blood sample in sufficient quantity for chemical analysis. However, it was estimated that $83 \%$ of the motorists stopped provided either a urine or blood sample irrespective of the amount.

2. Demographic characteristics: The drivers encountered in the two communities had very similar demographic characteristics, and only small differences between the motorists from the two areas were noted. Their answers to the demographic questions are included in Appendix G. Of particular interest are questions $29,33,36$ through 38 and 42. Responses to those questions are repeated here in Table 14.

The Memphis motorists were either white or black, whereas the Dallas sample included many Mexican Americans as well. More blacks were interviewed, on a percent basis, in Memphis than in Dallas. The Memphis drivers interviewed tended to live mainly in Memphis; the Dallas drivers tended to be from Dallas as well as towns within the county. The Dallas drivers tended to be younger than the Memphis drivers in that a larger fraction of drivers 19 years and younger were stopped in Dallas. The age group, 30 to 39 , contained the largest percentage of motorists stopped in each community.

The income distributions for each community are quite simflar. There was a larger fraction of motorists in Dallas in the lower income bracket $(\leq \$ 2,499)$ and in the upper income bracket $(\$ 30,000+)$ than in Memphis. However, a larger fraction of Memphis drivers were found in the middle income range $(\$ 10,000$ to $\$ 20,000)$ than in Dallas. The Dallas drivers tended to have somewhat less education, with about $34 \%$ having less than a high school education compared to $31 \%$ in Memphis. 
A large fraction of motorists in each community were coming from their own home, with the percentage being greatest in Memphis. However, a large fraction of Dallas drivers were coming from work, school or a sport/ recreation factlity.

No tests for significance were performed on any of the motorists responses displayed in Table 14 nor in Appendix G. It is unlikely that many of the differences between the two communities could be shown to be significantly different at the $\alpha<0.05$ level.

Information about the vehicle being driven was recorded for all motorists stopped, regardless of whether or not they cooperated. Those findings are displayed in Table 15. There was very little difference between the populations found in the vehicles in the two communities. In comparing the number of people in the living driver's vehicles with the distribution found in the fatally infured driver's vehicles (Table F-8) It was found that the living driver's vehicles tended to be more highly populated. For instance, $71.5 \%$ of the fatally injured drivers were alone at the time of the crash, but between $58.0 \%$ and $59.7 \%$ of the living drivers were alone in the car at the time of the interview.

Finally, the Dallas living drivers tended to drive relatively new famlly and sporty cars and pickups; while Memphis living drivers drove relatively new family cars and pickups.

3. Motorists responses concerning the use of drugs and medications: Each driver inerviewed was asked a serles of questions concerning his use of drugs and medications. First, he was asked if he was currently taking any mediclne, pills, or drugs and if so, how often, how recently, whether it is a prescription or not and the name of the drug. Answers to these questions were recorded in questions 43 through 72 on the survey instrument in Appendix $D$.

During the editing of the survey quesionnaires, each drug mentioned by the motorists was classified into one of 25 groups. The names of the drugs mentioned are shown in Appendix $\mathrm{H}$ by drug groups. The large range of prescription and nonprescription drug types, coupled with the relatively common response that the driver did not know exactly what drug he was taking, made impractical an analysis of significance for the different drug groups. However, it was noted that aspirin was the most commonly mentioned drug ( 71 drivers), followed by multiple vitamins (49), and high blood pressure medication (32). Eleven drivers mentioned they were taking valium. 


\section{DEMOGRAPHIC CHARACTERISTICS OF RESPONDENTS}

Percentage of Motorists

Dallas

Memphis

Race

White

$61.1 \%$

$57.0 \%$

Black

31.3

42.3

Latin

7.2

0.2

other

0.4

0.5

City or Town of Residence

Dallas, Texas

71.9

0.0

Memphis, Tennessee

0.0

82.4

Nearby towns in county

18.8

5.3

Rural areas in county

1.1

0.2

Adjacent counties

3.7

1.5

Outstate

2.5

2.4

Other state

1.4

8.2

Part time resident

0.3

0.0

Age
$16-17$
$18-19$
$20-24$
$25-29$
$30-39$
$40-49$
$50-59$
$60-69$
$70+$
Income
Less than $\$ 1,000$
$1,000-2,499$
$2,500-4,999$
$5,000-7,499$
$7,500-9,999$
$10,000-14,999$
$15,000-19,999$
$20,000-29,999$
$30,000+$
Unknown

4.8

6.0

16.6

18.2

22.8

14.9

10.6

5.2

0.8

2.7

4.4

20.4

15.5

23.5

16.8

10.2

4.9

1.7

2.8

1.6

3.6

7.0

13.0

13.6

21.7

12.8

10.1

5.4

10.0
3.0

6.4

14.0

10.5

27.9

15.3

9.8

3.0

8.5 
TABLE 14 (Concluded)

Percentage of Motorists

Dallas

Memph1s

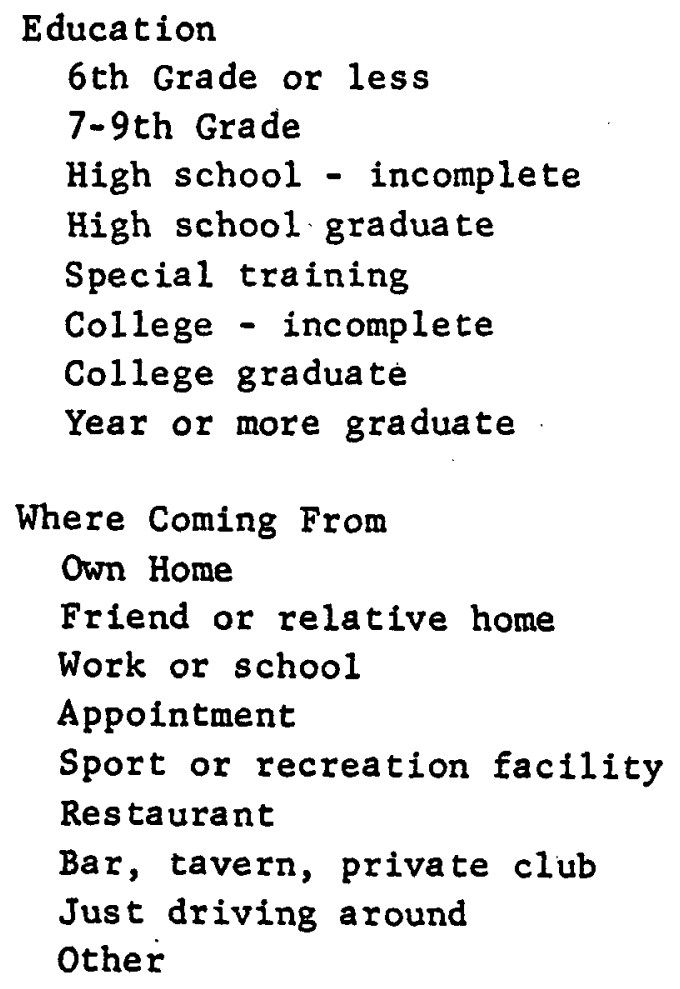

$\begin{array}{rr}6.8 & 6.6 \\ 9.9 & 10.5 \\ 16.8 & 13.9 \\ 23.4 & 27.7 \\ 6.0 & 6.1 \\ 24.0 & 22.4 \\ 8.2 & 7.5 \\ 4.9 & 5.4\end{array}$

25.9

30.7

18.4

19.2

22.9

20.2

12.5

11.7

5.6

2.9

5.2

4.4

4.0

4.4

2.7

2.0

2.7

4.6 


\section{OTHER OBSERVED CHARACTERISTICS OF RESPONDENTS}

Percentage of Motorists Dallas Memphis

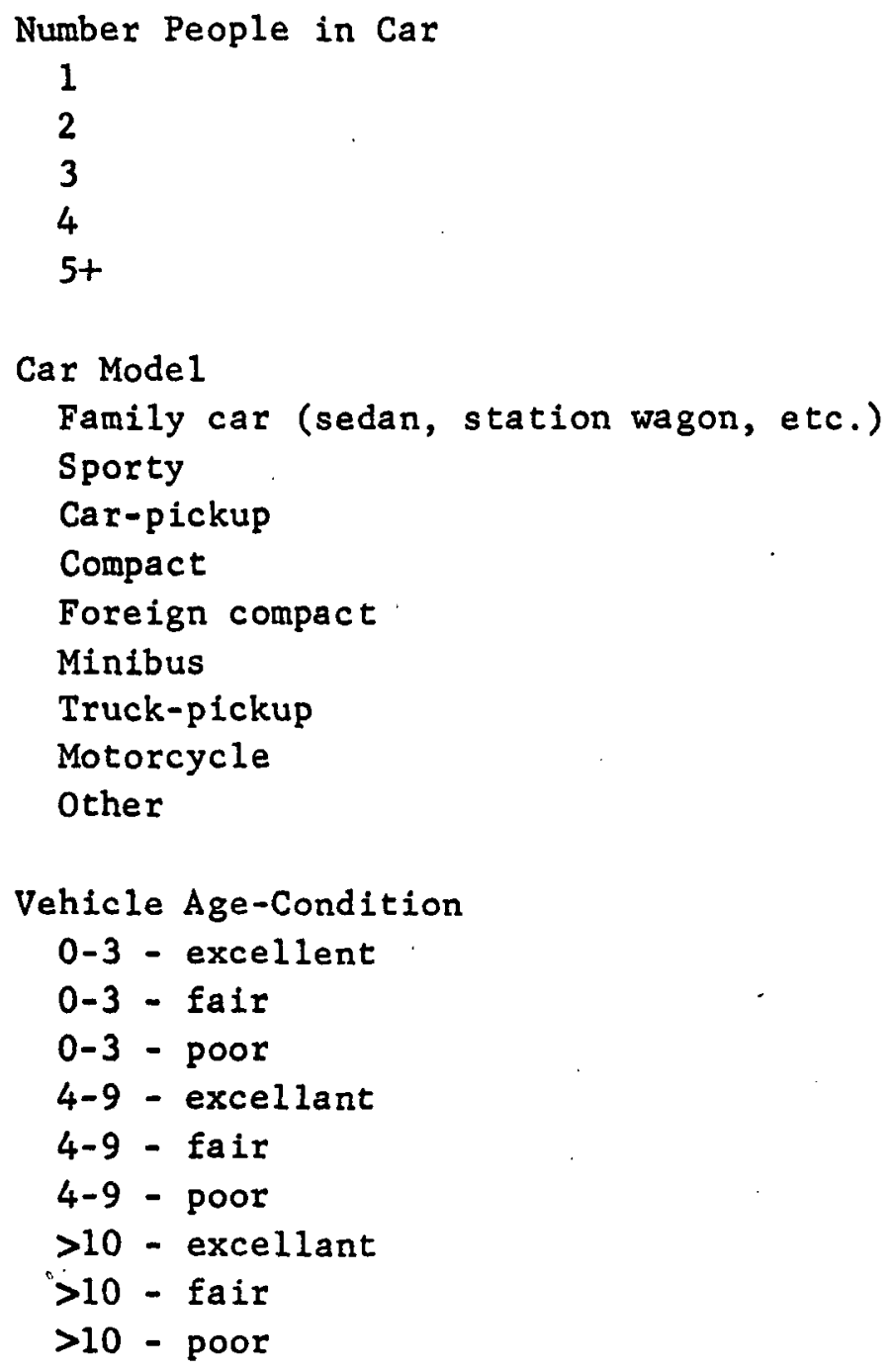

Car Model

Family car (sedan, station wagon, etc.)

Sporty

Car-pickup

Compact

Foreign compact

Minibus

Truck-pickup

Motorcycle

other

Vehicle Age-Condition

0-3 - excellent

0-3 - fair

0-3 - poor

4-9 - excellant

4-9 - fair

4-9 - poor

$>10$ - excellant

$>10$ - fair

$>10$ - poor

8.6

3.9

2.9

23.6

10.2

3.0

3.5

55.5

72.8

12.1

5.3

2.7

1.8

6.9

4.6

4.5 .

3.0

1.5

0.2

14.2

10.4

0.9

0.2

1.7

1.6

37.3

36.9

11.0

7.6

0.8

0.0

9.4

13.1

26.3

29.4

3.2

2.8

1.2

1.4

7.0

4.6

3.9

4.4 


\section{Driver Drug Findings}

The urine, blood and bile samples collected from the fatally injured drivers by the medical examiners in the 22 areas (including Dallas and Memphis) and the urine and blood samples obtained from the living drivers stopped in the Dallas and Memphis surveys were analyzed to detect drug incidence. Quantitative tests were performed on these fluid specimens for 43 drugs (see Table 3 ) which were classified into seven drug groups: (1) sedatives and hypnotics, (2) tranquilizers, (3) stimulants and antidepressants, (4) antihistamines and decongestants, (5) narcotic analgesics, (6) hallucinogens, and (7) miscellaneous. Quantitative tests for the hallucinogen, LSD, were performed using only the urine samples collected from the fatally injured drivers. In addition, quantitative determinations of the blood alcohol content were performed on the blood samples collected from the fatally injured drivers and on both breath and blood samples obtained from the living drivers. Qualitative tests were also performed for nicotine (evidence of tobacco smoking) and salicylates (evidence of aspirin) using the living driver and fatally injured driver fluid specimens collected.

The total chemical analysis scheme 1nvolved: the preparation of specimens, including hydrolysis of glucuronides and sulfate ethers, and extraction of the hydrolyzed specimens using a nonionic resin; the qualitative examination of the extracts by thin-layer chromatography; and finally the quantitative confirmation of thin-layer findings by gas chromatography. Blood alcochol was determined using a gas chromatographic technique on blood head-space. LSD was assayed using radiolmmunoassay techniques.

The statistical analysis of the fluid sample findings considered drug findings confirmed by gas chromatography and quantitated in any body fluid at any level of concentration. The concentration of the drug in the fluld sample was not ut1lized as a response.

A discussion is presented in Appendix I of the positive drug findings in blood samples from both fatally injured and living drivers. Four levels of concentration are considered there: trace amounts, therapeutic, toxic and lethal concentration. These data are presented for informaion only and were not used in any of the subsequent analysis. 
1. Eatally injured driver drug findings: The incidences of drugs other than alcohol in fatally injured drivers are presented in Tables 16 through 20 for five fluid sample combinations: (1) urine separately, (2) blood separately, (3) bile separately, (4) blood and urine, and (5) blood, urine and bile, respectively. The findings are described for each of the seven drug groups (sedatives/hypnotics, tranquilizers, stimulants/antidepressants, antihistamines/decongestants, narcotic analgesics, hallucinogens, and miscellaneous) one or more drugs, nicotine and salicylates. The drug incidences for each fluid combination are also presented separately for the City of Dallas, the City of Memphis, and the total of all the areas submitting fatally injured driver spec1mens. The $95 \%$ confidence interval for each incidence is also displayed in the drug incidence tables.

Table 21 presents the incidences of quantitated drugs (by individual drugs and drug groups) in all of the 587 fatally injured drivers for whom both blood and urine samples were available. The findings are listed for urine and blood individually and for the combination of the two fluids.

For cases in which both urine and blood findings were available (see Table 20), it was determined that the incidence of one or more drugs was about $12 \%$ (with a $95 \%$ confidence interval of $\pm 8.4 \%$ ) for Dallas fatally injured drivers, about $24 \%( \pm 14.6 \%)$ for Memphis fatally injured drivers, and $14.3 \%( \pm 2.8 \%)$ overall. Table 21 shows that the most commonly detected drug was the antihistamine and decongestant pheny1propanolamine, with the sedative phenobarbital second. Another antihistamine and decongestant, chlorpheniramine, the narcotic codine and the stimulant, amphetamine, were also frequently encountered.

The above drug findings are comparable to the results reported in an earlier study concerned with drug use among drivers.* In that study, $17.69 \%$ of the fatally injured drivers, for whom both blood and urine smaples were available, evidence one or more drugs. Also, almost two-thirds of the drugs found in the earlier study were of the sedative/ hyponotic type with phenobarbital the single drug most commonly detected. The second most frequently detected drug was phenylpropanolamine. In addition to these two drugs, the stimulants, amphetamine and metamphetamine, were also commonly encountered.

* Glauz, W. D., and R. R. Blackburn, "Drug Use Among Drivers," Contract No. DOT-HS-119-2-440, (MRI Project 3668-E), Midwest Research Institute Final Report, February 1975. (DOT-HS-801411). 
TABLE 16

INCIDENCE OF DRUGS IN FATALLY INJURED DRIVERS

FOR WHOM URINE SAMPLES WERE AVAILABLE

$\begin{array}{ccc}\text { Dallas (63 Drivers) } & \begin{array}{c}95 \% \\ \text { Confidence }\end{array} & \frac{\text { Memphis (33 Drivers) }}{95 \%} \\ \text { Type of Drug } & \text { No. Percent Interval } & \text { No. Percent Intence } \\ \text { Norval }\end{array}$

Sedatives and Hypnotics

Tranquilizers

Stimulants and

Antidepressants

Antihistamines and

Decongestants

Narcotic Analgesics

Hallucinogens

Miscellaneous

Total Drivers With Any

One or More Drugs

$\begin{array}{lcrr}\text { Nicotine } & 40 & 63.49 & \pm 11.90 \\ \text { Salicylates } & 11 & 17.46 & \pm 9.37\end{array}$

$\begin{array}{lll}3 & 4.76 & \pm 5.25 \\ 1 & 1.59 & \pm 3.10 \\ 1 & 1.59 & \pm 3.10 \\ & & \\ 1 & 1.59 & \pm 3.10 \\ & & \\ 2 & 3.17 & \pm 4.33 \\ 0 & 0.00 & \text { a/ } \\ 0 & 0.00 & \text { al }\end{array}$

$7 \quad 11.11 \quad \pm 7.76$

$\begin{array}{lll}2 & 6.06 & \pm 8.13 \\ 0 & 0.00 & \text { a/ } \\ 0 & 0.00 & \underline{a} / \\ & & \\ 5 & 15.15 & \pm 12.23 \\ & & \\ 1 & 3.03 & \pm 5.84 \\ 0 & 0.00 & \text { a } / \\ 0 & 0.00 & \text { a } /\end{array}$

$\begin{array}{lll}7 & 21.21 & +13.96\end{array}$

$22 \quad 66.67 \pm 16.09$

$7 \quad 21.21 \quad \pm 13.96$
A11 Fatally Injured Drivers (637 Drivers)

Confidence

No. Percent

Interva 1.

$\begin{array}{rll}31 & 4.87 & \pm 1.67 \\ 4 & 0.63 & \pm 0.61 \\ 9 & 1.41 & \pm 0.92 \\ 34 & 5.34 & \pm 1.75 \\ 16 & 2.51 & \pm 1.22 \\ 0 & 0.00 & \text { a/ } \\ 6 & 0.94 & \pm 0.75\end{array}$

$\begin{array}{lll}86 & 13.50 \quad \pm 2.65\end{array}$

$413 \quad 64.84$

$\pm 3.71$

$\begin{array}{lll}105 & 16.48 \quad \pm 2.88\end{array}$

a/ Indeterminable from the data collected. 
INCIDENCE OF DRUGS IN FATALLY INJURED DRIVERS

FOR WHOM BLOOD SAMPLES WERE AVA ILABLE

\begin{tabular}{|c|c|c|c|c|c|c|c|c|c|}
\hline \multirow[b]{2}{*}{ Type of Drug } & \multicolumn{3}{|c|}{ Dallas (76 Drivers) } & \multicolumn{3}{|c|}{ Memphis ( 45 Drivers) } & \multicolumn{3}{|c|}{$\begin{array}{l}\text { All Fatally Injured } \\
\text { Drivers ( } 825 \text { Drivers) }\end{array}$} \\
\hline & No. & Percent & $\begin{array}{c}95 \% \\
\text { Confidence } \\
\text { Interva } 1 \\
\end{array}$ & №. & Percent & $\begin{array}{c}95 \% \\
\text { Confidence } \\
\text { Interva } 1 \\
\end{array}$ & No. & Percent & $\begin{array}{c}95 \% \\
\text { Confidence } \\
\text { Interva } 1 \\
\end{array}$ \\
\hline Sedatives and Hypnotics & 2 & 2.63 & \pm 3.61 & 2 & 4.44 & \pm 6.12 & 37 & 4.48 & \pm 1.41 \\
\hline Tranquilizers & 1 & 1.32 & \pm 2.57 & 1 & 2.22 & \pm 4.31 & 4 & 0.48 & \pm 0.47 \\
\hline $\begin{array}{c}\text { Antihis tamines and } \\
\text { Decongestants }\end{array}$ & 0 & 0.00 & a $/$ & 2 & 4.44 & \pm 6.12 & 2 & 0.24 & \pm 0.34 \\
\hline Narcotic Analgesics & 0 & 0.00 & a $/$ & 0 & 0.00 & a $/$ & 4 & 0.48 & \pm 0.47 \\
\hline Ha llucinogens & 0 & 0.00 & a $/$ & 0 & 0.00 & a $/$ & 0 & 0.00 & a/ \\
\hline Miscellaneous & 0 & 0.00 & $\bar{a} /$ & 0 & 0.00 & a & 1 & 0.12 & \pm 0.24 \\
\hline Nicotine & 12 & 15.79 & \pm 8.19 & 8 & 17.78 & \pm 11.17 & 113 & 13.70 & \pm 2.35 \\
\hline Salicylates & 10 & 13.16 & \pm 7.60 & 6 & 13.33 & \pm 9.94 & 78 & 9.45 & \pm 2.00 \\
\hline
\end{tabular}

a/ Indeterminable from the data collected. 
INCIDENCES OF DRUGS IN FATALLY INJURED DRIVERS FOR WHOM BILE SAMPLES WERE AVAIIABLE

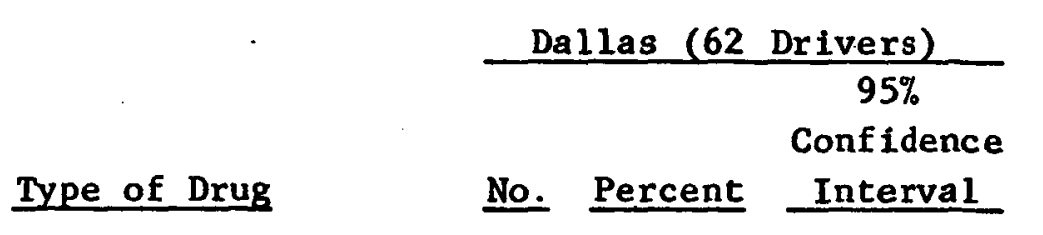

Sedatives and Hypnotics

Tranquilizers

Stimulants and

Antihistamines and Decongestants

Narcotic Analgesics

\section{Ha 1lucinogens}

Miscellaneous

Total Drivers With

One or More Drugs

Nicotine

Salicylates

\section{2}

0

1

3.23

0.00

$\pm 4.41$

al

$\pm 3.14$

$0 \quad 0.00$

a'

$1 \quad 1.61$

$\pm 3.14$

$0 \quad 0.00$

$0 \cdot 0.00$

al

$4 \quad 6.45$

$\pm 6.12$

$10 \quad 16.13$

$\pm 9.15$

$8 \quad 12.90$

$\pm 8.35$

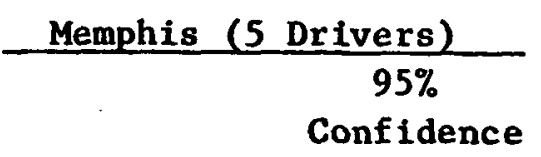

No. Percent Interval

0

$0 \quad 0.00$

$0 \quad 0.00$

$0 \quad 0.00$

$0 \quad 0.00$

$0 \quad 0.00$

$0 \quad 0.00$

a/
a/
a $/$

a/

af

a/

a/

$0 \quad 0.00$

a)

$0 \quad 0.00$

al

120.00

$\pm 35.06$
A11 Fatally Injured Drivers (492 Drivers)

95\%

Confidence

No. Percent Interval

$\begin{array}{rll}16 & 3.25 & \pm 1.57 \\ 1 & 0.20 & \pm 0.40 \\ 1 & 0.20 & \pm 0.40 \\ 5 & 1.02 & \pm 0.89 \\ 7 & 1.42 & \pm 1.05 \\ 0 & 0.00 & \underline{a} / \\ 1 & 0.20 & \pm 0.40 \\ 28 & 5.69 & \pm 2.05 \\ & & \\ 76 & 15.45 & \pm 3.19 \\ 32 & 6.50 & \pm 2.18\end{array}$

a/ Indeterminable from the data collected. 
INCIDENCES OF DRUGS IN FATALLY INJURED DRIVERS FOR WHOM BOTH BLOOD AND URINE SAMPLES WERE AVAILABLE

\section{Type of Drug}

Sedatives and Hypnotics

Tranquilizers

Stimulants and

Antidepressants

Antihistamines and

Decongestants

Narcotic Analgesics

Ha1lucinogens

Miscella neous

Total Drivers With

One or More Drugs

\begin{tabular}{|c|c|c|c|}
\hline Nicotine & 37 & 63.79 & \pm 12.37 \\
\hline ates & 11 & 18.97 & +10.0 \\
\hline
\end{tabular}

$\begin{array}{lll}3 & 5.17 & \pm 5.71 \\ 1 & 1.72 & \pm 3.35 \\ 1 & 1.72 & \pm 3.35 \\ & & \pm 3.35 \\ 1 & 1.72 & \pm 3.70 \\ 2 & 3.45 & \pm 4.70 \\ 0 & 0.0 & \because \underline{a} / \\ 0 & 0.0 & \underline{a} /\end{array}$

$7 \quad 12.06 \quad \pm 8.39$

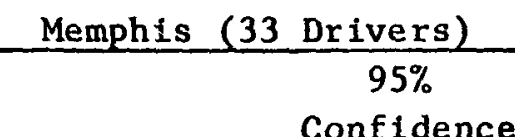

No. Percent

Confidence

No. Percent Interva 1

$8 \quad 24.24 \quad \pm 14.62$

$22 \quad 66.67 \pm 16.09$

$7 \quad 21.21 \quad \pm 13.96$
All Fatally Injured Drivers (587 Drivers) $95 \%$

Confidence

No. Percent Interval

$30 \quad 5.11 \quad \pm 1.78$

$\begin{array}{lll}4 & 0.68 \quad \pm 0.67\end{array}$

$7 \quad 1.19 \quad \pm 0.88$

$31 \quad 5.28 \quad \pm 1.81$

$15 \quad 2.56 \quad \pm 1.28$

$\begin{array}{lll}0 & 0.0 \quad \text { a } /\end{array}$

$\begin{array}{lll}6 & 1.02 \quad \pm 0.81\end{array}$

$84 \quad 14.31^{\prime} \pm 2.83$

$380 \quad 64.74 \quad \pm 3.87$

$102 \quad 17.38 \quad \pm 3.07$

a/ Indeterminable from the data collected. 
TABLE 20

INCIDENCES OF DRUGS IN FATALLY INJURED DRIVERS FOR WHOM BLOOD, URINE AND BILE SAMPLES WERE AVAILABLE

Dallas (44 Drivers)

$95 \%$

Confidence

Type of Drug

Sedatives and Hypnotics

Tranquilizers

Stimulants and Antidepressants

\section{Decongest}

Narcotic Analgesics

Hallucinogens

Miscellaneous

Total Drivers With One or More Drugs

Nicotine

Salicylates
No. Percent Interval

$\begin{array}{lll}3 & 6.82 & \pm 7.45 \\ 1 & 2.27 & \pm 4.41 \\ 1 & 2.27 & \pm 4.41\end{array}$

$\begin{array}{lll}1 & 2.27 & \pm 4.41 \\ 1 & 2.27 & \pm 4.41 \\ 0 & 0.00 & \underline{\mathrm{a} /} \\ 0 & 0.00 & \underline{\mathrm{a}} /\end{array}$.

$6 \quad 13.64 \pm 10.13$

$\begin{array}{lll}29 & 65.91 & \pm 14.01 \\ 9 & 20.45 & \pm 11.92\end{array}$

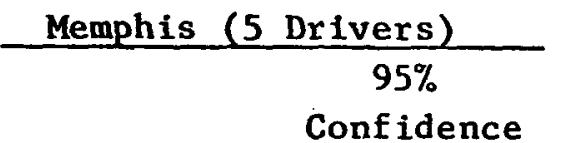

No. Percent

Interva 1$$
0
$$

0.00

20.00

0.00
a/ $\pm 35.06$

0

0.00 a/

$0 \quad 0.00$

al

0

0.00

$0 \quad 0.00$

o

0.00

a/

al

120.00

$\pm 35.06$

$.480 .00 \quad \pm 35.06$

$120.00 \pm 35.06$
All Fatally Injured Drivers (326 Drivers) $95 \%$ Confidence No. Percent Interval

$\begin{array}{rrr}18 & 5.52 & \pm 2.48 \\ 4 & 1.23 & \pm 1.20 \\ 7 & 2.15 & \pm 5.17\end{array}$

$21 \quad 6.44 \quad \pm 2.67$

$9 \begin{array}{lll}2.76 & \pm 1.78\end{array}$

$0 \quad 0.00 \quad$ al

$5 \quad 1.53 \quad- \pm 1.34$

$57 \quad 17.48 \quad \pm 4.12$

219. $67.18 \quad \pm 5.10$

$63 \quad 19.33 \quad \pm 4.29$

a/ Indeterminable from the data collected. 
QUANTITATED DRUGS IN 587 FATALLY INJURED DRIVERS FOR WHOM BOTH BLOOD AND URINE SAMPLES WERE AVA ILABLE

\section{Drug}

Amobarbital

Dipheny lhydantoin

Me thaqua lone

Pentobarbita 1

Phenobarbital

Secobarbital

Sedatives and

Hypnotics

Chlorpromazine

Meprobama te

Tranquilizers

Amitriptyline

Amphetamine

Stimulants and

Antidepressants

Chlorpheniramine

Diphenhydramine

Me thapyriline

Phenylpropanolamine

Antihistamines and

Decongestants

Cocaine

Codeine

Me thadone

Morphine

Propoxyphene

Narcotic Analgesics

Ha llucinogens

Phendimetrazine

Procaine

Quinine

Miscellaneous
Urine

Number Percent

Blood

Number Percent
Total Drivers

Number Percent

$\begin{array}{rrrrrr}3 & 0.51 & 3 & 0.51 & 3 & 0.51 \\ 0 & 0.00 & 1 & 0.17 & 1 & 0.17 \\ 1 & 0.17 & 3 & 0.51 & 3 & 0.51 \\ 4 & 0.68 & 3 & 0.51 & 4 & 0.68 \\ 18 & 3.07 & 14 & 2.39 & 18 & 3.07 \\ 1 & 0.17 & 1 & 0.17 & 1 & 0.17\end{array}$

27

4.60

25

4.26

30

5.11

0.17

0.17

0.34

0.34

0.34

0.68

1

2

0.17

1.02

0.17

0.17

1.19

0.34

0.17

0.17

0.00

0.00

3.92

1.87

0.34

0.51

23

5.28

0.34

31

5.28

31

0.17

1.19

0.00

0.17

0.00

0.51

0.00

0.68

11

0.34

0.51

3.92

23

0.17

1.02

1.19

0.85

0.34

2.56

0.00

0.00

0.00

0.00

0.17

0.17

0.51

1.02

1

80

13.63

38

6.47

84

0.17

1.19

0.17

0.85

0.34

2. 56

15

0.00

Total Drivers
0.34

0.17

0.51

1.02 
N1cotine was found in $64.7 \%( \pm 3.9 \%)$ of the fatally infured drivers and salicylates were found in $17.4 \%( \pm 3.1 \%)$ of the dead drivers.

The incidence of LSD in fatally infured drivers was examined considering only the urine samples. LSD was found in $1.2 \%(8 / 669)$ of the fatally injured drivers. All of the dead drivers evidencing LSD were males, 25 years old or less. Five of the elght $(62.5 \%)$ were fudged to be culpable, which is not significantly different from the total fatally injured driver population. The eight drivers evidencing LSD were from the following areas:

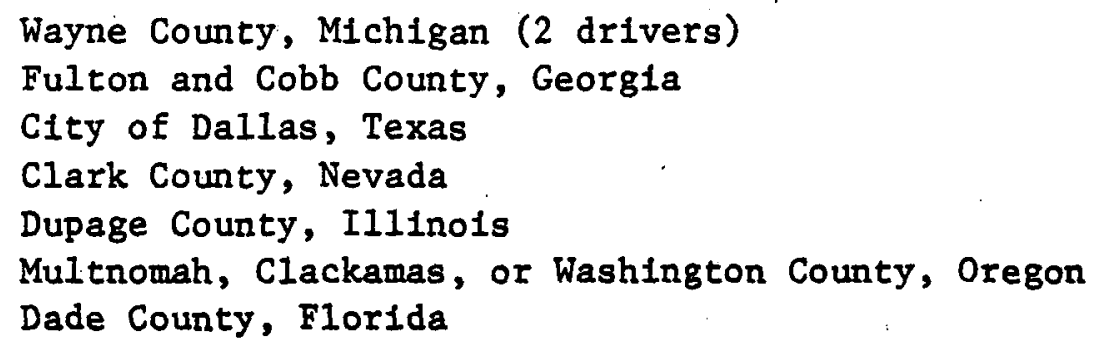

No other analysis of the LSD findings was performed.

2. Living driver drug incidences: The incidences of drugs other than alcohol in living drivers were examined in a manner similar to that used for the fatally infured drivers. The findings are presented in Tables 22 through 24 for three fluid sample combinations: (1) urine separately, (2) blood separately, and (3) blood and urine, respectively. The results are presented for each of the seven drug groups, one or more drugs, nicotine and salicylates. The drug incidences for each fluid combination are also presented separately for the City of Dallas, the City of Memphis, and the sum from both cities. The $95 \%$ confidence interval for each incidence is also displayed in the tables.

Table 25 displays the incidences of individual drugs (and drug groups) found in living drivers for whom both blood and urine samples were avallable. The findings are listed for Dallas and Memphis individually and for the combination of both cities.

For cases for which both urine and blood findings were aval1able (see Table 24), the Incidence of one or more drugs was about $8.6 \%$ $( \pm 2.6 \%)$ for the Dallas living drivers and $6.7 \%( \pm 2.9 \%)$ for the Memphis Iiving drivers for about $7.9 \%( \pm 1.9 \%)$ overall. The number of living drivers involved was relatively small; only 40 out of 463 Dallas drivers and 19 out of 282 Memphis drivers evidenced one or more drugs. 
INC IDENCE OF DRUGS IN LIVING DRIVERS

FOR WHOM URINE SAMPLES WERE AVA ILABLE

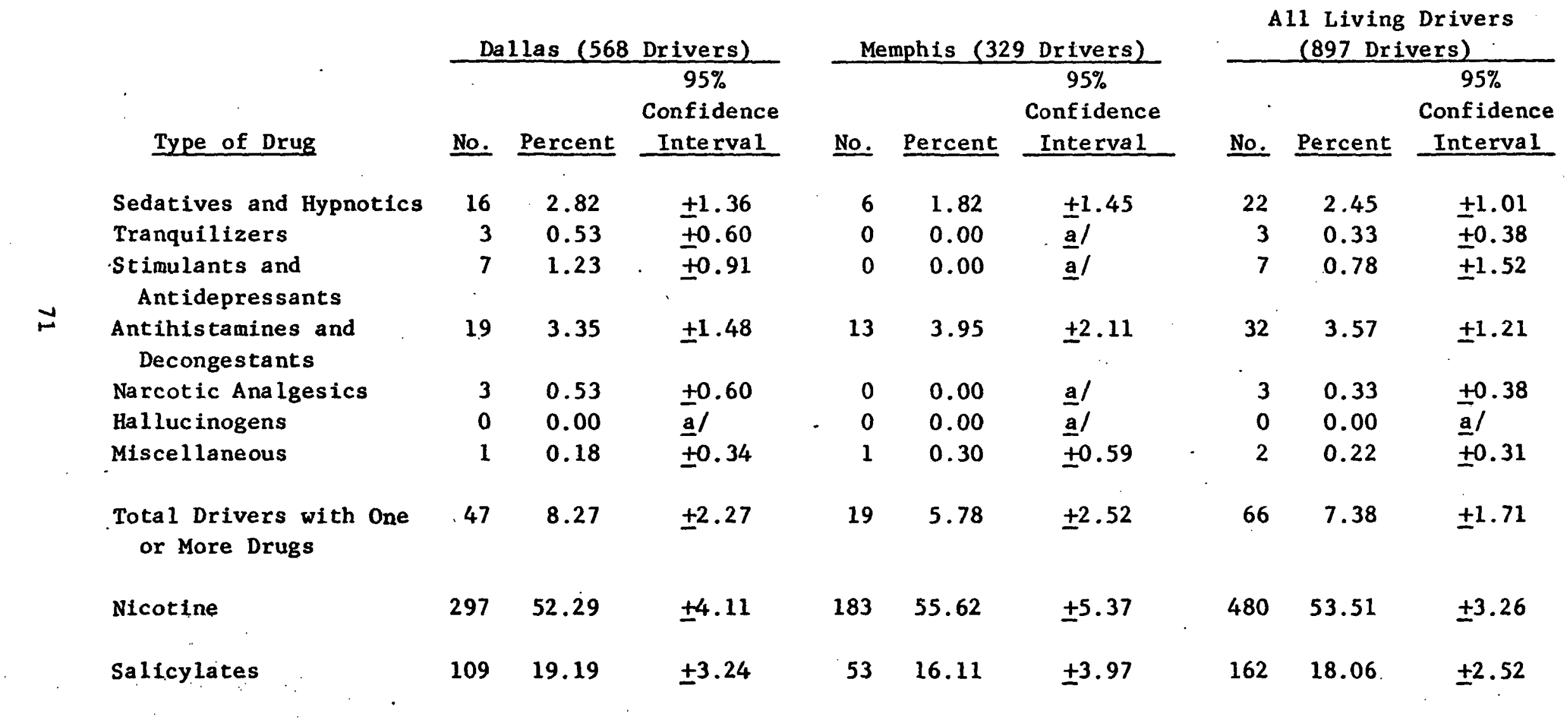

a/ Indeterminable from the data collected. 
INCIDENCE OF DRUGS IN LIVING DRIVERS

FOR WHOM BLOOD SAMPLES WERE AVA ILABLE

\begin{tabular}{|c|c|c|c|c|c|c|c|c|c|}
\hline & & 1 las $(509$ & Drivers) & & emphis $(3$ & 08 Drivers) & & $\begin{array}{l}1 \text { Living } \\
(817 \mathrm{Dr}\end{array}$ & $\begin{array}{l}\text { Drivers } \\
\text { vers) }\end{array}$ \\
\hline Sedatives and Hypnotics & 8 & 1.57 & \pm 1.09 & 5 & 1.62 & \pm 1.41 & 13 & 1.59 & \pm 0.86 \\
\hline Tranquilizers & 0 & 0.00 & a & 0 & 0.00 & a $/$ & 0 & 0.00 & al \\
\hline $\begin{array}{c}\text { Antihistamines and } \\
\text { Decongestants }\end{array}$ & 0 & 0.00 & a/ & $\mathbf{0}$. & 0.00 & a $/$ & 0 & 0.00 & a/ \\
\hline Narcotic Analgesics & 0 & 0.00 & a $/$ & 0 & 0.00 & $\underline{a} /$ & 0 & 0.00 & af \\
\hline Hallucinogens & 0 & 0.00 & a $/$ & 0 & 0.00 & a & 0 & 0.00 & af \\
\hline Miscellaneous & 0 & 0.00 & a/ & $\mathbf{1}$ & 0.32 & \pm 0.64 & 1 & 0.12 & \pm 0.24 \\
\hline Nicotine & 1 & 0.20 & \pm 0.38 & $\mathbf{1}$ & 0.32 & \pm 0.64 & 2 & 0.24 & \pm 0.34 \\
\hline Salicylates & 58 & 11.39 & \pm 2.76 & 29 & 9.42 & \pm 3.26 & 87 & 10.65 & \pm 2.12 \\
\hline
\end{tabular}

af Indeterminable from the data collected. 
INCIDENCE OF DRUGS IN LIVING DRIVERS FOR WHOM BOTH BLOOD AND URINE SAMPLES WERE AVAILABLE

Type of Drug

Sedatives and Hypnotics

Tranquilizers

Stimulants and

Antidepressants

\section{Decongestants}

Natcotic Analgesics

Hallucinogens

Miscellaneous

Total Drivers With

One or More Drugs

Nicotine

Salicylates

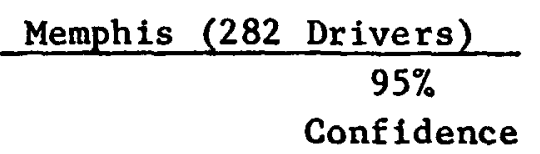

Interval

13

3
4

2.81

0.65

0.86

\pm 1.52
\pm 0.73
\pm 0.84

$18 \quad 3.89$

$\pm 1.76$

$2 \quad 0.43 \quad+0.60$

$0 \quad 0.0 \quad \underline{\mathrm{a}} /$

$1 \quad 0.22 \pm 0.42$

$40 \quad 8.65 \quad \pm 2.56$

$252 \quad 54.43 \quad \pm 4.54$

$95 \quad 20.52 \quad \pm 3.68$
Confidence

No. Percent Interval

6

6

$\begin{array}{ll}2.13 & \pm 1.68 \\ 0.0 & \text { a/ } \\ 0.0 & \text { a/ }\end{array}$

$13 \quad 4.61$

$\pm 2.45$

$0 \quad 0.0$

$0 \quad 0.0$

$2 \quad 0.71$

al

$\pm 0.98$

$19 \quad 6.74 \quad \pm 2.93$

$165 \quad 58.51 \quad \pm 5.75$

$48 \quad 17.02 \quad \pm 4.39$
A11 Living Drivers (745 Drivers) $95 \%$

Confidence

No. Percent Interval

$\begin{array}{rrr}20 & 2.68 & \pm 1.20 \\ 3 & 0.40 & \pm 0.45 \\ 4 & 0.54 & \pm 0.52\end{array}$

$31 \quad 4.16 \pm 1.43$

$1 \quad 0.13 \pm 0.26$

$0 \quad 0.0 \quad$ a/

$3 \quad 0.40 \pm 0.45$

$59 \quad 7.92 \quad \pm 1.94$

$417 \quad 55.97 \quad \pm 3.56$

$143 \quad 19.19 \pm 2.83$

a/ Indeterminable from the data collected. 
TABLE 25

IYICIDENCE OF SPECIFIC DRUGS FOUND IN LIVING DRIVERS FOR 'WHOM BOTH BLOOD AND URINE SAMPLES WERE AVA ILABLE

\begin{tabular}{|c|c|c|c|}
\hline & $\begin{array}{c}\text { Dallas } \\
\text { (463 Drivers) }\end{array}$ & $\begin{array}{c}\text { Memphis } \\
\text { (282 Drivers) } \\
\end{array}$ & $\begin{array}{l}\text { Both Cities } \\
\text { ( } 745 \text { Drivers) }\end{array}$ \\
\hline upe of Drug & Number Percent & Number Percent & Number Percent \\
\hline
\end{tabular}

\begin{tabular}{|c|c|c|c|c|c|c|}
\hline Butabarbita 1 & 1 & 0.22 & 0 & 0.00 & 1 & 0.13 \\
\hline Diphenylhydantoin & 1 & 0.22 & 0 & 0.00 & 1 & 0.13 \\
\hline Phenobarbital & 12 & 2.59 & 6 & 2.13 & 18 & 2.42 \\
\hline \multicolumn{7}{|l|}{ Sedatives and } \\
\hline Hypnotics & 13 & 2.81 & 6 & 2.13 & 19 & 2.55 \\
\hline Meprobamate & 1 & 0.22 & 0 & 0.00 & 1 & 0.13 \\
\hline Qxazepam & 1 & $0: 22$ & 0 & 0.00 & 1 & 0.13 \\
\hline Thtoridazine & 1 & 0.22 & 0 & 0.00 & 1 & 0.13 \\
\hline Tranquilizers & 3 & 0.65 & 0 & 0.00 & 3 & 0.40 \\
\hline Amphetamine & 4 & 0.86 & 0 & 0.00 & 4 & 0.54 \\
\hline \multicolumn{7}{|l|}{ Stimulants and } \\
\hline Antidepressants & 4 & 0.86 & 0 & 0.00 & 4 & 0.54 \\
\hline Chlorpheniramine & 8 & 1.73 & 2 & 0.71 & 10 & 1.34 \\
\hline Diphenhydramine & 0 & 0.00 & 1 & 0.35 & 1 & 0.13 \\
\hline Phenylpropanolamine & 16 & 3.46 & 12 & 4.26 & 28 & 3.76 \\
\hline \multicolumn{7}{|l|}{ Antihistamines and } \\
\hline Deconges tants & 18 & 3.89 & 13 & 4.61 & 31 & 4.16 \\
\hline Morphine & 1 & 0.22 & 0 & 0.00 & 1 & 0.13 \\
\hline Propoxyphene & 1 & 0.22 & 0 & 0.00 & 1 & 0.13 \\
\hline Narcotic Analgesics & 2 & 0.43 & 0 & 0.00 & 2 & 0.27 \\
\hline Hallucinogens & 0 & 0.00 & 0 & 0.00 & 0 & 0.00 \\
\hline Quinine & 1 & 0.22 & 2 & 0.71 & 3 & 0.40 \\
\hline Miscellaneous & 1. & 0.22 & 2 & 0.71 & 3 & 0.40 \\
\hline \multicolumn{7}{|l|}{ Total Drivers With } \\
\hline One or More Drugs & 40 & 8.64 & 19 & 6.74 & 59. & 7.92 \\
\hline Nicotine & 252 & 54.4 & 165 & 58.5 & 417 & 56.0 \\
\hline Salicylates & 95 & 20.5 & 48 & 17.0 & 143 & 19.2 \\
\hline
\end{tabular}


As with the fatally injured drivers, the most commonly detected drug among the living drivers was the antihistamine and decongestant, phenylpropanolamine, with the sedative, phenobarbital, second (see Table 25). Another antihistamine and decongestant, chlorpheniramine, was also found to be prevalent, more among the Dallas living drivers than among Memphis drivers.

These drug findings were compared with those in a recent study on drug use among drivers.* In that study, $4.19 \%$ of the 1iving drivers, for whom both blood and urine samples were avilable, evidenced one or more drugs in his system. This is much lower than that found in the current study $(7.92 \%)$. The preponderance of drugs found in the previous study were of the sedative/hypnotic type (generally phenobarbital). With the exception of the tranquilizer, meprobamate, no other drug or drug group was detected in more than a few individuals. Antihistamines and decongestants were not common at all, contrary to the current findings.

About $56 \%( \pm 3.6 \%)$ of the living drivers had been smoking tobacco while $19.2 \%( \pm 2.8 \%)$ of the drivers had been using salicylates.

Almost all of the drugs found in drivers for whom both blood and urine samples were available were detected either from the urine samples or were found in both the urine and blood samples. Only one of the living driver drug detections resulted solely from the blood samples. Th1s is almost the same situation for the drugs detected from the fatally injured drivers. Here, only five of the fatally injured driver drug detections resulted solely from the blood samples.

3. Statistical importance of the drug findings: The statistical survey design for the fatal incidences is a stratified cluster framework. The 24 submission areas (including the Citles of Dallas and Memphis) represent clusters of data which are classifiable by geography. The mathematical structure of the living driver data is the same, with the survey locations (sites) within each city representing clusters of data and the two cities being the "strata." The fatally injured and living driver drug incidences and their variances were calculated using

* Glauz, W. D., and R. R. Blackburn, "Drug Use Among Drivers," Contract No. DOT-HS-119-2-440, (MRI Project 3668-E), Midwest Research Institute Final report, February 1975 (DOT-HS-801411). 
the equations in Appendix $\mathrm{J}$. The variance equations were used to describe the precision of the observed incldences in Tables 16 through 20 and in Tables 22 through 24. The intracluster correlation for either the living or fatally injured driver data was not significantly different from zero (via Barlett's test). The fatally infured driver drug incidences for any particular fluid sample combinations did not differ significantly from area to area including Dallas and Memphis. The incidences of drugs in the living drivers were also compared by site within each survey community and between the two communities of Dallas and Memphis. The Incidences were found not to differ significantly between survey locations or between cities.

Twenty of the 32 survey sites in Memphis were fatal crash sites for which fluid specimens were obtained from the fatally infured driver and analyzed for drugs. These 20 sites are referred to as "matched" sites. In addition living driver surveys were conducted at 12 sites ("unmatched") in Memphis for which no comparable fatally infured driver specimens were avallable for analysis. In Dallas, 43 of the 73 survey sites were matched, so that 63 of the total 105 survey sites used in the study were matched.

A statistical comparison of the drug usage in the matched and unmatched data sets revealed no matching "effect." In other words, there is no statistical evidence that association with a fatal fluid specimen(s) influences the living driver drug incidences for three drug groups $\left(x^{2}(1)=1.37\right.$ for the sedative/hypnotic drug group, $x^{2}(1)=0$ for the. antihistamine/decongestants drug group, and $x^{2}(1)=0.82$ for the group, one or more drugs). The other drug groups contained insuffictent sample sizes to make any statistical statement. All subsequent drug finding results presented in this report are given for the totality of living or fatally infured driver data.

\section{E. Relative Risk of a Fatal Accident Involvement}

The relative incidence of drugs in fatally injured drivers was compared with the relative incidence of drugs in living drivers. The results of that comparison are presented in this subsection. From these comparisons one is able to make certain inferences about the relative chances, or risks, of belng fatally injured whlle driving a motor vehicle after having infected - arious drugs. The comparisons were made separately for Dallas and memphis, and for the combination of the two communities. The relative risks were also determined by comparing the incldences of drugs in all fatally injured drivers with the incldence of drugs in all living drivers. 
Comparative data for Dallas living and fatally injured drivers evidencing drugs, other than alcohol, at any level of concentration are presented in Tables 26 through 28 for three fluid sample combinations: (1) urine separately, (2) blood separately, and (3) blood and urine, respectively. The findings are described for each of the seven drug groups, one or more drugs, nicotine and salicylates. The $95 \%$ confidence interval for each incidence is also displayed in the tables. The same comparative data are given in Tables 29 through 31 for Memphis drivers, in Tables 32 through 34 for Memphis plus Dallas drivers, and in Tables 35 through 37. for all living and all fatally injured driver data collected.

The relative chance, or risk, of being fatally injured if having ingested a specific drug is evaluated by simply dividing the percentage of fatally injured drivers having evidences of that drug by the corresponding percentage of living drivers. This relative risk is displayed in the third to last column of Tables 26 through 37 . The next to the last and last columns in these tables present the lower and upper $95 \%$ confidence limits, respectively, for each relative risk value. The confidence limits were evaluated using the equation given in Appendix $J$ for the variance of the relative risk.

The totality of the fatally injured driver data is statistically homogeneous and therefore serves as a description of the incidence of drug use among dead drivers. The same is true about the totality of living driver data. Thus, the totality of all drug findings for both fatally injured and living drivers is the statistically preferred estimator for the Incidence of drug usage for any location. From a statistical perspective, the relative risks based on all the data collected are to be preferred over the risks calculated for Dallas or Memphis alone since the increased sample size results in a more precise estimate of the relative risk. Insufficient data are avallable for Dallas or Memphis alone upon which to draw statistically valid conclusions about the risks of a drug involved fatal crash in each community. Also, there is no statistical evidence to Indicate drug usage among living drivers was any different at crash sites for which fluid samples were available from the dead driver than at those crash sites for which fluid samples were not available.

The comparisons of the relative incidences of drugs in all fatally injured drivers wth the relative incidences of drugs in all the living drivers indicate that fatally injured drivers are significantly more likely to have been using drugs than the similarly exposed (1iving) drivers. 
COMPARATIVE DATA FOR DALLAS DRIVERS EVIDENCING

DRUGS AND FOR WHOM URINE SAMPLES WERE AVAILABLE

\begin{tabular}{|c|c|c|c|c|c|c|c|c|c|}
\hline \multirow[b]{4}{*}{ Type of Drug } & \multicolumn{3}{|c|}{ Living Drivers } & \multicolumn{3}{|c|}{$\begin{array}{c}\text { Fatally } \\
\text { Injured Drivers }\end{array}$} & \\
\hline & \multirow[b]{3}{*}{ No. } & \multirow[b]{3}{*}{ Percent } & \multirow{3}{*}{$\begin{array}{c}95 \% \\
\text { Confidence } \\
\text { Interva } 1 \\
\end{array}$} & \multirow[b]{3}{*}{ No. } & \multirow[b]{3}{*}{ Percent } & \multirow{3}{*}{$\begin{array}{c}95 \% \\
\text { Confidence } \\
\text { Interva } 1 \\
\end{array}$} & \multicolumn{3}{|c|}{$\begin{array}{c}\text { Relative Risk of } \\
\text { Being Fatally Injured }\end{array}$} \\
\hline & & & & & & & & $95 \%$ Conf & ce Limits \\
\hline & & & & & & & No. & Lower & Upper \\
\hline atives and Hypnotics & 16 & 2.82 & \pm 1.36 & 3 & 4.76 & \pm 5.25 & 1.688 & 0.259 & 4.634 \\
\hline nquilizers & 3 & 0.53 & \pm 0.60 & 1 & 1.59 & \pm 3.10 & 3.000 & 0.000 & 38.576 \\
\hline $\begin{array}{l}\text { mulants and } \\
\text { ntidepressants }\end{array}$ & 7 & 1.23 & \pm 0.91 & 1 & 1.59 & \pm 3.10 & 1.293 & 0.000 & 6.630 \\
\hline $\begin{array}{l}\text { ihistamines and } \\
\text { econgestants }\end{array}$ & 19 & 3.35 & \pm 1.48 & 1 & 1.59 & \pm 3.10 & 0.475 & 0.000 & 1.671 \\
\hline cotic Analgesics & 3. & 0.53 & \pm 0.60 & 2 & 3.17 & \pm 4.33 & 5.981 & 0.059 & 63.465 \\
\hline lucinogens & $\mathbf{0}$ & 0.00 & a $/$ & 0 & 0.00 & a $/$ & a $/$ & a $/$ & a $/$ \\
\hline cellaneous & 1 & 0.18 & \pm 0.34 & 0 & 0.00 & a $/$ & $\overline{0} .000$ & $\bar{a} /$ & $\bar{a} /$ \\
\hline or More Drugs & 47 & 8.27 & \pm 2.27 & 7 & 11.11 & \pm 7.76 & 1.343 & 0.559 & 2.514 \\
\hline otine & 297 & 52.29 & \pm 4.11 & 40 & 63.49 & \pm 11.90 & 1.214 & 0.994 & 1.460 \\
\hline icylates & 109 & 19.19 & \pm 3.24 & 11 & 17.46 & \pm 9.37 & 0.910 & 0.498 & 1.435 \\
\hline ple Size & 568 & & & 63 & & & & & \\
\hline
\end{tabular}

a/ Indeterminable from the data collected. 
TABLE 27

COMPARATIVE DATA FOR DALLAS DRIVERS EVIDENCING

DRUGS AND FOR WHOM BLOOD SAMPLES WERE AVAILABLE

Type of Drug

Sedatives and Hypnotics

Tranquilizers

Stimulants and

Antidepressants

Antihistamines and

Decongestants

Narcotic Analgesics

Hallucinogens

Miscellaneous

Qne or More Drugs

Nicotine

Salicylates

Sample Size

509

Fatally

\section{Living Drivers}

$95 \%$

Confidence

No. Percent Interval

8

8

0

$\begin{array}{ll}1.57 & \pm 1.09 \\ 0.00 & \text { al } \\ 0.00 & \text { al }\end{array}$

$0 \quad 0.00$

a/

$0 \quad 0.00$

$0 \quad 0.00$

$0 \quad 0.00$

a/

a/

$8 \quad 1.57$

$\pm 1.09$

$1 \quad 0.20$

$\pm 0.38$

$\pm 2.76$

11.39

58 $\frac{\text { Injured Drivers }}{95 \%}$

Confidence

No. Percent Interval

2

2

2

2.63

1.32

$\pm 3.61$

$\pm 2.57$

$1 \quad 1.32$

$\pm 2.57$

$0 \quad 0.00$

a/

0.00

0.00

a/

al

0.00

a /

$4 \quad 5.26 \quad \pm 5.02$

$12 \quad 15.79$

$\pm 8.19$

$10 \quad 13.16$

76

$\pm 7.60$
Relative Risk of Being Fatally Injured 95\% Confidence Limits

No. Lower Upper

\subsection{5}

0.015

a/

6.649

a/

a/

a/

a/ a/

a/

a/ a/

al

a)

a/

a/

$\begin{array}{lll}3.350 & 0.701 & 11.284\end{array}$

$78.95 \quad 20.932$

$\infty$

1.55

0.596

1.980

a/ Indeterminable from the data collected. 
COMPARATIVE DATA FOR DALLAS DRIVERS EV IDENCING DRUGS AND FOR WHOM BOTH BLOOD AND URINE SAMPLES WERE AVA ILABLE

\begin{tabular}{|c|c|c|c|c|c|c|c|c|c|c|c|}
\hline \multirow[b]{5}{*}{ Type of Drug } & \multirow{2}{*}{\multicolumn{4}{|c|}{ Living Drivers }} & \multirow{2}{*}{\multicolumn{3}{|c|}{$\begin{array}{c}\text { Fatally } \\
\text { In iured Drivers }\end{array}$}} & \multirow{3}{*}{\multicolumn{4}{|c|}{$\begin{array}{c}\text { Relative Risk of } \\
\text { Being Fatally Injured }\end{array}$}} \\
\hline & & & & & & & & & & & \\
\hline & \multirow[b]{3}{*}{ No. } & \multirow[b]{3}{*}{ Percent } & \multirow{3}{*}{$\begin{array}{c}95 \% \\
\text { Confidence } \\
\text { Interval } \\
\end{array}$} & & \multirow[b]{3}{*}{ No. } & & $95 \%$ & & & & \\
\hline & & & & & & & Confidence & \multirow[b]{2}{*}{ No. } & \multicolumn{3}{|c|}{ 95\% Confidence Limits } \\
\hline & & & & & & Percent & Interval & & Lower & Upper & \\
\hline Sedatives and Hypnotics & 13 & 2.81 & \pm 1.51 & & 3 & 5.17 & \pm 5.71 & 1.712 & 0.257 & 4.887 & \\
\hline Tranquilizers & 3 & 0.65 & \pm 0.73 & & 1 & 1.72 & \pm 3.35 & 2.646 & 0.0 & 33.032 & \\
\hline $\begin{array}{l}\text { Stimulants and } \\
\text { Antidepressants }\end{array}$ & 4 & 0.86 & \pm 0.84 & & 1 & 1.72 & \pm 3.35 & 2.000 & 0.0 & 16.129 & \\
\hline $\begin{array}{c}\text { Antihistamines and } \\
\text { Decongestants }\end{array}$ & 18 & 3.89 & \pm 1.76 & & 1 & 1.72 & \pm 3.35 & 0.442 & 0.0 & 1.573 & . \\
\hline Narcotic Analgesics & 2 & 0.43 & \pm 0.60 & & 2 & 3.45 & \pm 4.70 & 15.682 & 0.135 & $\infty$ & \\
\hline Hallucinogens & 0 & 0.0 & $\bar{a} /$ & & $\mathbf{0}$ & 0.0 & $\bar{a} /$ & a/ & a $/$ & a $/$ & \\
\hline Miscellaneous & 1 & 0.22 & \pm 0.42 & & $\mathbf{0}$ & 0.0 & al & 0.0 & a / & $\underline{a} /$ & \\
\hline One or More Drugs & 40 & 8.64 & \pm 2.56 & & 7 & 12.06 & \pm 8.39 & 1.396 & 0.575 & 2.661 & \\
\hline Nicotine & 252 & 54.43 & \pm 4.54 & & 37 & 63.79 & \pm 12.37 & 1.172 & 0.952 & 1.421 & \\
\hline Salicylates & 95 & 20.52 & \pm 3.68 & $\cdot$ & 11 & 18.97 & \pm 10.09 & 0.924 & 0.506 & 1.467 & \\
\hline Sample Size & 463 & & & & 58 & & & & & & \\
\hline
\end{tabular}

a/ Indeterminable from the data collected. 
TABLE 29

COMPARATIVE DATA FOR MEMPHIS DRIVERS EVIDENCING

DRUGS AND FOR WHOM URINE SAMPLES WERE AVAILABLE

Type of Drug

Sedatives and Hypnotics

Tranquilizers

Stimulants and

Antidepressants

$\infty \quad$ Antihistamines and

Decongestants

Narcotic Analgesics

Hallucinogens

Miscellaneous

One or More Drugs

Nicotine

Salicylates

Sample Size

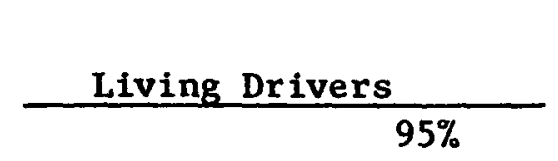

Confidence

No. Percent Interval

$6 \quad 1.82$

$0 \quad 0.00$

$0 \quad 0.00$

\pm 1.45
a/
al

13

3.95

$\pm 2.11$

$\begin{array}{ll}0 & 0.00\end{array}$

$0 \quad 0.00$

$1 \quad 0.30$

a/

a/

$+0.59$

$19 \quad 5.78$

$\pm 2.52$

183

53

329

\section{Fatally}

$\frac{\text { Injured Drivers }}{95 \%}$

Confidence

No. Percent Interval
Relative Risk of Being Fatally Injured 95\% Confidence Limits

№. Lower Upper

$\begin{array}{llllll}2 & 6.06 & \pm 8.13 & 3.333 & 0.075 & 15.32 \\ 0 & 0.00 & \text { a } / & \text { a/ } & \text { a/ } & \text { a/ } \\ 0 & 0.00 & \text { a } / & \text { a } / & \text { a } / & \text { a/ }\end{array}$

$5 \quad 15.15 \quad \pm 12.23$

3.836

1.163

9.842

13.03

$0 \quad 0.00$

$0 \quad 0.00$

$\pm 5.84$

a)

a/

$\stackrel{\infty}{0.0}$

al

al

$7 \quad 21.21$

$\pm 13.96$

3.670

1.472

1.199

0.926

1.317

0.589

2.357

a/ Indeterminable from the data collected. 
COMPARATIVE DATA FOR MEMPHIS DRIVERS EVIDENCING DRUGS AND FOR WHOM BLOOD SAMPLES WERE AVAILABLE

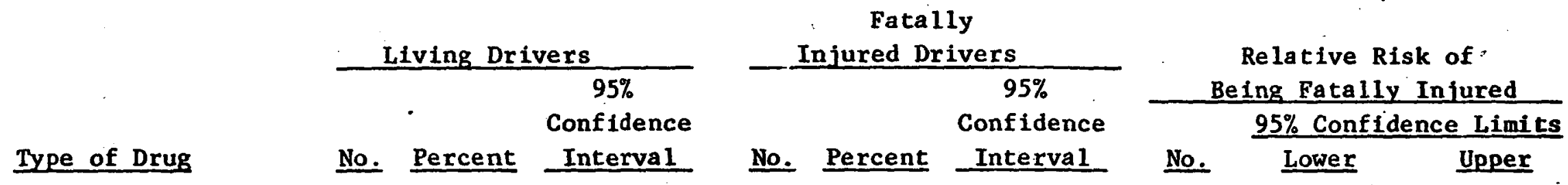

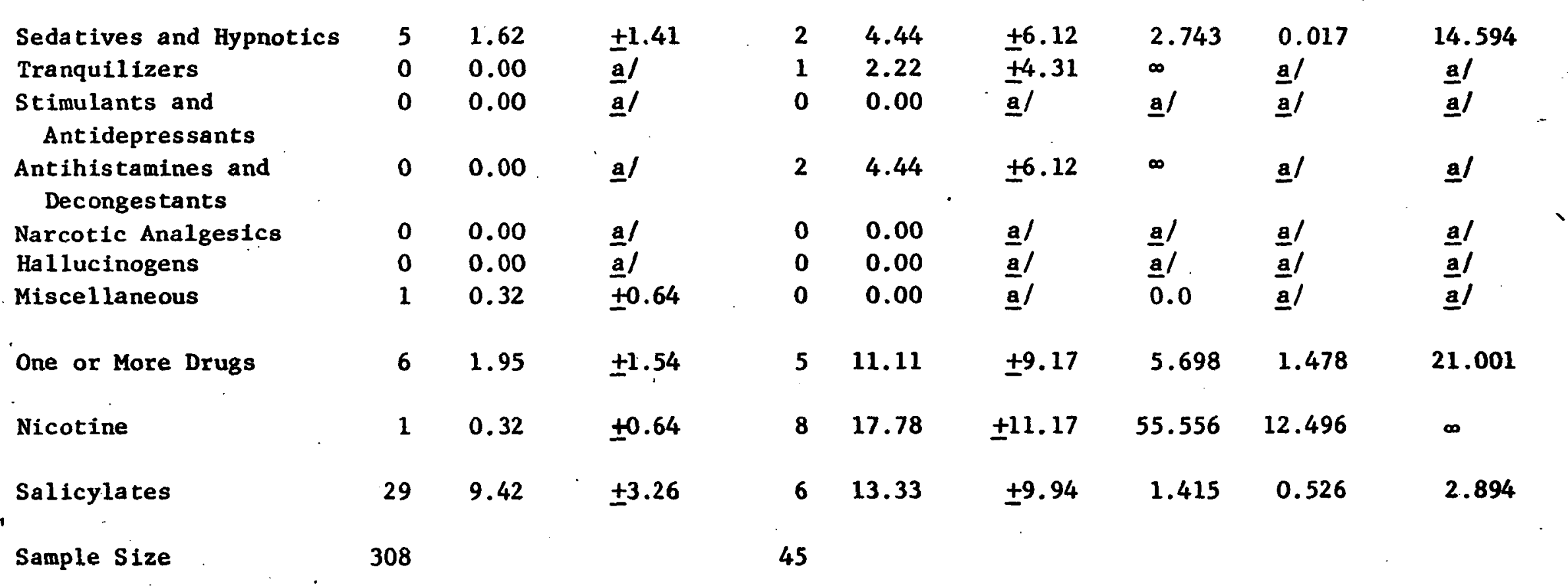

a/ Indeterminable from the data collected. 
TABLE 31

COMPARATIVE DATA FOR MEMPHIS DRIVERS EVIDENCING DRUGS AND FOR WHOM BOTH BLOOD AND URINE SAMPLES WERE AVAILABLE

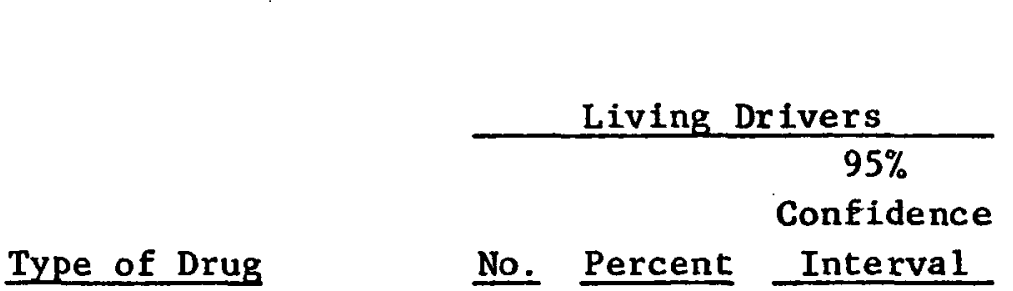

\begin{tabular}{|c|c|c|c|}
\hline Sedatives and Hypnotics & 6 & 2.13 & \pm 1.68 \\
\hline Tranquilizers & 0 & 0.0 & a/ \\
\hline $\begin{array}{l}\text { Stimulants and } \\
\text { Antidepressants }\end{array}$ & 0 & 0.0 & al \\
\hline $\begin{array}{l}\text { Antihistamines and } \\
\text { Decongestants }\end{array}$ & 13 & 4.61 & \pm 2.45 \\
\hline Narcotic Analgesics & 0 & 0.0 & al \\
\hline Hallucinogens & 0 & 0.0 & a/ \\
\hline Miscellaneous & 2 & 0.71 & \pm 0.98 \\
\hline One or More Drugs & 19 & 6.74 & \pm 2.93 \\
\hline Nicotine & 165 & 58.51 & \pm 5.75 \\
\hline Salicylates & 48 & 17.02 & \pm 4.39 \\
\hline Sample Size & 282 & & \\
\hline
\end{tabular}

Fatally

Injured Drivers
$95 \%$
Nonfidence
No. Percent Interval

$\begin{array}{lll}2 & 6.06 & \pm 8.13 \\ 1 & 3.03 & \pm 5.84 \\ 0 & 0.0 & \underline{\mathbf{a}} /\end{array}$

$5 \quad 15.15 \pm 12.23$

$1 \quad 3.03 \quad \pm 5.84$

$\begin{array}{lll}0 & 0.0 & \text { a/ } \\ 0 & 0.0 & \text { a } /\end{array}$

$8 \quad 24.24 \quad \pm 14.60$

$22 \quad 66.67 \quad+16.09$

$7 \quad 21.21 \quad \pm 13.96$

33
Relative Risk of Being Fatally Injured 95\% Confidence Limits No. Lower Upper

$\begin{array}{lll}2.845 & 0.064 & 12.912 \\ \infty & \text { a/ } & \text { a/ } \\ \text { a/ } & \text { a/ } & \text { a / }\end{array}$

$\begin{array}{lll}3.286 & 0.998 & 8.407\end{array}$

$\infty$

$\infty \quad$ al

al al

0.0 al

a /

al

$\begin{array}{lll}3.596 & 1.552 & 7.501\end{array}$

$\begin{array}{lll}1.139 & 0.880 & 1.439\end{array}$

$1.246 \quad 0.554 \quad 2.254$

a/ Indeterminable from the data collected. 
COMPARATIVE DATA FOR MEMPHIS PLUS DALLAS DRIVERS EVIDENCING DRUGS AND FOR WHOM URINE SAMPLES WERE AVA ILABLE

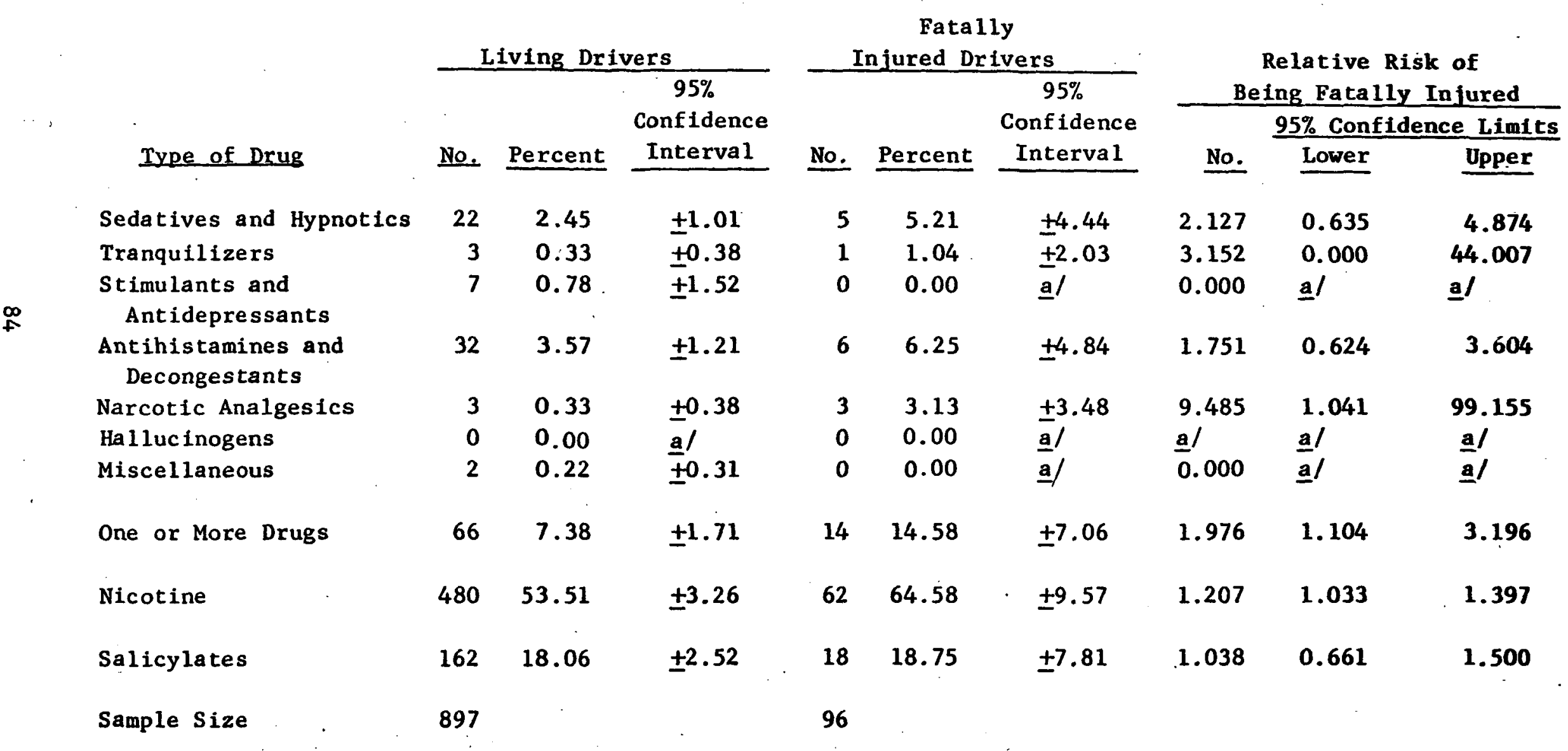

a/ Indeterminable from the data collected. 
COMPARATIVE DATA FOR MEMPHIS PLUS DALLAS DRIVERS EVIDENCING DRUGS AND FOR WHOM BLOOD SAMPLES WERE AVAILABLE

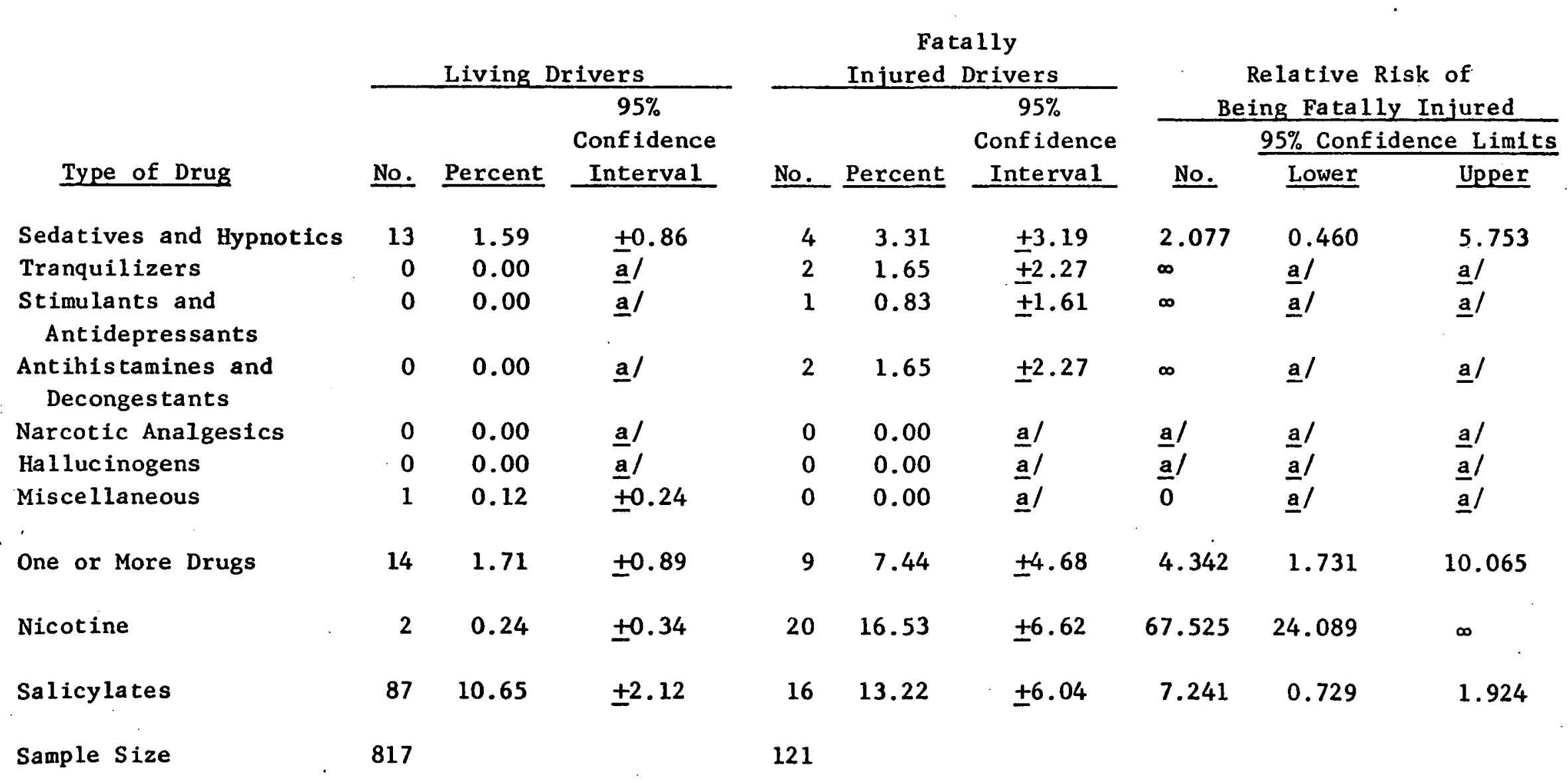

a/ Indeterminable from the data collected. 
TABLE 34

COMPARATIVE DATA FOR MEMPHIS PLUS DALIAS DRIVERS EVIDENCING DRUGS AND FOR WHOM BOTH BLOOD AND URINE SAMPLES WERE AVA ILABLE

Type of Drug

Sedatives and Hypnotics

Tranquilizers

Stimulants and

Antidepressants

Antihistamines and

Decongestants

Narcotic Analgesics

Hallucinogens

Miscellaneous

One or More Drugs

Nicotine

Salicylates

Sample Size

a/ Indeterminable from the data collected.

745

\section{Fatally}

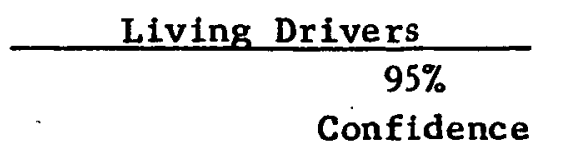

No. Percent Interval

$\begin{array}{rrl}20 & 2.68 & \pm 1.20 \\ 3 & 0.40 & \pm 0.45 \\ 4 & 0.54 & \pm 0.52 \\ 31 & 4.16 & \pm 1.43 \\ 1 & 0.13 & \pm 0.26 \\ 0 & 0.00 & \pm / \\ 3 & 0.40 & \pm 0.45 \\ 59 & 7.92 & \pm 1.94 \\ 417 & 55.97 & \pm 3.56 \\ 143 & .19 .19 & \pm 2.83\end{array}$

Injured Drivers $95 \%$

Confidence

$5 \quad 5.49$

$+4.68$

$$
\pm 3.01
$$$$
\pm 2.14
$$

1.10

6.59

$\pm 5.10$

$3 \quad 3.30$

$0 \quad 0.00$

0

0.00

$\pm 3.67$

a $/$

15

16.48

a $/$

$\pm 7.62$

$\pm 9.81$

64.84

18

19.78

$\pm 8.18$

91

59

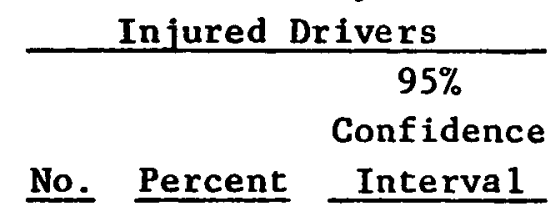

Relative Risk of Being Fatally Injured 95\% Confidence Limits

№. Lower Upper.

2.045

$0.599 \quad 4.865$

5.463

0.049

57.728

2.049

0.000

16.554

1.584

0.563

3.277

24.590

1.860

a/

0.000

a/

$\infty$

a'

2.081

1.181

3.366

1.158

0.987

1.346

1.031

0.655

1.496 
TABLE 35

COMPARATIVE DATA FOR ALL DRIVERS EVIDENCING DRUGS AND FOR WHOM URINE SAMPLES WERE AVA ILABLE

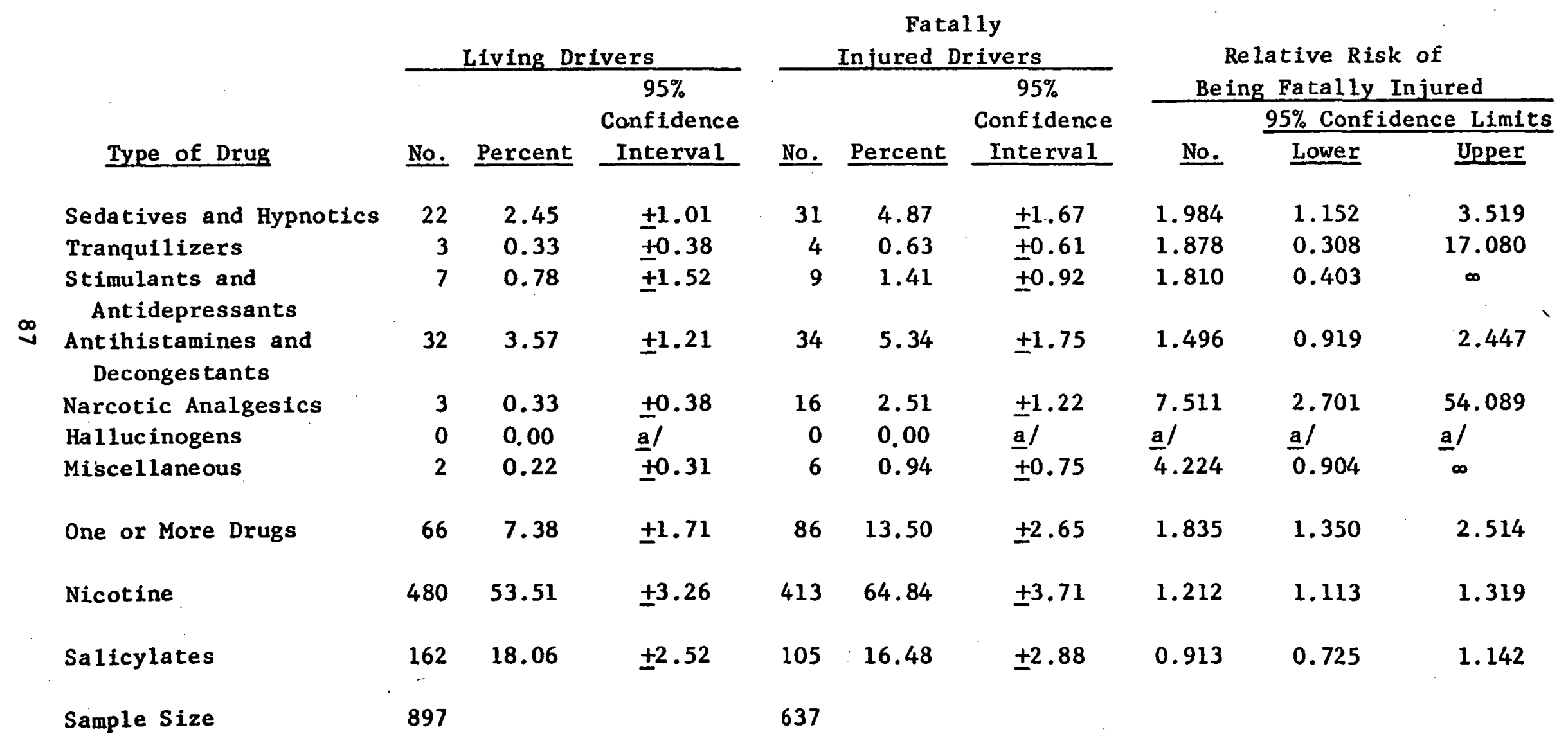

a/ Indeterminable from the data collected. 
COMPARATIVE DATA FOR ALL DRIVERS EVIDENCING DRUGS AND FOR WHOM BLOOD SAMPLES WERE AVA ILABLE

Type of Drug

Sedatives and Hypnotics

Tranquilizers

Stimulants and Antidepressants

Ant ihistamines and

Decongestants

Narcotic Analgesics

Hallucinogens

Miscellaneous

One or More Drugs

Nicotine

Salicylates

Sample Size

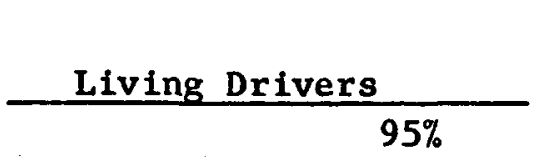

Confidence

No. Percent Interval

$\begin{array}{rll}13 & 1.59 & \pm 0.86 \\ 0 & 0.00 & \underline{a} / \\ 0 & 0.00 & \underline{a} / \\ 0 & 0.00 & \text { a/ } \\ 0 & 0.00 & \underline{a} / \\ 0 & 0.00 & \underline{a} / \\ 1 & 0.12 & \pm 0.24 \\ 14 & 1.71 & \pm 0.89 \\ 2 & 0.24 & \pm 0.34 \\ 87 & 10.65 & \pm 2.12\end{array}$

817

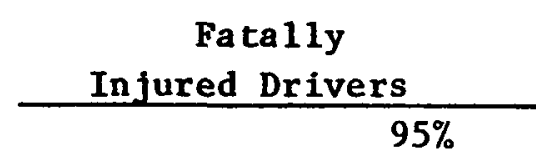

Confidence

No. Percent Interval

$\begin{gathered}\text { Relative Risk of } \\ \text { Being Fatally Injured }\end{gathered}$
No. $\frac{95 \% \text { Confidence Limits }}{\text { Lower }}$ Upper

$\begin{array}{rrr}37 & 4.48 & \pm 1.41 \\ 4 & 0.48 & \pm 0.47 \\ 2 & 0.24 & \pm 0.34\end{array}$

2.819

$\infty$

$\infty$

1.571

a/

al

5.648

a/

$2 \quad 0.24 \quad \pm 0.34$

$\infty$

a/

a/

$4 \quad 0.48$

$0 \quad 0.00$

$\pm 0.47$

al

$\pm 0.24$

al ${ }^{\infty}$

0.990

a /

0.000

al

50

6.06

$\pm 1.63$

3.537

2.077

6.737

$113 \quad 13.70$

$\pm 2.35$

55.952

24.579

$\pm 2.00$

0.888

0.659

1.193

a/ Indeterminable from the data collected. 
TABLE 37

COMPARATIVE DATA FOR ALL DRIVERS EVIDENCING

DRUGS AND FOR WHOM BOTH BLOOD AND URINE SAMPLES WERE AVA ILABLE

Fatally

\begin{tabular}{ccc} 
Living Drivers & & Injured \\
$\begin{array}{c}95 \% \\
\text { Confidence } \\
\text { No. Privers }\end{array}$ & & $\begin{array}{c}95 \% \\
\text { Confidence } \\
\text { Interval }\end{array}$ \\
\hline
\end{tabular}

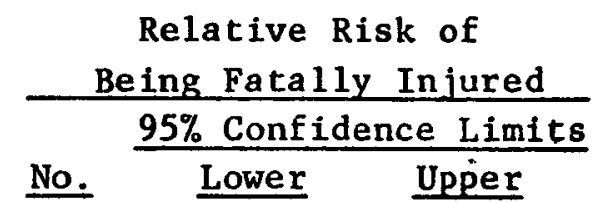

Sedatives and Hypnotics Tranquilizers

Stimulants and Antidepressants

Antihistamines and Decongestants

Narcotic Analgesics

Ha 1 luc inogens

Miscel laneous

One or More Drugs

Nicotine

Salicylates

Sample Size

$\begin{array}{ll}2.68 & \pm 1.20 \\ 0.40 & \pm 0.45 \\ 0.54 & \pm 0.52\end{array}$

$31 \quad 4.16 \pm 1.43$

$10.13 \pm 0.26$

$\begin{array}{lll}0 & 0.0 & \text { a } /\end{array}$

$59 \quad 7.92 \quad \pm 1.94$

$417 \quad 55.97 \quad \pm 3.56$

$143 \quad 19.19 \quad \pm 2.83$

745
$3 \quad 0.40 \quad \pm 0.45$

$\begin{array}{rlr}30 & 5.11 & \pm 1.78 \\ 4 & 0.68 & \pm 0.67 \\ 7 & 1.19 & \pm 0.88\end{array}$

$31 \quad 5.28 \quad \pm 1.81$

$15 \quad 2.56 \quad \pm 1.28$

$0 \quad 0.0$

$6 \quad 1.02$

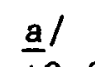

$\pm 0.81$

$84 \quad 14.31$

$\pm 2.83$

$380 \quad 64.74$

$\pm 3.87$

$102 \quad 17.38$

$\pm 3.07$

587
$1.904 \quad 1.079 \quad 3.512$

$\begin{array}{lll}1.692 & 0.278 & 15.349\end{array}$

$2.221 \quad 0.613 \quad 11.444$

$\begin{array}{lll}1.269 & 0.766 & 2.103\end{array}$

$19.042 \quad 5.064 \quad \infty$

a/ a/ a/

2.538 $0.599 \quad 21.268$

$\begin{array}{lll}1.807 & 1.318 & 2.506\end{array}$

$1.210 \quad 1.059 \quad 1.264$

$0.906 \quad 0.715 \quad 1.142$

a/ Indeterminable from the data collected. 
The comparisons in Table 37 imply that drivers usine one or more drugs have a greater chance of being fatally injured in a vehicular crash than similarly exposed drivers not using drugs--they have a relative risk of about 1.8 (with a $95 \%$ confidence interval of 1.3 to 2.5 ). The danger may be greatest with narcotic analgesics with a relative risk of about 19 (with a 95\% confidence interval of 5.1 to infinity); followed by sedatives and hypnotics with a relative risk of about 1.9 (with a $95 \%$ confidence interval of 1.1 to 3.5 ); and nicotine at 1.2 (with a $95 \%$ confidence interval of 1.1 to 1.3 ). The relative risks for the other drug groups (tranquilizers, stimulants and antidepressants, antihistamines and decongestants, and miscellaneous) were all greater than unity, but data samples are not large enough to make very powerful statements regarding their significance. (The lower confidence limits on the relative risk for these latter drug groups were all less than unity.)

The relative risk estimates for nicotine drawn from the blood findings only are very large (see Tables 30, 33, 36 and 39). The assoclated $95 \%$ confidence limits for these risks are also extremely large. The reasons for these conditions are that nicotine was found in the blood of only two living drivers (one each in Dallas and Memphis); it was more prevalently found in the blood of the fatally injured drivers. The significance of these findings suggest that the fatally infured drivers were smoking shortly before or at the time of the crash. Living drivers were not smoking from the time they were stopped until sometime after the blood samples were drawn, perhaps a time lapse of about 10 to $15 \mathrm{~min}$ in most cases.

The relative risk data in. Table 37 were compared with similar data obtained in a previous study.* The comparative data from the previous study are repeated here in Table 38 for completeness. The results in the two tables are quite different. In the past study, the relative risk of being fatally injured and using one or more drugs was 4.22. This is almost twice the risk found in the current study (Table 37). In addition, both the magnitude of the relative risk for Individual drug types and the order of drug types in terms of decreasing risks are different in the two tables.

* Glauz, W. D., R. R. Blackburn, "Drug Use Among Drivers," Contract No. DOT-HS-119-2-440, (MRI Project 3668-E) Midwest Research Institute Final Report, February 1975 (DOT-HS-801-411). 
TABLE 38

COMPARATIVE DATA FOR DRIVERS EVIDENCING DRUGS AT ANY LEVEL*

\begin{tabular}{|c|c|c|c|c|c|}
\hline \multirow[b]{2}{*}{ Drug Type } & \multirow{2}{*}{$\frac{\text { Living }}{\text { No. }}$} & Drivers & \multicolumn{2}{|c|}{$\begin{array}{l}\text { Fatally } \\
\text { Injured } \\
\text { Drivers }\end{array}$} & \multirow{2}{*}{$\begin{array}{l}\text { Relative Chance } \\
\text { of Being } \\
\text { Fatally Injured }\end{array}$} \\
\hline & & Percent & No. & Percent & \\
\hline $\begin{array}{l}\text { Sedatives and Hypnotice } \\
\text { Stimulants and }\end{array}$ & 19 & 2.49 & 56 & 11.13 & 4.47 \\
\hline $\begin{array}{l}\text { Antidepressants } \\
\text { Antihistamines and }\end{array}$ & 1 & 0.13 & 27 & 5.37 & 40.99 \\
\hline Decongestants & 2 & 0.26 & 17 & 3.38 & 12.90 \\
\hline Tranquilizers & 10 & 1.31 & 17 & 3.38 & 2.58 \\
\hline Narcotic Analgesics & 2 & 0.26 & 7 & 1.39 & 5.31 \\
\hline Miscellaneous & 0 & 0.00 & 8 & 1.59 & - \\
\hline One or more Drugs & 32 & 4.19 & 89 & 17.69 & 4.22 \\
\hline Sample Size & 763 & & 503 & & \\
\hline
\end{tabular}

* Glauz, W. D., R. R. Blackburn, "Drug Use Among Drivers," Contract No. DOT-HS-119-2-440, February 1975 (DOT-HS-801-411). 


\section{F. Alcohol Usage Among Drivers}

1. Usage of alcohol dependent of other drugs: The study reconfirmed the fact that alcohol is the most abused drug among driver, and it plays the leading role among drugs as a causative factor in fatal crashes. Comparative data for alcohol considering all living and all fatally injured driver data are presented in Table 39. The blood alcohol concentration (BAC) data shown were determined from blood samples and are presented for different levels of BAC including the categorles "negative" and any positive BAC. The $95 \%$ confidence interval for each relative incidence is also displayed in the table.

Overall, $16.5 \%$ of the living drivers stopped and interviewed had been drinking and $4.5 \%$ could be presumed drunk, on the basis of a $B A C$ of 0.10 or more. The site-by-site BAC findings are displayed in Appendix $\mathrm{K}$ for both Dallas and Memphis. The BAC results in Apperidix $\mathrm{K}$ were determined from the breathalyzer tests administered to the motorists during the interviews. There is little evidence that any of the sites in either city is statistically more likely to have produced drunk drivers than the others.

As shown in Table $41,65.7 \%$ of the fatally infured drivers had consumed some alcohol. Most of these, or $53.6 \%$, had enough alcohol to be presumed intoxicated in most states (BAC 0.10 ).

Table 39 also displays the relative risk of being fatally injured if having ingested alcohol. The alcohol data are grouped according to BAC level. The last three columns are a restatement of the relative risk columns but normalized to 1.00 for sober drivers, in agreement with standard practice. The lower and upper $95 \%$ confidence limits for both the relative risk and the normalized relative risk are also shown in Table 41.

From Table 41 it is seen that drivers who would be intoxicated in most states (BAC of $0.10 \%$ or more) were found to be far more likely to be fatally injured in a crash than sober drivers. In agreement with previous findings, the relative chance increased drastically with BAC, being 3.27 in the $\mathrm{BAC}$ range $0.05 \%$ to $0.09 \%$ (with a $95 \%$ confidence interval of 2.13 to 5.03 ); 10.41 in the $B A C$ range $0.10 \%$ to $0.14 \%$ (w1th a $95 \%$ confidence interval of 6.55 to 17.86 ); 30.31 in the BAC range $0.15 \%$ to $0.19 \%$ (with a $95 \%$ confidence interval of 17.17 to 69.07 ); and an uncertain but extremely high figure at greater BAC's. 
TABI.E 39

COAPARATIVE DATA FUR AL,COHOL CONS IDFRING ALL DRIVERS

FOR WIKM BOTH BI OOD AND URINE SAMILLES WERE AVALLABIE

\begin{tabular}{|c|c|c|c|c|c|c|c|c|c|c|c|c|}
\hline \multirow[b]{3}{*}{ Alcohol BAC Level } & \multicolumn{3}{|c|}{$\begin{array}{r}\text { Living Drivers } \\
\text { (729 Drivers) } \\
\end{array}$} & \multicolumn{3}{|c|}{$\begin{array}{l}\text { Fatally Infured Drlvers } \\
\text { (556_Drivers) }\end{array}$} & \multirow{2}{*}{\multicolumn{3}{|c|}{$\begin{array}{l}\text { Relative Risk of } \\
\text { Belng Facally Injured } \\
\end{array}$}} & \multirow{2}{*}{\multicolumn{3}{|c|}{$\begin{array}{c}\text { Normalized } \\
\text { Relative Risk of } \\
\text { Belng Fatally Injureda/ }\end{array}$}} \\
\hline & \multirow[b]{2}{*}{ №. } & \multirow[b]{2}{*}{ Percent } & \multirow{2}{*}{$\begin{array}{c}95 \% \\
\text { Conf Idence } \\
\text { Incerval } \\
\end{array}$} & \multirow[b]{2}{*}{ No. } & \multirow[b]{2}{*}{ Percent } & \multirow{2}{*}{$\begin{array}{c}95 \% \\
\text { Conf idence } \\
\text { Interval } \\
\end{array}$} & & & & & & \\
\hline & & & & & & & №. & Lower & Upper & No:- & Lower & Upper \\
\hline Negative & 609 & 83.54 & \pm 2.69 & 191 & 34.35 & \pm 3.95 & $0.4+11$ & 0.369 & 0.456 & 1.000 & 0.898 & 1.109 \\
\hline $0.01-0.04$ & 46 & 6.31 & \pm 1.77 & 25 & 4.50 & \pm 1.73 & 0.713 & 0.429 & 1.140 & 1.735 & 1.044 & 2.774 \\
\hline $0.05-0.09$ & 41 & 5.62 & \pm 1.67 & 42 & 7.55 & \pm 2.20 & 1.343 & 0.875 & 2.067 & 3.268 & 2.129 & 5.029 \\
\hline $0.10-0.14$ & 19 & 2.61 & \pm 1.16 & 62 & 11.15 & \pm 2.62 & 4.278 & 2.690 & 7.339 & 10.409 & 6.545 & 17.856 \\
\hline $0.15-0.19$ & 8 & 1.10 & \pm 0.76 & 76 & 13.67 & \pm 2.86 & 12.456 & 7.056 & 28.386 & 30.307 & 17.168 & 69.066 \\
\hline $0.20-0.24$ & 4 & 0.55 & \pm 0.54 & 81 & 14.57 & \pm 2.93 & 26.551 & 13.287 & 102.944 & 64.601 & 32.328 & 250.472 \\
\hline $0.25 t$ & 2 & 0.27 & \pm 0.38 & 79 & 14.21 & \pm 2.90 & 51.790 & 22.166 & $16,295.0$ & 126.010 & 53.932 & $39,647,0$ \\
\hline Any Posltive BAC & 120 & 16.46 & \pm 2.69 & 365 & 65.65 & \pm 3.95 & 3.988 & 3.415 & 4.715 & 9.703 & 8.309 & 11.472 \\
\hline
\end{tabular}

a/ Relative risk is normalized to 1.000 for "negatlve" Bac. 
TABLE 40

TIME OF DAY VERSUS PERCENTAGE OF DRINKING AND DRIVING FOR FATALLY INJURED DRIVERS

\begin{tabular}{|c|c|c|c|c|c|c|c|c|c|}
\hline \multirow[b]{2}{*}{ Time } & \multicolumn{8}{|c|}{ Blood Alcohol Concentration Level } & \multirow[b]{2}{*}{$\begin{array}{c}\text { Sample } \\
\text { size } \\
\end{array}$} \\
\hline & $\underline{0.00}$ & $0.01-0.04$ & $0.05-0.09$ & $0.10-0.14$ & $0.15-0.19$ & $0.20+$ & $\begin{array}{l}\text { Any Positive } \\
(0.01+) \\
\end{array}$ & $\underline{0.10+}$ & \\
\hline $0001-0400$ & 13.64 & 2.84 & 9.09 & 15.34 & 17.61 & 41.48 & 86.36 & 74.43 & 176 \\
\hline $0401-0800$ & 46.43 & 1.79 & 1.79 & 16.07 & 17.86 & 16.07 & 53.57 & 50.00 & 56 \\
\hline $0801-1200$ & 61.70 & 8.51 & 8.51 & 2.13 & 6.38 & 12.77 & 38.30 & 21.28 & 47 \\
\hline $1201-1600$ & 67.92 & 7.55 & 3.77 & 5.66 & 5.66 & 9.43 & 32.08 & 20.75 & 53 \\
\hline $1601-2000$ & 46.99 & 4.82 & 9.64 & 6.02 & 4.82 & 27.71 & 53.01 & 38.55 & 83 \\
\hline $2001-2400$ & 26.24 & 4.96 & 7.80 & 12.06 & 17.73 & 31.21 & 73.76 & 60.99 & 141 \\
\hline Total & 34.35 & 4.50 & 7.55 & 11.15 & 13.67 & 28.78 & 65.65 & 53.60 & 556 \\
\hline
\end{tabular}


TABLE 41

TIME OF DAY VERSUS PERCENTAGE OF DRINKING AND DRIVING FOR LIVING DRIVERS

Blood Alcohol Concentration Level

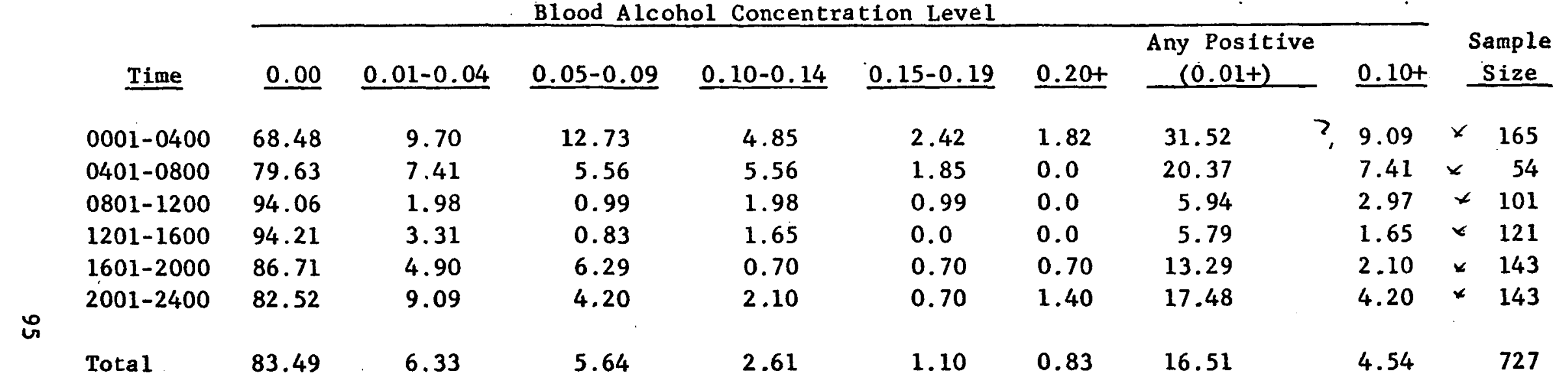


Data on the time of day versus the percentage of drinking and driving for fatally injured and living drivers are shown in Tables 40 and 41 , respectively. In further confirmation of previous findings, alcohol usage depends strongly on time of day for both the fatally injured drivers (at time of crash) and the living drivers (at time of interview). For both sets of drivers, the mafority of all the drunk drivers was detected in the late evening and early morning hours.

2. Usage of alcohol in combination with other drugs: The relationships between alcohol usage and drug usage were examined for both the fatally injured and living drivers. Table 42 presents the drug groups found in combination with alcohol in the fatally injured drivers. Table 43 presents the same information but for the living drivers Among the fatally injured drivers, the use of antihistamines and decongestants and one or more drugs were found to be significantly related, in a negative sense, with alcohol usage. Of the fatally injured drivers evidencing one or more drugs, $57.1 \%$ also had positive BAC's $(0.01 \%+)$. A significantly higher percentage (68.4\%) of the dead drivers not using drugs had positive BAC's. The same negative association was found between alcohol usage and the other drug groups, except the miscellaneous group, but these drug incidence levels were too small for any statistical significance. There is no statistical evidence to indicate that alcohol and drug usage are related among living drivers.

\section{G. Fatally Injured and Living Driver Factors Compared with Drug Usage}

The finding that alcohol usage depends strongly on time of day for both the fatally injured and living drivers prompted a similar investigation for other drugs. The relationship between time of day and drug usage was examined for the seven drug groups and the cateogry, one or more drugs for both the fatally injured and living drivers. The only significant finding was that antihistamines and decongestants were over-involved in the morning and late afternoon to early evening hours among living drivers. Drug usage among the fatally injured drivers was mildiy dependant on time of day, but in an opposite sense to that found for alcohol usage. However, the relationships between time of day and drug usage were not statistically significant.

A number of other fatally infured and living driver factors were compared with drug usage and examined for statistical importance. Fatally injured driver factors included area type, number of vehicles involved, 
TABLE 42

DRUGS COMBINED WITH ALCOHOL IN

FATALLY INJURED DRIVERS

\section{Type of Drivers}

A11 Drivers
Non-Drug Users
Drivers Evidencing:
Sedatives and Hypnotics
Tranquilizers
Stimulants and
Antidepressants
Antihistamines and
Decongestants
Narcotic Analgesics
Hallucinogens
Miscellaneous
One or More Drugs

\begin{tabular}{|c|c|c|c|}
\hline \multicolumn{3}{|c|}{$B A C^{\prime} s$} & Sample \\
\hline 0.00 & $0.01-0.09$ & $0.10 t$ & Size \\
\hline $33.2 \%$ & $11.9 \%$ & $54.9 \%$ & 587 \\
\hline $31.6 \%$ & $10.5 \%$ & $57.9 \%$ & 503 \\
\hline $36.7 \%$ & $23.3 \%$ & $40.0 \%$ & 30 \\
\hline $75.0 \%$ & $25.0 \%$ & $0.0 \%$ & 4 \\
\hline $28.6 \%$ & $42.8 \%$ & $28.6 \%$ & 7 \\
\hline $58.1 \%$ & $12.9 \%$ & $29.0 \%$ & 31 \\
\hline $40.0 \%$ & $26.7 \%$ & $33.3 \%$ & 15 \\
\hline a / & a $/$ & a / & 0 \\
\hline $0.0 \%$ & $16.7 \%$ & $83.3 \%$ & 6 \\
\hline $42.9 \%$ & $20.2 \%$ & $36.9 \%$ & 84 \\
\hline
\end{tabular}

a/ Indeterminable from the data collected. 


\section{TABLE 43}

DRUGS COMBINED WITH ALCOHOL IN

LIVING DRIVERS

\section{Type of Drivers}

AlI Drivers
Non-Drug Users
Drivers Evidencing:
Sedatives and Hypnotics
Tranquilizers
Stimulants and
Antidepressants
Antihistamines and
Decongestants
Narcotic Analgesics
Hallucinogens
Miscellaneous
One or More Drugs

\begin{tabular}{|c|c|c|c|}
\hline \multicolumn{3}{|c|}{ BAC's } & \multirow{2}{*}{$\begin{array}{c}\text { Sample } \\
\text { Size } \\
\end{array}$} \\
\hline 0.00 & $0.01-0.09$ & $0.10+$ & \\
\hline $81.7 \%$ & $11.7 \%$ & $6.6 \%$ & 745 \\
\hline $81.9 \%$ & $.11 .4 \%$ & $6.7 \%$ & 686 \\
\hline $90.0 \%$ & $10.0 \%$ & $0.0 \%$ & 20 \\
\hline $66.7 \%$ & $33.3 \%$ & $0.0 \%$ & 3 \\
\hline $25.0 \%$ & $25.0 \%$ & $50.0 \%$ & 4 \\
\hline $87.1 \%$ & $9.7 \%$ & $3.2 \%$ & 31 \\
\hline $100.0 \%$ & $0.0 \%$ & $0.0 \%$ & 1 \\
\hline$\frac{a /}{33} .3 \%$ & $\frac{a}{66} / .7 \%$ & $\frac{a /}{0.0 \%}$ & $\begin{array}{l}0 \\
3\end{array}$ \\
\hline $79.7 \%$ & $15.2 \%$ & $5.1 \%$ & 59 \\
\hline
\end{tabular}

a/ Indeterminable from the data collected. 
accident type, vehicle type, number of people in vehicle, season of the year, sex, age and culpability of the driver. The results of the fatally injured driver comparisons are given in Table 44. Living driver factors examined were vehicle age and condition, income, marital status, sex, race, and season of the year. The results of the living driver comparisons are given in Table 45. The use of antihistamines and decongestants was significantly related to season among fatally infured drivers but not among living drivers. Fatally injured drivers had used these drugs relatively more frequently in the fall and less in the summer. For living drivers, however, season of the year was significantly related to the use of salicylates and the category "one or more drugs." Salicylates were overinvolved in the summer and fall and under-involved in the other seasons. The use of one or more drugs was over-represented in the fall and winter and under-represented in the spring and summer.

The age of the fatally injured drivers were significantly related to usage of one or more drugs. 01der drivers (50 years and older) were more 1ikely to have been using one or more drugs while very young (19 years or less) and middle aged drivers ( 30 through 49 ) were less likely to have been using one or more drugs.

Culpability of the fatally injured drivers was not found to be related to drug usage.

Fatally injured female drivers were over-involved in usage of one or more drugs. A total of $23.1 \%$ of the fatally injured female drivers were using one or more drugs, compared to only $13.0 \%$ of the fatally infured male drivers. The $14.3 \%$ incidence of one or more drugs found for all fatally injured drivers is distorted by only $1.3 \%$ by the inclusion of fatally injured females, because they constituted only a small portion of the sample (13.3\%).

The high incidence of drug usage among female fatalities prompted a reexamination of the relative risks by including 'only males in the calculations. The relative risks of a fatal accident, considering males only, are given in Table 46. The risks are lower for each drug group (except for narcotic analgesics and miscellaneous) than the risks determined from a combination of male and female fatally injured drivers. The greatest changes in risk were for sedatives and hypnotics, which decreased from 1.90 for all drivers to 1.61 for males only (in addition the lower confidence limit went below unity); the risk for tranquilizers decreased from 
CORRELATES TO DRUG USAGE AND DRIVING AMONG FATALLY INJURED DRIVERS

\section{Comparisona/}

\section{Area Type}

Number Vehicles Involved

Accident Type

Vehicle Type of Driver

Number People in Vehicle

Season of Year

Season of Year with Use of Antihistamines/Decongestants

Season of Year with Use of Salicylates

Time of Day of Crash

Time of Day of Crash with Use of Sedatives/Hypnotics

Time of Day of Crash with Use of Antihistamines/ Decongestants

Sex of Driver

Age of Driver

Culpability of Driver

Culpability of Driver with Use of Sedatives/Hypnotics

Culpability of Driver with Use of Antihistamines/ Decongestants

Culpability of Driver with Use of Analgesics/Narcotics
Confidence Level of Relationship

Not significant

Not significant.

Not significant

Not significant

Not significant

Not significant

$p<0.025$

Not significant

Not significant

Not significant

Not significant

$$
\begin{aligned}
& \mathrm{P}<0.05 \\
& \mathrm{P}<0.10
\end{aligned}
$$

Not significant

Not significant

Not igificant

Not significant

a/ The comparisons listed are with the use of one or more drugs unless otherwise noted. 
CORRELATES TO DRUG USAGE AND DRIVING AMONG LIVING DRIVERS
Confidence Leve 1 of Relationship

Vehicle Age

Vehicle Condition

Driver Age

Driver Income

Driver Marital Status

Season of Year

Season of Year with Use of Sedatives/Hypnotics

Season of Year with Use of Salicylates

Season of Year with Use of Antihistamines/Decongestants

Time of Day

Time of Day with Use of Sedatives/Hypnotics

Time of Day with Use of Antihistamines/Decongestants

Race of Driver
Not significant

Not significant

Not significant

Not significant

Not significant

$\mathrm{p}<0.10$

Not significant

$\mathrm{p}<0.01$

Not significant

Not significant

Not significant

$\mathrm{p}<0.025$

Not significant

a/ The comparisons listed are with the use of one or more drugs unless otherwise noted. 
COMPARATIVE DATA FOR MALE ONLY DRIVERS EVIDENCING DRUGS AND FOR WHOM BOTH BLOOD AND URINE SAMPLES WERE AVAILABLE

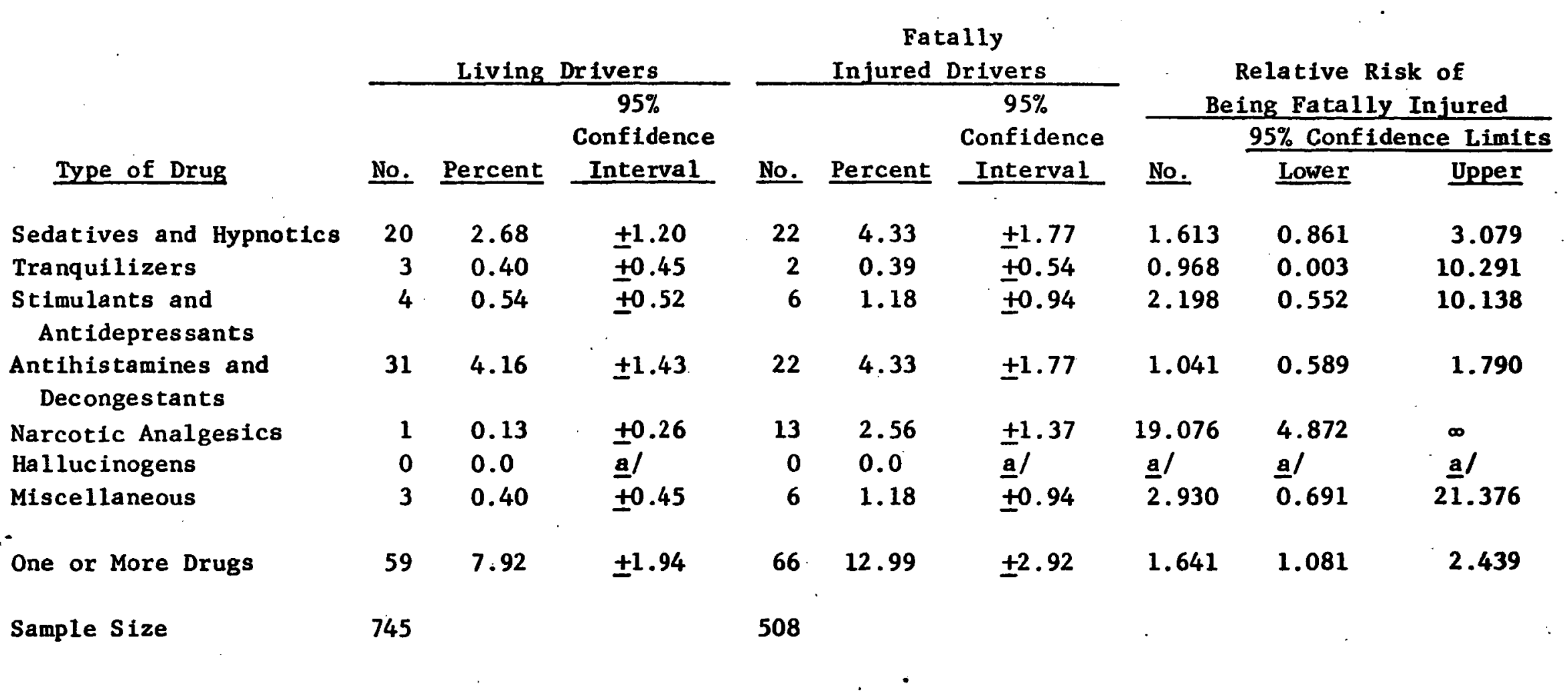

a/ Indeterminable from the data collected. 
1.69 to 0.97 ; the risks for antihistamines and decongestants decreased from 1.27 to 1.04 ; the risks for miscellaneous drugs increased from 2.54 to 2.93 ; and the risk for one or more drugs decreased from 1.81 to 1.64 .

\section{H. Other Findings}

There is, in general, no site effect on drug incidences among drivers, as indicated by the insignificant $(\approx 0)$ value of the intracluster correlation coefficient. Nevertheless, an analysis was conducted to compare the drug incidences of living drivers at drug-involved fatal crash sites with those at nondrug-involved fatal crash sites. Such comparisons were made within Memphis alone, Dallas alone, and the sum of both cities. These comparisons resulted in no statistically significant difference in living driver drug incidence according to whether or not the survey site corresponded to a drug-invovled fatal crash site. The chi-square test results are given in Table 47 for three drug groups and the three sets of drivers. Statistically significant conclusions could not be made for the other drug groups because of insufficient sample sizes.

From the above results it can be said that the drug incidences among living drivers are not over-represented at drug-involved fatal crash sites. It should be remembered, however, that the very small sample sizes involved do not allow powerful distinctions of this type to be made.

The small samples involved in determining the incidence of individual drug groups among living drivers at drug-involved fatal crash sites can be seen from Figure 3. The information displayed in this figure shows the progression of the sample size screening effects for both the fatally injured and living driver data to arrive at a final "match" of the two sets of data. Considering the blood plus urine drug findings, it is seen that only two living drivers were found to have any drug in their system at the drug-involved fatal crash sites. The drugs detected in these two living drivers did not match the drugs found in the fatally injured drivers. This shows the extremely low probability (zero in this study) of finding a given drug among living drivers at a fatal crash site where the same drug was found in the fatally injured driver. 
TABLE 47

\section{CHI-SQUARE TEST RESULTS FOR THREE DRUG GROUPS}

\begin{tabular}{lccc} 
& \multicolumn{2}{c}{ Drug Groups } & \\
Drivers & $\begin{array}{l}\text { Sedatives/ } \\
\text { Hypnotics }\end{array}$ & $\begin{array}{c}\text { Antinistamines } \\
\text { Decongestants }\end{array}$ & $\begin{array}{c}\text { One or } \\
\text { More Drugs }\end{array}$ \\
Memphis & 0.20 & 1.73 & 0.64 \\
Dallas & 1.10 & 1.20 & 1.77 \\
Memphis and Dallas & 0.31 & 1.03 & 1.72
\end{tabular}


FATALLY INJURED DRIVER LIVING (CONTROL) DRIVER

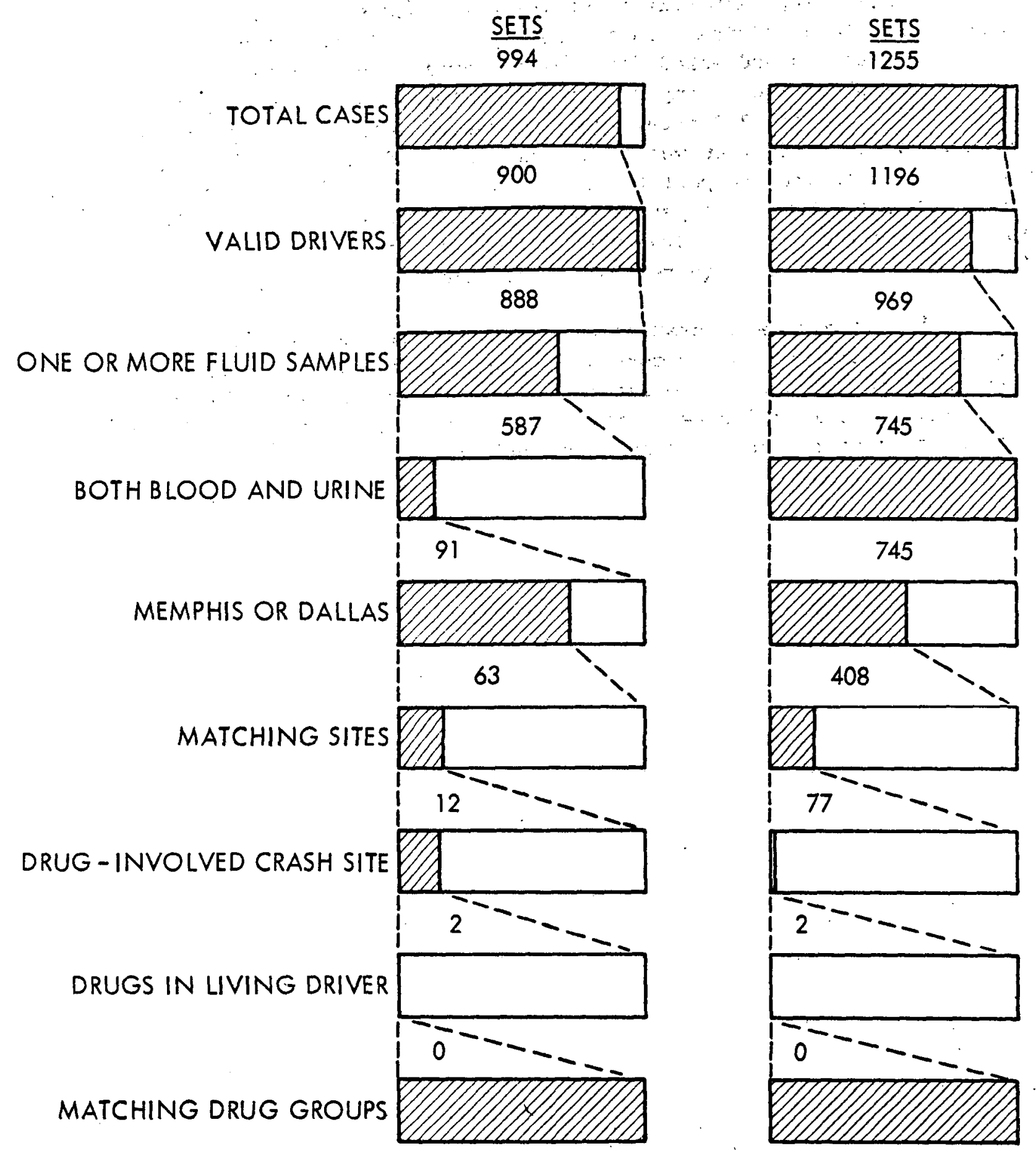

SAMPLE SIZE SCREENING EFFECTS

Figure 3 - Sample Size Screening Effects 
Finally, approximately $8 \%$ of the motorists stopped at random would not agree to participate in the survey. In addition, abut $24 \%$ of the motorists stopped and asked for a blood sample would not agree to provide the sample. The living drivers who refused to provide a blood sample (and a resultant BAC determination) were compared to cooperators for whom a BAC determination was made from the blood sample. The comparisons were made with respect to time of day $\left(x^{2}(5)=7.33\right)$, location Dallas separately, Memphis separately, and Dallas plus Memphis $\left(x^{2}(3)=\right.$ $2.89)$ and where known, other drug usage - one or more drugs $\left(\chi^{2}(1)=\right.$ 0.28 ). None of these chi-square tests were significant.

Thus, there is no statistical evidence that refuses differ from cooperators in terms of one or more drug usage, location, or temporal patterns. Although no direct evidence, by definition, is available for ascertaining refusal influence on the study, indirectly, the refusals do not appear to distort the research findings. 


\section{CONCLUSIONS AND RECOMMENDATIONS}

Several conclusions can be drawn from the results reported upon herein. First of all, it is possible to obtain cooperation from medical examiners to provide fluid specimens from fatally injured drivers for analysis of drugs. This cooperation is enhanced by paying the medical examiners for their service. Secondly, legal and political concerns make it difficult to select communities for living driver surveys. One cannot go to a given community and start to conduct roadside surveys without the consent and assistance of community officials. Many times the decision of a community not to cooperate in a survey is based upon political pressure.

Thirdly, once community approval for the survey is obtained, it is possible to stop motorists randomly and secure the voluntary cooperation of most of them in providing fluid samples for drug analysis The motorists' cooperation is also enhanced by paying them for their blood (and urine) samples. In general, the procedures developed for collecting the fluid samples from both fatally injured and living drivers proved to be very satisfactory. An exception to this is the marijuana sampling procedure which employed the use of swabs. This technique is not yet efficient enough to use for reliable results.

The incidence of drug usage among fatally injured drivers is not geographically dependent. of all the fatally injured drivers examined, $14.3 \%$ were found to have used one or more drugs before the crash. The most frequently detected drugs among the fatally injured drivers are antihistamines/decongestants, narcotics, and stimulants.

The incidence of drug usage among living drivers is not significantly variable from site-to-site and from city-to-city. of the living drivers examined, $7.9 \%$ were found to be using one or more drugs prior to the interview. The most frequently detected drugs among the living drivers are antihistamines/decongestants and sedatives.

The results of the drug analysis indicate that fatally injured drivers are significantly more likely to use drugs than similarly exposed (living) drivers. The relative risk of being involved in a fatal crash is the greatest for drivers using narcotic analgesics, sedatives/hypnotics, one or more drugs, and nicotine, respectively. The relative risk is about 1.8 for the group of 43 drugs tested as a whole. The change of being involved in a fatal crash for drivers who smoke is about 1.2 times as great as for the drivers who do not smoke. 
The age and sex of the fatally infured drivers are significantly related to the usage of one or more drugs. Older drivers ( 50 years and older) are more likely to use one or more drugs while the very young ( 19 years or less) and middle aged drivers ( 30 through 49) are less likely to use one or more drugs. Fatally injured female drivers are more likely to have been using one or more drugs than male drivers.

No positive relationship was found between alcohol and drug usage. And, finally, the results reconfirmed that alcohol is by far the most abused drug.

The conclusions drawn from this study contain the basis for a primary recommendation: NHTSA must determine the extent to which they wish to pursue the problem of drug use among drivers. The problem is definitely not as significant as that of alcohol. Only $14.3 \%$ of the fatally injured drivers were found to have used one or more drugs, compared to $65.7 \%$ that had a positive BAC or $53.6 \%$ that had a BAC of $0.10 \%$ or more. Although it is true that fatally injured drivers are significantly more likely to have been using drugs than similarly exposed (living) drivers, the relative risk of 1.8 for the group of 43 drugs tested as a whole certainly does not compare with the relative risk of 10.4 or greater for drivers with BACs of $0.10 \%$ or more.

The benefits to be received, in terms of lives saved, pursuing the drug/driver problem must be realistically assessed. They must be balanced not only against the costs of research yet to be performed, but the cost and effectiveness of countermeasures against the problem. Then, these benefits and costs must be weighed against those of altemate traffic safety problems, such as drinking and driving.

If a decision is made to continue to investigate drug use among drivers, certain further secondary recommendations are warranted. First, the results obtained in this study need to be verified by collecting additional living and fatally injured driver data. However, more sensitive chemical analysis procedures need to be used for the drug detections. For example, some of the tranquilizers investigated are suspected to be frequently used, but the sensitivity level of the chemical analysis procedures employed precludes detections of most of these except at mid-to-high therapeutic levels and above. The same is true for many of the drugs in the other drug graps investigated.

Secondly, although the techniques for some other drugs were sufficiently sensitive, the drugs were not detected. Such drugs should 
be omitted from drug screens in future studies. The funds that would otherwise be spent in screening for unused drugs could be more effectively spent in the detection of more prevalently used (or suspected to be used) drugs.

It is not advisable in future drug use studies to collect blood samples from the motorists if the same chemical analyses procedures, as were used herein, are us ed for drug detection. Very little information about drug incidence in both living and fatally injured drivers was learned from the blood samples collected. However, if more sensitive chemical analyses techniques were used for drug detection, the blood sample would be the recommended fluid sample collected from drivers for two reasons. First, the blood sample is no more difficult to obtain from drivers, especially living drivers, than the urine sample. Secondly, the blood findings can be logically divided into levels of concentration (trace, therapeutic, toxic, and lethal) for a determination of the condition "under the influence" once that category is defined.

In addition, it is recommended that females be included in future living driver sample population. Since fatally injured female drivers were far more likely to have been using one or more drugs than male drivers, it is important to determine if the associated risks of a fatal crash are greater for female than male drivers.

It is further recommended that future drug use studies not be overly concerned with obtaining a perfect match between the fatally injured and living driver samples. It is unduly costly and unnecessary to use only those living driver samples collected at fatal crash sites for which fluid specimens were obtained from the fatally injured driver and analyzed for drugs. This study showed that drug usage among fatally injured drivers is not geographically dependent and that drug usage among living drivers is not significantly variable from site-to-site or from city-to-city. Therefore, a more simplistic and economical matching criteria can be used to compare drug usage between fatally injured and living drivers.

Finally, the procedures for marijuana sampling and chemical analysis of this drug should be improved. One milliliter plasma spec1mens were extracted from the blood samples collected and shipped to White Memorial Medical Center in Los Angeles, California, for marijuana analysis. When these results become available they should be incorporated with the data presented herein. 
APPENDIX A

ACQUISITION OF DRIVER SPECIMENS AND DATA

$$
A-1
$$


MEDICAL EXAMINES COOPERATING IN PROGRAM

Dr. Werner U. Spitz

Office of Chief Medical Examiner, Wayne County

400 East Lafayette

Detroit, Michigan 48226

Dr. Robert R. Stivers

Chief Medical Examiner

62 Butler Street, S.E.

Atlanta, Georgia 30303

Dr. Charles S. Petty

Dallas County Medical Examiner

P.0. Box 35728

Dallas, Texas 75235

Mr. R. W. Prah1, Chief Investigator

Coroner's office

480 Fourth Street

Oakland, California 94607

Ferrin B. Moreland, Ph.D.

Chief Toxicologist

Office of the Medical Examiner

of Harris County

1502 Taub Loop

Houston, Texas 77025

Dr. John Coe

Medical Examiner

Hennepin County Medical Examiner's

office

510 Park Avenue

Minneapolis, Minnesota 55415

Peter Lipkovic, M.D.

Duval County Coroner

2100 Jefferson Street

Jacksonville, Florida 32206

Richard Mayne, Chief Deputy Coroner

District Health office

625 Shadow Lane, Box 4426

Las Vegas, Nevada 89106
Dr. T. F. Hegert

Medical Examiner, District 9,

1416 South Orange Aveune

Orlando, Florida 32800

Dr. Bonita J. Peterson

Jackson County Medical Examiner

General Hospital, Room 13H

24 th and Cherry

Kansas City, Missouri 64108

Robert K. Matthews

Coroner of DuPage County

421 North County Farm Road

Wheaton, Illinois 60187

Dr. Arthur Schwartz, District Medical

Examiner

Room 303

Volusia County Courthouse Annex

Daytona Beach, Florida 32015

Dr. James $T$. Weston

Chief State Medical Investigator

Basic Sciences Building

University of New Mexico

915 Stanford Drive, N.E.

Albuquerque, New Mexico 87131

Dr. Larry V. Lewman

301 N.E. Knott

Portland, Oregon 97212

Robert H. Phillips

Snohomish County Coroner

Room B 20

Court House

Everett, Washington 98201

Bernard Kemps, Coroner

Outagamie County

1412 West Franklin Street

Appleton, Wisconsin 54911 
William F. Young, Jr. County Coroner 137 West Jefferson Street Butler, Pennsylvania 16001

Gary L. McClure

Randolph County Coroner

1019 State Street

Chester, Illinois 62233

Dr. James $K$. Martin

206 Fifth Avenue

Eau Claire, Wisconsin 54701

Dr. Stafford

Toxicology Laboratory

University of Tennessee

3 North Dunlap

Memphis, Tennessee 38163

Dr. Ronald $\mathrm{K}$. Wright

Assistant Medical Examiner

1700 N.W. 10th Avenue

Miami, Florida 33136

Dr. John R. Feegel

Chief Medical Examiner, District 13 3407 Bay to Bay B1vd.

Tampa, Florida 33609 


\section{GRATH DATA INFORMTIOS PORY}

Mursa Contract No, DOT-HS $-4-00941$

All information on this form is tor research purposes only and is sertetly confidential. Please complete efther pert $A$ and Part $B$ or Pars $A$ only and enclose a copy of the pollce aceldent report. This rapare is to be fllled out for ench tecally injured driver wehin your jurtsdiction. (This includes those for whoe no phyelological samples are provided.)

\section{PARTA}

Coroner or Medical Examiner

NAYE:

TITL:

ADDRESS:

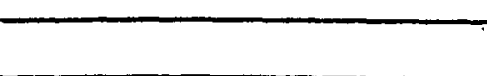

Coroner or Medical Examfnar Case No.:

Date of Crash:

Tim of Crash

Day of weak of Crash:

Date of Desth.

TIm of Deceh:

Dace Sanple Taken:

T1me Sample Taken:

Sample(s) Provided:

Bl ood B11.

urine

Swabs

Reason Any of Above Samples Noc Provided:

(Blood)

(8110)

(Urine)

(Swabe)

List of Druge and dmounce idminlatered Becween Itwe of Accident and Deach

1.

2.

3.

\section{I0 Be Eilled out by art}

TRI coda $\frac{1}{112}$ $\frac{1}{12355}$

4102 code $\frac{}{67}$

Crash Dace S9110 11112 13

Gasan than 14 15:16-17

Crash Day $\frac{}{\text { Id }}$ Deach Dece $\overline{1920121 \quad 2212324}$ Jackn TIme $\frac{}{2526: 2728}$

Sample Dace 29301313213336

Sample iime $\frac{}{3526: 3718}$

Stepien $\frac{}{39+04642}$

Reecente

(B1000)

$81000) \longdiv { 4 3 4 4 }$

(a114) is 46

(Urine) $\frac{}{4748}$

(Swabs) $\frac{}{6950}$

Oruys and nenouncs

$3 1 9 2 \longdiv { 3 3 5 4 }$

353615758

596016162

(OVER)

Figure A-1 - Crash Data Form for Fatally Injured Drivers 


\section{PART B}

Location of Crash:

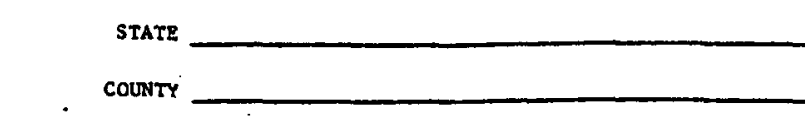

STREET ADDRESS

Area Type: 1. Rural

2, Suburban

3. Urban

Number Vehlcles involvad:

Type of Accident (check one applitcable):

1. Head-On

2. Rear-End

3. Angle

4. Fixed object

5. Run Off Road

6. Overturn

7. Other (spectify)

Type Vehicles Involved (paseanger car, truck, motorcycles, train, ete.)

Vehicle (1)

$:$

vehicle

(2)

Vehiele (3)

ocher vehicles

Which Vehicle ( $1,2,3$, etc., above) was ortven by the Facally Injured Driver:

Nehicle (1)
venicle (2)
vehicle (3)
Vehicle (All others)

Check Condtiton(e) That Moec Likely Concribueed to the Crash

1. Viceis's Condicton ox Behavior:

2. Other Drtver's Condltion or Behavior:

3. Othar (Speeify):

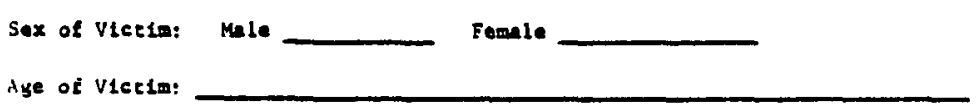

Te be chiled our by ans

sar code 4

(kay punch

ciey

seate

Couney $\frac{}{10}$

Ares typo $\frac{}{11}$

No. venicle $\frac{}{12}$

Type Aeczdent $\frac{}{03: 4}$

Type vehscte (1)

$$
\text { (2) } \frac{\overline{15}}{16}
$$

Facal vinicle 24

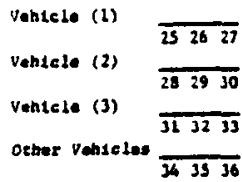

Condition $\overline{3738}$

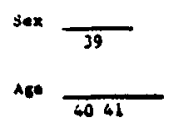

Please describe any further Informetion available concerning this crash and the victis. 
DOT Contract No. DOT-HS $-4-00941$

SPECIMEN COLLECTION FROM

FATALLY INJURED DRIVERS

\section{Requirements}

The following specimens, if possible, from fatally injured drivers who are dead within four hours of the crash: (1)blood; (2) urine; (3) bile; and (4) alcohol washings of the fingers and face. Please fill out the enclosed ID cards in duplicate. Return one to MRI with the specimens, the other should be kept in your files. Please complete the Crash Data Forms as soon as possible. Also please provide, on the Crash Data Forms, a written explanation if all specimens cannot be provided.

\section{Instructions}

1. Blood collection: The kit contains two foam cartons, each containing five red-top vacutainers, and one foam carton containing one graytop vacutainer. Also included in the kit is a "Monoject" double needle in a pink plastic case, a plastic vacutainer tube-and-needle-holder and plastic bottle marked "Blood" on a red label.

Blood samples should be obtained from the femoral artery if possible. If this is not possible, please state source of blood on the ID card. Disinfect the area with an aqueous disinfectant before taking the blood sample.

To collect blood, screw needle into end of tube-and-needle-holder and remove plastic sheath to expose needle. Place a vacutainer tube (rubber end first) into the tube holder and contact the rubber with the end of the inner needle. Do not puncture the seal at this point. Holding the tubeand-needle-holder with tube inserted, insert the outer needle into blood vessel--be careful not to push on the tube or else the seal will be broken prematurely. When blood vessel is punctured, slowly push the tube over the inner needle and puncture the seal. The vacuum in the tube will draw in the blood. Remove the tube of blood and, keeping the needle in the blood vessel, push another empty tube over the Inner needle. Repeat this to produce 11 vacutainer tubes of blood (10 red-top tubes of blood and one gray-top tube of blood). Please fill the gray-top tube last. Discard the needle and holder. Place the gray-top vacutainer of blood back into its foam carton and card sheath. Place the contents of the 10 red-top vacutainers into the plastic screw-top bottle marked "Blood", and tighten firmly. Discard the empty vacutainers and their two foam containers.

Figure A-2 - Specimen Collection Kit Instruction Sheet 
2. Urine collection: The kit contains a plastic screw cap bottle with yellow label, "urine." Place as much urine in the bottle as possible (50 ml), screw the cap back on firmly. No preservative is necessary.

3. Bile collection: The kit contains a plastic screw cap bottle with a green label "bile." Place as much bile as possible in the bottle $(30 \mathrm{ml})$, and screw the cap back on firmly. No preservative is necessary.

4. Alcohol washings of the fingers and face: The kit contains a foam carton containing four glass tubes with swabs and one glass tube with $70 \%$ alcohol solution. The swab tubes are marked "left hand," "right hand," "lips" and "palate." Remove the appropriate swab from the swab tube, dip in the alcohol and swab the appropriate area. For the two hands, swab the thumb and tips of the fingers. For the palate, swab the roof of the mouth behind the front teeth. For the lips, swab the fleshy part of the lips, where a clgarette would normally contact the lips. Place the moist swabs back in their respective tubes, screw the caps on firmly and replace in the foam container and card sheath. Discard the alcohol bottle.

PLEASE PLACE ALL THE SPECIMENS IN A REFRIGERATOR UNTIL READY TO MAIL. (DO NOT FREEZE). Place two "blue ice" bags in the freezer to cool for shipment. These bags must be frozen before shipment.

5. Complete the Identification Card in duplicate. Place one copy in the plastic bag provided and place in the kit box. Retain the other copy for your files.

6. Place all the refrigerated specimens (and the ID card) in the foam kit box with the alcohol swab kit uppermost. Place the two frozen "blue ice" bags on the top of the specimens. Place the foam box in the cardboard box, seal the box with tape and mail back to Midwest Research Institute by Air Mail Special Delivery, C.O.D.--do not pay for the postage--MRI will assume all postage fees at the destination in Kansas City. Please mail out the specimens on Mondays and Tuesdays only; this will ensure that we will receive the specimens without a weekend delay.

7. Please complete the Crash Data Forms as soon as possible. Always complete Part A; complete Part B if police accident report is not available. File one copy safely and mail the other copy to MRI, along with the police accident report, if available, in the envelope provided.

Thank you

Please feel free to call us at (816) 561-0202, Ext. 242 if you have any questions 
NHTSA Contract NO. DOT-HS-4-00941, MRI Project iHo. 3963-E(2)

ACCIDENT IDENTIFICATION CARD - FATALLY IHJURED DRIVER

MRI Code

Nane of Driver Coroner's Case No.

Location of Crash: State County

Address (Crash)

Date of Crash Time of Crash

Time of Death Time of Sample

Name of Coroner

Site of Blood Sample: Femoral artery

other (detail)

Known drugs administered between time of accident and death:

Drug Amount

Drug Amount

Figure A-3 - Specimen Collection Kit ID Card 
APPENDIX B

STUDY SURVEILIANCE BY THE MRI HUMAN SUBJECTS COMMITTEE

$B-1$ 
MUDEST RESEARCH INSTITUTE

Hunan Subjeces Counleree

\section{Survelllance Porm}

During the three month, partod from ro

I certsfy that:

A.
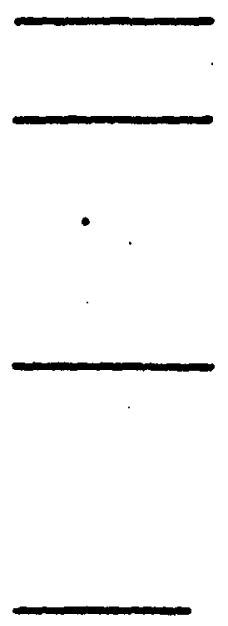

B.

c.

D.

E.

PROSECT NUMBER
1. I did no research involving humans.

2. I did research Involving human volunteers, and the plan has been approved by the Human subjects Comittee and no change has been made in experimental procedure or in the method of obtaining patient consent.

3. I have made changes in the experimental procedure and/or in the method of obtaining consent, and these changes have received the approval of the Huan SubJects Comonitiee.

4. I plan to make changes in the experimental procedure and/or in the wethod of obtaining consent, and the Human Subjects Combltee has been notifled of these. changes.

For all research involving humans, I have oblained * olgned statement of consent from every subject.

I did observational research only. (The manipulation of an independent variable was not involved.)

I did research involving human material, and this has been approved by the Hums Subjects Comnittee.

I did research involving confidential information from human subjects, and this has been approved by the Human Subjects Coumittee.

THIS COMPLETED FOPA SHALI BE RETURNED TO THE CHAIRMAN OF THE MONITORING SUBCOAGTTEE WITHIN ONE WIER OR TLE COAPLETION OF EACH QUARTER OF THE WORK ON THE CONTRACT OR GRANT. 
1. Excerpts from the Minutes of the Human Subjects Comnittee Meeting, May 21, 1975.

MRI Proposal E-2136, "A Comparison of Drug Use in Driver Fatalities and Similarly Exposed Drivers," submitted by Mr. Blackburn, co-principal investigator. Dr. Glauz was also present to answer questions. Mr. Blackburn explained that the program will involve roadside surveys and the collection of breath, urine, blood, and lip-swab samples. A local police officer, registered nurse, or medical technician and others will assist the MRI team at the site. Only male subjects will be accepted, and they will be rewarded by a small monetary fee after they have voluntarily consented to participate. Consent will be gained informally after the MRI team member has explained the survey and the subject has read a letter written by the town's mayor endorsing the survey. Typescripts of the project explanation and the request for a blood sample were presented to the committee. Anonimity of the data will be preserved by not identifying the subjects. Blood samples will not be taken from minors, and care will be taken to determine that subjects giving blood have gained majority under local law. A potential risk to the subjects, other than the taking of their blood, includes the possibility of arrest, should the driver be found to be under the influence of alcohol or drugs. Such drivers will not be identified and the field supervisor will determine if aid is required in getting the person home. The police officer will be committed not to file charges against these individuals. The project team has adopted procedural steps to minimize the risk of making the survey in a traffic situation.

It was determined that the potential benefits from identifying significant factors contributing to highway deaths outweigh risks to the subjects, and that these risks have been minimized by the principal investigators. Mr. Dinwiddie moved that the proposal be approved. Dr. Castles seconded the motion, which was passed unanimously by those present and voting (Dr. Castles, Mr. Coburn, Mr. Dinwiddie Dr. House, Dr. McKeel, and Mr. Breed). Dr. House accepted the appointment of chairman of the monitoring subcomittee. He will advise the chairman of his choice of subcomittee members. 
2. Excerpts from the Minutes of the Human Subjects Comittee Meeting, August 25, 1975.

MRI Project 3963-E, "A Comparison of Drug Use in Driver Fatalities and Similarly Exposed Drivers." The subcomittee report was submitted for information only. There were no comments.

3. Excerpts from the Minutes. of the Human Subjects Committee Meeting, February 18, 1977.

MRI Project 3963-E, "A Comparison of Drug Use in Driver Fatalities and Similarly Exposed Drivers." Dr. House presented the final subcomittee review of the program, which involved 1,218 living subjects and 942 fatally injured subjects. There were no infections incurred in taking blood samples, no instances of subjects fainting, no problems in subjects volunteering their names, or other emergent problems. Mrs. Park moved that the report be approved. Dr. Graham seconded and the motion passed unanimously with Mr. Breed, Dr. Castles, Dr. Graham, Dr. House, Mrs. Park and Mr. Thronberry present and voting. 
APPENDIX C

LETTERS OF INTRODUCTION GIVEN TO THE MOTORISTS REQUESTING THEIR VOLUNTARY COOPERATION IN THE SURVEY

3

C-1 


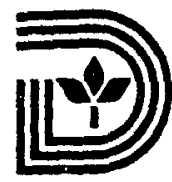

CITY OF DALLAS

Dear Motorist:

You have been selected to participate in a Highway Safety Roadside Drug Usage Survey -- a study necessary for the benefit of the public at large to determine the incidence of drugs in a sample of the Dallas, Texas, driving population.

This survey is a crucial part of a highway safety research program and is being conducted by a research team from the Midwest Research Institute of Kansas City, Missouri. The funds were provided by the U. S. Department of Transportation.

This survey has the full support of City officials.

We are inviting you to assist Dallas and the National Highway Traffic Safety Administration in this study. Answers to any questions asked you and any fluid samples collected will be confidential. No identifying information such as name, address or drivers license number will be associated with the data collected. Under no circumstances will any information given to the survey staff be used against you or anyone else.

You are being offered this unique opportunity to participate in a meaningful program on traffic safety. However, you are under no obligation to do so. The information you give is a matter of your own conscience and free decision.

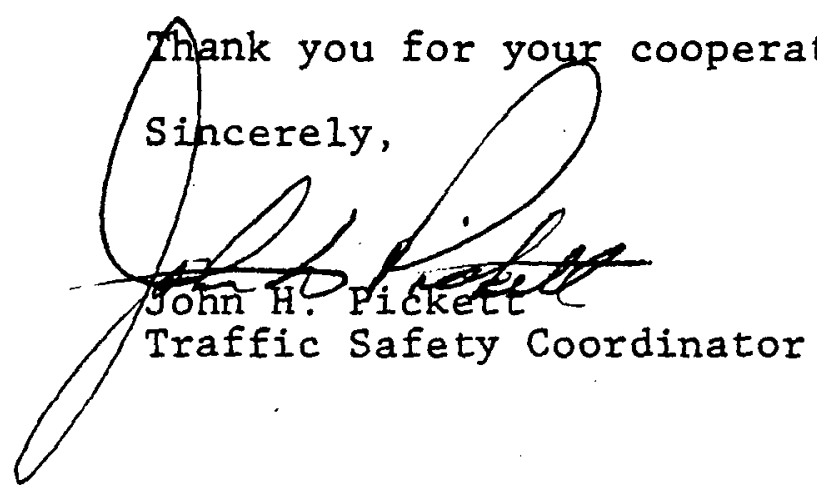




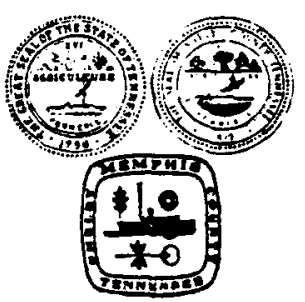

\section{MEMPHIS \& SHELBY COUNTY TRAFFIC SAFETY COORDINATING COMMITTEE SHELBY COUNTY COURT HOUSE 140 ADAMS ROOM 304 TELEPHONE $328-3068$ MEMPHIS. TENMESSET 38103}

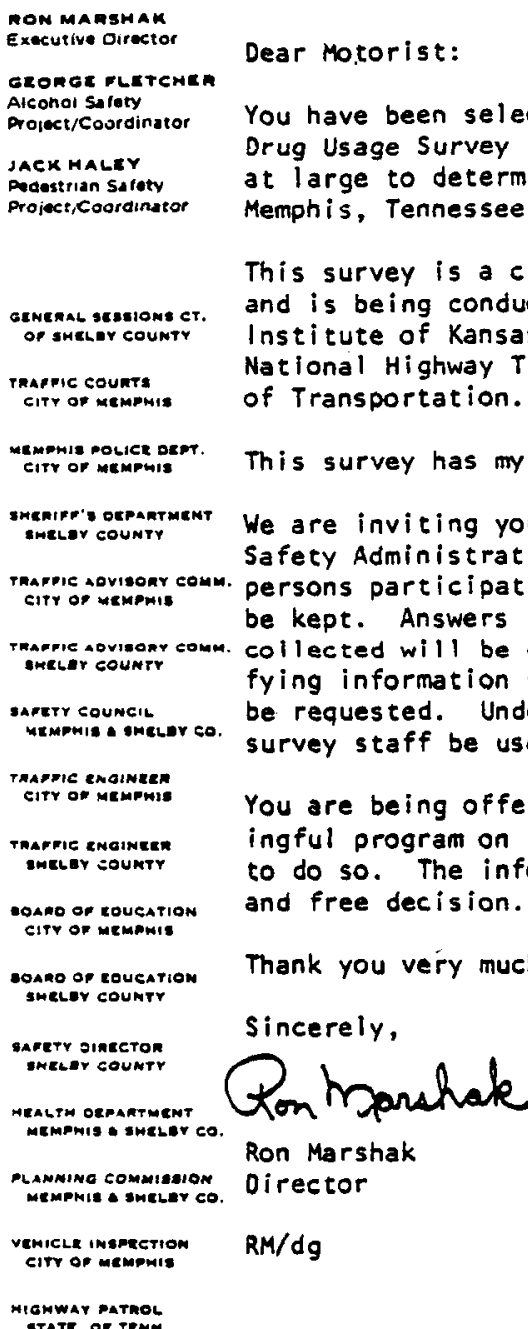
GEMENAL SKBEHONE CY
OP SHELEY COUNTY

TRAenic COURT: TRANIC COURTE
CITY OO MEMPMis of Transportation.

MEMPHIS POLICR DEMT

SHERIFT'S DEPARTMENT aneler countr

marple aovisome comm.

Thaerie aovinaner comon.

aneler countr

saretr council

MEMPMIS amelor co.

TMAstie enginzen

TMARIE ENGINETER

conio or goucation and free decision.

city or meng

sonao op eoucatiom

sheley countr

sincerely,

SARETY OIAECTOR

eneley countr

MEALTH DRAARTMENT

Tanding comingos

DANNING COMMIESION

VEMICLR IMARECTION

Ron Marshak

Oirector

$R M / d g$

higmwar mathol

This survey is a crucial part of a traffic safety research program and is being conducted by a research team from Midwest Research Institute of Kansas City, Missouri. The funds were provided by the National Highway Traffic Safety Administration of the U. S. Department

This survey has my full support as well as that of other city officials.

We are inviting you to assist Memphis and the National Highway Traffic Safety Administration in this study. No record of the identity of persons participating in or refusing to participate in the survey shall be kept. Answers to any questions asked you and any fiuid samples collected will be confidential and completely anonymous since no identifying information such as name, address, or drivers license number will be requested. Under no circumstances will any information given to the survey staff be used against you or anyone else.

You are being offered this unique opportunity to participate in a meaningful program on traffic safety. However, you are under no obligation to do so. The information you give is a matter of your own consciance

Thank you very much for your cooperation in this survey. 
APPENDIX D

SURVEY INSTRUMENT, SURVEY SITE IDENTIFIER SHEET, AND OCCUPATION CHECK LIST 
1. Sample Number $\frac{1}{1} \frac{}{2} \frac{}{3} \frac{}{4} \frac{}{5}$ (Columon"2" 1s Community Number)

2. Sampling Period $\frac{}{6}$

3. Location Number $\frac{}{7} \frac{}{8}$

Duplicate Items 9 through 15 from . Identifier Sheet.
16. Day of Week (on which survey begas)

$$
\begin{aligned}
& \text { 1() Monday } \\
& 2(\text { ) Tuesday } \\
& 3(\text { ) Wednesday } \\
& 4(\text { ) Thursday } \\
& 5(\text { ) Eriday } \\
& 6(\text { ) Saturday } \\
& 7 \text { () Sunday }
\end{aligned}
$$

17. Date

$$
\begin{gathered}
\overline{17} \overline{18} \overline{19} \overline{20} \overline{21} \overline{22} \\
\text { day month year }
\end{gathered}
$$

23. Interview

$$
\begin{aligned}
& 1(\text { ) Accepted, w1lling } \\
& 2(\text { ) Accepted, unwlling } \\
& 3(\text { ) Refused, excuse or polite } \\
& 4(\text { ) Refused, belligerent }
\end{aligned}
$$

$\begin{aligned} & \text { 24. Time Intervilew Began } \\ & \text { (24-hour clock) }\end{aligned} \frac{}{25}: \frac{}{26} \frac{}{27}$ (Code midnight as 00:00)

28. Estimate of Impairment

$1($ ) None

2( ) A litele

3 ( ) A lot

4( ) Don't know

If impaired, why

29. Race

1( ) White

2() Black

$3($ ) Latio

4() Oriental

5( ) American Indian

6( ) Other (specify)

30. Number of people in car
31. Car Model

1 ( ) Family car (sedan, station wagon, etc.)

2( ) Sporty and high performance (hot rods, sport cars)

3( ) Car-P1ckup (E1 Camino, Ranchero)

4 () Compacts (PInto, Maverick, etc.)

$5($ ) Forelgn Compacts (VW, Renault, etc.)

6() Minibus

7 () Truck Pickup

8( ) Motorcycle

9( ) Other

32. Vehicle Age and Condition

$1($ ) 0.3 - Excellent

2( ) - Fair

$3($ ) - Poor

4 ( ) 4-9 - Bxcellent

$5($ ) - Fair

6( ) - Poor

7 ( ) $\geq 10$ - Excellent

8()$\quad-$ Fair

$9($ ) - Poor

Supervisor

Nurse

Recorder 
33. What c1ty or town do you live in, and what county?

1( ) Dallas, Texas

2( ) Memphis, Tennessee

3( ) Third Comminity

4() Surrounding towns in county

5( ) Other rural areas in the county

6( ) Ad jacent counties

7 ( ) Outstate

8 ( ) Other state

9 ( ) Part time resident of survey community

34. What is your martital status?

1( ) Married

2( ) Married with children

$3($ ) Divorced

$4($ ) Separzied

$5($ ) Widowed

6( ) Single (never married)

35. (If not married) With whom do you live?

i( ) Alone

2( ) Parent

3 ( ) Other relative

4() A friend

5( ) A group (Halfway House, Salvation Army, commune, etc.) $>4$ people

$6($ ) Military

7 ( ) Other (specify)

36. In what age group do you fall? (Show Card 1)

1( ) $16-17$

$6($ ) $40-49$

2 ( ) $18-19$

7 ( ) $50-59$

$3($ ) 20-24

8() $60-69$

4 ( ) 25-29

5 ( ) 30-39

37. What is the total annual income for your or your Eamily? (Show Card 1)

L( ) Less than $\$ 1,000$ 6( ) $\$ 10,000$ - $\$ 14,999$

2( ) $\$ 1,000-\$ 2,499$ T( ) $\$ 15,000-\$ 19,999$

3()$\$ 2,500-\$ 4,999 \quad 8() \$ 20,000-\$ 29,999$

4()$\$ 5,000 \cdot \$ 7,499 \quad 9() \$ 30,000$ or more

$5(\quad) \$ 7,500-\$ 9,999$

38. What is the highest educational level you've actained?

1( ) 6th grade or less

2( ) 7 - 9th grade

$3($ ) High school, incomplete

4 () High school graduate

S( ) Special, non-college training (1.e., business, trade, technical, etc.)

6( ) College, incomplete

$7($ ) College graduate

8 ( ) 1 Year or more graduate work
39. Whet is your present employment status? 1( ) Unemployed, not looking for work

2( ) Unemployed, looking for work

$3($ ) Retired

4( ) Full-time student

5( ) Working full-time

6( ) Part-time employed

7 ( ) Part-time student

8( ) Other (specify)

$9($ ) Refused to answer

40. What kfnd of work do you do? (Probe and refer to occupation check 1 ist)

OI( ) Professional

02( ) Sent-professional

03 () Manager, Proprietor or Executive

04() Farm Owner

$05($ ) Sales

06( ) Farm Manager

07 ( ) Craftsman or Foreman

08( ) Clertcal Worker

O9( ) Operatives

10 ( ) Service or Protective

11 ( ) Farm Labor or Farm Foreman

12( ) Laborer (except farm)

13( ) Other (specify)

14( ) Does not apply

15( .) Refused to answer

42. Where were you coming from when we stopped you? 1( ) own home

2( ) Friend's or relative's home

3 () Work or school

4( ) Appointment (meeting, shopping, business)

$5($ ) Sport or recreational factlity

6( ) Restaurant

7( ) Bar, cavern or private club

8( ) Just driving around

9 ( ) Other (specify) 
43. Are you currently taking any medicines, pills, drugs or agything of that sort? (If so, How long has it been since you took the medication?" (Probe)

Would you please tell us the type or name of the medication

$\frac{43}{44} \frac{\text { Write in }}{49} \frac{\text { Write in }}{\frac{50}{55} \frac{\text { Write in }}{56}}$
$\frac{\text { Write in }}{67} \frac{\text { Write in }}{\text { Wr }}$

Iimes/Day

(1 for once/day or less) (9 for as neaded)

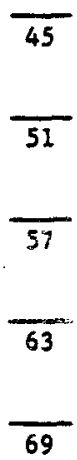

\begin{tabular}{|c|c|c|}
\hline $\begin{array}{r}\text { Hours } \\
\text { Last }\end{array}$ & $\begin{array}{l}\text { Since } \\
\text { Took }\end{array}$ & Presciption? \\
\hline 46 & 47 & $(1)$ \\
\hline 52 & 53 & ()$\left._{54}\right)$ \\
\hline 58 & 59 & $\left({ }_{60}\right)$ \\
\hline 64 & 65 & $\left({ }_{66}\right)$ \\
\hline$\overline{70}$ & 71 & $\ldots\left({ }_{72}\right)$ \\
\hline
\end{tabular}

73. Drinking is an accepted part of buslness and social activity for many people. Do you ever drink alcoholic beverages? (If "yes" ask -- how many drinks have you had in the last 4 hours?)

$x$ Enter number

98() None

99 ( ) Don't drink Go to Question 78

75. How long ago did you finigh your last drink?

$1($ ) Less than 4 hours ago

2 () Less than 3 hours ago

3 () Less than 2 hours ago

4 () Less than 1 hour ago

$5($ ) Less than 30 minutes ago

6( ) Less than 15 minutes ago

7 () Was drinking when stopped

76. Now, I'd like you to blow late this tube. Inis is part of the procedure for gathering data for this survey.

$x \mathrm{XX} \frac{}{76} \frac{}{77}$ (Enter BAC)

97( ) Negative or zero reading

98( ) Refused

$99($ ) Equipment or operator problem

78. This completes the questioning. The results of the Breathalyzer test will be available in about 2 minutes. While you are waiting for the results, I would like you to give us a urine sample. We have a tollet facility in this van for your conventence.

l( ) Accepted, willing

2( ) Accepted, unwilling

3 ( ) Accepted to mall

4( ) Accepted, small sample and mailer

5( ) Refused, excuse or polite

6( ) Refused, belligerent
79. Blood sample

1( ) Given, willing

2( ) Given, unwilling

3( ) Refused, excuse or polite

4( ) Refused, belligerent

$5($ ) Not requested-under age

6( ) Not requested-health reason

7 () Could not locate vein

80. Some medications leave residues on the lips and fingers. As a final part of the intarviat, I would like for you to let us collect threes swab samples from you.

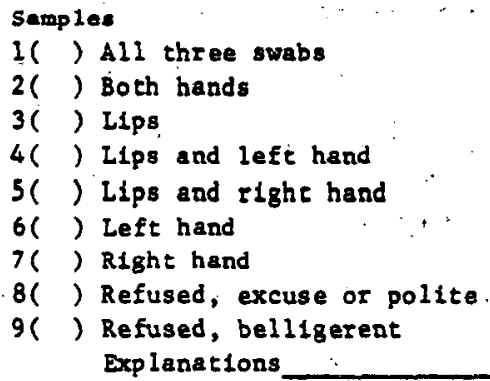

Thank you very much for your cooperation and for your time. 


\section{SITE IDENTIFIER SHEET}

1. Sampling Period

2. Location Number

3. Date $\frac{}{\text { day }} \frac{}{\text { month }} \frac{}{\text { year }}$

9. Area Type

1( ) Rura1

2( ) Suburban

$3($ ) Urban

10. Road Type

1( ) Freeway Exit

2( ) City Street - One Way

$3($ ) City Street - Two Way - 4 or more Lanes

4( ) City Street - Two Way - 2 or 3 Lanes

5( ) Highway - Divided

6( ) Highway - Two Way - 4 or more Lanes

7( ) Highway - Two Way - 2 or 3 Lanes

11. Relative Traffic Volume

1( ) Low

2( ) Medium

3( ) High

12. 1-Hour, 1-Way Traffic Count

$\frac{12}{13} \overline{14} \overline{15}$

16. At this site:

Last Sample Number

First Sample Number

17. Comments:

$D-5$ 
Code

01 Professional: clergyman, dentist, physician, engineer, lawyer, professor, teacher, scientist, etc.

02

Semi-professional: accountant, actor, pilot, armed forces officer, artist, draftsman, librarian, musician, medical technician, etc.

Manager, proprietor, or executive: sales manager, store manager, factory supervisor, owner of own business, contractor, banker, government official, manufacturer, etc.

Farm Owner

Sales: life insurance, real estate, industrial or farm goods, etc.

Farm Manager

07

Craftsman or foreman: baker, carpenter, plumber, tailor, factory foreman, etc.

Clerical worker: sales clerk, office clerk, bookkeeper, ticket agent, etc.

Operatives: bus driver, chauffeur, deliveryman, route man, taxical: driver, truck or traller-truck driver, etc.

Service or protective: armed-forces enlisted man, barber, beautician; policeman, waiter, fireman, etc.

11 Farm Laborer or Farm Foreman

12 Laborer (except farm): carpenter's helper, fisherman, garage laborer, gardener, longshoreman, truck driver's helper, warehouseman, etc.

13

Other

14

Refuse to Answer 


\section{APPENDIX E}

DATA TYPE AND CODING FORMAT

$$
\text { E-1 }
$$




\section{Card Types}

Type 1: Living Driver Interviews

Type 2: Living Driver Lab Resules

Type 3: Fatally Injured Driver Lab Results

Type 4: Crash Data Form

II. Coding of Living Driver Interview

Code directly from interview form.

III. Coding of Chemical Analysis Data (Dead Drivers and Living Drivers)

Col. 1: Card Type ( 3 = Dead driver, 2 = Living driver)

Co1. 2-5: Last four digits of MRI Sample Code. (Ignore "A" designation at this point)

Co1. 6-7: Area Code (city or community)

Col. 8-9: Location number, Dallas or Memphis only. (Leave blank for other communities)

Col. 10-12: BAC, No decimal point. Special codes as follows:

$$
\begin{aligned}
& \text { *: } 999 \text { (no sample) } \\
& \text { - : blank (negative) } \\
& >.30: 301 \\
& \text { trace: } 001
\end{aligned}
$$

Col. 13-18: Nicotine and Salicylate iscidence; 1 means present, blank means not present or so sample. Colums are:

13 Urine, $\mathbb{N}$

14 Urine, $S$

15 Blood, N

16 Blood, S

17 Bile, $N$ Blank for Livizg Driver

18 Bile, S Blank for Li:ing Driver 


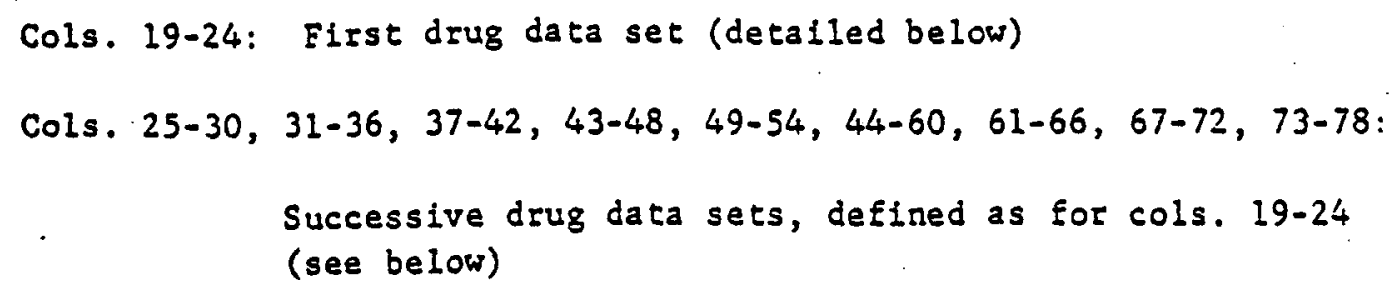

The six digit fields accomplish 3 main purposes:

1. They indicate amount and type of drug detected;

2. They indicate when no fluid sample was available;

3. They indicate, for living drivers, when the urine sample was via a waling tube.

The six digits are as follows:

1. Fluid type: 1 = Urine

$$
\begin{aligned}
& 2=\text { Blood } \\
& 3=\text { Bile } \\
& 4=\text { Urine Mailer (see below) }
\end{aligned}
$$

2-3. Drug type: $01-43$ : existing drug codes $99=*$ (no sample)

4-6. Drug amount: XX.X

muderstood deciasl poine, not punched

$$
\text { 999: } \geq 100.0
$$

Punch one field for every drug confirsed by G. $C$.

If same drug confirmed for 2 fluids, punch 2 fields.

Punch one field for every fluid uisstag (shown as *) (No special field for bile for living drivers)

Punch an extra field for living drivers for whom urine sample was by a maller (1ndicated by an "A" designation with the sample code.) The field will simply be a " 4 " followed by 5 blanks.

Note: Ignore the mailed sample if the associated regular sample (same sample code, without the A) included a urine sample which was analyzed, even if the results were different. 


\section{Coding of Crash Data}

Co1. 1: Card Type (4)

Co1. 2-5: Last 4 digits of MRI Sample Code. .

Co1. 6-7: Area Code (city or community).

Col. 8-9: Location number, Dallas or Memphis only. (Leave blank for other communities)

Co1. 10-15: Date of Crash (Day, month, year; rather than as shown on information form).

Col. 16-19: Time of Crash (24 hr clock).

Col. 20-23: Time of Death (24 hr clock).

Co1. 24: Day of Crash $(1-7 ;$ Monday $=1)$.

Co1. 25-28: Samples provided: $1=$ yes, blank $=$ no.

$$
\begin{array}{ll}
\text { 25: } & \text { Blood } \\
\text { 26: } & \text { Bile } \\
\text { 27: } & \text { Orine } \\
\text { 28: } & \text { Swabs }
\end{array}
$$

Col. 29: Area Type ( $1=$ Rural, 2 = Suburban, $3=$ Urban).

Col. 30: Number of Vehicles Involved.

Co1. 31: Type of Accident (1-7, See information form).

Co1. 32: Vehicle Type of victim $(1=$ car, $2=$ pickup truck, $3=$ other truck, 4 = motorcycle, 5 = other).

Co1. 33: Number of people invictim's vehicle.

Col. 34: Total number of fatalities, all vehicles.

Col. 35: Total number of injuries, all vehicles.

Col. 36: Victim culpability $(1=$ yes, blank $=$ no). Code as a "l" (culpable) if:

a) Single vehicle accident, or

b) victim's condition or behavior most likely contributed to the crash, or 
c) Medical examiner's comments strongly implicate the victim--for example, victim going wrong way, at excessive speed, through red light, etc.

Col. 37: Sex of Victim $(1=$ male, $2=$ female $)$.

Co1. 38-39: Age of Victim. 
APPENDIX $F$

FREQUENCY TABULATIONS OF FATALLY INJURED DRIVER CRASH DATA

F-1 
NUMBER OF FATALLY INJURED DRIVERS BY COLLECTION AREA

\section{Collection Areas}

Wayne County, Michigan (including parts of Detroit Fulton and Cobb Counties, Georgia (including parts of Atlanta)

Dallas County, Texas (excluding Dallas)

City of Dallas, Texas

Alameda County, California (including Oakland)

Harris County, Texas (including parts of Houston)

Hennepin County, Minnesota (including Minneapolis)

Duval, Clay and Nassau Counties, Florida (including Jacksonville)

Clark County, Nevada (including Las Vegas)

Orange and Osceola Counties, Florida (including Orlando)

Jackson County, Missouri (including Kansas C1ty)

DuPage County, Illinois. (including Wheaton)

Volusia, Putnam and Ilagler Counties, Florida (including Daytona Beach)

Bernalillo County, New Mexico (including Albuquerque)

Multnomah, Clackamas and Washington Counties, Oregon (including Portland)

Snohomish County, Washington (including Everett)

Outagamie County, Wisconsin (including Appleton)

Butler County, Pennsylvania (including Butler)

Randolph County, Illinois (including Chester)

Eau Claire and Jackson Counties, Wisconsin (including

Eau Claire)

Shelby County, Tennessee (excluding Memphis)

City of Memphis, Tennessee

Dade County, Florida (including Miami)

Hillsborough County, Florida (including Tampa)

Tota 1
Number Percent

86

9.6

52

5.8

42

4.7

81

56

9.0

69

6.2

19

7.7

63

2.1

7.0

26

2.9

44

4.9

40

4.4

36

4.0

13

1.4

26

2.9

39

4.3

18

2.0

11

1.2

14

1.6

0.3

0.3

20.2

$45 \quad 5.0$

$68 \quad 7.6$

$44 \quad 4.9$

$900 . \quad 100.0$ 
TABLE F-2

\section{YEAR OF FATAL CRASH}

$\begin{array}{rrr}\text { Year } & \text { Number } & \text { Percent } \\ 1974 & 117 & 13.0 \\ 1975 & 732 & 81.3 \\ 1976 & 51 & 5.7 \\ \text { Tota1 } & 900 & 100.0\end{array}$

TABLE F-4

TIME OF DAY OF THE FATAL CRASH

Time Interval Number Percent

$\begin{array}{rrr}0001-0400 & 255 & 29.3 \\ 0401-0800 & 90 & 10.3 \\ 0801-1200 & 91 & 10.4 \\ 1201-1600 & 107 & 12.3 \\ 1601-2000 & 130 & 14.9 \\ 2001-2400 & 199 & 22.8 \\ & & \\ \text { Tota1 } & 872 & 100.0\end{array}$

TABLE F-3

MONTH OF YEAR OF FATAL CRASH

Month Number Percent

$\begin{array}{llr}\text { January } & 80 & 8.9 \\ \text { February } & 71 & 7.9 \\ \text { March } & 68 & 7.6 \\ \text { April } & 81 & 9.0 \\ \text { May } & 79 & 8.8 \\ \text { June } & 84 & 9.3 \\ \text { July } & 76 & 8.5 \\ \text { August } & 63 & 7.0 \\ \text { September } & 53 & 5.9 \\ \text { October } & 56 & 6.2 \\ \text { November } & 91 & 10.1 \\ \text { December } & 97 & 10.8 \\ & & \\ \text { Total } & 899 & 100.0\end{array}$

TABLE F-5

DAY OF WEEK OF THE FATAL CRASH

Day of Week Number Percent

$\begin{array}{lrr}\text { Monday } & 125 & 13.9 \\ \text { Tuesday } & 107 & 11.9 \\ \text { Wednesday } & 113 & 12.6 \\ \text { Thursday } & 92 & 10.2 \\ \text { Friday } & 124 & 13.8 \\ \text { Saturday } & 180 & 20.0 \\ \text { Sunday } & 159 & 17.7 \\ & & \\ \text { Total } & 900 & 100.0\end{array}$




\section{TABLE F-6}

\begin{tabular}{|c|c|c|}
\hline Aree Type & Number & Percent \\
\hline Rura1 & 169 & 25.8 \\
\hline Suburban & 225 & 34.4 \\
\hline Urban & 260 & 39.8 \\
\hline Tota1 & 654 & 100.0 \\
\hline
\end{tabular}

TABLE $\quad F-7$

NUMBER OF VEHICLES INVOLVED

IN THE FATAL CRASH

Number Number

of of

Vehicles Crashes Percent

$\begin{array}{rrr}1 & 454 & 51.4 \\ 2 & 387 & 43.8 \\ 3 & 34 & 3.8 \\ 4 & 9 & 1.0\end{array}$

Total $\quad 884 \quad 100.0$

Total Number of Known Vehicles in the Crashes $=1,366$ 


\section{TABLE $\mathrm{F}-8$}

\section{NUMBER OF PEOPLE IN FATALLY}

INJURED DRIVERS' VEHICLE

$\begin{array}{cc}\text { Number } & \text { Number } \\ \text { of } & \text { of }\end{array}$

People Crashes Percent

$\begin{array}{rrr}1 & 524 & 71.5 \\ 2 & 148 & 20.2 \\ 3 & 33 & 4.5 \\ 4 & 20 & 2.7 \\ 5 & 5 & 0.7 \\ 6 & 0 & 0.0 \\ 7 & 2 & 0.3 \\ 8 & 1 & 0.1\end{array}$

$\begin{array}{lll}\text { Tota1 } & 733 & 100.0\end{array}$

Total Number of Known People in the Crashes $=1,046$

TABLE F-9

\section{TYPE OF ACCIDENT}

$\begin{array}{lrrr}\begin{array}{lrr}\text { Type of } \\ \text { Accident }\end{array} & \text { Number } & & \text { Percent } \\ & & \\ \text { Head On } & 166 & 18.7 \\ \text { Rear End } & 61 & 6.9 \\ \text { Angle } & 233 & 26.3 \\ \text { Fixed Object } & 283 & 31.9 \\ \text { Ran Off Road } & 63 & 7.1 \\ \text { Overturn } & 58 & 6.5 \\ \text { Other } & 23 & 2.6 \\ & & \\ \text { Total } & 887 & 100.0\end{array}$


TABLE $\mathrm{F}-10$

FATALLY INJURED DRIVERS' VEHICLE TYPE

\begin{tabular}{lrr} 
Vehicle Type & Number & Percent \\
\cline { 2 - 2 } Car & 670 & 74.8 \\
Pickup Truck & 74 & 8.3 \\
Other Truck & 28 & 3.1 \\
Motorcycle & 114 & 12.7 \\
Other & 10 & 1.1 \\
& & \\
Total & 896 & 100.0
\end{tabular}

TABLE F-11

SEX OF THE FATALLY INJURED DRIVERS

\begin{tabular}{|c|c|c|}
\hline Sex & Number & Percent \\
\hline Male & 751 & 83.7 \\
\hline Female & 146 & 16.3 \\
\hline Tota1 & 897 & 100.0 \\
\hline
\end{tabular}

TABLE $F-12$

AGE OF THE FATALLY INJURED DRIVERS

\begin{tabular}{rrrrr} 
Age Group & Number & Percent & $\begin{array}{c}\text { Cumulative } \\
\text { Percent }\end{array}$ \\
\cline { 5 - 5 } Less than 16 & 9 & 1.0 & 1.0 \\
$16-17$ & 49 & 5.6 & 6.6 \\
$18-19$ & 86 & 9.7 & 16.3 \\
$20-24$ & 194 & 22.0 & 38.3 \\
$25-29$ & 146 & 16.5 & 54.8 \\
$30-39$ & 148 & 16.8 & 71.6 \\
$40-49$ & 75 & 8.5 & 80.1 \\
$50-59$ & 86 & 9.7 & 89.8 \\
$60-69$ & 50 & 5.7 & 95.5 \\
70 and Over & 40 & 4.5 & 100.0 \\
& & &
\end{tabular}

$$
\text { F-6 }
$$


TABLE F-13

\section{CULPABILITY OF THE FATALLY INJURED DRIVERS}

$\begin{array}{lrr}\text { Culpability } & \text { Number } & \text { Percent } \\ \text { Not Culpable } & 254 & 28.2 \\ \text { Culpable } & 646 & 71.8 \\ \text { Total } & 900 & 100.0\end{array}$

TABLE $\quad$ - 14

TOTAL NUMBER OF FATALITIES IN ALL VEHICLES INVOLVED IN THE FATAL CRASHES

Number of Number of

Fatalities Crashes

Percent

1

789

89.3

2

78

8.8

3

15

1.7

4

0

0.0

5

2

0.2

$\begin{array}{lll}\text { Total } & 884 & 100.0\end{array}$

Total number of known fatalities in the crashes $=1,000$. 


\section{TABLE $\quad$-15}

TOTAL NUMBER OF NON-FATAL INJURIES IN ALL

VEHICLES INVOLVED IN THE FATAL CRASHES

\begin{tabular}{ccr}
$\begin{array}{c}\text { Number of } \\
\text { Non-Fatal } \\
\text { Injuries }\end{array}$ & $\begin{array}{c}\text { Number of } \\
\text { Crashes }\end{array}$ & Percent \\
\cline { 2 - 2 } 0 & 669 & \\
\hline 1 & 138 & 74.3 \\
2 & 46 & 15.3 \\
3 & 27 & 5.1 \\
4 & 12 & 3.0 \\
5 & 3 & 1.3 \\
6 & 4 & 0.3 \\
7 & 1 & 0.4 \\
Total & & 0.1 \\
& 231 & 100.0
\end{tabular}

Total number of non-fatal injuries in the crash $=405$. 


\section{APPENDIX G}

RESPONSES FROM SURVEY INSTRUMENT

$$
\text { G-1 }
$$




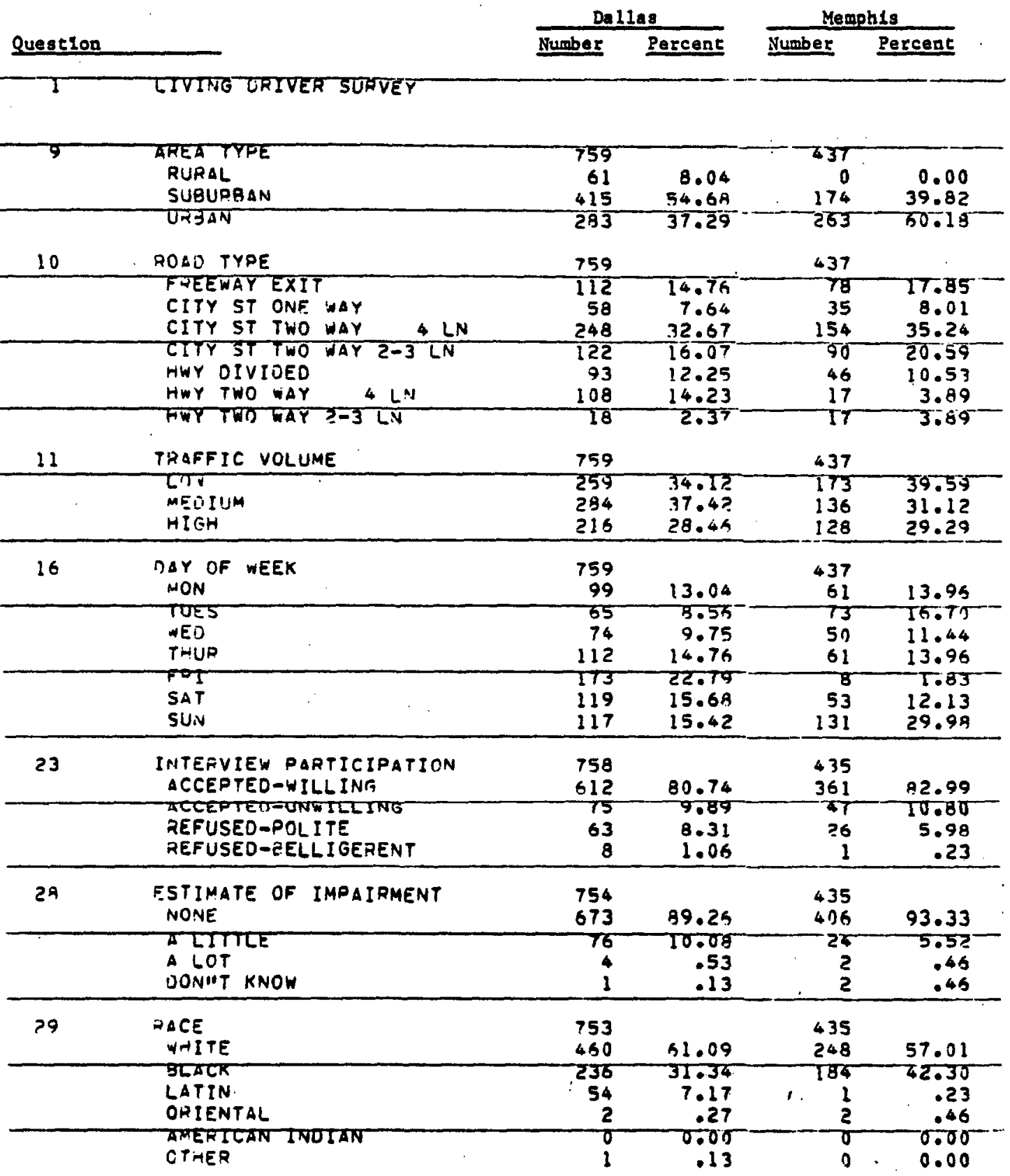




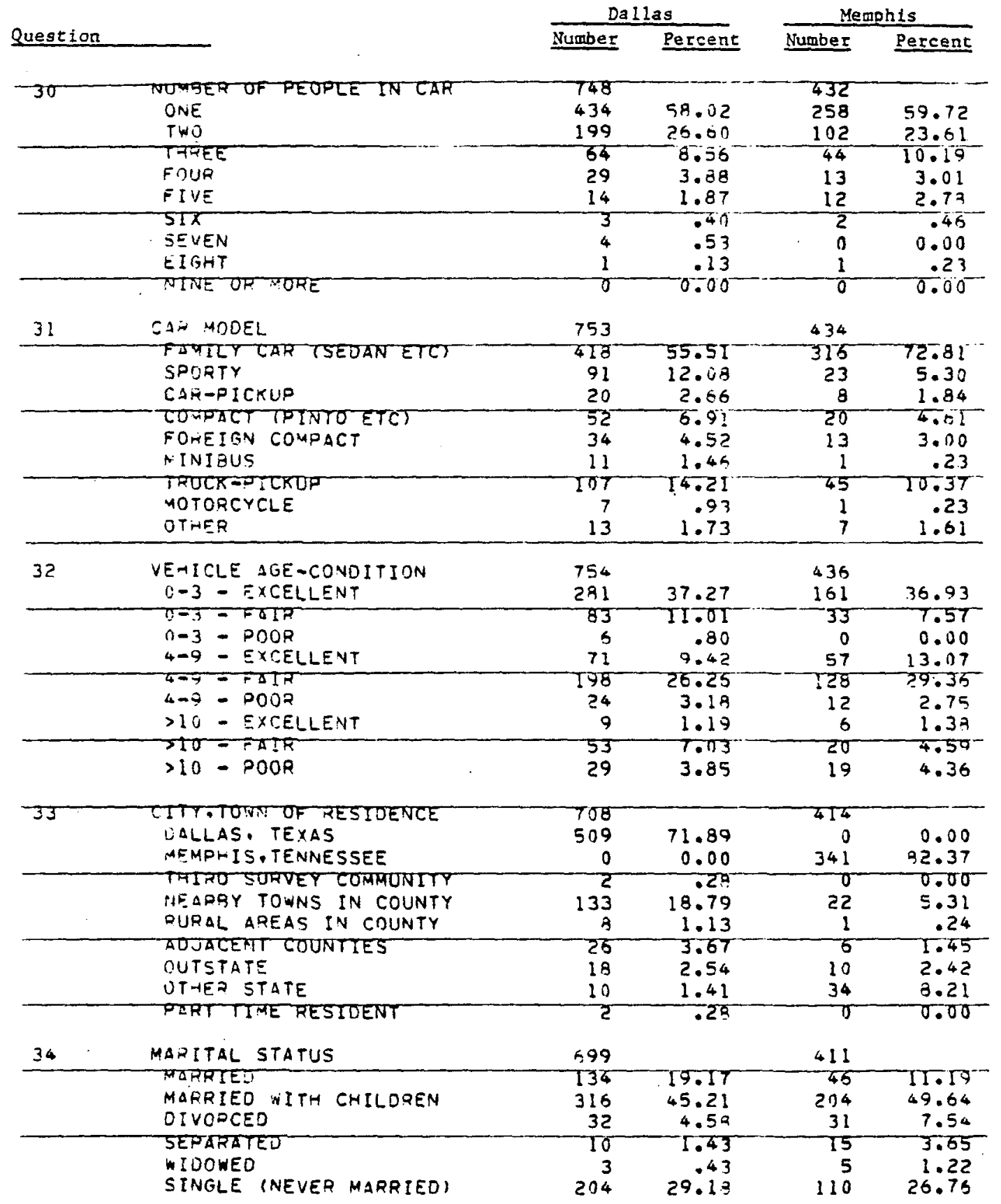




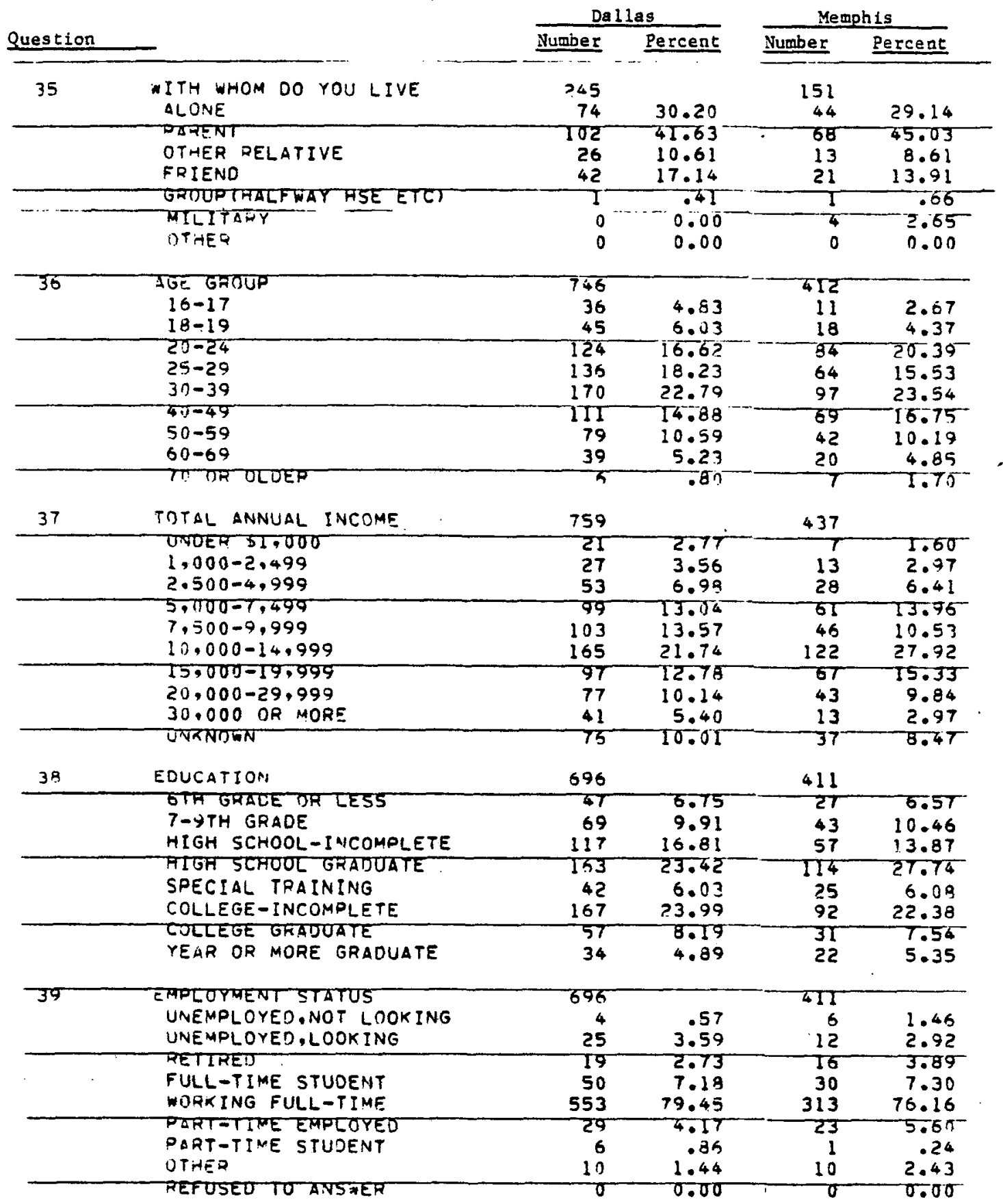




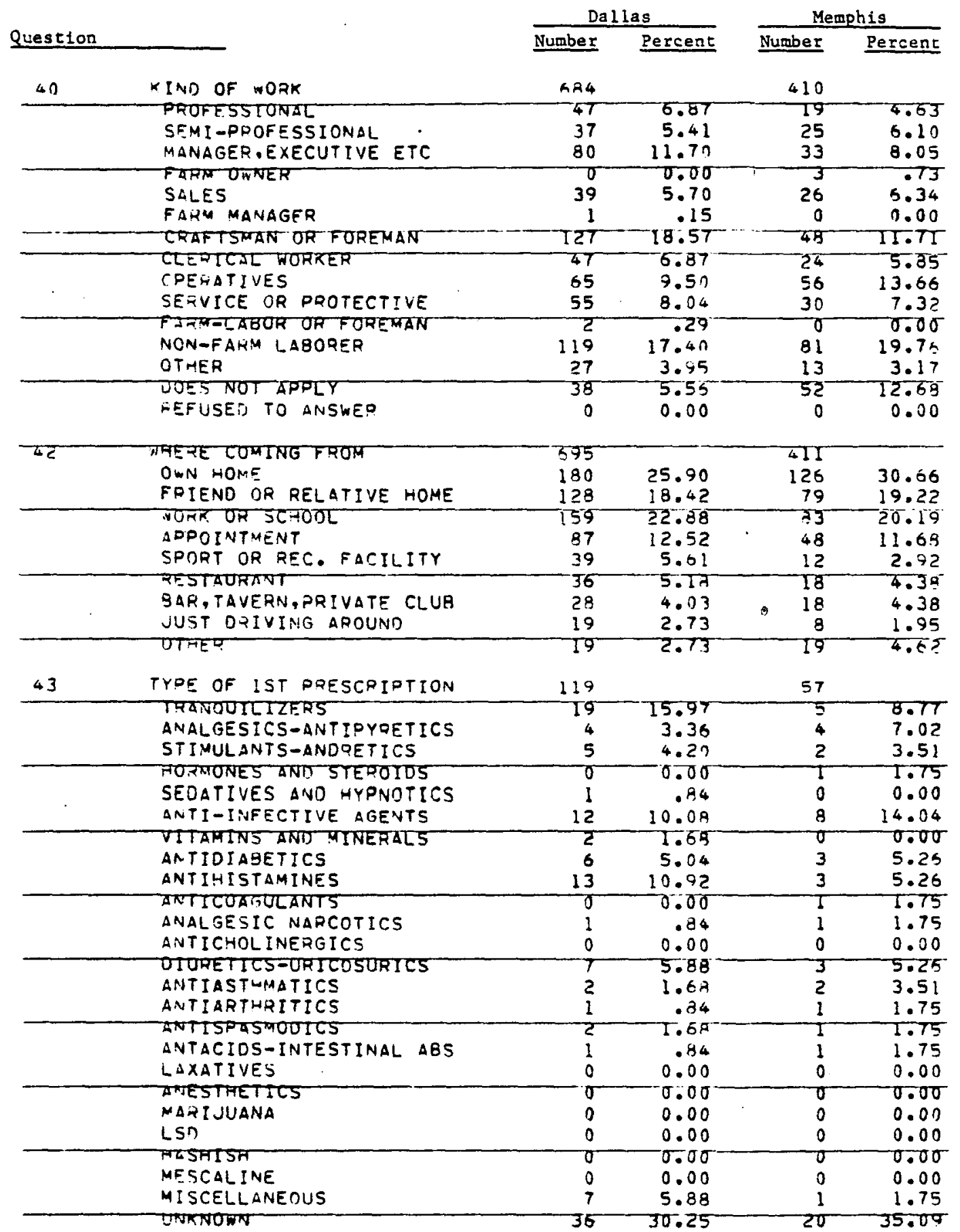




\begin{tabular}{|c|c|c|c|c|c|}
\hline \multirow[b]{2}{*}{ Question } & & \multicolumn{2}{|c|}{ Dallas } & \multicolumn{2}{|c|}{ Memphis } \\
\hline & & Number & Percent & Number & Percent \\
\hline 49 & TYPE OF 2ND PRESCRIPTION & 40 & & 23 & \\
\hline • & $\begin{array}{l}\text { TPROUILIZERS } \\
\text { ANALGESICS-ANTIPYRETICS } \\
\text { ST IMULANTS-ANORETICS }\end{array}$ & $\begin{array}{l}8 \\
2 \\
0\end{array}$ & $\begin{array}{r}20.00 \\
5.00 \\
0.00\end{array}$ & $\begin{array}{l}3 \\
1 \\
0\end{array}$ & $\begin{array}{l}13.04 \\
4.35 \\
0.00\end{array}$ \\
\hline & $\begin{array}{l}\text { FOPNONES AIND STEROTDS } \\
\text { SEDATIVES AND HYPNOTICS } \\
\text { ANTI-INFECTIVE AGENTS }\end{array}$ & $\begin{array}{l}1 \\
0 \\
3\end{array}$ & $\begin{array}{l}2.50 \\
0.00 \\
7.50\end{array}$ & $\begin{array}{l}0 \\
0 \\
3\end{array}$ & $\begin{array}{r}0.00 \\
0.00 \\
13.04\end{array}$ \\
\hline & VITAMINS AND PINER ALS & 0 & 0.00 & T & -4.35 \\
\hline & $\begin{array}{l}\text { ARTTOTAEETTCS } \\
\text { ANTIHISTAMINES } \\
\text { ANTICOAGULANTS }\end{array}$ & $\begin{array}{l}1 \\
1 \\
1\end{array}$ & $\begin{array}{l}2.5 n \\
2.5 n \\
2.5 n\end{array}$ & $\begin{array}{l}1 \\
0 \\
0\end{array}$ & $\begin{array}{l}4.35 \\
0.09 \\
0.00\end{array}$ \\
\hline & $\begin{array}{l}\text { ANALGESTC NARCOTICS } \\
\text { ANTICHOLINERSICS } \\
\text { DIUPETICS-UAICOSURICS }\end{array}$ & $\begin{array}{l}0 \\
0 \\
0\end{array}$ & $\begin{array}{l}0.07 \\
0.00 \\
0.00\end{array}$ & $\begin{array}{l}0 \\
0 \\
1\end{array}$ & $\begin{array}{l}0.00 \\
0.00 \\
4.35\end{array}$ \\
\hline & $\begin{array}{l}\text { DNTIASTHMATTCS } \\
\text { ANTI ARTHRITICS } \\
\text { ANTISPASMODICS }\end{array}$ & $\begin{array}{l}3 \\
0 \\
0\end{array}$ & $\begin{array}{l}7.50 \\
0.00 \\
0.00\end{array}$ & $\begin{array}{l}0 \\
0 \\
0\end{array}$ & $\begin{array}{l}0.00 \\
0.00 \\
0.00\end{array}$ \\
\hline & $\begin{array}{l}\text { ANTACIDS-INTESTINAL ABS } \\
\text { LAXATIVES } \\
\text { ANESTHETICS }\end{array}$ & $\begin{array}{l}1 \\
0 \\
0\end{array}$ & $\begin{array}{l}2.50 \\
0.00 \\
0.00\end{array}$ & $\begin{array}{l}0 \\
0 \\
0\end{array}$ & $\begin{array}{l}0.00 \\
0.00 \\
0.00\end{array}$ \\
\hline & MLGIJUANA & 0 & 0.00 & 0 & 0.00 \\
\hline & $\begin{array}{l}\text { LST } \\
\text { HASHISH }\end{array}$ & $\begin{array}{l}0 \\
0\end{array}$ & $\begin{array}{l}0.00 \\
0.00\end{array}$ & $\begin{array}{l}0 \\
0\end{array}$ & $\begin{array}{l}0.00 \\
0.00\end{array}$ \\
\hline & $\begin{array}{l}\text { PESCRLINE } \\
\text { MI SCELLANEOUS } \\
\text { UNKNOWN }\end{array}$ & $\begin{array}{r}0 \\
6 \\
13 \\
\end{array}$ & $\begin{array}{r}0.00 \\
15.00 \\
32.50 \\
\end{array}$ & $\begin{array}{r}0 \\
0 \\
13 \\
\end{array}$ & $\begin{array}{r}0.00 \\
0.00 \\
56.52 \\
\end{array}$ \\
\hline 55 & $\begin{array}{l}\text { TYPE OF 3RD PRESCRIPTION } \\
\text { TRAYQUILIZERS }\end{array}$ & 11 & 9.09 & $\begin{array}{l}6 \\
0\end{array}$ & 0.00 \\
\hline & $\begin{array}{l}\text { ANIALGESICS-ANT IPYRETICS } \\
\text { STI WULANTS-ANORETICS } \\
\text { HOAMONES ANO STEROIOS }\end{array}$ & $\begin{array}{l}0 \\
0 \\
0\end{array}$ & $\begin{array}{l}0.00 \\
0.00 \\
0.00\end{array}$ & $\begin{array}{l}0 \\
1 \\
0\end{array}$ & $\begin{array}{r}0.00 \\
16.67 \\
0.00\end{array}$ \\
\hline & $\begin{array}{l}\text { SEDATIVES ATVO FYONOTICS } \\
\text { ANTI-INFECTIVE AGENTS } \\
\text { VITAMINS AND HINERALS }\end{array}$ & $\begin{array}{l}0 \\
1 \\
2\end{array}$ & $\begin{array}{r}0.00 \\
9.09 \\
18.18\end{array}$ & $\begin{array}{l}0 \\
0 \\
0\end{array}$ & $\begin{array}{l}0.00 \\
0.00 \\
0.00\end{array}$ \\
\hline & $\begin{array}{l}\text { AMTTOTAEETICS } \\
\text { ANTIHISTAMINES } \\
\text { AMTICOAGULANTS }\end{array}$ & $\begin{array}{l}1 \\
1 \\
0\end{array}$ & $\begin{array}{r}9.09 \\
9.09 \\
0.00\end{array}$ & $\begin{array}{l}1 \\
1 \\
0\end{array}$ & $\begin{array}{r}16.07 \\
16.67 \\
0.00\end{array}$ \\
\hline & AINALGESIC NARCOTICS & $\mathbf{0}$ & 0.00 & 0 & -0.00 \\
\hline & $\begin{array}{l}\text { ANT ICHOL INERG ICS } \\
\text { DIURET I ES-UR I COSUR ICS }\end{array}$ & $\begin{array}{l}0 \\
1\end{array}$ & $\begin{array}{l}0.00 \\
9.09\end{array}$ & 0 & $\begin{array}{r}0.00 \\
16.67 \\
\end{array}$ \\
\hline & $\begin{array}{l}\text { ANTI TASTHFATICS } \\
\text { ANTI IARTHRITICS } \\
\text { ANTISPASMODICS }\end{array}$ & $\begin{array}{l}0 \\
0 \\
0\end{array}$ & $\begin{array}{l}0.017 \\
0.00 \\
0.00\end{array}$ & $\begin{array}{l}0 \\
0 \\
1\end{array}$ & $\begin{array}{r}0.00 \\
0.00 \\
16.67\end{array}$ \\
\hline & $\begin{array}{l}\text { DNTACTDS-INTESTINAL AES } \\
\text { LAXATIVES } \\
\text { ANESTHETICS }\end{array}$ & $\begin{array}{l}0 \\
0 \\
0\end{array}$ & $\begin{array}{l}0.00 \\
0.00 \\
0.00\end{array}$ & $\begin{array}{l}0 \\
0 \\
0\end{array}$ & $\begin{array}{l}0.00 \\
0.00 \\
0.00\end{array}$ \\
\hline & $\begin{array}{l}\text { MARIJUANA } \\
\text { LSD } \\
\text { HASHISH }\end{array}$ & $\begin{array}{l}0 \\
0 \\
0\end{array}$ & $\begin{array}{l}0.00 \\
0.00 \\
0.00\end{array}$ & $\begin{array}{l}0 \\
0 \\
0\end{array}$ & $\begin{array}{l}0.00 \\
0.00 \\
0.00\end{array}$ \\
\hline & $\begin{array}{l}\text { MESCALINE } \\
\text { MISCELLANEOUS } \\
\text { UNKNOWN }\end{array}$ & $\begin{array}{l}0 \\
0 \\
4\end{array}$ & $\begin{array}{r}0.00 \\
0.00 \\
36.36\end{array}$ & $\begin{array}{l}0 \\
0 \\
1\end{array}$ & $\begin{array}{r}0.00 \\
0.00 \\
16.67\end{array}$ \\
\hline
\end{tabular}




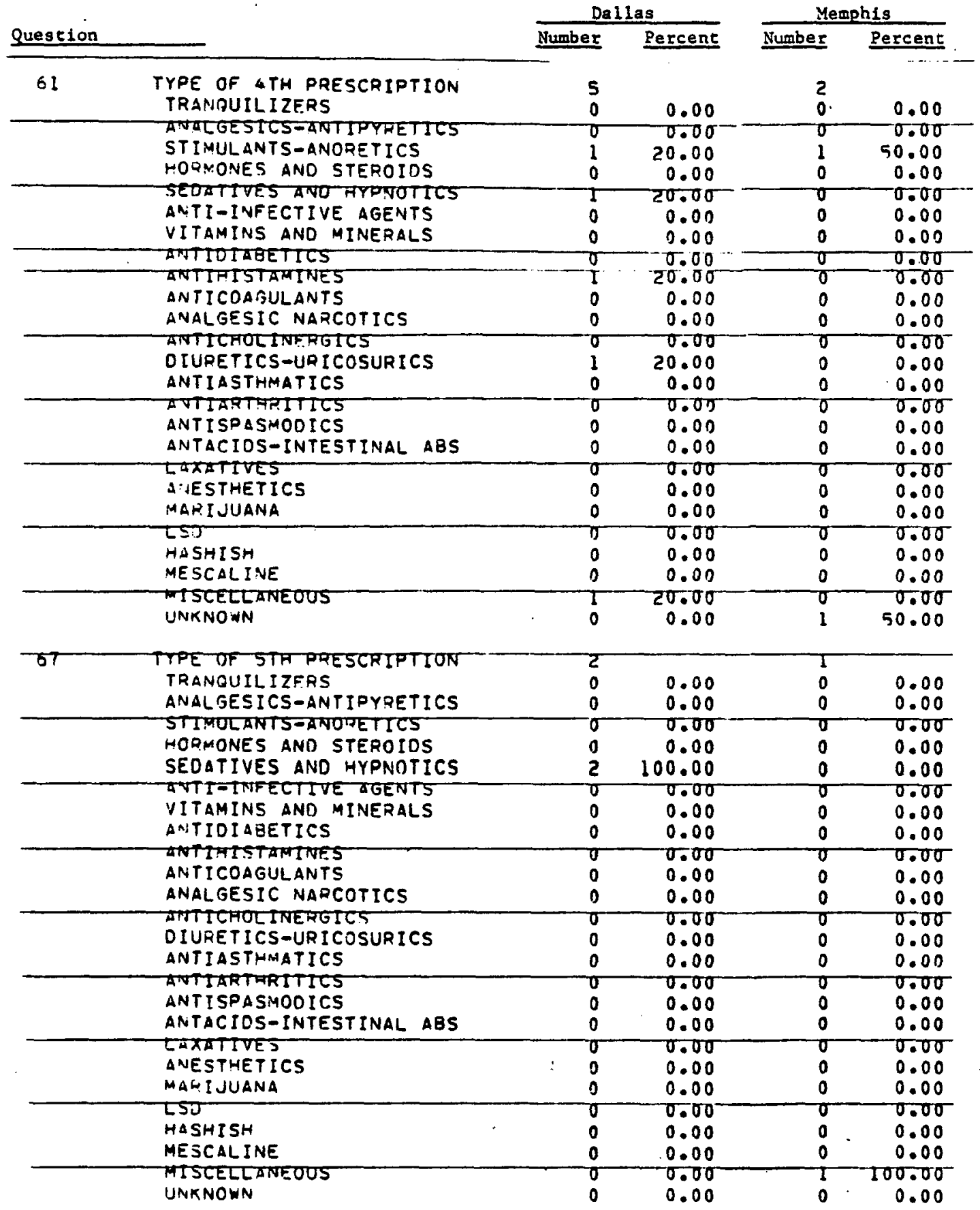




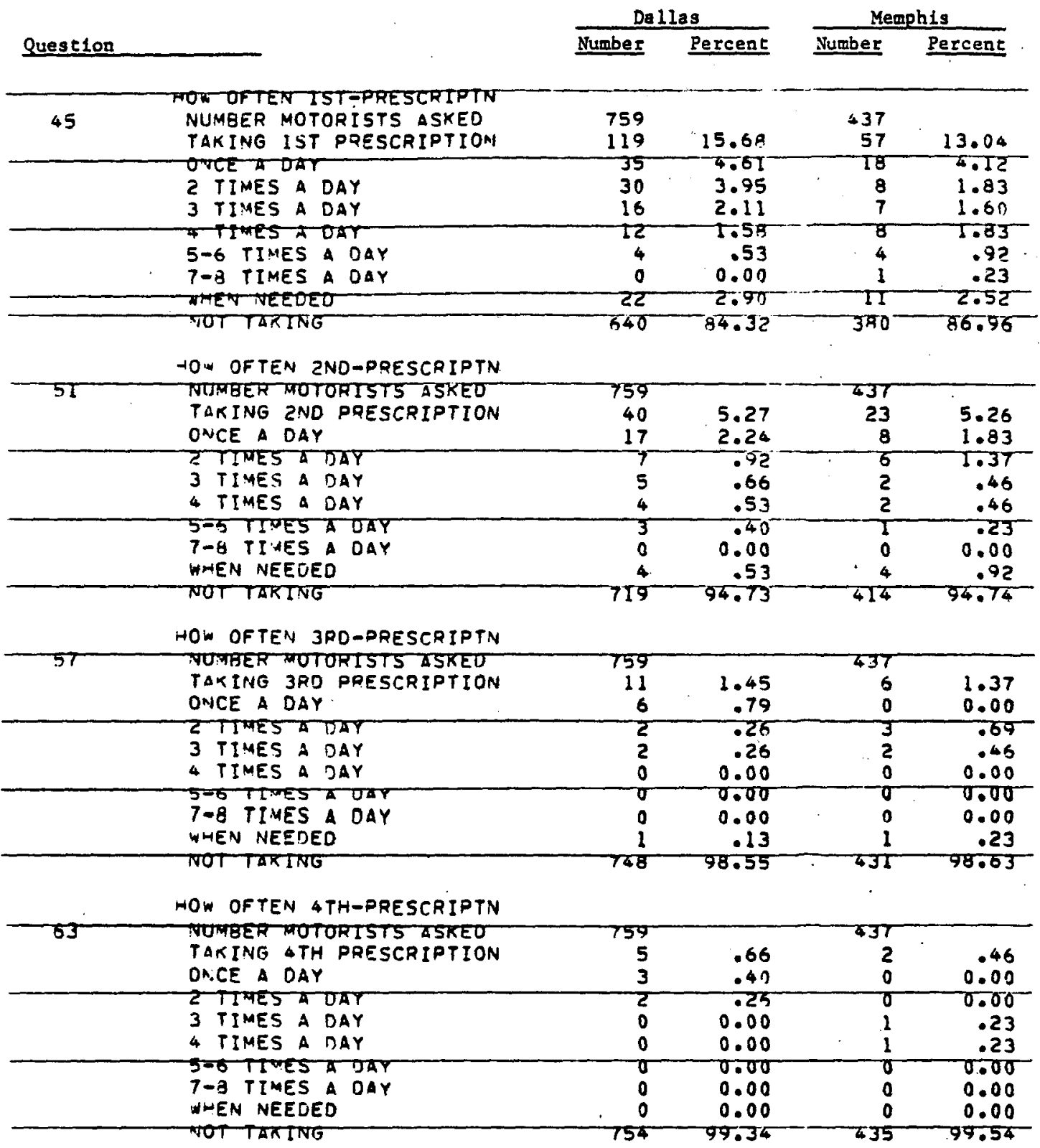




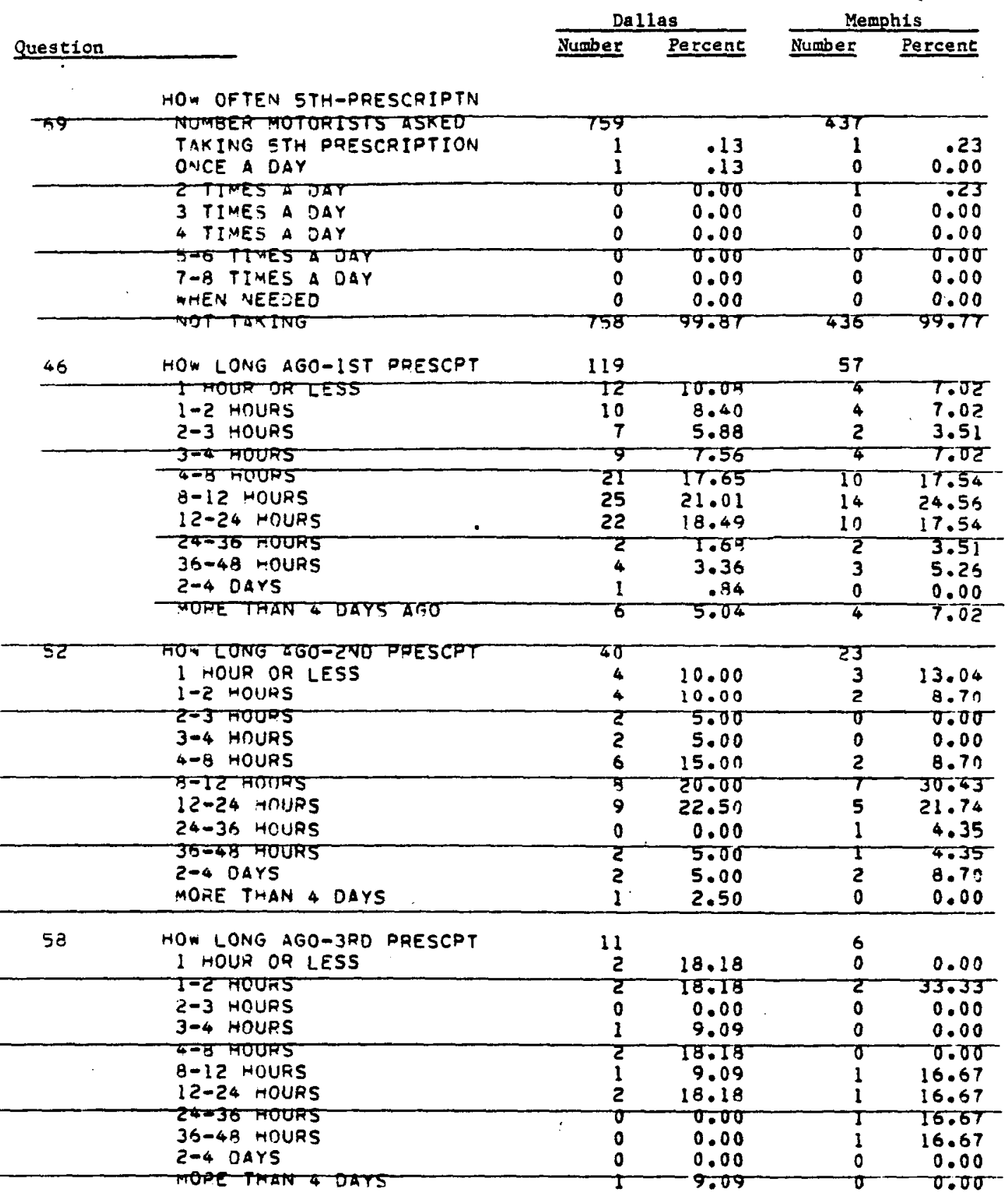




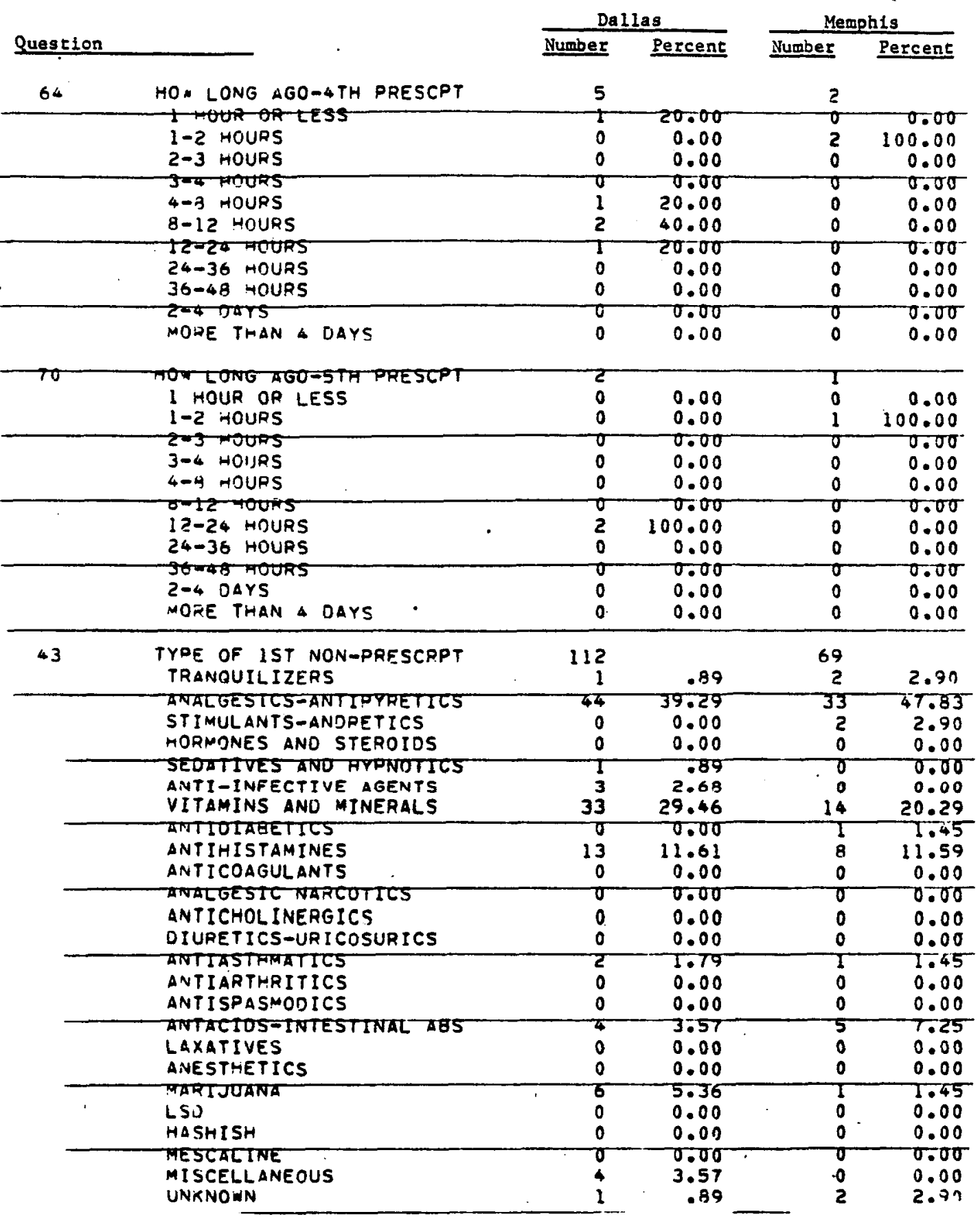




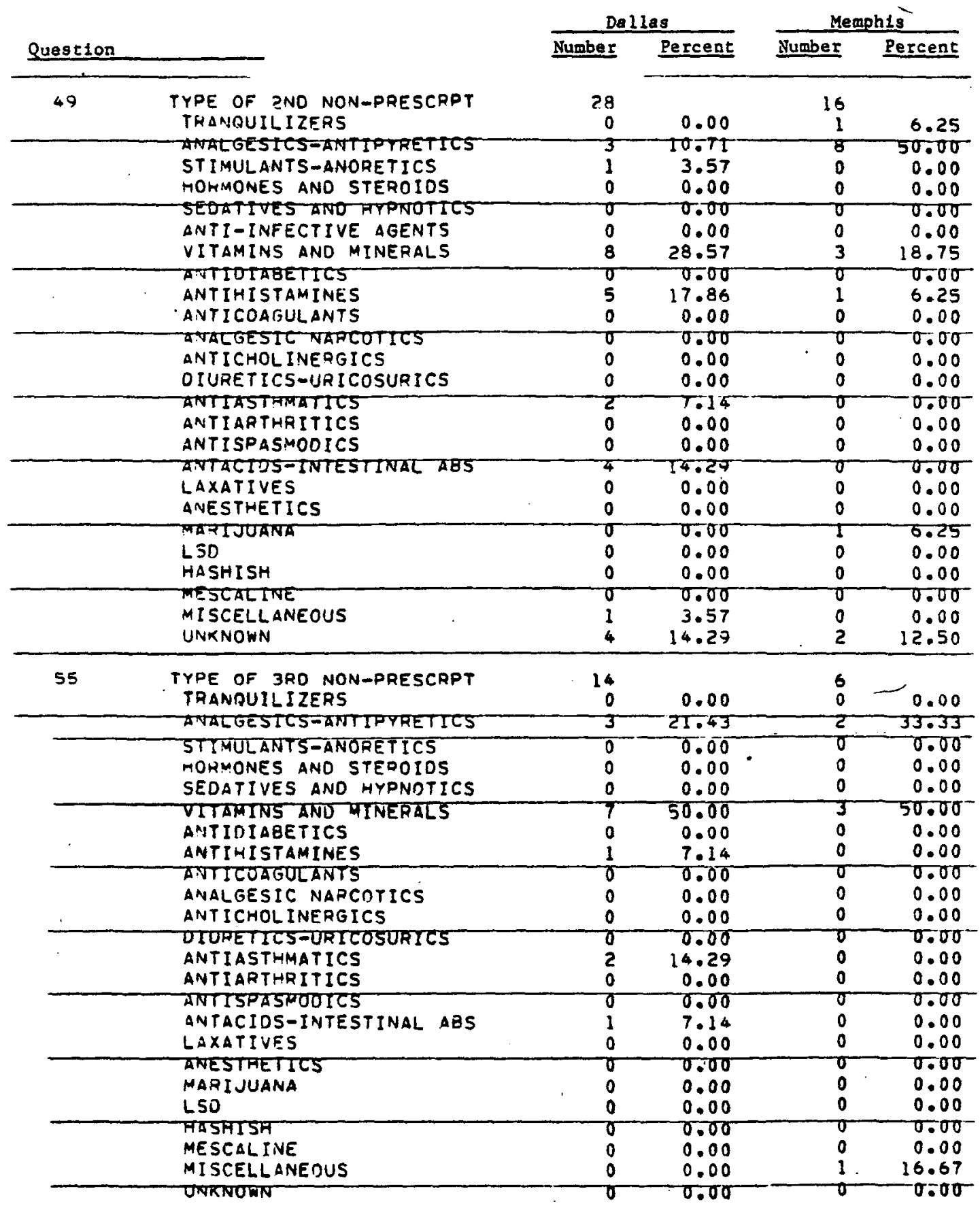




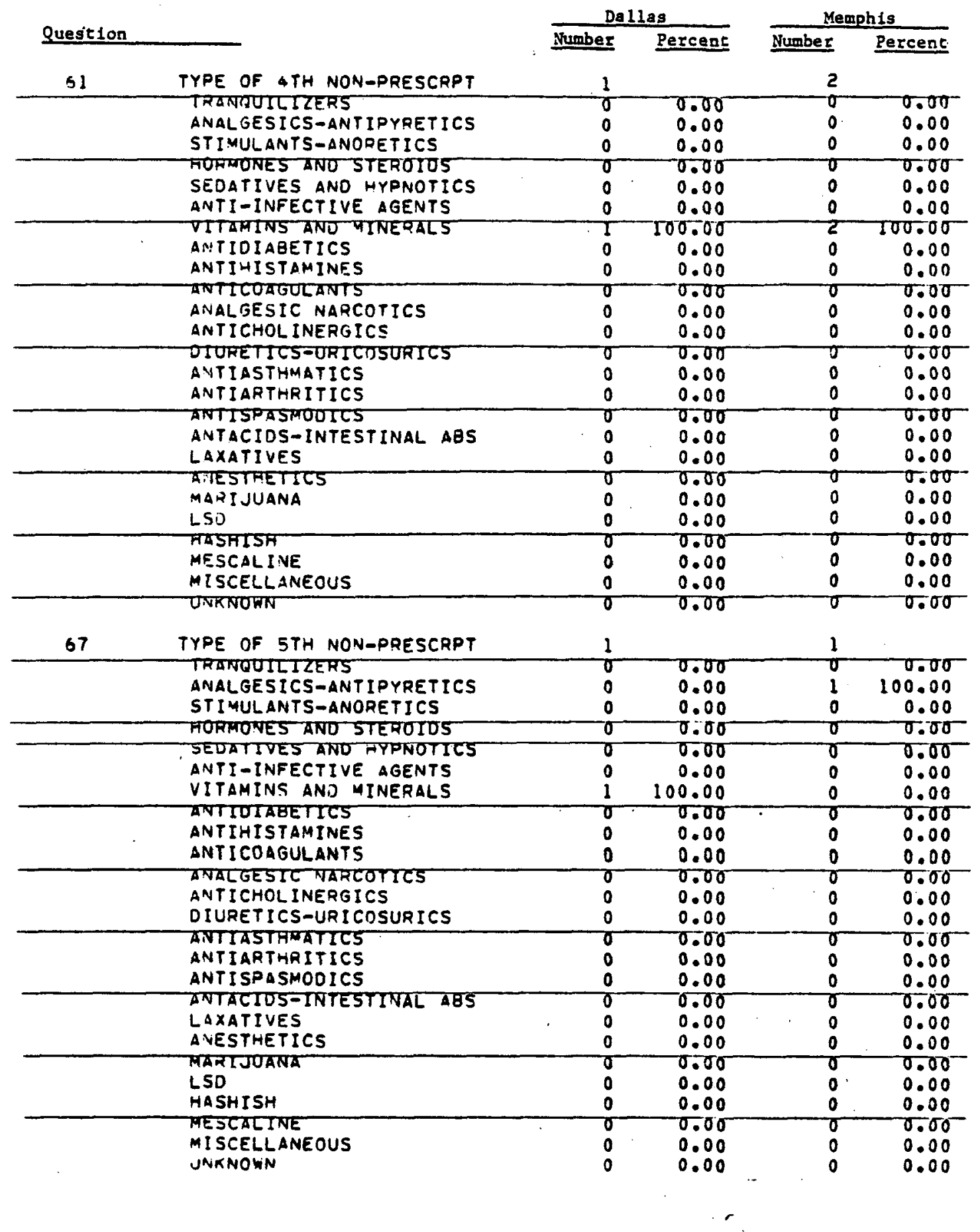




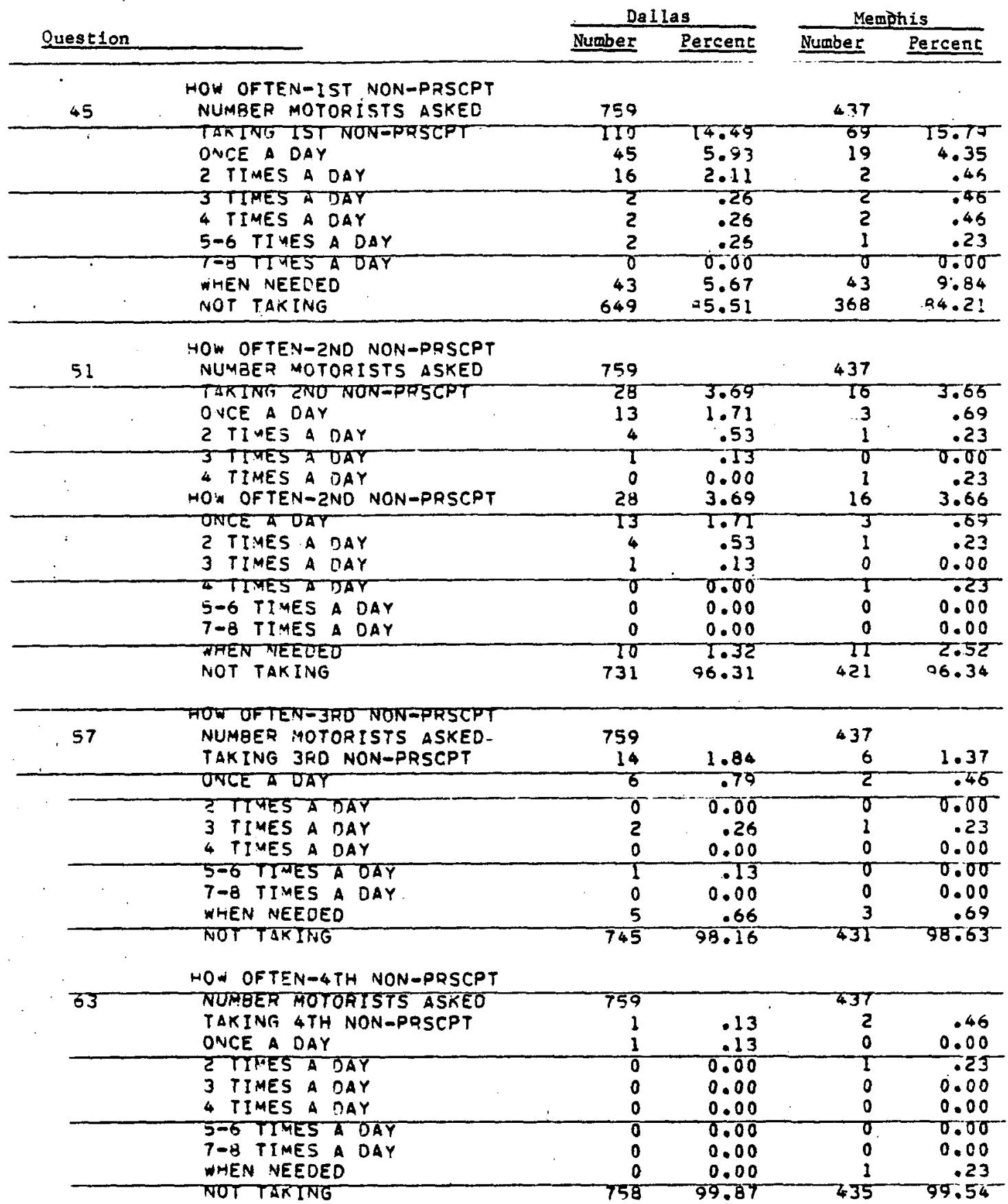




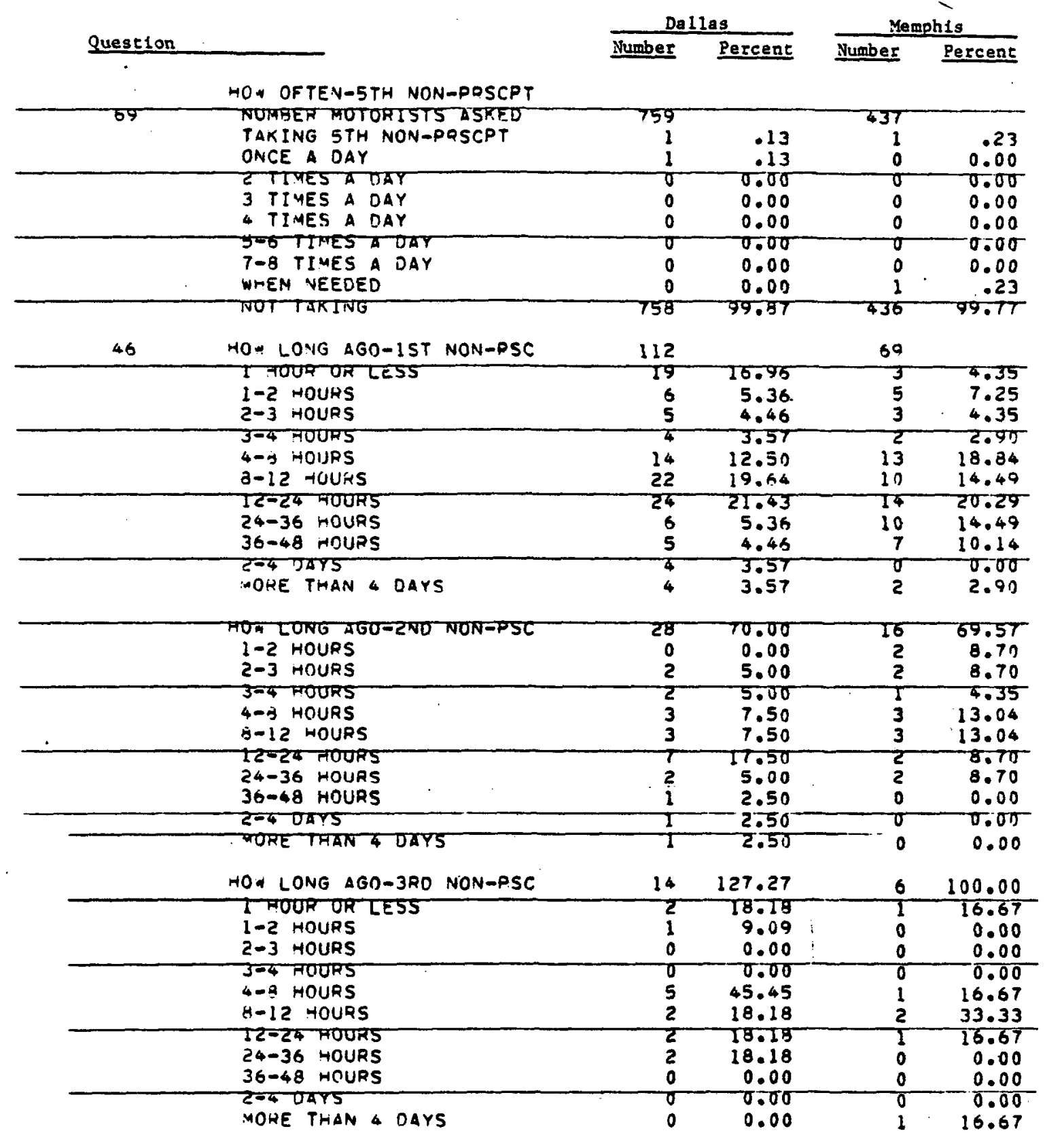




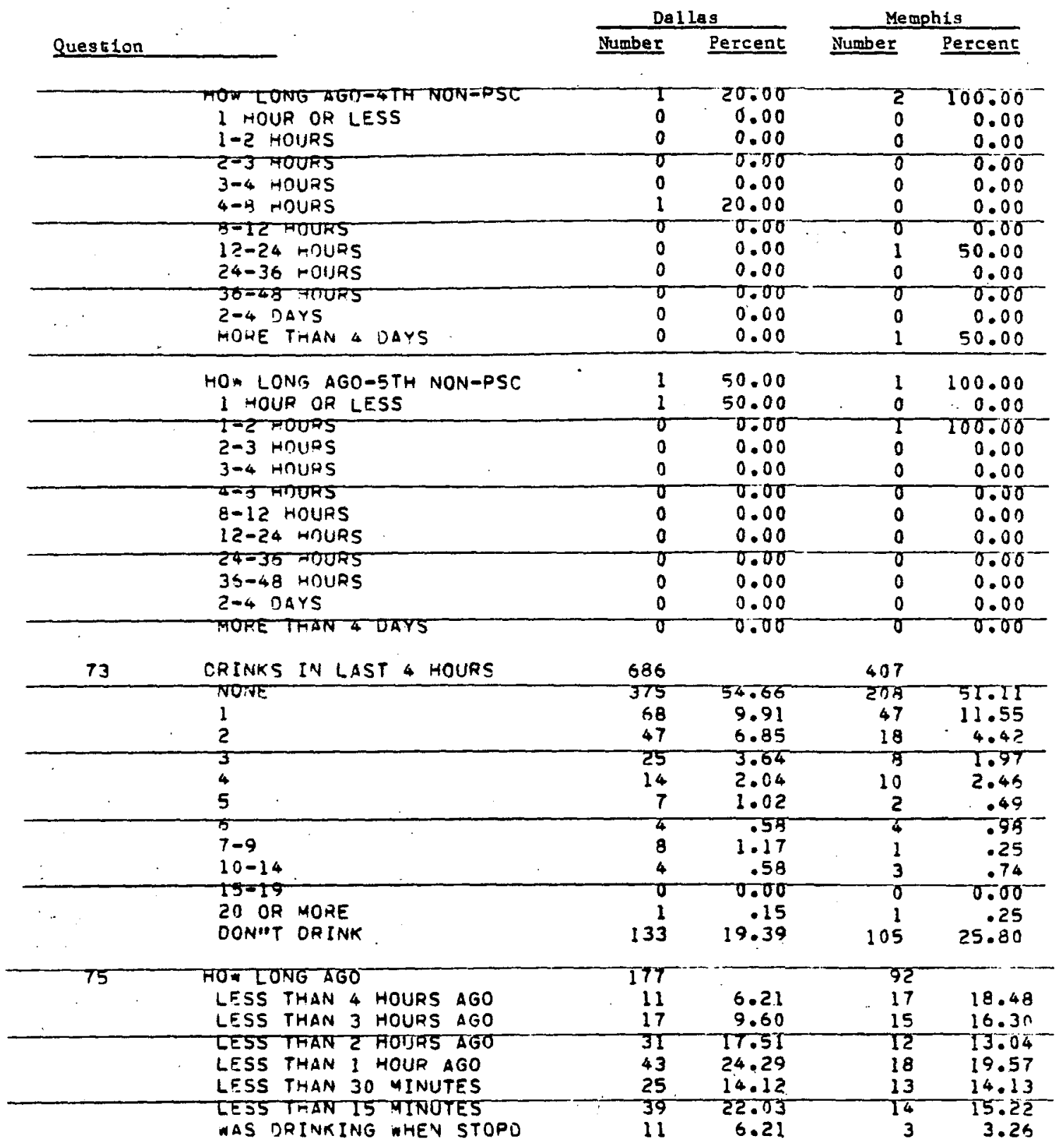




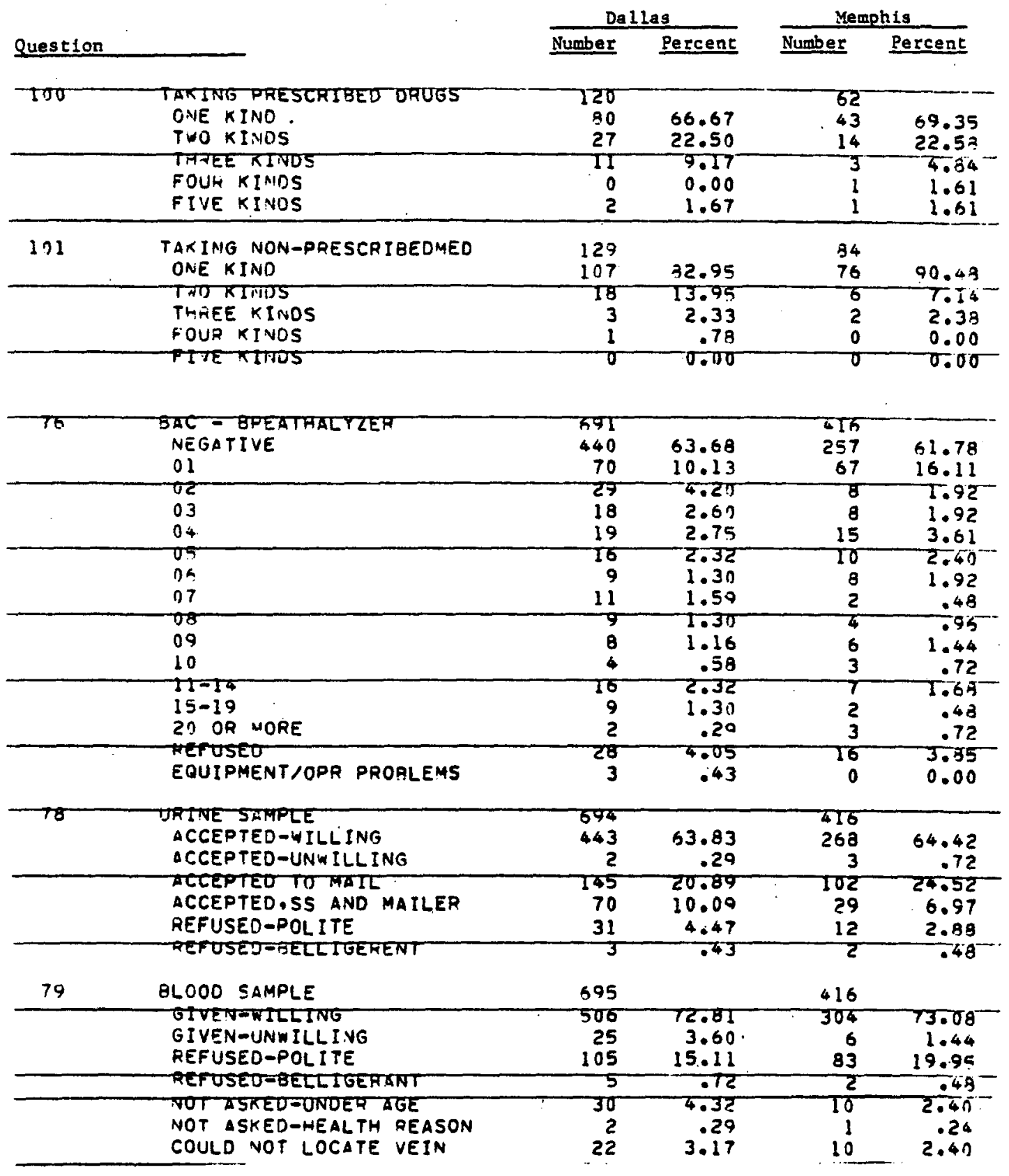




\begin{tabular}{|c|c|c|c|c|c|}
\hline \multirow[b]{2}{*}{ Question } & & \multicolumn{2}{|c|}{ Da1las } & \multicolumn{2}{|c|}{ Memphis } \\
\hline & & Number & Percent & Number & Percent \\
\hline 80 & $\begin{array}{l}\text { SWAB SAMPLES } \\
\text { ALL THREE SWABS }\end{array}$ & $\begin{array}{l}607 \\
551\end{array}$ & 90.77 & $\begin{array}{l}757 \\
303\end{array}$ & 84.37 \\
\hline & $\begin{array}{l}\text { BOTH PANUS } \\
\text { LIPS } \\
\text { LIPS AND LEFT HANO }\end{array}$ & $\begin{array}{l}1 \\
0 \\
0\end{array}$ & $\begin{array}{l}.15 \\
0.00 \\
0.00\end{array}$ & $\begin{array}{l}1 \\
0 \\
0\end{array}$ & $\begin{array}{l}.22 \\
0.00 \\
0.00\end{array}$ \\
\hline & $\begin{array}{l}\text { LIPS ANIT QTGAT RAIND } \\
\text { LEFT HANO } \\
\text { RIGHT HANO }\end{array}$ & $\begin{array}{l}1 \\
0 \\
0\end{array}$ & $\begin{array}{l}.16 \\
0.00 \\
0.00\end{array}$ & $\begin{array}{l}0 \\
0 \\
0\end{array}$ & $\begin{array}{l}0.00 \\
0.00 \\
0.00\end{array}$ \\
\hline & $\begin{array}{l}\text { PEFUSED-POLITE } \\
\text { REFUSED-SELLIGEPENT }\end{array}$ & $\begin{array}{r}53 \\
1\end{array}$ & $\begin{array}{r}9.73 \\
.15\end{array}$ & $\begin{array}{r}51 \\
2\end{array}$ & $\begin{array}{r}14.29 \\
.56\end{array}$ \\
\hline
\end{tabular}


APPENDIX H

MEDICATIONS AND DRUGS MENTIONED IN LIVING DRIVER SURVEYS

$\mathrm{H}-1$ 


\section{DRUG GROUPS}

1. Tranquilizers

2. Analgesics and Antipyretics

3. Stimulants and Anorectics

4. Hormones and Steroids

5. Sedatives and Hypnotics

6. Anti-infective Agents - Antibiotics

7. Vitamins and Minerals

8. Antidiabetics

9. Antihistamines

10. Anticoagulants

11. Analgesic Narcotics

12. Anticholinergics

13. Diuretics and Uricosurics

14. Antias thmatics

15. Antiarthritics

16. Antispasmodics

17. Antacids and Intestinal Absorbents

18. Laxatives

19. Anesthetics

20. Marijuana

21. L.S.D.

22. Hashish

23. Mescaline

24. Miscellaneous

25. Unknown 
Group 1 - Tranquilizers

1. Librium 1

2. Valium 11

3. Tranquilizer 1

4. Reserpine 1

5. Equanil 1

6. Serap 2

7. Aldomet 3

8. Anti-hypertension 2

9. Medication for hypertension 8

10. Librax 1

11. Mellaril 1

12. Etrafon 1

13. Esimil 1

14. Lithium 1

15. Thorazine 1

16. Chlorpromazine 1

17. Aldactazide 1

18. Aldactone 1

19. Serax 1

Group 2 - Analgesics and Antipyretics

1. Aspirin 71

2. Bufferin 2

3. Exedrin 2

4. Tylenol 6

5. Darvon 5

6. Empirin 1

7. Anacin 4

8. BC Tablets 2

9. Talevin 1

10. Peritrate 2

11. Tandearil 1

12. Pyridium 1

13. Datril 1

14. Percodan 1

Group 3 - Stimulants and Anorectics

1. Diet Pill

2. Elavil

3. Digitalis

4. Nitroglycerin 
Group 3 - Stimulants and Anorectics

5. Didrex 1

6. Biphetamine 1

7. Winstrol 1

8. Appedrine Diet Pills 1

9.. Unknown Stimulant 1

Group 4 - Hormones and Steroids

1. Thyroid medication 1

Group 5 - Sedatives and Hypnotics

1. Phenaphen 1

2. Secona 1

3. Sominex 1

4. Dalmane 1

5. Tuinal 1

Group 6 - Anti-infective Agents - Antibiotics

$\begin{array}{ll}\text { 1. Penicillin } & 5 \\ \text { 2. Tetracycline } & 7 \\ \text { 3. Micrin } & 1 \\ \text { 4. Achromycin } & 1 \\ \text { 5. Antibiotic for tooth infection } & 1 \\ \text { 6. Antibiotic for } \\ \text { 7. Antibiotic shot } \\ \text { 8. Decongestant } & 1 \\ \text { 9. Desenex } & 3 \\ \text { 10. Ampicillin } & 1 \\ \text { 11. Iike Peniciliin } & 2 \\ \text { 12. Streptomyacin } & 1\end{array}$

Group 7 - Vitamins and Minerals

1. Multiple Vitamins 49

2. Calcium Tablets 1

3. Vitamin $\mathrm{C}$

4. Vitamin $E$. 8

5. Vitamin A 1

6. Vitamin $B_{12}$ Shot 3

7. The ragram - M 1

8. Geritol 1

9. Kelp (iodine) 2 
Group 7 - Vitamins and Minerals

10. Lecithin 1

11. Minerals 1

12. Vitamin $\mathrm{B}_{6} \quad 1$

13. Vitamin B 1

14. Sodium Fluoride 1

15. Selenium 1

Group 8 - Antidiabetics

1. Insulin 2

2. Lente Insulin 1

3. Orinase 1

4. Pills for Diabetes 6

5. Diabinese 3

Group 9-Antihistamines

1. Ornade 3

2. Contac 6

3. Actifed 1

4. Dristan 6

5. Allerest 2

6. Ornade Spansules 1

7. Nyquil 1

8. Sinutabs 2

9. Chlortrimeton 3

10. Sinus Tablets 8

11. Antihistamine 4

12. Coricidin 4

13. Coricidin II 1

14. Tuss Ornade 1

15. Sinarest 1

16. Benadryl 1

17. Dimetapp 1

18. Napril 1

19. Sinulin 1

20. Drixoral 1

Group 10 - Anticoagulants

1. Coumadin 1

2. Anticoagulant 2 
Group 11 - Analgesic Narcotics

1. Codeine 2

Group 12 - Anticholinergics

1. Donnatal 1

Group 13 - Diuretics and Uricosurics

1. Diuretics 7

2. Lasix 2

3. Ayazide 1

4. Hygroton 2

5. Hydrochlorithazide 1

6. Water Pill 1

Group 14 - Antiasthmatics

1. Tedral 1

2. Bronkotabs 1

3. Quibron 1

4. Asthma Spray 1

5. Asthma Medication 1

6. Norisodrine 1

7. Bronkometer 1

8. Sudafed 2

9. Marax 1

10. Bronchial Dilator 2

11. Bronchitis Medication 1

12. Lung Dialator 1

13. Primatine 1

Group 15 - Antiarthritics

1. Pill for Arthritis 2

Group 16 - Antispasmodics

1. Dilantin 3

2. Mysoline 1 


\section{Group 17 - Antacids and Intestina1 Absorbents}

1. Gelusil 2

2. Pepto Bismol 1

3. Alka-Seltzer 2

4. Medication for Hyperacidity 1

5. Rolaids 1

6. Maalox 4

7. Antacids 1

8. Alka-Seltzer Plus 4

9. Mylanta 1

10. Digel 1

11. Win Ge1 1

Group 20 - Marijuana

1. Pot - Marijuana 3

Group 24 - Miscellaneous

1. Atromid - S 1

2. Lomotil 1

3. Equagesic 1

4. Vicks 44

5. Sulfur 1

6. Lanoxin 1

7. Lenodopa 1

8. Quinamum 1

9. Apresoline 1

10. Vasodialator (Prevent hardening of arteries) 1

11. Be11-A1R - PB 非 60

12. Afrin Spray (decongestant) 1

13. Doan's Pills 1

14. Sinex (decongestant) 1

15. Sinade (decongestant) 2

16: Inderal 3

17. Isordill 2

Group 25 - Unknown

1. Allergy shots 2

2. Cold capsules 2

3. Eye drops 1

4. Blood thinner 1

5. Medication for ulcers 2 
Group 25 - Unknown

6. Hay fever medication 1

7. Nerve Pills 3

8. Unknown Drug 1

9. Cough Drops 1

10. Shot for Nerves 1

11. Medication for back pains Contains Codeine 1

12. Medication for Flu 1

13. Unknown drug for Arthrit1s 1

14. Unknown drug (antihistamine or Antibiotic) 1

15. Large pink Pill (Breathing) 1

16. White Water Pill 1

17. Nasal Spray : 1

18. Arnex : 1

19. Histavagrin 1

20. Idanmin 1

21. Endocine 1

22. Cough Medicine 1

23. Heart Pill 1

24. Pain $P 111$

25. Muscle Relaxant 6

26. High Blood Pressure Medication 32

27. Spec $T$

28. Dinatab Cap II 1

29. Pituitary Gland Supplement 1

30. Debid 1

31. Meltab 1

32. Agc Airet 1

33. Gout Pill 2

34. Dina Bold 1

35. Tembids 1

36. Kidney Medication (non- 1 perscription)

37. Chronotab 1

38. Glycerine 1

39. Kidney Medication 1 (perscription)

40. Calcium Glucamate 1

41. Cold Pill (Copavin) 1

42. Medicine for Chest Cold 1

43. ARM (allergy) 1

44. Headache Medication 1

(prescribed) 
Group 25 - Unknown

45. Prescription for Dry Mouth 1 and Lips

46. Low Blood Pressure Medication 1

47. Pill for High Cholestral 1

48. Pill for Bowels 1

49. Primazone 1

50. Phlebitis Medicine 1

51. Lexophlin (lung dialator) 1

52. Pills for Inner Ear Problem 1

(Dizziness) 


\section{APPENDIX I}

POSITIVE DRUG FINDINGS IN BLOOD SAMPLES BY LEVEL OF CONCENTRATION

$$
\text { I-1 }
$$


The statistical analysis of the fluid sample findings for the 43 drugs I1sted in Table 3 (see Section II, Part G), included only the findings confirmed by gas chromatography (GC) and quantitated at any level of concentration. The concentrations of the quantitated drugs, although available, were not utilized as parameters in the analysis. The decision to consider only one level of drug concentration stemed from the lack of universally acceptable criterla that could be used to partition the drug findings into different levels.

A number of factors complicate the formulation of a simple, but meaningful concentration level criteria. For a study such as the one reported herein, where multiple fluid specimens are examined for drugs, it is possible to detect a given drug in none, one or any combination of the samples collected from an individual. In addition, the concentration of the drug found can vary between fluid specimens. The drug detected and its concentration depend upon several conditions such as the drug taken, its dosage, and the time(s) between ingestion and the collection of the fluid samples. Also, the drug findings in one fluid can not be equated to the drug findings in a missing fluid sample. In other words, a urine sample can not be substituted for a missing bile sample or vice versa.

In a recent study on drug use among drivers, * a simple concentration level criterla was used in the analysis. Two concentration levels were used to divide the drug findings from drivers providing both a blood and urine sample. One level was the same as is used in this report. The second level used was more stringent in that it included only those drugs confirmed by $G C$ and quantitated in the blood (any concentration) and/or confirmed and quantitated in the urine (and/or bile for the fatally injured drivers) at concentrations of $1.0 \mu \mathrm{g} / \mathrm{ml}$ or greater. The second level of concentration was somewhat arbitrary, although it did conveniently split the overall drug findings into two approximately equal sized groups, which was a statistical advantage. The approach, like the one used herein, placed the drug findings on a common basis. That was, detections of a given.drug were accepted from either a blood or urine sample according to the criteria provided both fluid samples were available for analysis. The approach, however, had a shortcoming in that a common concentration division was used for each fluid sample for all quantitated drugs. For blood, the concentration division was set at "confirmed by GC" (trace or larger amount detected).

* Glauz, W. D. and R. R. Blackburn, "Drug Use Among Drivers," Contract No. DOT-HS-119-2-440 (MRI Project 3668-E) Midwest Research Institute Final Report, February 1975 (DOT HS-801411). 
A drug not-confirmed in the blood by GC was either not present or below the sensitivity limit of detection. The same criteria were used in this study.

It is not appropriate to speak of a common concentration division for all drugs if one is interested in determining an "under the influence" category from the drug findings. First, the blood findings alone should be used for this determination as dictated by pharmacological theory. Secondly, different concentration divisions should be acknowledged for individual drugs since their dosages, distribution and excretion vary.

Data from the literature were collected to establish three levels of concentration in the blood for each of the 43 drugs included in the quantitated drug screen. These levels are: therapeutic, toxic, and letha1. The concentration limits found for the three levels along with the sensitivity limit of the chemical analysis employed in this study are presented in Table I-1 for each of the 43 drugs.

Several facts are readily apparent from a comparison of the analytical sensitivity limit for each drug with the limits of the different concentration levels. The analytical procedures used to detect sedatives and hypnotics appear to be very reasonable in that the sensitivity limit of the screen is well below the lower limit of the therapeutic range. However, such is not the case for tranquilizers. Here the sensitivity limit for six of the eight tranquilizers considered is at or above the lower limit of the therapeutic range. Some of the tranquilizers investigated are suspected to be frequently used, but the sensitivity level precludes detections of most of the tranquilizers except at mid-to-high therapeutic levels. The sensitivity level for almost all the drugs in the stimulant and antidepressant group is above the therapeutic range. Likewise, the sensitivity limit for most of the drugs in the rest of the drug groups, except hallucinogens, is within the therapeutic range.

The above observations would suggest that the concentrations of drugs other than those in the sedative/hypnotic group and one or two tranquilizers would need to be in the mid to upper therapeutic range or larger before the drug could be detected in the blood. This was verifled by listing the positive drug findings in the blood for both the fatally infured and living drivers.

Table I-2 shows the positive drug findings in the 825 blood samples analyzed from the fatally injured drivers. Four concentration levels are presented: trace amounts, therapeutic, toxic, and lethal 
levels. Most of the findings are for drugs in the sedative/hypnotic and narcotic analgesics group and for two tranquilizers. About half of the detections are at the trace level. It is interesting to note that six of the fatally injured drivers had toxic levels of drugs in their system, while one driver had a lethal level of morphine.

Table I-3 shows the positive drug findings for the 817 blood samples analyzed from the living drivers. All the findings are for three drugs in the sedative/hypnotic group and one in the miscellaneous group. Most of these detections are at the trace level. One driver had a toxic level of phenobarbital in his system. 
TABLE I-1

LIMITS FOR THREE CONCENTRATION LEVELS OF DRUGS IN BLOOD

\section{Type of Drug}

Sedative and Eypootics

Phenobarbital (luminal)

Pentobarbital (Nembutal)

Amobarbltal (Amytal)

Secobarbltal (Seconal)

Butabarbital (Butisol)

Butobarbital (Butethal)

Dipheny lhydantoln (Dilantin)

Glucechimide (Doriden)

Methaqualone (Quaalude)

\section{Tranquillzers}

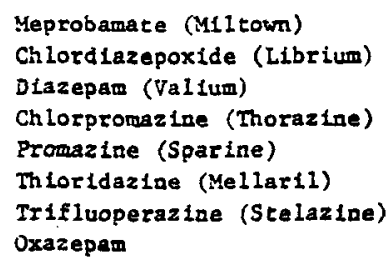

Stimulants and Antidepressants

Methylohenidate (Ritalin)

Imipramine (Tofranil)

Aaltriptyline (Elavil)

Amphetamine (Dexeditine)

Methamphetamine (Desoxya)

Ant1htstamines and Decongestants

Chlorpheniramine

Diphenhydramine

Tripe lennamine

Mechapyriline

Thenylpropanolamine

\section{Narcotic Analgestes}

Nalorphine (Nalilne)
Sorphine
Codelne
Meperldine (Demerol)
Cocalne
Methadone (Dolophine)
Hydromorphone (Dilaudid)
Propoxyphene (Darvon)

dalluctnogens

Dimethyltryptamine (DMT)

Diechyltrypeamlne (DET)

Mescaline

2,5-Dimethoxy-4-methy lamphetamine (STP)

\section{Miscellaneous}

Phend Lmetrazine

Procalne

Lobellne

Quinine
Chemical Analysis Sensitivity Limit (1) $/ \mathrm{m} 1)$

Therapeutic
Level
$(1 \mathrm{~g} / \mathrm{ml})$

Toxic

Level

( $\mathrm{gg} / \mathrm{ml})$

Leche I

Level

(Hg/m1)

$\begin{array}{llcr}0.25 & 8.0-20.0 & 40.0-60.0 & 80.0+ \\ 0.25 & 1.0-2.0 & 7.0-? & 10.0+ \\ 0.25 & 3.0-5.0 & 10.0-30.0 & 30.0+ \\ 0.25 & 1.0-2.0 & 7.0-? & 10.0+ \\ 0.25 & 5.0-8.0 & 10.0-30.0 & 30.0+ \\ 0.25 & 3.0-5.0 & 10.0-30.0 & 30.0+ \\ 0.50 & 2.0-20.0 & 50.0-? & 100.0+ \\ 1.00 & 3.0-10.0 & 10.0-80.0 & 80.0+ \\ 0.25 & 1.0-5.0 & 10.0-30.0 & 30.0+\end{array}$

1.00

1.00

0.50

0.50

0.50

0.50

0.50

1.00

4.00

0.25

0.25

0.25

2.00

0.50

0.50

0.50

0.50

0.50

0.50

0.25

0.25

0.25

0.50

0.25

0.25

0.25

0.50

0.50

0.50

0.50
5. $0-10.0$

1. 0-3.0

$0.2-2.5$

$0.5-0.9$

0.5-0.9

$1.0-1.5$

$0.2-1.9$

$0.5-$ ?

$\begin{array}{cc}100.0-? & 200.0+ \\ 5.0-? & 20.0+ \\ 5.0-? & 20.0+ \\ 1.0-2.0 & 3.0+ \\ 1.0-2.0 & 3.0+ \\ 10.0-? & 20.0+ \\ 2.0-? & \text { NA } \\ \text { WA } & \text { NA }\end{array}$

II

$0.7-$ ?

$0.4-$ ?

$\begin{array}{llr}0.02-0.03 & 0.5-? & 2.0+ \\ 0.03-? & 5.0-? & 40.0+\end{array}$

$\begin{array}{llr}0.02-0.03 & 0.5-? & 2.0+ \\ 0.03-? & 5.0-? & 40.0+\end{array}$

$2.0 \div$

10.04

$\begin{array}{llr}0.02-0.03 & 0.5-? & 2.0+ \\ 0.03-? & 5.0-? & 40.0+\end{array}$

$\overline{\text { A }}=$ Not Avallable.

2.00

0.50

0.50

0.25
$0.02-$ ?

$0.1-$ ?

$0.1-$ ?

$0.1-$ ?

$0.1-$ ?

NA

$0.05=$ ?

$0.03-$ ?

$0.3-0.6$

NA

$0.1-0.8$

. $0.01-?$

$0.05-0.20$
20.0-30.0 30.04

10.0-? $\quad 10.0+$

10.0-? 10.04

iA $1.2+$

$\mathrm{NA}-\mathrm{NA}$
0.05-?

$0.10-$ ?

$0.20-$ ?

$1.00-?$

$\begin{array}{lr}\text { NA } & \text { NA } \\ \text { NA } & 4.0+ \\ \text { NA } & \text { NA } \\ 5.0-? & 30.0+ \\ \text { NA } & 1.0+ \\ \text { NA } & 4.0+ \\ \text { NA } & 0.1+ \\ 5.0-20.0 & 50.0+\end{array}$

$\begin{array}{ll}\text { NA } & \text { NA } \\ \text { NA } & \text { NA } \\ \text { NA } & \text { NA }\end{array}$

$\begin{array}{ll}N A & \text { NA } \\ N A & \text { NA } \\ N A & N A \\ N A & 12.0 ? \cdot\end{array}$


TABLE I-2

POSITIVE DRUG FINDINGS BY CONCENTRATION LEVEL IN 825 FATALLY INJURED DRIVER BLOOD SAMPLES

Type of Drug

Concentration Leve1

Trace* Therapeutic: Toxic Lethal

Sedatives and Hypnotics

Phenobarbital (Lumina1)

Pentobarbital (Nembutal)

Amobarbital (Amytal)

Secobarbital (Secona1)

Diphenylhydantoin (Dilantin)

Methaqualone (Quaalude)

Tranquilizers

Meprobamate (Miltown)

Chlorpromazine (Thorazine)

Stimulants and Antidepressants

Amitriptyline (Elavil)

Amphetamine (Dexedrine)

Antihistamines and Decongestants

Ch lorpheniramine

Diphenhydramine

Narcotic Analgesics

Morphine

Codeine

Miscellaneous

Quinine

Totals
14

1

6

0

1

0

1

1

0

0

5
4
0
1
1
4

0

1

0

0

0

1 
TABLE I-3

POSITIVE DRUG FINDINGS BY CONCENTRATION LEVEL IN 817

LIVING DRIVER BLOOD SAMPLES

Type of Drug

Sedatives and Hypnotics

Phenobarbital (Luminal)

Butabarbital (Butisol)

Dipheny lhydanto in (Dilantin)
10

1

0

Concentration Level

Trace* Therapeutic Toxic Lethal

\section{Misce1laneous}

Quinine

Totals $\underline{0}$

11
1

0

1
1

$0 \quad 0$

* A trace concentration level here is defined for each specific drug. It is an amount either found at the quantifiable level (sensitivity limit) or found at a quantitated level below the accepted therapeutic level. 


\section{APPENDIX $\mathrm{J}$}

STATISTICAL EQUATIONS EMPLOYED 
A majority of the data analyses conducted in the study dealt with the production of the drug incidence or proportion estimates from the living and dead driver data and ratio (relative risk) estimates from the combination of both sets of data. The equations used to generate these estimates are described in this Appendix.

The data structure is similar for both living and dead driver data sets, in that they can be described in a stratified cluster framework. Living driver data are clustered around sites where driver fatalities have occurred; fatally injured driver data are clustered around the 24 submission areas. Two strata were examined: location (Memphis or Dallas), and drug involvement (yes or no). The responses considered were the proportions of positive drug incidences.

Within stratum $h$, the (living or dead driver) proportion estimate and its variance are given by: *

$$
\begin{gathered}
P_{h}=\sum_{i=1}^{n_{h}} a_{i h} / \sum_{i=1}^{n_{h}} m_{i h} \\
v_{\left(p_{h}\right)}=\frac{1}{n_{h} \bar{m}_{h}^{2}} \frac{\sum_{i=1}^{n_{h}} a_{i h}^{2}-2 p_{h} \sum_{i=1}^{n_{h}} a_{i h} m_{i h}+p_{h}{ }^{2} \sum_{i=1}^{n_{h}} m_{i h}^{2}}{n_{h}-1}
\end{gathered}
$$

where

$$
\begin{aligned}
p_{h} & =\text { survey proportion (in stratum } h \text { ) } \\
a_{i h} & =\text { number of positives in } i^{\text {th }} \text { cluster (in stratum } h \text { ) } \\
m_{i h} & =\text { number of samples in } i^{\text {th }} \text { cluster (in stratum } h \text { ) } \\
n_{h} & =\text { number of clusters (in stratum } h \text { ) } \\
\bar{m}_{h} & =\text { average cluster size (in stratum } h) .
\end{aligned}
$$

The $\mathrm{P}_{\mathrm{h}}$ 's must be added over all strata resulting in the overall estimate given by: **

$$
\mathrm{P}=\sum_{\mathrm{h}=1}^{\mathrm{L}} \mathrm{W}_{\mathrm{h}} \mathrm{P}_{\mathrm{h}}
$$

* Cochran, W. G., Sampling Techniques, John Wiley and Sons, Inc. (1963). ** Cochran, W. G., Sampling Techniques, John Wiley and Sons, Inc., Chapter 5 (1963). 


$$
V_{(p)}=\frac{\sum_{h=1}^{L} W_{h}^{2} p_{h}\left(1-p_{h}\right)}{n_{h}}
$$

where $W_{h}$ is the $h^{\text {th }}$ stratum size; i.e., ratio of number of units of $h^{\text {th }}$ stratum to number of units in the population.

In addition to investigating the incidence of drug use among living and dead drivers, it was also of interest to produce the relative risk quantity $R=p_{D} / p_{L}$ (where $p_{D}$ and $p_{L}$ refer to incidence proportions among dead and living drivers, respectively). These quantities have variances given by:*

$$
\mathrm{V}(\mathrm{R}) \cong \frac{\mathrm{R}^{2}}{\mathrm{n}}\left[\frac{\mathrm{V}\left(\mathrm{p}_{\mathrm{L}}\right)}{\mathrm{P}_{\mathrm{L}}^{2}}+\frac{\mathrm{V}\left(\mathrm{P}_{\mathrm{D}}\right)}{\mathrm{p}_{\mathrm{D}}^{2}}-\frac{2 \mathrm{CV}\left(\mathrm{p}_{\mathrm{L}} \mathrm{P}_{\mathrm{D}}\right)}{\mathrm{P}_{\mathrm{L}} \mathrm{P}_{\mathrm{D}}}\right]
$$

where $\quad \operatorname{CV}\left(\mathrm{p}_{\mathrm{L}} \mathrm{p}_{\mathrm{D}}\right)=\left[\mathrm{V}\left(\mathrm{P}_{\mathrm{L}}\right) \mathrm{V}\left(\mathrm{P}_{\mathrm{D}}\right)\right]^{1 / 2} \times$ the correlation between $\mathrm{P}_{\mathrm{L}}$ and $\mathrm{P}_{\mathrm{D}}$.

* Cochran, W. G., Sampling Techniques, John wiley and Sons, Inc., Chapter 6 (1963). 
APPENDIX K

DETAILED ALCOHOL FINDINGS FOR DALLAS AND MEMPHIS SITES USED IN THE SURVEYS

$$
\mathrm{K}-1
$$


rase $x-1$

9ITE-OY-SIIE RESUI.TS FOR MIIAS, IEXAS

\begin{tabular}{|c|c|c|c|c|c|c|c|c|c|c|c|c|c|c|c|c|}
\hline & \multirow[b]{2}{*}{$\begin{array}{l}\text { Site } \\
\text { Pentiber }\end{array}$} & \multirow[b]{2}{*}{$\begin{array}{l}\text { Survey } \\
\text { Number }\end{array}$} & \multirow{2}{*}{$\begin{array}{l}\text { 8ex of } \\
\text { ratality } \\
\text { Injured } \\
\text { Driyer }\end{array}$} & \multirow{2}{*}{$\begin{array}{c}\text { KIt } \\
\text { Muaber } \\
\text { of } \\
\text { yetele }\end{array}$} & \multirow[b]{2}{*}{ Locec1on } & \multirow{2}{*}{$\begin{array}{c}\text { Date } \\
\text { of } \\
\text { Survoy }\end{array}$} & \multirow{2}{*}{$\begin{array}{l}\text { Day } \\
\text { of Neek } \\
\text { of Survey }\end{array}$} & \multirow{2}{*}{ IIIterve! of Survey } & \multirow{2}{*}{$\begin{array}{l}\text { Mumber } \\
\text { Drivaro } \\
\text { glopped }\end{array}$} & \multirow{2}{*}{$\begin{array}{l}\text { Number } \\
\text { Accepting } \\
\text { Inrervieu }\end{array}$} & \multirow[b]{2}{*}{$\begin{array}{l}\text { Muber } \\
\text { anc'e }\end{array}$} & \multicolumn{4}{|c|}{ MC Level } & \multirow[b]{2}{*}{$\underline{0.19 t}$} \\
\hline & & & & & & & & & & & & 으 & $\begin{array}{l}0.01- \\
0.04\end{array}$ & $\begin{array}{l}0.05- \\
0.09 \\
\end{array}$ & $\begin{array}{l}0.10- \\
0.14 \\
\end{array}$ & \\
\hline & 17 & I & Hale & 992 & $\begin{array}{l}\text { Colorede Doulevard and Jetfereon } \\
\text { Boulevard }\end{array}$ & $5-30-75$ & Friday & 1: 30 AH - 3:30 A4 & 7 & 3 & 4 & 3 & 0 & - & - & $\mathbf{I}$ \\
\hline & 18 & 1 & Malo & 890 & EO 3500 W. Camp WIOdom Rond & $6-4-75$ & Niuraday & 0:30 PM - 10:30 m & 14 & 10 & 10 & 10 & - & $\mathbf{0}$ & o & 0 \\
\hline & $\begin{array}{l}19 \\
20\end{array}$ & 1 & $\begin{array}{l}\text { Mule } \\
\text { Male }\end{array}$ & $\begin{array}{l}893 \\
827\end{array}$ & $\begin{array}{l}\text { St. Frencle and San Loendro } \\
\text { l-20 and Berry Avenwe }\end{array}$ & $\begin{array}{l}5-30-75 \\
5-31-75\end{array}$ & $\begin{array}{l}\text { Frlday } \\
\text { Seturday }\end{array}$ & $\begin{array}{l}\text { 11:30 PH- 1:30 AM } \\
9: 00 \mathrm{HH}-11: 00 \mathrm{IMH}\end{array}$ & 10 & 8 & ? & 4 & 2 & 1 & i & $\begin{array}{l}0 \\
i\end{array}$ \\
\hline & 21 & i & Male & 029 & $\begin{array}{l}\text { R. L. Mhornton Freaway and } \\
\text { Horsealle Street }\end{array}$ & $6-1-75$ & Sunday & $11: 00 \mathrm{mH}-1: 00 \mathrm{AH}$ & 13 & 10 & 10 & 7 & 2 & 1 & 0 & 0 \\
\hline & 22 & I & Male & 578 & 800 s. Maltiton Walker Bouleverd & $6-2-75$ & Monday & $9: 00 \mathrm{MM}-11: 00 \mathrm{PM}$ & 17 & 11 & 11 & - & 2 & I & o & $\mathbf{0}$ \\
\hline & 24 & $\mathbf{I}$ & Male & 270 & 9900 Bruton Roed & $6-4-75$ & Wednesday & $1: 30 \mathrm{AH}-3.30 \mathrm{AH}$ & 12 & 9 & 9 & - & $\mathbf{1}$ & $\mathbf{0}$ & 0 & $\mathbf{0}$ \\
\hline & 25 & I & Male 10 & 268 & st. Lowls and Harwood streate & $6-4-75$ & Tliuruday & $11: 30 \mathrm{mM}-1: 30 \mathrm{AM}$ & - & 4 & 4 & 2 & 2 & o & D & 1 \\
\hline & 26 & $\mathbf{I}$ & Male & 375 & 5637 Hilltery Porkway & $6-1-75$ & Sunday & 2:00 PH - 4:00 PM & 6 & 6 & 6 & 2 & 2 & I & 0 & 1 \\
\hline & 27 & $\mathbf{I}$ & Fuanle & 948 & 2325 Greonvllle Avenue & $5-31-75$ & Saturday & 1:30 AH $-9: 30 \mathrm{AH}$ & 17 & 9 & 9 & 9 & - & $\mathbf{0}$ & D & 0 \\
\hline & 28 & 1 & Malo & 951 & 9300 Block llaxry litinea Doulovard & $6-2-75$ & Monduy & $1: 30 \mathrm{AH}-3: 30 \mathrm{AH}$ & $\boldsymbol{7}$ & s & 5 & o & 3 & I & 1 & 0. \\
\hline \multirow[t]{12}{*}{ is } & 29 & 1 & male & 978 & 2500 Block W. Beckley Avenue & $6-1-73$ & Sundey & $6: 00 \mathrm{AH}-8: 00 \mathrm{AH}$ & 13 & 10 & 10 & 7 & I & 2 & 0 & $\begin{array}{l}0 \\
0\end{array}$ \\
\hline & 30 & 2 & Malo & 1004 & $\begin{array}{l}\text { Walton Walker and Mortinuest } \\
\text { III ghway }\end{array}$ & $7-26-75$ & sacurdey. & $12: 30 \mathrm{mH}-2: 30 \mathrm{mt}$ & 7 & 7 & 7 & 2 & 2 & I & 2 & 0 \\
\hline & 32 & 2 & melo & 945 & $\begin{array}{l}13910 \mathrm{~N} \text {. Cantral Expresawey - } \\
\text { Ex1L } 23\end{array}$ & $7-26-75$ & Satcurday & 4:00 PM - 6:00 PM & 11 & 6 & 6 & 2 & 8 & 1 & 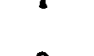 & \\
\hline & 33 & $\begin{array}{l}2 \\
2\end{array}$ & Mole & 975 & 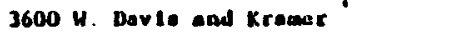 & $7-28-75$ & Hondey & $9: 30 \mathrm{AH}-11: 30 \mathrm{AM}$ & 10 & 7 & 7 & 6 & 1 & $\mathbf{0}$ & D & $\begin{array}{l}0 \\
0\end{array}$ \\
\hline & 35 & 2 & $\begin{array}{l}\text { Male } \\
\text { Hallo }\end{array}$ & - & 2700 s. Heetcoorse Averuue & $7-27-75$ & Sunduy & 2:00 PM - 4:00 PM & a & - & 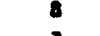 & 5 & 2 & 1 & 0 & : \\
\hline & 36 & 2 & $\begin{array}{l}\text { Manlo } \\
\text { Male }\end{array}$ & $\begin{array}{l}947 \\
639\end{array}$ & $\begin{array}{l}\text { Codar Creat and Itth } \\
\text { Canty and Horth Tyler }\end{array}$ & $\begin{array}{l}0-2-75 \\
7-2 i-75\end{array}$ & $\begin{array}{l}\text { Seturdey } \\
\text { Sunday }\end{array}$ & $\begin{array}{l}12: 10 \mathrm{AH}-2: 30 \mathrm{AM} \\
1: 00 \mathrm{PH}-3: 00 \mathrm{MH}\end{array}$ & $?$ & 8 & $\begin{array}{l}7 \\
6\end{array}$ & 3 & $\begin{array}{l}3 \\
2\end{array}$ & 2 & $\begin{array}{l}0 \\
0\end{array}$ & 0 \\
\hline & 37 & 2 & Male & 1002 & $\begin{array}{l}\text { Luwuvlew Avenus and R. L. } \\
\text { Thornton Freeway }\end{array}$ & $7-25-73$ & Erldey & 6:00 PH $-8: 00 \mathrm{PH}$ & 11 & 8 & 8 & $?$ & $i$ & 0 & 0 & 0 \\
\hline & 38 & 2 & Hoto & 1084 & 231 H. Merselle Avonus & $1-24-75$ & Thurgday & 2:00 PM - 4:00 PM & 9 & 9 & 9 & 7 & 2 & o & D & 0 \\
\hline & 39 & 2 & Male & 1088 & 6825 S. Conltal Expreonuay & $7-26-75$ & Saturday & $8: 30 \mathrm{AH}-10: 30 \mathrm{AH}$ & B & - & - & 4 & 3 & I & o & a \\
\hline & 40 & 2 & Malo & 1087 & $\begin{array}{l}\text { Clerence and S. Ceatrol } \\
\text { Expreseusay }\end{array}$ & $7-28-75$ & thonday & $6: 30 \mathrm{FM}-8: 30 \mathrm{PM}$ & 9 & 7 & 7 & 7 & a & 0 & o & $\mathbf{0}$ \\
\hline & 41 & 2 & male & 952 & 2745 Heat Northwoat Iliglway & $8-1-75$ & Frtduy & $12: 90 \mathrm{AH}-2: 30 \mathrm{AH}$ & 6 & 6 & 5 & 2 & 2 & 0 & 1 & o \\
\hline & 42 & 2 & Hale & 1089 & $\begin{array}{l}4616 \text { H. Uni veralty end Ropor } \\
\text { Screet }\end{array}$ & $0-1-7.5$ & Erldey & $1: 00 \mathrm{HH}-9: 00 \mathrm{HH}$ & 7 & 4 & 3 & 2 & 1 & 0 & 0 & 0 \\
\hline & 43 & 3 & Mule & 950 & $\begin{array}{l}\text { Brutan Mued and st. Auguetinn } \\
\text { Drtve }\end{array}$ & $9-19-73$ & Friduy & 11:00 IH - 1:00 AM & 9 & 9 & 7 & 4 & 2 & 0 & 1 & o \\
\hline - & $\begin{array}{l}44 \\
45\end{array}$ & 3 & $\begin{array}{l}\text { Male } \\
\text { Male }\end{array}$ & $\begin{array}{r}943 \\
0013\end{array}$ & $\begin{array}{l}\text { Meloullan and Croeswous } \\
\text { Pacif lc Avenue and Paerl }\end{array}$ & $\begin{array}{l}9-25-75 \\
9-21-75\end{array}$ & $\begin{array}{l}\text { Thureday } \\
\text { Sunday }\end{array}$ & $\begin{array}{l}3: 00 \mathrm{PH}-1: 00 \mathrm{~mm} \\
11: 30 \mathrm{mH}-1: 30 \mathrm{AH}\end{array}$ & 7 & 7 & 1 & $\begin{array}{l}7 \\
6\end{array}$ & i & i & $\begin{array}{l}0 \\
0\end{array}$ & $\begin{array}{l}0 \\
0\end{array}$ \\
\hline
\end{tabular}




\begin{tabular}{|c|c|c|c|c|}
\hline $\begin{array}{l}\text { Sitte } \\
\text { Nimber }\end{array}$ & $\begin{array}{l}\text { Survey } \\
\text { Humber }\end{array}$ & $\begin{array}{l}\text { Sex of } \\
\text { latelly } \\
\text { Injured } \\
\text { Delver }\end{array}$ & $\begin{array}{c}\text { Kit } \\
\text { Mumber } \\
\text { of } \\
\text { Yictis }\end{array}$ & Lecacton \\
\hline 47 & $\mathbf{3}$ & Male & . & $\begin{array}{l}\text { Leke Highlend and Country Club } \\
\text { Drive }\end{array}$ \\
\hline 40 & 3 & $\operatorname{Pen} 1$. & - & 3100 L.edbettar \\
\hline 50 & 3 & Male & - & Opere end Marealls, Avellue \\
\hline si & 3 & Male & - & Rickover and Creatll sio Avenua \\
\hline 52 & 3 & Male & 1181 & W. Davla and Dagley \\
\hline 53 & 4 & Male & - & Lennvlew Park oud Scyeno Rand \\
\hline$\$ 4$ & 4 & Male & 1183 & I-20 RMAp EO from Buckner BIvd \\
\hline 35 & 4 & Male & 1180 & Ceder SprIngs end Inuoud Roed \\
\hline 56 & 4 & Male & - & 3195 Loop 12 \\
\hline 57 & 4 & Pemante & 1189 & 9325 Carpeuter Preeway \\
\hline 59 & 4 & Fomin 10 & 1179 & $\begin{array}{l}3400 \text { Slmpson stuart hoed and } \\
\text { Bunule V lew Ruad }\end{array}$ \\
\hline 60 & 5 & Male & 942 & Lene Freeway Ramp end loop 12 \\
\hline 61 & 5 & Male & - & 6575 c. F. Hawn Freeuay. \\
\hline 62 & 3 & Fomele & - & Tyree sereat ond beamon Avenue \\
\hline 63 & 5 & Male & - & 7200 พ. Morthweac III glway \\
\hline 64 & 5 & Famale & - & 1500 \&. Xlese Bowlovard \\
\hline 66 & $\mathbf{5}$ & Male & - & O700 s. Central Exprasaway \\
\hline 67 & 6 & Mala & - & 5400 Second Avesucet \\
\hline 68 & 6 & Male & - & 4404 Idalio Avenute \\
\hline 69 & 6 & Malo & 1343 & 2451 H. Stempune Preevay \\
\hline 20 & 6 & Male & 1342 & 1900 ook lown end Alamo street \\
\hline$\pi$ & 6 & Male & 1346 & 2500 Jolin Heat Roed \\
\hline 73 & 6 & Maso & - & D300 M. Hest woreland \\
\hline 75 & 7 & Male & 1323 & Klest and Southernlassd \\
\hline 76 & $\boldsymbol{\gamma}$ & Heste & 1374 & Elam Roed - Enet of Hastere \\
\hline ra & 7 & Mela & 1364 & Murduck Roed and Palrport \\
\hline 79 & 1 & Mạto & 1386 & Deckley and Greanbrier \\
\hline 80 & 8 & Veman ie & 1360 & Foreat Lane and Jakshitre Drive \\
\hline 81 & - 1 & Hale & 1361 & W. Duckuer and Edgelakd \\
\hline 84 & 9 & Male & 1410 & 9000 Perguson \\
\hline 85 & 9 & Hale & 1414 & $\begin{array}{l}\text { Richardson and S. Coulral } \\
\text { Expresumay }\end{array}$ \\
\hline 8) & 9 & Pemale & 1411 & Jon s. Clift street \\
\hline 88 & 9 & Femele & .1413 & 7010 Bruton Rosed \\
\hline 69 & 9 & Pomale & 1406 & 10700 fordet Lane \\
\hline 90 & 9 & Fom to & 1405 & 2800 seyenes koad \\
\hline 92 & 10 & prole & 1427 & 4200 Irving \\
\hline
\end{tabular}

TABE X-1 (Contlnued)

\begin{tabular}{|c|c|c|c|c|c|c|c|c|c|c|}
\hline & Day & & & Nuaber & & & $M C$ & Level & & \\
\hline $\begin{array}{c}\text { of } \\
\text { Survey } \\
\end{array}$ & $\begin{array}{l}\text { of Week } \\
\text { of Survey }\end{array}$ & $\begin{array}{l}\text { Tlme } \\
\text { Interval of Surver }\end{array}$ & $\begin{array}{l}\text { Drivere } \\
\text { Scopped }\end{array}$ & $\begin{array}{l}\text { Accepting } \\
\text { Interviey }\end{array}$ & $\begin{array}{l}\text { Munber } \\
\text { BAC'el }\end{array}$ & 2 & $\begin{array}{l}0.01- \\
0.04\end{array}$ & $\begin{array}{l}0.05- \\
0.09 \\
\end{array}$ & $\begin{array}{l}0.10- \\
0.14 \\
\end{array}$ & 0.15 \\
\hline $21-75$ & Sundey & 5:30 PM - 7:30 PH & 9 & 9 & 9 & 3 & 3 & 1 & 0 & $\mathbf{0}$ \\
\hline $26-75$ & Fridey & 8; 30 AM - 10:30 AM & 11 & 11 & 10 & 9 & 1 & $\mathbf{0}$ & 0 & 0 \\
\hline $9-25-75$ & Thureday & $11: 00 \mathrm{PH}-1: 00 \mathrm{AH}$ & 9 & 9 & 9 & 8 & 1 & o & o & 0 \\
\hline $9-26-75$ & Priday & 1:00 m - 3:00 PH & 8 & - & 8 & a & $\mathbf{0}$ & 0 & $\mathbf{0}$ & 0 \\
\hline $9-21-75$ & Sunday & 8:30 PH $-10: 30 \mathrm{FH}$ & 9 & 9 & 7 & 2 & 1 & 2 & I & $\mathbf{I}$ \\
\hline $11-7-75$ & Friday & $11: 30 \mathrm{PM}-1: 30 \mathrm{AH}$ & 10 & 9 & 9 & s & 2 & 1 & $\mathbf{0}$ & I \\
\hline $11-10-75$ & Monday & $6: 30 \mathrm{FM}-\mathrm{8:30} \mathrm{kM}$ & 10 & 10 & 10 & 20 & o & 0 & o & $\mathbf{0}$ \\
\hline $11-6-75$ & Theuraday & 9:30 PM $-11: 30 \mathrm{PH}$ & 10 & 10 & 10 & 5 & 3 & 2 & o & $\mathbf{0}$ \\
\hline $11-6-75$ & Thursuay & 1:00 AM - 9:00 AM & 10 & 10 & 10 & a & $\mathbf{0}$ & 1 & 1 & o \\
\hline $11-11-75$ & Tucsuday & $12: 30 \mathrm{AH}-2: 30 \mathrm{AH}$ & 9 & 9 & B & 4 & 1 & 3 & o & \\
\hline $11-11-75$ & Tuesuay & $11: 30 \mathrm{AM}-1: 30 \mathrm{mH}$ & 11 & 11 & 10 & 9 & 1 & a & 0 & 0 \\
\hline $12-19-75$ & Friday & $10: 30 \mathrm{PH}-1: 00 \mathrm{AH}$ & 12 & 12 & 8 & 4 & 2 & I & 1 & 0 \\
\hline $12-16-75$ & Tuesuny & $11: 00 \mathrm{PM}-1: 30 \mathrm{AM}$ & 10 & 10 & 10 & 6 & 1 & 2 & 1 & o \\
\hline $12-19-75$ & Frlduy & 1:00 FM - 3:30 I'M & 14 & 13 & 14 & 0 & s & a & 1 & 0 \\
\hline $12-22-75$ & Monday & 4:30 PH $-1: 00 \mathrm{MHI}$ & 12 & 12 & 12 & 11 & o & 1 & $\mathbf{0}$ & 0 \\
\hline $12-17-75$ & Wednesday & $12: 00 \mathrm{PM}-2: 30 \mathrm{PM}$ & 13 & 13 & 13 & 13 & $\mathbf{0}$ & a & $\mathbf{0}$ & 0 \\
\hline $12-18-75$ & nouraday & 5:30 PM $-8 ; 00 \mathrm{PM}$ & 12 & 12 & 11 & 8 & 2 & 1 & $\mathbf{0}$ & o \\
\hline $1-20-76$ & Tuevilay & $12: 00 \mathrm{IM}-2: 10 \mathrm{MM}$ & 13 & 13 & 12 & 9 & $\mathbf{3}$ & o & $\mathbf{0}$ & o \\
\hline $1-23-76$ & retuday & 4:30 m- 7:00 l'M & a & 1 & o & 6 & $\mathbf{0}$ & 2 & $\mathbf{0}$ & $\mathbf{0}$ \\
\hline $1-21-76$ & Nedneadey & 1:30 $\mathrm{FH}-4,00 \mathrm{HH}$ & 13 & 12 & 9 & J & $\mathbf{0}$ & 1 & $\mathbf{0}$ & 1 \\
\hline $1-28-76$ & Hedioceaday & 1:30 PH $-4: 00$ PH & II & 11 & 11 & ? & 3 & 1 & 0 & 0 \\
\hline $1-21-76$ & Woducaday & $5: 00 \mathrm{mH}-7: 30 \mathrm{~mm}$ & 13 & 13 & 11 & - & 2 & $t$ & o & 0 \\
\hline $1-24-76$ & Salurday & 12:00 AM $-2: 30 \mathrm{AH}$ & 9 & 9 & 9 & 3 & 1 & 2 & 1 & $\mathbf{0}$ \\
\hline $3-15-76$ & Munday & $11: 00 \mathrm{AM}-1: 30 \mathrm{AM}$ & 12 & 12 & 12 & 9 & 2 & 1 & - & $\mathbf{0}$ \\
\hline $3-1]-76$ & Saturday & 7:00 AH - 9:30 AM & 14 & 12 & 12 & 8 & 3 & 1 & 0 & 0 \\
\hline $3-13-76$ & Sacurday & $8: 00 \mathrm{rH}-10: 30 \mathrm{~mm}$ & 15 & 14 & 12 & $?$ & 3 & o & 1 & 1 \\
\hline $3-13-76$ & Heduouday & B:00 AM $-10: 30$ AM & 12 & 12 & 12 & 7 & 5 & $\mathbf{0}$ & 0 & o \\
\hline $4-26-16$ & Hunday & 10:00 AH - 12:30 AH & 11 & 11 & 11 & 11 & 0 & $\mathbf{0}$ & 0 & 0 \\
\hline $4-29-76$ & Thursday & 12:00 AM $-2: 30 \mathrm{AM}$ & $\mathbf{1 1}$ & 11 & $\mathbf{u}$ & 5 & 5 & I & 0 & 0 \\
\hline $6-11-76$ & Priday & 10:30 PH - 1:30 AM & 9 & 9 & 9 & 7 & 2 & $\mathbf{0}$ & 0 & $\mathbf{0}$ \\
\hline $6-15-76$ & Tole eday & $12: 30 \mathrm{PH}-3: 00 \mathrm{PM}$ & 11 & 11 & 10 & 9 & 1 & 0 & $\mathbf{0}$ & 0 \\
\hline $6-12-76$ & Sacturilay & $4: 00 \mathrm{lH}-6: 30 \mathrm{~lm}$ & 8 & 7 & 8 & 4 & $\mathbf{3}$ & $\mathbf{0}$ & - & $\mathrm{I}$ \\
\hline $6-18-76$ & Priduy & 11:00 IH - 1:30 AM & 8 & $\theta$ & 7 & 3 & 4 & o & 0 & $\mathbf{0}$ \\
\hline $6-13-76$ & Sunday & $12: 30$ AH - 3:00 AM & 10 & 10 & 9 & 4 & 5 & o & o & $\mathbf{0}$ \\
\hline $6-18-76$ & Friday & 4:00 PH - 6:30 PH & 10 & 10 & 9 & 5 & 3 & n & 0 & I \\
\hline$-7-76$ & Saturday & 1:30 AM-4:00 AM & 12 & 11 & 10 & 6 & $t$ & 2 & -1 & 0 \\
\hline
\end{tabular}


Sex of Rit

Fetally Munber

stte Survay Injured of

thmber tumber Driver victle

\section{Locakion}

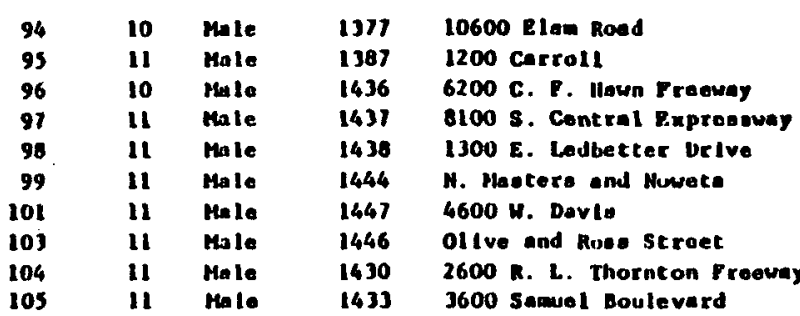

Totel
TAEIE K-1 (Concl udad)
Date Day
TImo
Number Number
Delvere Acceptlog Mumber $0.01-0.05-0.10$

Survey of Surver Interval of Survey Stopped Intorvten oAc'. 0 0.04. 0.09 0.14 0.15+

-6-76 Friday 10:00 PM - 12:30 AM

9-9-76 Thuraday

$10: 00 \mathrm{PM}-12: 30 \mathrm{AM}$
$12: 30 \mathrm{PM}-3 ; 00 \mathrm{PH}$

$12: 30 \mathrm{FH}-3: 00 \mathrm{PH}$

8:00 PH - 10:30 $\mathrm{mm}$

9-10-36 Friday

9-7-16 Tueaday 2:30 PHI - 5:00 $\mathrm{mH}$

9-12-76 Sunday 12:30 AM - 3:00 AH

9-12-76 Sunday 12:30 PH - 3:00 im

9-9-16 Tliursidar 1:00 AH - 9:30 AM

$9-12-16$ Sumlay $0: 00 \mathrm{AH}-10: 30 \mathrm{AH}$

9-12-76 Sumlay
9-13-16 Monday

$\begin{array}{rr}12 & 10 \\ 11 & 11 \\ 10 & 9 \\ 11 & 11 \\ 11 & 10 \\ 9 & 9 \\ 11 & 11 \\ 11 & 11 \\ 13 & 12 \\ 11 & 10 \\ 159 & 681\end{array}$

$\begin{array}{rrr}11 & 7 & 3 \\ 11 & 6 & 4 \\ 8 & 5 & 1 \\ 10 & 7 & 1 \\ 10 & 4 & 3 \\ 9 & 3 & 3 \\ 11 & 5 & 3 \\ 11 & 5 & 5 \\ 12 & 9 & 3 \\ 11 & 6 & 2 \\ 660 & 4 & 136\end{array}$

$660 \quad 440 \quad 136$

$\begin{array}{lll}1 & 0 & 0 \\ 0 & 0 & 1 \\ 2 & 0 & 0 \\ 2 & 0 & 0 \\ 3 & 0 & 0 \\ 2 & 1 & 0 \\ 0 & 0 & 0 \\ 0 & 1 & 0 \\ 0 & 0 & 0 \\ 1 & 2 & 0 \\ 33 & 20 & 11\end{array}$


TANLE K-2

SITE-BY-SITE RESULTS FOR HEMPHIS. TEMHESSEE

Sex of Kit
racality number slte Survey infured of Number Mugber Delver Yictio

1
2
3
4
5
6
7
8
9
10
12
11
14
15
16
11
18
19
20
21
22
23
24
25
26
21
28
31
32
33
34
35

rotel

Female 1357

$\begin{array}{ll}\text { Male } 1355 \\ \text { Malo } & 1354\end{array}$

$\begin{array}{ll}\text { Male } & 1354 \\ \text { Mole } & 1359\end{array}$

Female 1350

Malo 1356

Malo 1358

Femile 1401

Male 1399

Male 1391

Male 1392

Female 1397

Male $\quad 1419$

Male 1417

Malo

Male

Malo.

1415
1424
1416

1420

Dete Day Tumber Number

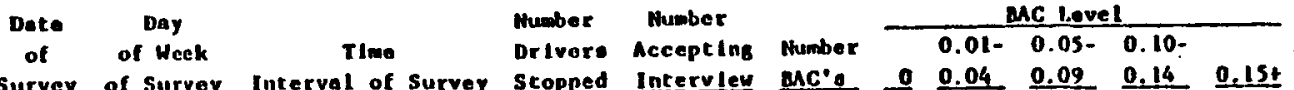

Location

Soutls Perkmay and Cummlings Deadrick - East or rendal

Dall Rond end Manchicater

Macon Roed and I-40

Jrd and Mallory - SD

H. Thuene end Hetkina

MIII Branch and HInclieator

Male 1221 4th street South of Foorg to
Hole
Male

Male 1221 4th street South of coorg
Hole
Male

Mala 1135 I-5s and orooks Moad

Male - McLean and Madison

Eprpt and central

South Parkway $W$ and Sulft

nanuy Thumas and defferson 491 Poplor

Higlitand and Dunn

Clealsed and Sth street

ELvlo Presley and carlicon

-240 and Mt. Horiat

S 3rd sicreet $H$ of I-5S

N. Thooens at Memplils Mobtlo City

Cliel sea and Ell Ington

New Allen and Ridgemont

Soutlicril Avenue $E$ of Paktorion

Cactleman and Cedrick

atues and Donbletree

1-24 and Morris:

S. Parkway and Lnellea

s. Milerd Street and Monconnah

CK Bridge

Clark hoad and Clark Core

Hotwes Roed and Ha Idrup
11-17-75 Monday 3:30 PH - 6:30 m 11-19-75 Mondiny 5:30 AM - 6:30 AH II-23-25 Medneaday 3:30 $\mathrm{IH}-6: 30 \mathrm{mH}$ 11-24-75 Suuday 3:30 $\mathrm{m}-6: 30 \mathrm{mH}$ $11-24-75$ Tuesday 11:30 AH $-2: 30 \mathrm{mH}$ 11-24-75 Tuesday 12:36 TH $-2: 30 \mathrm{MH}$ $12-16-75$ Tinesilay
$12: 14-75$ Swudny
$1: 30$ AH $-6: 30$ AH 12-14-75 Sw+udny 3: 30 AH - 6:30 AM

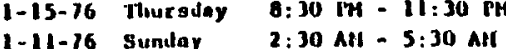
1-11-16 Sunday 2:30 All - 5:30 AHC 1-15-16 Tluernday 7:00 AH - 10:00 AH 1-14-76 Hedneaday 8:30 PM- 11:30 $\mathrm{mM}$ 1-11-76 Sunday 9:30 AH - 12:30 $\mathrm{Mm}$ 3-6-76 Saturday 9:00 IM - 12:00 AM $3-8-76$ Silay $11: 00 \mathrm{PM}-2: 00 \mathrm{AM}$ 3-0-76 Mnday 11:00 AM - 4:00 AM 4-7-76 Sinday 1:00 AM - 4:00 AM 4-23-76 Prling 1:00 AM - 10:N0 AM 4-19.76 Hunday $1: 30 \mathrm{AH}-10: 30 \mathrm{PH}$ 4-20-76 Tuesilay 9:30 AH- 12:30 PM 4-21-76 Hedneaday 11:30 $\mathrm{MH}-2: 30 \mathrm{AH}$ 5-17-76 Hutrey 3:30 PH- 6:00 PH 5-18-76 Tuesday 12:30 AH - 3: J0 AH 5-18-76 Tuesday 10:30 $\mathrm{mH}-1: 30 \mathrm{AH}$ 5-16-76 Sunday 6:00 PH-9:00 m 5-20-76 Thurstay 8:00 PH - 11:00 I'H 5-15-76 Salurday 3:30 $\mathrm{PH}-6: 30 \mathrm{PH}$ 6-26-76 Saturday 5:30 PM - 8:30 MM 6-27-76 Sumday S:30 AM- $8: 30 \mathrm{AM}$ 6-26-76 Saturday 11:00 im - 2:00 AH $\begin{array}{lll}9-2-76 & \text { Thuratay } & 2: 00 \mathrm{~mm}-5: 00 \mathrm{IH} \\ 0-29-76 & \text { Sumilay } & 4: 30 \mathrm{FH}-1: 30 \mathrm{JH}\end{array}$

9-1-76 Medneoday 2:30 IM - 5:30 PM 8-29-76 Sundar 12:00 AM- 3:00 AH

$\begin{array}{rrrrrrrr}13 & 12 & 12 & 10 & 2 & 0 & 0 & 0 \\ 12 & 12 & 12 & 12 & 0 & 0 & 0 & 0 \\ 13 & 12 & 12 & 1 & 3 & 1 & 0 & 0 \\ 14 & 12 & 12 & 10 & 1 & 1 & 0 & 0 \\ 15 & 14 & 13 & 10 & 2 & 1 & 0 & 0 \\ 15 & 13 & 13 & 6 & 5 & 2 & 0 & 0 \\ 13 & 13 & 12 & 1 & 1 & 2 & 1 & 0 \\ 14 & 14 & 14 & 9 & 4 & 1 & 0 & 0 \\ 14 & 12 & 12 & 3 & 6 & 1 & 1 & 1 \\ 16 & 14 & 14 & 13 & 1 & 0 & 0 & 0 \\ 18 & 16 & 16 & 9 & 6 & 1 & 0 & 0 \\ 11 & 15 & 14 & 10 & 4 & 0 & 0 & 0 \\ 11 & 11 & 11 & 5 & 5 & 0 & 0 & 1 \\ 12 & 11 & 11 & 4 & 3 & 2 & 1 & 1 \\ 10 & 10 & 10 & 3 & 3 & 3 & 1 & 0 \\ 13 & 8 & 8 & 7 & 1 & 0 & 0 & 0 \\ 12 & 10 & 10 & 7 & 2 & 1 & 0 & 0 \\ 12 & 12 & 12 & 11 & 1 & 0 & 0 & 0 \\ 1 & 1 & 1 & 3 & 3 & 1 & 0 & 0 \\ 12 & 11 & 11 & 6 & 5 & 0 & 0 & 0 \\ 16 & 16 & 15 & 1 & 2 & 4 & 1 & 1 \\ 15 & 15 & 15 & 9 & 4 & 0 & 2 & 0 \\ 15 & 15 & 15 & 10 & 3 & 2 & 0 & 0 \\ 11 & 16 & 15 & 13 & 2 & 0 & 0 & 0 \\ 15 & 15 & 14 & 9 & 5 & 0 & 0 & 0 \\ 12 & 12 & 12 & 9 & 3 & 0 & 0 & 0 \\ 15 & 13 & 13 & 7 & 4 & 1 & 0 & 1 \\ 15 & 12 & 13 & 3 & 5 & 2 & 3 & 0 \\ 14 & 13 & 13 & 10 & 2 & 1 & 0 & 0 \\ 11 & 16 & 15 & 13 & 1 & 1 & 0 & 0 \\ 12 & 12 & 12 & 6 & 4 & 2 & 0 & 0 \\ 16 & 14 & 12 & 7 & 5 & 0 & 0 & 0 \\ 131 & 408 & 400 & 251 & 98 & 30 & 19 & 5\end{array}$

